\title{
THE OPTIMAL TREATMENT OF MIDSHAFT CLAVICLE FRACTURES
}




\section{THE OPTIMAL TREATMENT OF MIDSHAFT CLAVICLE FRACTURES \\ Denise van der Ven}




\section{The optimal treatment of midshaft clavicle fractures}

PhD Thesis, University of Twente, The Netherlands

Copyright @ D D.J.C. van der Ven, 2018. All right reserved.

No part of this thesis may be reproduced, stored or transmitted, in any form of by any means, without permission of the author.

ISBN 978-90-365-4470-2

DOl is: $10.3990 / 1.9789036544702$

https://doi.org/10.3990/1.9789036544702

Publication of this thesis was additionally supported by:

Meander Medical Centre, University Twente

Cover: Roy Sanders \& Denise van der Ven

Lay out: Roy Sanders

Printing: Glideprint, Enschede, The Netherlands 


\section{THE OPTIMAL TREATMENT OF MIDSHAFT CLAVICLE FRACTURES}

De optimale behandeling van midschacht clavicula fracturen

\section{PROEFSCHRIFT}

ter verkrijging van

de graad van doctor aan de Universiteit Twente op gezag van de rector magnificus,

prof.dr. T.T.M. Palstra

volgens besluit van het College voor Promoties

in het openbaar te verdedigen

op donderdag 15 februari 2018 om 14:45 uur

door

\section{Denise Josephina Christina van der Ven}

Geboren op 11 juli 1990

te Maastricht 
De promotor(en)

Prof.dr. I.A.M.J Broeders

De co-promotor(en)

Dr. G.D.J van Olden

Dr. T.K. Timmers 



\section{Contents}

Chapter one

General introduction

Part 1 - Fundamentals of clavicle fractures

\begin{tabular}{lll}
\hline Chapter two & $\begin{array}{l}\text { Definitions used in the management of clavicle } \\
\text { fractures: can we actually compare study results? }\end{array}$ & 17 \\
Chapter three & $\begin{array}{l}\text { Musculoskeletal modeling of midshaft clavicle } \\
\text { fractures by using finite element analysis }\end{array}$ & 39 \\
\hline Part 2-Imaging & & 53 \\
\hline Chapter four & $\begin{array}{l}\text { Radiographic shortening is not a good indication } \\
\text { for surgical intervention for midshaft clavicle } \\
\end{array}$ & \\
\hline
\end{tabular}

\section{Part 3 - Treatment}

Chapter five

Plate fixation versus conservative treatment of

displaced midshaft clavicle fractures: functional outcome and patients satisfaction during a mean

follow-up of 5 years.

Chapter six

Surgical versus conservative treatment of midshaft

clavicle fractures in patients aged 16 years and

older: a systematic review, meta-analysis and

comparison of randomized controlled trials

Chapter seven

Mini-invasive plate osteosynthesis (MIPO) using VA-

LCP Anterior Clavicle Plate

Chapter eight

Displaced clavicle fractures in cyclists: return to

athletic activity after anteroinferior plate fixation 


\section{Part 4 - General discussion and summary}

\begin{tabular}{lll}
\hline Chapter nine & General discussion \& future perspectives & 153 \\
Chapter ten & Nederlandse samenvatting & 167 \\
Chapter eleven & Review committee & 179 \\
& List of publications & 183 \\
& Acknowledgements & 187 \\
& Curriculum vitae auctoris & 195 \\
Addendum 1 & Conservative Treatment of displaced midshaft & 199 \\
& clavicular fractures: the measurement of shortening & \\
Addendum 2 & and its implications. & 213 \\
& Biomechanical testing of anterior and superior plate & \\
& positioning in midshaft clavicular fractures based & \\
Addendum 3 & on a finite elements model & 227 \\
Addendum 4 & Appendix Clavicle modeling & Rehabilitation protocol of conservative treatment
\end{tabular}




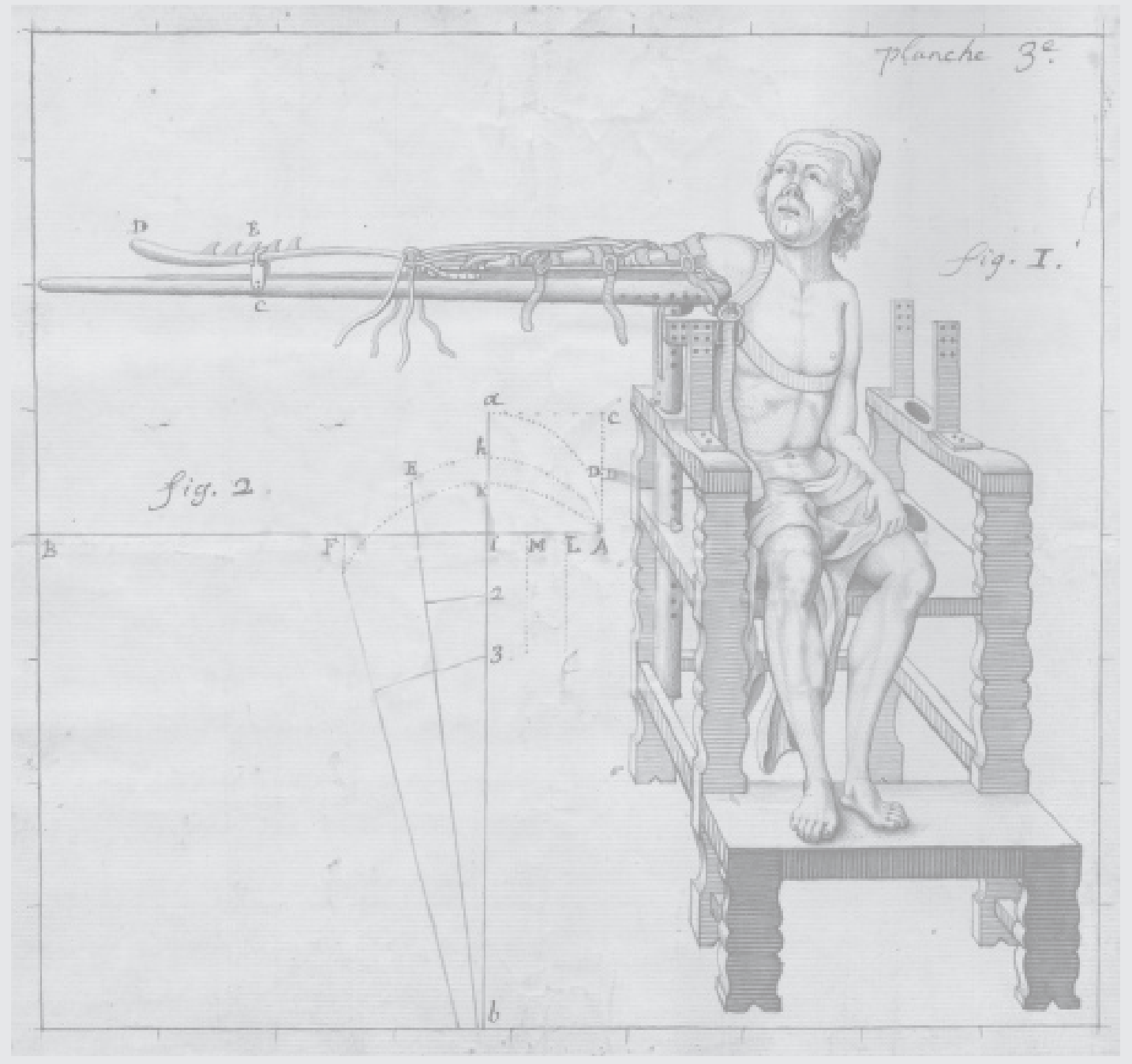




\section{CHAPTER ONE}

General introduction 
Clavicle (n.) or "collarbone" originates in 1610s, middle French clavicule also "small key" from clavicula (used c. 980 in a translation Avicenna), which means tendril, door-bolt, or small key. Derived form the Latin word clavicula (a little key, key; vinetendril; pivot). The earliest know usage of clavicle in English dates from the $17^{\text {th }}$ century. The bone rotates along its axis like a key when the shoulder is abducted and it is roughly the same shape as key from a Roman door lock.' This refers to the anatomical structure including the s-shape of the bone and the "key" connection of the sternum with the shoulder girdle. The clavicle articulates at one end with the sternum and with the acromion of the scapula at the other, making it the only bony connection between the trunk and the upper limb.

\section{History of treatment}

Early reports of clavicle fractures date back to Hippocrates (written 400 B.C.E) ${ }^{2}$, who noted, "when a fractured clavicle is fairly broken across it is more easily treated, but when broken obliquely it is more difficult to manage". He explained this theory as "for a bone fairly broken across can be more easily restored to its natural state, and with proper care the upper part may be brought down by means of suitable position and proper bandaging, and even if not properly set, the projecting part of the bone is not very sharp. But in oblique fractures the case is similar to that of bones which have been torn away, as formerly described; for they do not admit of being restored to their place, and the prominence of the bone is very sharp". He is the first to describe the displacement of the fractured bone parts caused by the attached muscles, ligaments, and the weight of the arm. Furthermore, the importance of anatomical reposition and challenges that exist in treatment of displaced clavicle fractures. Based upon his theory Hippocrates stated that: "It is of great importance that the patient should lie in a recumbent posture. Fourteen days will be sufficient if he keep quiet, and twenty at most.". Nowadays, we cannot imagine advising patients to lie down for weeks. Certainly, since clavicle fractures occur in a young and active population. Treatment of these fractures is, therefore, aimed at quickly restoring function and prevention disability. Throughout history there are several studies and theories that contributed to a better understanding of the biomechanics, normal bone physiology and fracture healing. Leading to the development and adjustments of different treatment strategies for displaced clavicle fractures. 


\section{Bone healing theories}

One of the first described bone healing theories are those of Wolff's law ${ }^{3}$, Perren's strain theory ${ }^{4}$ and Frost's concept of the "mechanostat".5. These theories consider the response of bone to the mechanical environment. Bone is a unique tissue that completely regenerates, rather than healing with a scar after injury like many other tissues. Wolff's law of the transformation of bone (1892) describes the physiological response of normal bone to the mechanical environment during growth and remodeling. It explains interaction of bone to the applied stresses and its unique characteristic of altering its mechanical properties according to them. The application of this law to the clinical setting of fracture healing together with the interplay between parameters as implant rigidity, relative or absolute fracture stability, fracture gap size, and interfragmentary strain are all efforts to express and compute the complex phenomena of bone fracture repair. Perren's theory $(1978)^{4}$ deals with the physiological response of broken bone to the mechanical environment. Frost $(1987)^{5}$ described bone homeostasis as a "mechanostat" responding to variations in the mechanical environment. To be able to understand these concepts is the mechanical response of bone tissue to strain. Strain is defined as: 'a change in length of a material at a given mechanical load'. That load may be applied as compression, distraction or rotation (torsion). ${ }^{4}$ All living, biological material is subject to strain and we know some tissues respond to it. The strain tolerance of a tissue is the maximum strain at which a tissue will continue to exhibit normal physiological function. ${ }^{4}$ Beyond this level of strain, tissues will either fail to function normally or will fail. Every, limb, ligament, and muscle applies force and tension on the clavicle. The sternohyoid, pectoralis major and deltoid muscles find their origin on the clavicle; the sternocleidomastoid, subclavius and trapezius muscles insert on the clavicle. It is further connected to the coracoid process with the coracoclavicular ligament, to the first rib with the costoclavicular ligament, and to the contra lateral clavicle through the interclavicular ligament. ${ }^{6}$ The clavicle acts as a strut to enable motion of the arm and, therefore, is subjected to both tensile and compressive loads. The clavicle deflects with torsion or twisting because of the three-dimensional curvilinear-shaped structure. ${ }^{7}$ Perren ${ }^{4}$ stated that the strain tolerance of lamellar bone is $2 \%$. Beyond this, it will fracture. The bone-healing organ that then forms will differentiate with time through different tissues that can tolerate various levels of strain, with the granulation tissue that initially forms within a fracture site having a strain tolerance of $100 \%$. The diamond concept of Giannoudis ${ }^{8}$ uses these mechanical theories as the basis for his concept of fracture healing. Describing the bone fracture healing as a diamond model with four 
interactions. The fourth element; mechanical stability is essential for the formation of a callus that bridges the fracture site allowing loads to be transmitted across the fracture line. The progressive maturation of the fracture callus from woven to lamellar bone depends on this stability. Surgical interventions such as the application of systems of internal or external stabilization are designed to improve stability of fixation and thereby enhance healing. The other three keys are biological elements for fracture healing. A complex of interactions between: 1) the potent osteogenic cell populations; 2) the growth factors (osteoinductive stimulus); and 3) the osteoconductive matrix scaffolds.

\section{Clinical studies}

In 1960 Neer ${ }^{9}$ published the first clinical studies describing patients symptoms after treatment of clavicle fractures and complications such as nonunion. In his study he paraphrases the clavicle bone as a nonconformist."It is the first bone to ossify in the embryo, and it continues throughout life to enjoy a remarkable reputation for its ability to form bone and heal". In his studies he stated fractures of the middle and outer third should be seen as a different entity. He stated that no nonunion or as he called "ununited" fractures of the middle third are seen. All nonunions that occurred were in de outer third en due to tears of the coracoclavicular ligament. When this ligament was intact, prompt union was the rule. When nonunions occurred the cause should be sought in an inadequate operation technique; local tissue damage, removal of the valuable bone, soft part stripping, inadequate internal fixation and infection. Subsequently, midshaft clavicle fractures were treated conservatively with provision of a sling, collar and cuff or figure-of-eight bandage. In 1997, a study published by Hill et al. ${ }^{10}$ stated that closed treatment of displaced middlethird fractures of the clavicle gives poor results. After these results more studies found a higher rate of nonunion and mal-union after conservative treatment than previously thought."1" This caused a shift in the management of clavicle fracture towards a more operatively treatment strategy. Treatment mostly based on radiographic examination; amount of shortening and dislocation. In current literature, the long-term outcomes of these studies are raising new questions and causing discussion. Recent research has not shown convincingly that operative treatment is better for these kinds of fractures on the long term. ${ }^{12}$ Therefore, factors that are causing these misconceptions should be identified. 


\section{Thesis outline}

The aim of this thesis was to make a next step in the optimal treatment of displaced midshaft clavicle fractures. Where treatment is not solely based on radiographic examination. But working towards more patient oriented treatment and individualized strategies with the use of uniform definitions.

\section{Part 1 - Fundamentals of clavicle fractures}

This first part of the thesis starts with the biomechanical principles of clavicle fractures and clavicle fracture management. The mechanical environment of the clavicle and the definitions used in clavicle management throughout literature are evaluated.

In Chapter 2, the definitions used in current literature regarding clavicle fracture management are outlined. Although frequently used, no uniform definitions exist. There are numerous studies comparing functional outcome and complications, with definitions that vary significantly. Also, a wide variation in operation indications, the basis of a treatment strategy, is used. With this systematic review, we evaluated whether we can actually compare current study results.

In Chapter 3, a musculoskeletal model is developed including all muscles and ligaments that find their origin or insertion at the clavicle bone. With this model a better understanding of the forces acting on the clavicle in intended. Giving more insight on the magnitude and direction of forces acting on the clavicle. Eventually, extrapolate these results to a better understanding of stable fixation and optimal positioning of the clavicle plate.

\section{Part 2 - Imaging}

In the second module of this thesis presentation, the imaging of clavicle fractures is outlined. Most treatment is still based upon radiographic features of the fracture. Plain radiography is the most common way in which clavicle fractures are radiological assessed. Radiographic examination includes an anterior-posterior (AP) radiograph and a clavicle radiograph with some horizontal angle $\left(15^{\circ}-45^{\circ}\right)$.

In Chapter 4, the used operation indications are evaluated. The currently described indications for surgical treatment as seen on radiograph examination are: complete displacement and clavicle shortening exceeding 15-20 mm. Since these factors have been reported in the literature to be associated with potential shoulder 
dysfunction. This study questions whether operative treatment can be based on radiographic examination alone.

\section{Part 3 - Treatment}

In the final part of this thesis, the treatment strategies are further investigated. In a cohort study of 97 patients we compared plate fixation with conservative treatment. In Chapter 5, the short term and long-term result of this cohort with a follow-up of five years are presented.

Followed by a meta-analysis of treatment of midshaft clavicle fractures in Chapter $\boldsymbol{6}$. A systematic review and meta-analysis of all randomized controlled trials and observational studies in current literature regarding (operative or conservative) treatment of midshaft clavicle fractures was performed.

Conservative treatment consists of provision of a sling, collar and cuff or figure-ofeight bandage during the initial phase and early mobilization (after one week) as the pain decreases. The standard surgical techniques for clavicle fractures are open reduction and internal plate fixation or intramedullary fixation. There are several complications described, such as deep infection, non-union, implant failure, refracture after implant removal, and poor cosmetic appearance.

In Chapter 7, a new operation technique was described using minimal invasive plate osteosynthesis (MIPO). The main advantage of the (MIPO) technique is reduction of soft tissue disruption and preservation of blood supply to the fracture, which might enhance the healing process and reduce postoperative complications.

Finally, in Chapter 8, the operative and rehabilitation strategy is extrapolated to an important (sub) group of patients. Return to athletic activity of cyclists after plate fixation is described. 


\section{REFERENCES}

1. https://yeditepeanatomy 1 files.wordpress. com/2012/10/anatomy-monthly november2012-issue-2.pdf

2. Hippocrates. On The Articulations. 400 B.C.E.

3. Wolff J. Das gesetz der transformation der knochen. Berlin: Verlag von Augsut Hirschwald 1892

4. Perren SM, Boitzy A. Cellular differentiation and bone biomechanics during the consolidation of a fracture. Anat. Clin. 1978; 1:13-28.

5. Frost HM Bone "Mass" and the "Mechanostat": A Proposal The Anatomical Record 1987: 219:1-9

6. Rowe CR. An atlas of anatomy and treatment of midclavicular fractures. Clin Orthop Relat Res. 1968;58:29-42.

7. Boresi AP, Schmidt RJ, Sidebottom OM. Deflection of curved beams. Advanced mechanics of materials. New York: Wiley \& Sons; 1993. p. 385-91.

8. Giannoudis PV, Thomas A. EinhornDavid Marsh Fracture healing: The diamond concept. Injury. 2007 Sep; 38 Suppl 4:S3-6.

9. Neer CS. Nonunion of the clavicle. J Am Med Assoc 1960; 172: 1006-1011.

10. Hill JM, McGuire MH, Crosby LA. Closed treatment of displaced middle- third fractures of the clavicle gives poor results. J Bone Joint Surg Br 1997, 79:537-539.

11. Canadian Orthopaedic Trauma Society. Nonoperative treatment compared with plate fixation of displaced midshaft clavicular fractures. A multicentre randomized clinical trial. J Bone Joint Surg Am 2007, 89:1-10.

12. Mckee RC1, Whelan DB, Schemitsch EH, Mckee MD. Operative versus nonoperative care of displaced midshaft clavicular fractures: a meta-analysis of randomized clinical trials. J Bone Joint Surg Am. 2012 Apr 18; 94(8): 675-84. doi: 10.2106/JBJS.J.01364. 


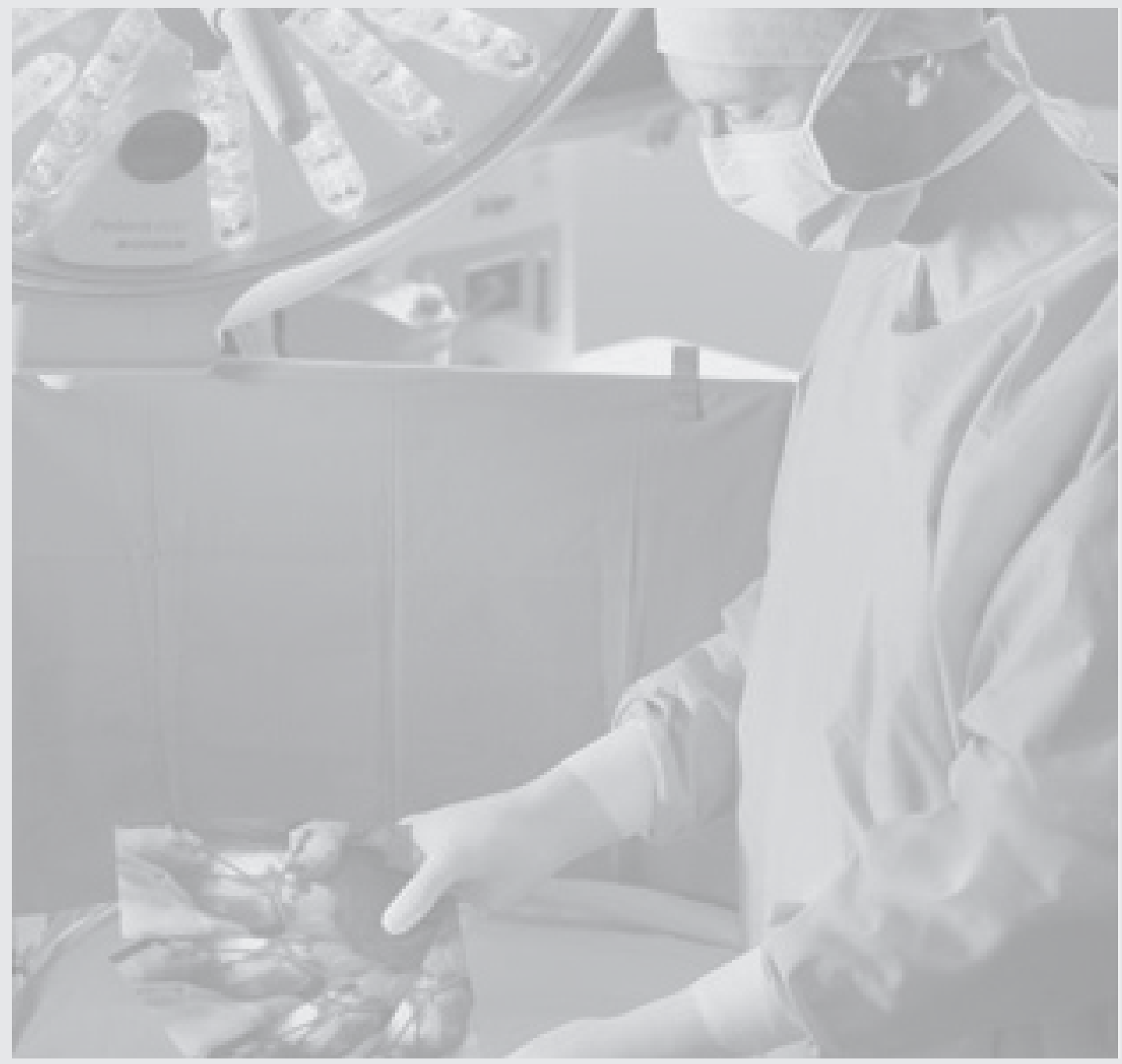




\section{CHAPTER TWO}

\section{Definitions used in the management of clavicle fractures: can we actually compare study results?}

D.J.C. van der Ven, D.P.J Smeeing, T.K. Timmers, J. Pogorzelski,

P.J. Millett, F. Hietbrink, R.M. Houwert, O. A.J. van der Meijden

Submitted 


\section{ABSTRACT}

\section{Background}

Even though there are numerous studies analyzing outcomes after operative fixation of clavicle fractures, the definitions used to describe (disorders of) healing and complications vary substantially. Therefore, the aim of this systematic review was to identify and evaluate these published definitions.

\section{Study design}

Level III, Systematic review of Level I to Level III studies.

\section{Methods}

Published randomized controlled trials (RCT) and observational studies comparing either surgical and conservative treatment, or plate and intramedullary fixation for the treatment of acute midshaft clavicle fractures were included in this systematic review. The primary outcomes extracted were the definitions used for healing disorders: non-union, mal-union, and delayed union. Secondary parameters included the definitions of "fracture dislocation and shortening", "implant related irritation", and "infection".

\section{Results}

Criteria total of 37 studies were included. Of those, 14 were RCTs and 23 studies were observational, consisting of eleven prospective and twelve retrospective studies. A wide variety in reported definitions was observed among the studies. Only 16 of 37 (43\%) studies reported a definition for nonunion, 11 studies for mal-union and 5 studies did define delayed union. Twenty-three studies reported infections rates including a definition. Twenty-one studies defined implant related irritation as a complication. In 6 studies implant related irritation was followed by implant removal and in 15 studies this was unknown.

\section{Conclusion}

In the current literature concerning clavicle fracture treatment, a wide variety of definitions for fracture healing disorders, or complications exist. Until more consensuses are reached, we must be aware of the limitations of current data interpretation when comparing different studies. 


\section{INTRODUCTION}

Voltaire stated, "If you want to converse with me, first define your terms."The optimal treatment of displaced midshaft clavicle fractures is a permanent topic of debate in current literature ${ }^{23,50}$ and one of the reasons for this is the lack of standardized definitions. In the past few years, several systematic reviews and meta-analyses have been published comparing different treatment options for displaced clavicle fractures with contradicting results. ${ }^{4,18,34}$ Applied definitions of fracture union appeared to vary considerably amongst most of the studies. As a result, studies of patients with similar injuries undergoing similar treatment might report differences in time to heal due to different definitions of fracture union and not to the natural history of the disease or treatment. In general, the determination of fracture healing seems to be a highly subjective process and at present there is no consensus definition of nonunion in literature. ${ }^{17}$ This lack of agreement among clinicians and researchers poses an obstacle for clinical trials as the effectiveness of both standard and novel fracture healing therapies is fundamentally based on the demonstration of improved fracture healing. In addition, the use of inconsistent criteria to assess disorders of fracture healing across studies, further limits the generalizability of their results. ${ }^{12}$ Also, inconsistencies in definitions of possible indications for surgical treatment, such as fracture dislocation and shortening, have also been observed and may adversely influence the comparability of different studies. $2,3,8,19,20,26,30,31$. $37,43,44,46,49,51,53,43,57,58,59-61,63$ In general, uniformity in the use of definitions might aid in better interpreting study results and in the timing of possible secondary interventions. Therefore, the aim of this systematic review was to give an overview of the published definitions of healing, disorders of healing and complications used in clavicle fracture management and identify lack of consensus.

\section{METHODS}

This systematic review was structured according to the PRISMA Checklist. No ethical committee approval was necessary for this literature review. ${ }^{42}$

\section{Inclusion and exclusion criteria}

A literature search was performed focusing on studies reporting outcomes after midshaft clavicle fractures. Only randomized controlled trials (RCTs) and observational studies concerning the comparison of surgical and conservative treatment or the comparison of surgical fixation by plate or intramedullary fixation for acute midshaft clavicle fractures were included in this systematic review. Studies were excluded if they were not published in the English language. 


\section{Search strategy and selection criteria}

Published randomized controlled trials (RCTs) and observational studies concerning the comparison of surgical and conservative treatment or the comparison of surgical fixation by plate or intramedullary fixation for acute midshaft clavicle fractures were included in this systematic review. The search strategy was based on two recently published reviews from our research group. Reviewers searched Medline, Embase, CINAHL and the Cochrane library. Article written in English, French or German that were available in full text were included. A minimum follow-up time was not required for inclusion. Letters, comments, abstracts for conferences, case reports, study protocols, reviews, biomechanical studies, animal studies, studies that included patients with (only) floating shoulders, studies describing a surgical technique and noncomparative studies were excluded. Eligibility was resolved by discussion. ${ }^{23,50}$ The search syntax of both studies is provided in Appendix 1. On March 30, 2017, both search strategies were repeated to find additional studies published between 2016 and March 2017. Studies in which fracture healing or nonunion was not reported as outcome parameter were excluded for this review. The search syntax of both reviews is provided in Appendix 1 .

\section{Data extraction}

The following data were extracted: first author, year of publication, study design, level of evidence, and outcomes parameters. The primary outcomes extracted were the definitions used for healing disorders: "non-union", "delayed union", and "mal-union". Secondary parameters included the definitions of "fracture dislocation and shortening", "implant related irritation", and "infection". Data extraction was performed by two independent reviewers (DV and DS). Disagreements were resolved by discussion with a third independent reviewer (RH). One included study, previously published by two of the authors (DV and TT), was assessed by two other reviewers (DS and $\mathrm{RH}) .^{56}$

\section{RESULTS}

\section{Search}

The two previously published systematic reviews had included 40 studies. ${ }^{23,50}$ Six additional studies were found following an update of the search. ${ }^{744,48,49,63,64}$ After removing duplicates (3 articles), studies were screened full text for eligibility. Six studies were excluded because the articles did not report on our primary outcome parameter. $72,1,32,33,63,65$ Cross-referencing and citation checking did not result in additional studies. Therefore, 37 studies met the inclusion criteria. Of all included 
studies 14 were RCTs, and 23 were observational, of which 11 were prospective studies and 12 were retrospective studies.

\section{Definitions in literature - Primary outcome parameters}

Healing disorders

Sixteen studies of included 37 studies (43\%) included a definition for nonunion. Eight (50\%) studies used only radiological criteria and seven (44\%) studies combined radiological criteria and clinical criteria. The clinical criteria used were pain and/or motion at the fracture site (Table 1). One (6\%) study only included a time period. The time period for the diagnoses of nonunion varies from 4 months to one year after surgery.

Mal-union rates were reported in 23 of 37 studies (62\%), with 11 (48\%) of these 23 studies actually defined malunion. One (9\%) study used a radiographic criterium, 2 (18\%) studies clinical criteria and 8 (72\%) combined the 2. Six (54\%) studies used the term "symptomatic" malunion in their definition (Table 2).

The diagnosis for delayed union varies from 3 months to 1 year after trauma or surgery. Of the 15 studies, which included delayed union, 10 (67\%) studies did not include a definition. (Table 3)

\section{Definitions in literature - Secondary outcome parameters}

\section{Operation indication criteria}

Various definitions of indications for surgical treatment are reported (Table 4). A wide variety in classifications (i.e. Robinson/Edinburgh classification and AO classification) and descriptions for dislocation or displacement are used. Thirty-three (89\%) studies did report dislocation as an operation indication. Ten (30\%) studies did not define dislocation or used a classification that not includes dislocation (i.e. Orthopaedic Trauma Association classification).

Only 7 (19\%) studies did define shortening with different degrees of shortening leading to an unfortunate outcome are being reported; varying from 15-20mm. Twenty-four (65\%) studies did not report shortening and 6 (16\%) studies did report it, but did not use a definition for it.

\section{Implant related irritation}

Twenty-one (57\%) studies defined implant related irritation as a complication. In $6(29 \%)$ studies implant related irritation was followed by implant removal and in $15(71 \%)$ studies it was unknown if implant related irritation was followed by a second operation to remove it. Thirteen (45\%) studies did not report and 3 (8\%) did not define implant related irritation. (Table 5) Two studies considered irritation a discomfort coexisting with the treatment and not a complication. ${ }^{45,50}$ 
Table 1. Definitions of nonunion used in the literature

\section{Year Study Definition of nonunion} design

\begin{tabular}{|c|c|c|c|c|}
\hline Althausen et al. ${ }^{1}$ & 2013 & $\mathrm{RC}$ & ND & ND \\
\hline Andrade-Silva et al. ${ }^{2}$ & 2015 & $\mathrm{RCT}$ & Fracture not healed & Six months \\
\hline Assobhi et al. ${ }^{3}$ & 2011 & $\mathrm{RCT}$ & ND & ND \\
\hline Böhme et al. ${ }^{6}$ & 2011 & PC & ND & ND \\
\hline COTS $^{8}$ & 2007 & $\mathrm{RCT}$ & $\begin{array}{c}\text { The lack of radiographic healing } \\
\text { with clinical evidence of pain and } \\
\text { motion at the fracture site }\end{array}$ & One year \\
\hline Chen et al. ${ }^{9}$ & 2011 & $\mathrm{RCT}$ & ND & ND \\
\hline Chen et al. ${ }^{10}$ & 2012 & $\mathrm{RC}$ & $\begin{array}{c}\text { The presence of a complete gap at } \\
\text { the fracture site }\end{array}$ & Six months \\
\hline Daniilidis et al. ${ }^{13}$ & 2013 & $\mathrm{RC}$ & ND & ND \\
\hline Dhakad et al. ${ }^{16}$ & 2016 & PC & ND & ND \\
\hline Ferran et al. ${ }^{19}$ & 2010 & $\mathrm{RCT}$ & ND & ND \\
\hline Fu et al. ${ }^{20}$ & 2012 & $\mathrm{RC}$ & $\begin{array}{l}\text { The lack of radiographic healing } \\
\text { with tenderness on motion of the } \\
\text { fracture site }\end{array}$ & Six months \\
\hline Grassi et al. ${ }^{22}$ & 2001 & $\mathrm{RC}$ & ND & ND \\
\hline Jones et al. ${ }^{26}$ & 2014 & $\mathrm{RC}$ & ND & ND \\
\hline Jubel et al. ${ }^{27}$ & 2002 & $\mathrm{RC}$ & ND & ND \\
\hline Judd et al. ${ }^{28}$ & 2009 & $\mathrm{RCT}$ & ND & ND \\
\hline Kleweno et al..29 & 2011 & PC & ND & ND \\
\hline Khorami et al. ${ }^{30}$ & 2014 & $P C$ & ND & ND \\
\hline Kulshrestha et al. ${ }^{31}$ & 2011 & PC & $\begin{array}{c}\text { The lack of radiographic healing } \\
\text { with clinical evidence of pain and } \\
\text { crepitus at the fracture site. }\end{array}$ & Six months \\
\hline Liu et al. ${ }^{36}$ & 2010 & $\mathrm{RC}$ & ND & ND \\
\hline Mealean et al. ${ }^{37}$ & 2015 & $\mathrm{RCT}$ & $\begin{array}{c}\text { Without radiologic signs of bone } \\
\text { healing. }\end{array}$ & $\begin{array}{l}\text { More than four } \\
\text { months }\end{array}$ \\
\hline Mirtazaloei et al. ${ }^{40}$ & 2011 & $\mathrm{RCT}$ & $\begin{array}{l}\text { A lack of cortical bridging on } \\
\text { radiography of the clavicle }\end{array}$ & $\begin{array}{l}\text { Six months after } \\
\text { surgery }\end{array}$ \\
\hline Narsaria et al. ${ }^{43}$ & 2014 & $P C$ & $\begin{array}{c}\text { An unsuccessful healing of the } \\
\text { bone, clinically manifesting as pain } \\
\text { at the fracture site and radiologically } \\
\text { as a visible gap between the } \\
\text { fracture parts }\end{array}$ & Six months \\
\hline Naveen et al. $4^{4}$ & 2017 & $P C$ & ND & ND \\
\hline Robinson et al. ${ }^{46}$ & 2013 & $\mathrm{RCT}$ & The absence of radiographic union & $\begin{array}{l}\text { Six months or } \\
\text { longer after } \\
\text { injury }\end{array}$ \\
\hline
\end{tabular}


Table 1. Continued

\begin{tabular}{|c|c|c|c|c|}
\hline Author & Year & $\begin{array}{l}\text { Study } \\
\text { design }\end{array}$ & Definition of nonunion & Time period \\
\hline Saha et al. ${ }^{48}$ & 2014 & PC & ND & ND \\
\hline Shetty et al. ${ }^{49}$ & 2017 & $\mathrm{RCT}$ & ND & ND \\
\hline Smekal et al. ${ }^{51}$ & 2009 & PC & $\begin{array}{c}\text { A lack of radiologic signs of osseous } \\
\text { consolidation with clinical evidence } \\
\text { of pain and motion at the fracture } \\
\text { site }\end{array}$ & $\begin{array}{l}24 \text { week after } \\
\text { trauma }\end{array}$ \\
\hline Tabatabaei et al. ${ }^{53}$ & 2011 & PC & ND & ND \\
\hline Tarng et al. ${ }^{54}$ & 2012 & $\mathrm{RC}$ & ND & ND \\
\hline Thyagarajan et al..$^{55}$ & 2009 & $\mathrm{RC}$ & ND & ND \\
\hline Van der Meijden et al..$^{55}$ & 2015 & $\mathrm{RCT}$ & $\begin{array}{l}\text { A lack of radiographic evidence of } \\
\text { healing with clinical evidence of } \\
\text { pain and motion at the fracture }\end{array}$ & $\begin{array}{l}\text { Six months after } \\
\text { surgery }\end{array}$ \\
\hline Van der Ven et al..$^{57}$ & 2015 & PC & The absence of radiographic union & Six months \\
\hline Virtanen et al. ${ }^{58}$ & 2012 & $\mathrm{RCT}$ & $\begin{array}{l}\text { The absence of periosteal and } \\
\text { endosteal healing on radiographs }\end{array}$ & One year \\
\hline Wenninger et al..$^{59}$ & 2012 & $\mathrm{RC}$ & $\begin{array}{l}\text { A lack of callus formation on two } \\
\text { cortices on plain radiographs }\end{array}$ & Six months \\
\hline Witzel et al. ${ }^{60}$ & 2007 & $\mathrm{RCT}$ & ND & ND \\
\hline Wijdicks et al. ${ }^{61}$ & 2012 & $\mathrm{RC}$ & $\begin{array}{l}\text { An unsuccessful healing of the bone } \\
\text { that clinically could be associated } \\
\text { with pain and was visible on the } \\
\text { radiograph as a gap between the } \\
\text { fracture parts }\end{array}$ & Six months \\
\hline Woltz et al. ${ }^{64}$ & 2017 & $\mathrm{RCT}$ & $\begin{array}{c}\text { The absence of complete osseous } \\
\text { bridging of the fracture on the } \\
\text { radiograph }\end{array}$ & $\begin{array}{l}\text { More than six } \\
\text { months }\end{array}$ \\
\hline
\end{tabular}

ND: no definition reported; PC: prospective cohort study; RC: retrospective cohort study;

$\mathrm{RCT}$ : randomized controlled trial 
Part I - Fundamentals of clavicle fractures

Table 2. Definitions of malunion used in the literature

\begin{tabular}{|c|c|c|c|}
\hline Author & Year & $\begin{array}{l}\text { Study } \\
\text { design }\end{array}$ & $\begin{array}{l}\text { Definition of } \\
\text { malunion }\end{array}$ \\
\hline $\begin{array}{l}\text { Canadian Orthopaedic } \\
\text { Trauma Society }\end{array}$ & 2007 & $\mathrm{RCT}$ & $\begin{array}{l}\text { Radiographic: as loss of anatomic contour of the clavicle } \\
\text { Symptomatic: union of the fracture in a shortened, } \\
\text { angulated, or displaced position with weakness, easy } \\
\text { fatigability, pain with overhead activity, neurologic } \\
\text { symptoms, and shoulder asymmetry with a completed or } \\
\text { planned corrective osteotomy }\end{array}$ \\
\hline Chen et al. ${ }^{9}$ & 2011 & $\mathrm{RCT}$ & ND \\
\hline Chen et al. ${ }^{10}$ & 2012 & $\mathrm{RC}$ & $\begin{array}{c}\text { A remarkable angulation of the clavicle compared with } \\
\text { the uninjured side }\end{array}$ \\
\hline Dhakad et al. ${ }^{16}$ & 2017 & PC & ND \\
\hline Ferran et al. ${ }^{19}$ & 2010 & $\mathrm{RCT}$ & ND \\
\hline Fu et al. ${ }^{20}$ & 2012 & $\mathrm{RC}$ & $\begin{array}{l}\text { A loss of anatomic contour even in the presence of } \\
\text { exuberant callus formation. }\end{array}$ \\
\hline Judd et al. ${ }^{28}$ & 2009 & $\mathrm{RCT}$ & ND \\
\hline Kulshrestha et al. ${ }^{31}$ & 2011 & PC & $\begin{array}{l}\text { Union of the fracture in a shortened, angulated, or } \\
\text { displaced position identified on radiographs together with } \\
\text { cosmetic or functional complaints of the patient }\end{array}$ \\
\hline Liu et al. ${ }^{36}$ & 2010 & $\mathrm{RC}$ & ND \\
\hline Mirtazaloei et al. ${ }^{40}$ & 2011 & $\mathrm{RCT}$ & $\begin{array}{l}\text { A malunion was considered as an adverse effect when } \\
\text { patients with abnormal radiographic contour were } \\
\text { symptomatic in terms of pain, weakness, or neurovascular } \\
\text { symptoms. }\end{array}$ \\
\hline Naveen et al. ${ }^{44}$ & 2017 & PC & ND \\
\hline Robinson et al..$^{46}$ & 2013 & $\mathrm{RCT}$ & ND \\
\hline Saha et al. ${ }^{48}$ & 2014 & $P C$ & ND \\
\hline Shetty et al. ${ }^{49}$ & 2017 & $P C$ & ND \\
\hline Smekal et al. ${ }^{51}$ & 2009 & $P C$ & $\begin{array}{c}\text { A loss of anatomic alignment of the clavicle and symmetry } \\
\text { of the shoulder girdle. } \\
\text { Symptomatic malunion with sequelae such as pain, easy } \\
\text { fatigability and neurological symptoms and with the need } \\
\text { for corrective osteotomy. }\end{array}$ \\
\hline Tabatabaei et al. ${ }^{53}$ & 2011 & PC & ND \\
\hline Thyagarajan et al. ${ }^{55}$ & 2009 & $\mathrm{RC}$ & ND \\
\hline Van der Meijden et al. ${ }^{56}$ & 2015 & $\mathrm{RCT}$ & $\begin{array}{l}\text { Fracture union in a shortened, angulated, or displaced } \\
\text { position on radiographs with clinical symptoms }\end{array}$ \\
\hline Van der Ven et al. ${ }^{57}$ & 2015 & $P C$ & $\begin{array}{l}\text { Symptomatic malunion: A patient with symptoms severe } \\
\text { enough to warrant corrective osteotomy. }\end{array}$ \\
\hline Virtanen et al. ${ }^{58}$ & 2012 & $\mathrm{RCT}$ & $\begin{array}{c}\text { Symptomatic malunion: shortening of }>20 \text { mm, } \\
\text { angulation, or displacement of the clavicle combined with } \\
\text { sequelae such as pain, weakness, or a tendency to fatigue } \\
\text { easily. }\end{array}$ \\
\hline
\end{tabular}


Table 2. Continued

\begin{tabular}{lccc}
\hline Author & Year & $\begin{array}{c}\text { Study } \\
\text { design }\end{array}$ & \multicolumn{1}{c}{$\begin{array}{c}\text { Definition of } \\
\text { malunion }\end{array}$} \\
\hline Witzel et al. ${ }^{60}$ & 2007 & RCT & ND \\
Wijdicks et al. ${ }^{61}$ & 2012 & RC & $\begin{array}{c}\text { Symptomatic malunion: An incorrect anatomical position } \\
\text { of the clavicle in comparison to the (healthy) side resulting } \\
\text { in pain symptoms or a loss of function of the shoulder. }\end{array}$ \\
Woltz et al. ${ }^{64}$ & 2017 & RCT & $\begin{array}{r}\text { Symptomatic malunion if secondary surgery was } \\
\text { performed in an attempt to address symptoms thought to } \\
\text { be related to deformity of the clavicle }\end{array}$ \\
\hline
\end{tabular}

ND: no definition reported; PC: prospective cohort study; RC: retrospective cohort study; RCT: randomized controlled trial

Table 3. Definitions of delayed union used in the literature

\begin{tabular}{|c|c|c|c|c|}
\hline Author & Year & $\begin{array}{l}\text { Study } \\
\text { design }\end{array}$ & $\begin{array}{l}\text { Definition of } \\
\text { delayed union }\end{array}$ & Time period \\
\hline Chen et al..$^{9}$ & 2011 & $\mathrm{RCT}$ & ND & ND \\
\hline Chen et al. ${ }^{10}$ & 2012 & $\mathrm{RC}$ & $\begin{array}{c}\text { Fracture union later than } 24 \\
\text { weeks after trauma without any } \\
\text { intervention }\end{array}$ & 24 weeks \\
\hline Daniilidis et al. ${ }^{13}$ & 2003 & $\mathrm{RC}$ & ND & ND \\
\hline Dhakad et al. ${ }^{16}$ & 2017 & $P C$ & ND & ND \\
\hline Ferran et al. ${ }^{19}$ & 2010 & $\mathrm{RCT}$ & ND & ND \\
\hline Grassi et al. ${ }^{22}$ & 2001 & $\mathrm{RC}$ & ND & ND \\
\hline Jones et al. ${ }^{26}$ & 2014 & $\mathrm{RC}$ & ND & ND \\
\hline Judd et al. ${ }^{28}$ & 2009 & $\mathrm{RCT}$ & ND & ND \\
\hline Kleweno et al. ${ }^{29}$ & 2011 & $P C$ & ND & ND \\
\hline Khorami et al. ${ }^{30}$ & 2014 & $P C$ & ND & ND \\
\hline Kulshrestha et al. ${ }^{31}$ & 2011 & $P C$ & ND & ND \\
\hline Robinson et al. ${ }^{46}$ & 2013 & $\mathrm{RCT}$ & $\begin{array}{c}\text { As defined as progression to union } \\
\text { on three-dimensional CT }\end{array}$ & $\begin{array}{l}\text { One year of follow-up } \\
\text { in patients who had not } \\
\text { healed by six months }\end{array}$ \\
\hline Smekal et al. ${ }^{51}$ & 2009 & $P C$ & $\begin{array}{l}\text { As fracture union without further } \\
\text { surgical intervention. }\end{array}$ & $>24$ weeks after trauma \\
\hline Thyagarajan et al. ${ }^{55}$ & 2009 & $\mathrm{RC}$ & ND & ND \\
\hline Van der Ven et al..$^{57}$ & 2015 & PC & $\begin{array}{l}\text { Progression to union on three- } \\
\text { dimensional CT }\end{array}$ & $\begin{array}{l}\text { At one year of follow-up } \\
\text { in patients who had not } \\
\text { healed by six months }\end{array}$ \\
\hline Virtanen et al. ${ }^{.58}$ & 2012 & $\mathrm{RCT}$ & $\begin{array}{c}\text { The absence of bridging callus and } \\
\text { endosteal healing on radiographs } \\
\text { combined with pain and/or } \\
\text { instability in the fracture region }\end{array}$ & Three months \\
\hline
\end{tabular}

ND: no definition reported; PC: prospective cohort study; RC: retrospective cohort study; RCT: randomized controlled trial 
Part I - Fundamentals of clavicle fractures

Table 4. Operation indication criteria

\begin{tabular}{|c|c|c|c|}
\hline Author & Year & Dislocation & Shortening \\
\hline Althausen et al. ${ }^{1}$ & 2013 & NR & NR \\
\hline Andrade-Silva et al. ${ }^{2}$ & 2015 & $\begin{array}{l}\text { Displacement of }>2 \mathrm{~cm} \text { and/or } \\
\text { no contact between the two } \\
\text { fragments }\end{array}$ & NR \\
\hline Assobhi et al. ${ }^{3}$ & 2011 & No cortical bone contact & Shortening of over $15 \mathrm{~mm}$ \\
\hline Böhme et al. ${ }^{6}$ & 2011 & NR & NR \\
\hline $\begin{array}{l}\text { Canadian Orthopaedic } \\
\text { Trauma Society }\end{array}$ & 2007 & $\begin{array}{l}\text { No cortical contact between } \\
\text { the proximal and distal } \\
\text { fragments }\end{array}$ & NR \\
\hline Chen et al. ${ }^{9}$ & 2011 & ND & ND \\
\hline Chen et al. ${ }^{10}$ & 2012 & ND & NR \\
\hline Daniilidis et al. ${ }^{13}$ & 2013 & NR & NR \\
\hline Dhakad et al. ${ }^{16}$ & 2016 & NR & NR \\
\hline Ferran et al. ${ }^{19}$ & 2010 & ND & $\begin{array}{c}\text { If there was complete overlap } \\
\text { of bone ends or a displaced } \\
\text { butterfly fragment }\end{array}$ \\
\hline Fu et al. ${ }^{20}$ & 2012 & Robinson classification 2B & NR \\
\hline Grassi et al. ${ }^{22}$ & 2001 & ND & NR \\
\hline Jones et al. ${ }^{26}$ & 2014 & $\begin{array}{c}\text { Coronal displacement of at } \\
\text { least } 100 \%\end{array}$ & $\begin{array}{c}\text { A schematic figure was used to } \\
\text { define shortening. }\end{array}$ \\
\hline Jubel et al. ${ }^{27}$ & 2002 & ND & NR \\
\hline Judd et al. ${ }^{28}$ & 2009 & ND & ND \\
\hline Kleweno et al. ${ }^{29}$ & 2011 & ND & NR \\
\hline Khorami et al..$^{30}$ & 2014 & Robinson classification 2B2,2B1 & ND \\
\hline Kulshrestha et al. ${ }^{31}$ & 2011 & $\begin{array}{l}\text { No contact between the main } \\
\text { fracture fragments }\end{array}$ & NR \\
\hline Liu et al. ${ }^{36}$ & 2010 & ND & ND \\
\hline Mealean et al. ${ }^{37}$ & 2015 & Without cortical contact & ND \\
\hline Mirtazaloei et al. ${ }^{40}$ & 2011 & ND & ND \\
\hline Narsaria et al. ${ }^{43}$ & 2014 & $\begin{array}{l}\text { At least one shaft width } \\
\text { difference in height betwee } \\
\text { the fracture parts, regardless of } \\
\text { the reduction }\end{array}$ & $>15 \mathrm{~mm}$ \\
\hline Naveen et al. ${ }^{44}$ & 2017 & Robinson type 2B & NR \\
\hline Robinson et al. ${ }^{46}$ & 2013 & Edinbrugh type $2 \mathrm{~B}$ & NR \\
\hline Saha et al. ${ }^{48}$ & 2014 & ND & NR \\
\hline Shetty et al. ${ }^{49}$ & 2017 & AO type $A$ and $B$ & NR \\
\hline
\end{tabular}


Table 4. Continued

\begin{tabular}{|c|c|c|c|}
\hline Author & Year & Dislocation & Shortening \\
\hline Smekal et al. ${ }^{51}$ & 2009 & $\begin{array}{l}\text { No cortical contact between } \\
\text { the main fragments }\end{array}$ & NR \\
\hline Tabatabaei et al. ${ }^{53}$ & 2011 & $>2 \mathrm{~cm}$ & $>2 \mathrm{~cm}$ \\
\hline Tarng et al. ${ }^{54}$ & 2012 & Type 2B2 & NR \\
\hline Thyagarajan et al. ${ }^{55}$ & 2009 & $100 \%$ & $>2 \mathrm{~cm}$ \\
\hline Van der Meijden et al. ${ }^{56}$ & 2015 & $\begin{array}{l}\text { At least one shaft width of } \\
\text { distance on any radiograph } \\
\text { between major fracture } \\
\text { fragments, regardless of } \\
\text { fracture shortening }\end{array}$ & ND \\
\hline Van der Ven et al. ${ }^{57}$ & 2015 & $\begin{array}{l}\text { No cortical contact between } \\
\text { the proximal and distal } \\
\text { fragment }\end{array}$ & NR \\
\hline Virtanen et al. ${ }^{58}$ & 2012 & $\begin{array}{l}\text { Vertical displacement of an } \\
\text { anteroposterior radiograph } \\
\text { was at least equal to the } \\
\text { width of the clavicle, such that } \\
\text { there was no cortical contact } \\
\text { between the main diaphyseal } \\
\text { fragments. }\end{array}$ & $\begin{array}{c}\text { Difference in length between } \\
\text { the injured and the uninjured } \\
\text { clavicle }\end{array}$ \\
\hline Wenninger et al. ${ }^{59}$ & 2012 & $\begin{array}{l}\text { No contact between the main } \\
\text { proximal and distal fragment }\end{array}$ & NR \\
\hline Witzel et al..$^{60}$ & 2007 & $\begin{array}{l}\text { One third of the shaft or an } \\
\text { angular velocity of more than } \\
15 \text { degrees on a AP radiograph }\end{array}$ & NR \\
\hline Wijdicks et al. ${ }^{61}$ & 2012 & $\begin{array}{l}\text { At least one shaft width } \\
\text { difference in height between } \\
\text { the fracture parts, regardless of } \\
\text { the reduction }\end{array}$ & NR \\
\hline Woltz et al. ${ }^{64}$ & 2017 & $\begin{array}{l}\text { At least } 1 \text { shaft (Robinson type } \\
\text { 2B1 or 2B2 }\end{array}$ & NR \\
\hline
\end{tabular}

$N D=$ no definition, $N R=$ not reported 
Part I - Fundamentals of clavicle fractures

Table 5. Definitions of hardware irritation used in the literature

\begin{tabular}{|c|c|c|}
\hline Author & Year & Hardware irritation \\
\hline Althausen et al. ${ }^{1}$ & 2013 & NR \\
\hline Andrade-Silva et al. ${ }^{2}$ & 2015 & ND \\
\hline Assobhi et al. ${ }^{3}$ & 2011 & Prominence of implant under the skin \\
\hline Böhme et al. ${ }^{6}$ & 2011 & NR \\
\hline $\begin{array}{l}\text { Canadian Orthopaedic } \\
\text { Trauma Society }\end{array}$ & 2007 & Hardware related (plate irritation and removal) \\
\hline Chen et al. ${ }^{9}$ & 2011 & Telescoping: painful prominence of the medial protruding nail \\
\hline Chen et al. ${ }^{10}$ & 2012 & $\begin{array}{l}\text { Patients complaint of irritation and some clinical sign, such as } \\
\text { redness and swelling of the skin }\end{array}$ \\
\hline Daniilidis et al. ${ }^{13}$ & 2013 & NR \\
\hline Dhakad et al. ${ }^{16}$ & 2016 & NR \\
\hline Ferran et al. ${ }^{19}$ & 2010 & ND \\
\hline Fu et al. ${ }^{20}$ & 2012 & NR \\
\hline Grassi et al. ${ }^{22}$ & 2001 & NR \\
\hline Jones et al. ${ }^{26}$ & 2014 & NR \\
\hline Jubel et al. ${ }^{27}$ & 2002 & NR \\
\hline Judd et al. ${ }^{28}$ & 2009 & Prominence of the lateral aspect of the pin \\
\hline Kleweno et al. ${ }^{29}$ & 2011 & Prominent symptomatic pins \\
\hline Khorami et al. ${ }^{30}$ & 2014 & NR \\
\hline Kulshrestha et al. ${ }^{31}$ & 2011 & Implant irritation required removal \\
\hline Liu et al. ${ }^{36}$ & 2010 & ND \\
\hline Mealean et al. ${ }^{37}$ & 2015 & Local irritation or plate prominence \\
\hline Mirtazaloei et al. ${ }^{40}$ & 2011 & $\begin{array}{l}\text { Irritation and prominence of hardware, especially at the } \\
\text { medial site. Patients insisted early removal of the plate }\end{array}$ \\
\hline Narsaria et al. ${ }^{43}$ & 2014 & NR \\
\hline Naveen et al. ${ }^{44}$ & 2017 & Hardware prominence \\
\hline Robinson et al. ${ }^{46}$ & 2013 & Local symptoms of hardware prominence \\
\hline Saha et al. ${ }^{48}$ & 2014 & Soft tissue irriation. Hardware prominence under the skin \\
\hline Shetty et al. ${ }^{49}$ & 2017 & NR \\
\hline Smekal et al. ${ }^{51}$ & 2009 & $\begin{array}{l}\text { Medial skin irritation without telescoping with the need for cutting } \\
\text { back the nail under local anaesthesia }\end{array}$ \\
\hline Tabatabaei et al. ${ }^{53}$ & 2011 & Patient complained of symptomatic hardware \\
\hline Tarng et al. ${ }^{54}$ & 2012 & $\begin{array}{l}\text { Patient requesting implant removal due to skin tenting and } \\
\text { irritation }\end{array}$ \\
\hline Thyagarajan et al. ${ }^{55}$ & 2009 & Prominent metal work causing discomfort \\
\hline Van der Meijden et al. ${ }^{56}$ & 2015 & Implant related problems (soft tissue irriation) \\
\hline Van der Ven et al. ${ }^{57}$ & 2015 & Irritation requiring removal \\
\hline Virtanen et al. ${ }^{58}$ & 2012 & If fixation produced irritation \\
\hline Wenninger et al. ${ }^{59}$ & 2012 & Skin or soft tissue irritation \\
\hline Witzel et al. ${ }^{60}$ & 2007 & NR \\
\hline Wijdicks et al. ${ }^{61}$ & 2012 & $\begin{array}{c}\text { Assessed clinically and caused by prominence of the implant } \\
\text { material of in case of TEN medial or lateral protrusion }\end{array}$ \\
\hline Woltz et al. ${ }^{64}$ & 2017 & NR \\
\hline
\end{tabular}




\section{Infection}

Thirty-three (89\%) studies reported infections rates in their results. Ten (30\%) studies did report infection rates but did not use a definition for infection. Six (26\%) studies defined superficial infection as in requiring antibiotics and 1 (4\%) studies requiring re-intervention. For deep infections in one (5\%) study definition involves required

only antibiotics and in five (22\%) studies re-interventions. (Table 6)

Table 6. Definition infection used in literature

\begin{tabular}{lc}
\hline Infection & $\begin{array}{c}\text { Number of studies } \\
\mathbf{n}=\end{array}$ \\
\hline Superficial infection & 6 \\
Requiring antibiotics & 1 \\
Requiring re-intervention & 4 \\
No specification & 1 \\
Deep infection & 6 \\
Requiring antibiotics & 3 \\
Requiring re-intervention & \\
No specification & 8 \\
Infection & 10 \\
Requiring antibiotics and/or re-intervention & 4 \\
No definition & \\
Not reported & \\
\hline
\end{tabular}

\section{DISCUSSION}

The most important findings of this study were that a wide variation in definitions is used in the management of clavicle fractures and in several of the included studies definitions were not reported at all. The diversity of currently applied definitions, if reported at all, reflects the lack of consensus. This stresses the need for standardization of definitions used in the management of (clavicle) fractures.,52 In a systematic review of studies analyzing fracture healing in orthopedic trauma studies, the investigators reported that the majority of studies (62\%) used a combination of clinical and radiographic criteria, while only radiographic criteria were used in $37 \%$ of the studies, and clinical criteria only in $1 \% .{ }^{12}$ Plain radiography (an anterior-posterior [AP] view and a radiograph with a $\left(15^{\circ}-45^{\circ}\right)$ horizontal angle) is generally the most common way to assess fracture union radiological and a 
substantial number of studies defined fracture union based on these radiographic parameters alone. In a review of 77 clinical studies on long-bone fracture healing, which used clinical criteria to define fracture union, the three most commonly used clinical criteria were absence of pain or tenderness when weight bearing (49\%), absence of pain or tenderness on palpation or examination (39\%) and the ability to bear weight (18\%). ${ }^{12}$ When defining nonunion of clavicle fractures we found that 7 (50\%) studies used only radiological criteria and 6 (43\%) combined it with clinical criteria. The clinical criteria used were pain at the fracture site and motion or a gap present between the fracture parts. Herewith possibly excluding patients with an asymptomatic nonunion, which may influence study outcomes, the comparability of different studies and the timing of possible secondary interventions. Interestingly enough, more than half of the included studies (59\%) did not describe a definition for nonunion. Besides the lack of a definition for the existence of a non-union, further dissimilarities are seen in assessing the time period for nonunion and delayed union. This varies from 4 months until 1 year for nonunion 2, 8, 10, 20,31, 37, 40, 43, 51, 56-59,61,63 and 3 months to 1 year for delayed union. ${ }^{10,46,51,57,58}$ This raises the question if there exists a difference between the two entities as described in the current literature at all. Another often discussed problem after surgical treatment of displaced midshaft clavicle fractures is implant-related irritation..$^{25}$ In current literature a wide variation of reported irritation rates exist, ranging from 9\% to 44\% after plate fixation and 9\% to $62 \%$ after IM nailing ${ }^{25}$ and is mainly treated with surgical implant removal. In the studies included in this current review, the rationale for implant removal is often not clearly described. Implant related irritation does not always lead to implant removal and indications for implant removal vary; including implant-related irritation, implant failure, nonunion, patient's preference, or surgeon's preference to prevent future complications. Implant-related irritation is, thereby, a subjective endpoint and is influenced by a multitude of variables.

\section{CONCLUSION}

At present a wide variety of definitions for disorders of clavicle fracture healing, adverse events or functional outcome exist making it difficult to compare study data. Therefore, we propose standardized definitions for the analysis of clavicle fracture management. These definitions, which are based on radiographic findings, and clinical examination, should provide a better determination of fracture union in the future. Until consensus is reached, we must be aware of the limitations of the methods that we currently use. 


\section{REFERENCES}

1. Althausen PL, Shannon S, Lu M, O'Mara TJ, Bray TJ. Clinical and financial comparison of operative and nonoperative treatment of displaced clavicle fractures. J Shoulder Elbow Surg. 2013; 22(5):608-611.

2. Andrade-Silva $F B$, Kojima $K E$, Joeris $A$, Santos Silva J, Mattar R Jr. Single, superiorly placed reconstruction plate compared with flexible intramedullary nailing for midshaft clavicular fractures. J Bone Joint Surg Am 2015; 97:620-6. http://dx.doi.org/10.2106/ JBJS.N 00497

3. Assobhi JE. Reconstruction plate versus minimal invasive retrograde titanium elastic nail fixation for displaced midclavicular fractures. J Orthop Traumatol 2011; 12:185-92. http://dx.doi.org/10.1007/s10195-011-0158-7

4. Ban I, Branner U, Holck K, Krasheninnikoff M, Troelsen A. Clavicle fractures may be conservatively treated with acceptable results: a systematic review. Dan Med J. 2012; 59(7): A4457

5. Bhandari M, Guyatt GH, Swiontkowski MF, Tornetta P 3rd, Sprague S, Schemitsch EH. A lack of consensus in the assessment of fracture healing among orthopaedic surgeons. J Orthop Trauma. 2002; 16:562-6.

6. Bohme J, Bonk A, Bacher GO, Wilharm A, Hoffmann R, Josten C. [Current treatment concepts for mid-shaft fractures of the clavicle: results of a prospective multicentre study]. Z Orthop Unfall. 2011; 149(1): 68-76.

7. Calbiyik M, Ipek D, Taskoparan M. Prospective randomized study comparing results of fixation for clavicular shaft fractures with intramedullary nail or locking compression plate.Int Orthop. 2017 Jan; 41(1): 173-179. Doi: 10.1007/s00264016-3192-5. Epub 2016 May 2.

8. Canadian Orthopaedic Trauma Society. Nonoperative treatment compared with plate fixation of displaced midshaft clavicular fractures: a multicenter randomized clinical trial. J Bone Joint Surg Am. 2007; 89(1): 1-10.
9. Chen QY, Kou DQ, Cheng XJ, Zhang W, Wang W, Lin ZQ et al. Intramedullary nailing of clavicular midshaft fractures in adults using titanium elastic nail. Chin J Traumatol. 2011; 14(5): 269-276.

10. Chen YF, Wei HF, Zhang C, Zeng BF, Zhang CQ, Xue JF, et al. Retrospective comparison of titanium elastic nail (TEN) and reconstruction plate repair of displaced midshaft clavicular fractures. J Shoulder Elbow Surg 2012; 21:495-501. http://dx.doi. org/10.1016/ j.jse.2011.03.007

11. Constant CR, Murley AH. A clinical method of functional assessment of the shoulder. Clin Orthop Relat Res. 1987; 214:160-164.

12. Corrales LA, Morshed S, Bhandari M, Miclau T. Variability in the assessment of fracture healing in orthopaedic trauma studies. J Bone Joint Surg Am. 2008; 90:1862-1868.

13. Daniilidis K, Raschke MJ, Vogt B, Herbort M, Schliemann B, Gunther N et al. Comparison between conservative and surgical treatment of midshaft clavicle fractures: outcome of 151 cases. Technol Health Care. 2013; 21(2): 143-147.

14. Davis BJ, Roberts PJ, Moorcroft Cl, Brown MF, Thomas PB, Wade RH. Reliability of radiographs in defining union of internally fixed fractures. Injury. 2004; 35:557-61.

15. Dawson J, Rogers K, Fitzpatrick R, Carr A. The Oxford shoulder score revisited. Arch Orthop Trauma Surg. 2009; 129:119123.

16. Dhakad RK, Panwar M, Gupta S. Plating versus conservative treatment in mid shaft fractures of clavicle: A comparative study.J Clin Orthop Trauma. 2016 Oct-Dec; 7(Suppl 2): 166-170. Doi: 10.1016/j.jcot.2015.11.002. Epub 2016 Sep 1.

17. Dijkman BG, Sprague S, Schemitsch EH, Bhandari M. When is a fracture healed? Radiographic and clinical criteria revisited. J Orthop Trauma 2010; 24(Suppl 1): S76-80. Doi: 10.1097/BOT.0b013e3181ca3f97 
18. Duan X, Zhong G, Cen S, Huang F, Xiang $Z$. Plating versus intramedullary pin or conservative treatment for midshaft fracture of clavicle: a meta-analysis of randomized controlled trials. J Shoulder Elbow Surg. 2011; 20(6): 1008-1015.

19. Ferran NA, Hodgson P, Vannet N, Williams R, Evans RO. Locked intramedullary fixation vs plating for displaced and shortened midshaft clavicle fractures: a randomized clinical trial. J Shoulder Elbow Surg 2010; 19:783-9. http://dx.doi.org/10.1016/j.jse.2010.05.002

20. Fu TH, Tan BL, Liu HC, Wang JW. Anatomical reduction for treatment of displaced midshaft clavicular fractures: Knowles pinning vs. reconstruction plating. Orthopedics 2012; 35:e23-30. http://dx.doi. org/ 10.3928/01477447-20111122-05

21. George DM, McKay BP, Jaarsma RL. The long-term outcome of displaced mid-third clavicle fractures on scapular and shoulder function: variations between immediate surgery, delayed surgery, and nonsur- gical management. J Shoulder Elbow Surg. 2015;24(5):669-676.

22. GrassiFA, Tajana MS, D'Angelo F.Management of midclavicular frac- tures: comparison between nonoperative treatment and open intrame- dullary fixation in 80 patients. J Trauma. 2001;50(6):1096-1100.

23. Houwert RM, Smeeing DP, Ahmed Ali U, Hietbrink F, Kruyt MC, van der Meijden OA. Plate fixation or intramedullary fixation for midshaft clavicle fractures: a systematic review and meta-analysis of randomized controlled trials and observational studies.

24. J Shoulder Elbow Surg. 2016 Jul;25(7):1195203. doi: 10.1016/j.jse.2016.01.08

25. Hudak PL, Amadio PC, Bombardier C. Development of an upper extremity outcome measure: the DASH (Disabilities of the Arm, Shoulder and Hand) [corrected]. The Upper Extremity Collaborative Group (UECG). Am J Ind Med. 1996;29(6):602-608.
26. Hulsmans $M H$, van Heijl M, Houwert RM, Hammacher ER, Meylaerts SA, Verhofstad $\mathrm{MH}$ et al. High Irritation and Removal Rates After Plate or Nail Fixation in Patients With Displaced Midshaft Clavicle Fractures. Clin Orthop Relat Res. 2017 Feb;475(2):532-539. doi: 10.1007/s11999-016-5113-8. Epub 2016 Nov 9

27. Jones LD, Grammatopoulos G, Kambouroglou G. Titanium elastic nails, open reduction internal fixation and nonoperative management for middle third clavicle fractures: a comparative study. Eur J Orthop Surg Traumatol 2014;24:3239. http://dx.doi.org/10.1007/s00590-013 $-1191-4$

28. Jubel A, Andermahr J, Faymonville C, Binnebosel M, Prokop A, Rehm KE. [Reconstruction of shoulder-girdle symmetry after midcla- vicular fractures: stable, elastic intramedullary pinning versus ruck- sack bandage]. Chirurg. 2002;73(10):978-981.

29. Judd DB, Pallis MP, Smith E, Bottoni CR. Acute operative stabilization versus nonoperative management of clavicle fractures. Am J Orthop (Belle Mead NJ). 2009;38(7):341-345.

30. Kleweno $C P$, Jawa $A$, Wells JH, O'Brien TG, Higgins LD, Harris MB, et al. Midshaft clavicular fractures: comparison of intramedullary pin and plate fixation. J Shoulder Elbow Surg 2011;20:1114-7. http://dx.doi.org/10.1016/j.jse.2011.03.022

31. Khorami M, Fakour M, Mokarrami H, Arti HR, Nasab AM, Shahrivar F. The comparison of results of treatment of midshaft clavicle fracture between operative treatment with plate and non-operative treatment. Arch Bone Joint Surg. 2014;2(3):210-214.

32. Kulshrestha $V$, Roy $T$, Audige L. Operative versus nonoperative management of displaced midshaft clavicle fractures: a prospective cohort study. J Orthop Trauma. 2011;25(1):31-38. 
33. Lee YS, Huang HL, Lo TY, Hsieh YF, Huang CR. Surgical treatment of midclavicular fractures: a prospective comparison of Knowles pinning and plate fixation. Int Orthop 2008;32:541-5. http://dx.doi. org/10.1007/ s00264-007-0352-7

34. Lee YS, Lin CC, Huang CR, Chen CN, Liao WY. Operative treatment of midclavicular fractures in 62 elderly patients: Knowles pin versus plate. Orthopedics 2007;30:95964. http://dx.doi.org/10.3928/ 0147744720071101-13

35. Lenza M, Buchbinder R, Johnston RV, Belloti JC, Faloppa F. Surgical versus conservative interventions for treating fractures of the middle third of the clavicle. Cochrane Database Syst Rev. 2013;6:CD009363.

36. L'Insalata JC, Warren RF, Cohen SB, Altchek DW, Peterson MG. A self-administered questionnaire for assessment of symptoms and function of the shoulder. J Bone Joint Surg Am. 1997 May;79(5):738-48.

37. Liu GQ, Zhao L, Li L, Wang LM, Zhang JH. A meta-analysis of com- parison between operative and nonoperative treatment on the mid- shaft clavicle fractures. Life Sci J. 2014;11(8):810-816.

38. Melean PA, Zuniga A, Marsalli M, Fritis NA, CookER, Zilleruelo M et al.Surgical treatment of displaced middle-third clavicular fractures: a prospective, randomized trial in a working compensation population. J Shoulder Elbow Surg. 2015;24(4):587-592.

39. Mckee RC, Whelan DB, Schemitsch EH, Mckee MD. Operative versus nonoperative care of displaced midshaft clavicular fractures: a meta-analysis of randomized clinical trials. J Bone Joint Surg Am. 2012;94:675-84.

40. Michener LA, McClure PW, Sennett BJ. American Shoulder and Elbow Surgeons Standardized Shoulder Assessment Form, patient self-report section: reliability, validity, and responsiveness. J Shoulder Elbow Surg 2002; 11(6):587-94
41. Mirzatolooei F. Comparison between operative and nonoperative treatment methods in the management of comminuted fractures of the clavicle. Acta Orthop Traumatol Turc. 2011;45(1):34-40.

42. Morshed S, Corrales L, Genant H, Miclau T. Outcome assessment in clinical trials of fracture-healing. J Bone Joint Surg Am. 2008;90:62-67.

43. Moher D, Liberati A, Tetzlaff J, Altman DG, Group P. Preferred reporting items for systematic reviews and meta-analyses: the PRISMA statement. BMJ. 2009;339:b2535.

44. Narsaria N, Singh AK, Arun GR, Seth RR. Surgical fixation of displaced midshaft clavicle fractures: elastic intramedullary nailing versus precontoured plating. J Orthop Traumatol 2014;15:165-71. http:// dx.doi.org/10.1007/s10195-014-0298-7

45. Naveen BM, Joshi GR, Harikrishnan B. Management of mid-shaft clavicular fractures: comparison between nonoperative treatment and plate fixation in 60 patients.

46. Strategies Trauma Limb Reconstr. 2017 Apr;12(1):11-18. doi: 10.1007/s11751-0160272-4. Epub 2017 Jan 4.

47. Neer CS. Nonunion of the clavicle. J Am Med Assoc 1960; 172: 1006-1011.

48. Robinson CM, Goudie EB, Murray IR, Jenkins PJ, Ahktar MA, Read EO et al. Open reduction and plate fixation versus nonoperative treatment for displaced midshaft clavicular fractures: a multicenter, randomized, controlled trial. J Bone Joint Surg Am. 2013 Sep 4;95(17):1576-84. doi: 10.2106/JBJS.L.00307.

49. Rowe CR. An atlas of anatomy and treatment of midclavicular fractures. Clin Orthop Relat Res. 1968;58: 29-42.

50. Saha P, Datta P, Ayan S, Garg AK, Bandyopadhyay U, Kundu S. Plate versus titanium elastic nail in treatment of displaced midshaft clavicle fractures: a comparative study. Indian J Orthop 2014;48:587-93. http://dx.doi.org/10.4103/0019-5413.144227 
51. Shetty SK, Chandran R, Ballal A, Mathias LJ, Hegde A, Shetty A. To Operate or not to Operate the Mid-Shaft Fractures of the clavicle: A Comparative Study of Functional Outcomes of the Two Methods of Management.J Clin Diagn Res. 2017 Jan;11(1):RC01-RC03. doi: 10.7860/ JCDR/2017/22052.9143. Epub 2017 Jan 1.

52. Smeeing DP, van der Ven DJ, Hietbrink F, Timmers TK, van Heijl M, Kruyt MC et al. Surgical Versus Nonsurgical Treatment for Midshaft Clavicle Fractures in Patients Aged 16 Years and Older: A Systematic Review, Meta-analysis, and Comparison of Randomized Controlled Trials and Observational Studies.Am J Sports Med. 2016 Nov 18. pii: 036354651667361

53. Smekal V, Irenberger A, Struve P, Wambacher M, Krappinger D, Kralinger FS. Elastic stable intramedullary nailing versus nonoperative treatment of displaced midshaft clavicular fractures-a randomized, controlled, clinical trial. J Orthop Trauma. 2009 Feb;23(2):10612. doi: 10.1097/BOT.0b013e318190cf88.

54. Swiontkowski MF, Buckwalter JA, Keller RB, Haralson R. The outcomes movement in orthopaedic surgery: where we are and where we should go. J Bone Joint Surg Am. 1999;81:732-40.

55. Tabatabaei S, Shalamzari S. Treatment of displaced midshaft clavicular fractures: a comparison between smooth pin and LCDCP and reconstruction plate fixation. Pak J Med Sci 2011;27:1129-34.

56. Tarng YW, Yang SW, Fang YP, Hsu CJ. Surgical management of uncomplicated midshaft clavicle fractures: a comparison between titanium elastic nails and small reconstruction plates. J Shoulder Elbow Surg 2012;21:732-40. http://dx.doi. org/10.1016/j.jse.2011.08.065

57. Thyagarajan S, Day M, Dent C, Williams R, Evans R. Treatment of mid-shaft clavicle fractures: a comparative study. Int J Shoulder Surg 2009;3:23-7. http://dx.doi. org/10.4103/0973-6042.57895
58. van der Meijden OA, Houwert RM, Hulsmans M, Wijdicks FJ, Dijkgraaf MGW, Meylaerts SAG, et al. Operative treatment of dislocated midshaft clavicular fractures: plate or intramedullary nail fixation? A randomized controlled trial. J Bone Joint Surg Am 2015;97:613-9. http://dx.doi. org/10.2106/JBJS.N.00449

59. van der Ven DJC, Timmers TK, Flikweert $P E$, Van ljseldijk AL, van Olden GD. Plate fixation versus conservative treatment of dis- placed midshaft clavicle fractures: functional outcome and patients' satisfaction during a mean follow-up of 5 years. Injury. 2015;46(11):2223-2229.

60. Virtanen KJ, Remes V, Pajarinen J, Savolainen V, Bjorkenheim JM, Paavola M. Sling compared with plate osteosynthesis for treatment of displaced midshaft clavicular fractures: a randomized clinical trial. J Bone Joint Surg Am. 2012;94(17):1546-1553.

61. Wenninger JJ Jr, Dannenbaum JH, Branstetter JG, Arrington ED. Comparison of complication rates of intramedullary pin fixation versus plating of midshaft clavicle fractures in an active duty military population. J Surg Orthop Adv 2013;22:77-81. http://dx.doi.org/10.3113/ JSOA.2013.0077

62. Witzel K. [Intramedullary osteosynthesis in fractures of the mid-third of the clavicle in sports traumatology]. Z Orthop Unfall. 2007; 145(5):639-642.

63. Wijdicks FJ, Houwert $M$, Dijkgraaf $M$, de Lange D, Oosterhuis K, Clevers G, et al. Complications after plate fixation and elastic stable intramedullary nailing of dislocated midshaft clavicle fractures: a retrospective comparison. Int Orthop 2012;36:2139-45. http://dx.doi.org/ 10.1007/s00264-012$1615-5$

64. Williams GN, GangelTJ, Arciero RA, Uhorchak JM, Taylor DC. Comparison of the Single Assessment Numeric Evaluation method and two shoulder rating scales. Outcomes measures after shoulder surgery. Am J Sports Med. 1999 Mar-Apr;27(2):214-21. 
65. Woltz S, Krijnen P, Meylaerts SA, Pieterse $\mathrm{AH}$, Schipper IB. Shared decision making in the management of midshaft clavicular fractures: Nonoperative treatment or plate fixation.Injury. 2017 Feb 27. pii: S0020-1383(17)30126-2. doi: 10.1016/j. injury.2017.02.032. [Epub ahead of print]

66. Woltz S, Stegeman SA, Krijnen $P$, van Dijkman BA, van Thiel TP, Schep NW et al. Plate Fixation Compared with Nonoperative Treatment for Displaced Midshaft Clavicular Fractures: A Multicenter Randomized Controlled Trial.J Bone Joint Surg Am. 2017 Jan 18;99(2):106-112. doi: 10.2106/ JBJS.15.01394.
67. Zehir S, Zehir R, Sahin E, Calbiyik M. Comparison of novel intramedullary nailing with mini-invasive plating in surgical fixation of displaced midshaft clavicle fractures. Arch Orthop Trauma Surg 2015;135:339-44. http://dx.doi.org/10.1007/ s00402-014-2142-1 
Part I - Fundamentals of clavicle fractures

Appendix 1 Search strings: Smeeing et al. Surgical Versus Nonsurgical Treatment for Midshaft Clavicle Fractures in Patients Aged 16 Years and Older

\begin{tabular}{|c|c|c|}
\hline Database & Searchstring & Hits \\
\hline Pubmed & $\begin{array}{l}\text { (clavicle[MeSH Terms] OR clavicle[Title/Abstract] OR } \\
\text { clavicula[Title/Abstract] OR claviculae[Title/Abstract] OR } \\
\text { clavicular[Title/Abstract] OR collarbone[Title/Abstract] OR collar } \\
\text { bone[Title/Abstract]) AND } \\
\text { (Fractures, bone[MeSH Terms] OR fracture[Title/Abstract] OR } \\
\text { fractured[Title/Abstract] OR fractures[Title/Abstract]) AND } \\
\text { (midshaft[Title/Abstract] OR mid shaft[Title/Abstract] OR } \\
\text { midclavicular[Title/Abstract] OR mid clavicular[Title/Abstract] } \\
\text { OR midclavicle[Title/Abstract] OR mid clavicle[Title/Abstract] OR } \\
\text { middle third[Title/Abstract] OR mid third[Title/Abstract]) AND } \\
\text { (surgery[subheading] OR Fracture Healing[MeSH Terms] } \\
\text { OR Fracture Fixation[MeSH Terms] OR Surgical Procedures, } \\
\text { Operative[MeSH Terms] OR Physical Therapy Modalities[MeSH } \\
\text { Terms] OR orthopedics[MeSH Terms] OR orthopedics[Title/ } \\
\text { Abstract] OR orthopaedics[Title/Abstract] OR surgery[Title/ } \\
\text { Abstract] OR surgical[Title/Abstract] OR operative[Title/Abstract] } \\
\text { OR operation[Title/Abstract] OR conservative[Title/Abstract] OR } \\
\text { conventional[Title/Abstract] OR non-operative[Title/Abstract] OR } \\
\text { nonoperative[Title/Abstract] OR sling[Title/Abstract] OR figure- } \\
\text { of-eight bandage[Title/Abstract]) }\end{array}$ & 408 \\
\hline Embase & $\begin{array}{l}\text { ('clavicle'/exp OR clavicle:ti,ab OR clavicula:ti,ab OR claviculae:ti,ab } \\
\text { OR clavicular:ti,ab OR collarbone:ti,ab OR 'collar bone':ti,ab) AND } \\
\text { ('fracture'/exp OR fracture:ti,ab OR fractured:ti,ab OR } \\
\text { fractures:ti,ab) AND } \\
\text { (midshaft:ti,ab OR'mid shaft':ti,ab OR midclavicular:ti,ab OR'mid } \\
\text { clavicular':ti,ab OR midclavicle:ti,ab OR'mid clavicle':ti,ab OR } \\
\text { 'middle third':ti,ab OR'mid third':ti,ab) AND } \\
\text { ('surgery'/exp OR surgery:ti,ab OR surgical:ti,ab OR } \\
\text { operative:ti,ab OR operation:ti,ab OR'conservative treatment'/ } \\
\text { exp OR 'conservative treatment':ti,ab OR conservative:ti,ab OR } \\
\text { conventional:ti,ab OR'non-operative':ti,ab OR nonoperative:ti,ab) }\end{array}$ & 468 \\
\hline $\begin{array}{l}\text { The Cochrane } \\
\text { Library }\end{array}$ & (clavicle AND fracture) & 94 \\
\hline CINAHL & $\begin{array}{l}\text { (clavicle OR clavicula OR claviculae OR clavicular OR collarbone } \\
\text { OR collar bone) AND (fracture OR fractured OR fractures) AND } \\
\text { (midshaft OR mid shaft OR midclavicular OR mid clavicular OR } \\
\text { midclavicle OR mid clavicle OR middle third OR mid third) AND } \\
\text { (surgery OR surgical OR operative OR operation OR conservative } \\
\text { OR conventional OR non-operative OR nonoperative) }\end{array}$ & 110 \\
\hline
\end{tabular}


Search strings: Houwert et al. Plate fixation or intramedullary fixation for midshaft clavicle fractures: a systematic review and meta-analysis of randomized controlled trials and observational studies.

\begin{tabular}{lll}
\hline Database & Searchstring & Hits \\
\hline PubMed & $(((((($ surgery[Title/Abstract]) OR surgical[Title/Abstract]) OR & 245 \\
& operative[Title/Abstract]) OR operation[Title/Abstract])) AND \\
& $(((((c l a v i c l e[T i t l e / A b s t r a c t])$ OR clavicular[Title/Abstract]) OR \\
& collarbone[Title/Abstract]) OR clavicula[Title/Abstract]) OR \\
& claviculae[Title/Abstract])) AND ((fracture[Title/Abstract]) OR \\
& fractured[Title/Abstract]) OR fractures[Title/Abstract])) AND \\
& $((((((((($ midshaft[Title/Abstract]) OR mid shaft[Title/Abstract]) OR \\
& midschaft[Title/Abstract]) OR mid schaft[Title/Abstract]) OR mid \\
& clavicular[Title/Abstract]) OR midclavicular[Title/Abstract]) OR \\
& mid clavicle[Title/Abstract]) OR midclavicle[Title/Abstract]) OR \\
& middle third[Title/Abstract]) OR mid third[Title/Abstract]) \\
& 'surgery'/exp AND'clavicle fracture'/exp AND ('midshaft'OR & 313 \\
EMBASE & 'mid shaft'OR'midschaft'OR'mid schaft'OR'mid clavicular'OR \\
& 'midclavicular'OR'mid clavicle'OR'midclavicle'OR'middle third' \\
& OR'mid third') AND [embase]/lim \\
& Clavicle & \\
\hline
\end{tabular}




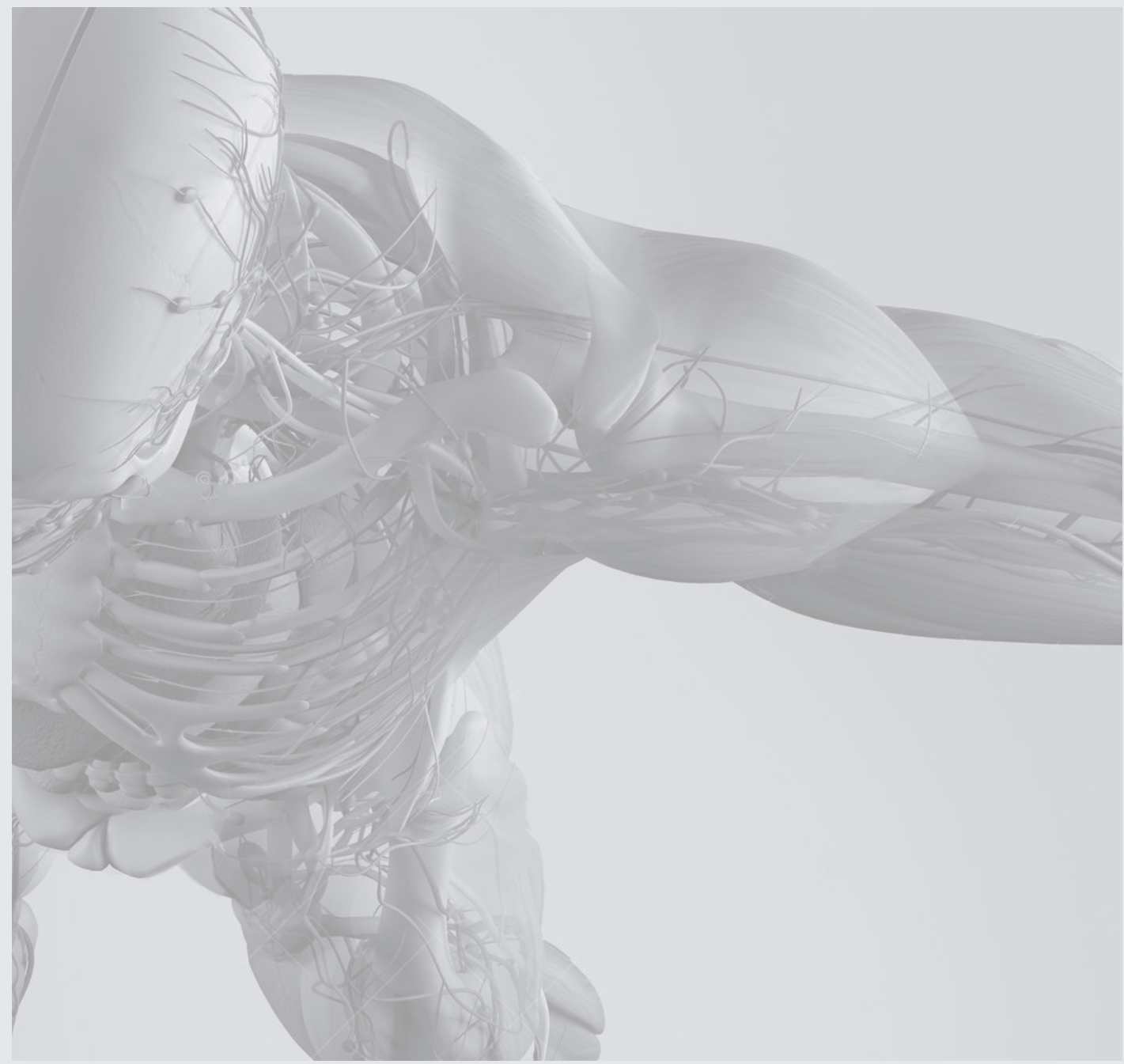




\section{CHAPTER THREE}

\section{Musculoskeletal modeling of midshaft clavicle fractures by using finite element analysis}




\section{ABSTRACT}

\section{Introduction}

Biomechanical studies present contradicting results regarding the position for plate fixation of the clavicle. Therefore, the aim of this study was to develop a musculoskeletal model in which muscles and ligaments are included. The model was developed to evaluate the magnitude and the direction of forces acting on the clavicle during rehabilitation and daily activities. This information could be applied to investigate whether anteroinferior and superior plate fixation can withstand these forces without permanentdeformation or breakage and thus provides stable fixation.

\section{Methods}

An existing musculoskeletal model, the Delft Shoulder and Elbow Model, was used to calculate muscle, ligament, and joint reaction forces on the clavicle. A clavicle finite element model with a midshaft fracture was made. Muscles, ligaments, joint reaction, and gravitational forces were added to the finite element model. Models of the superior and anteroinferior plate were made. A simulation of the plates and the bone was done to determine the von Mises stress, the displacement, and the strain, for both abduction and anteflexion.

\section{Results}

The simulated von Mises stresses stayed below the yield strength. The von Mises stress is higher for anteroinferior plate fixation. The displacement and the strain are similar for anteroinferior and superior plate fixation.

\section{Conclusion}

The superior plating method has a lower von Mises stress and strain. Nevertheless, the difference in von Mises stress and strain with the anteroinferior plating is minimal. Both plating methods can withstand the forces without permanent deformation or breakage and therefore provide a stable fixation. However, validation of the model is needed, before a recommendation about the plate positioning can be made. 


\section{INTRODUCTION}

Clavicle fractures are common in adults, accounting for $2.6-4 \%$ of all fractures. ${ }^{1-5}$ This injury is caused by a direct axial compressive force to the shoulder after a sudden stop or fall, and commonly afflicts a young and active population. ${ }^{3,6-9}$ The majority of fractures (69-80\%) is located in the middle-third of the clavicle. 3,5,6,10 The s-shape of the bone and the anatomy of the ligaments/muscles attached to the clavicle make this part the most likely to fracture. ${ }^{11}$ When the midshaft of the clavicle is fractured, muscles, ligaments, and the weight of the arm cause displacement of the bone parts. ${ }^{5,8,11}$ Clavicle fractures have traditionally been treated conservatively, even when substantially displaced.5,9,12 However, there is evidence that nonunion incidence is higher than previously believed.,12-19 Therefore, surgery should be considered as treatment option for displaced midshaft clavicle. Superior clavicle plating used to be the standard approach. Anteroinferior placement of the plate was introduced in an effort to decrease implant prominence, reducing the need for plate removal, and improve mechanical stability.

However, there is still no consensus regarding the ideal position of the clavicle plate. ${ }^{20}$ There are several in vitro biomechanical studies suggesting that superior placement of the plate is preferable, ${ }^{20-23}$ while the anteroinferior plate position is known for satisfactory clinical results. ${ }^{12,23-27}$ In both methods nonunion, refracture, hardware failure (screw pull-out, plate breakage, angulation or loosening), and deep infection are the most common complications. 14,27,28 Only static tests were performed to investigate the ideal plate position in order to minimize complications. The primary aim of this study was to develop a musculoskeletal clavicle model in which all attached muscles and ligaments are included. The secondary aim was to use this in vivo based model to evaluate the magnitude and the direction of forces acting on the clavicle during rehabilitation and daily activities. Herewith determine which plate positioning can provide to most stable fixation.

\section{METHODS}

Musculoskeletal modelling and finite element analysis (FEA) were used to determine the effects of activities of daily living on the clavicle. Also, plate stresses were determined for both superior and anteroinferior plate fixation. FEA is a numerical method, used to solve complex models with a lot of components. A mesh is calculated and material properties are defined. The mesh and properties determine how the object will react to forces. These forces can be chosen by the researcher and allow testing numerous movements, forces, plating orientations, fracture orientations, and bone mineralization, while keeping the rest of the 
biomechanical characteristics of the clavicle constant. Firstly, muscles, ligaments, and joint reaction forces were calculated by using the Delft Shoulder and Elbow Model (DSEM, Delft University, The Netherlands). This is an inverse dynamics musculoskeletal model and uses EMG and joint angle data to compute the forces in the shoulder joint..29-34 EMG data, joint data, and force data were available for 6 ranges of motion movements and 5 activities of daily living. ${ }^{31}$ Shoulder abduction and anteflexion had our main focus. The model outputs were given as forces (in Newton) in the local coordinate system of the clavicle (Appendix 1).Secondly, a clavicle finite element model (FEM) was made of the cortex (in SolidWorks 2016 x64 Edition, Dassault Systèmes S.A., Vélizy, France). The intermedullairy space was modelled as a cavity within the cortex. An oblique midshaft fracture was introduced into the model, by splitting the clavicle into two parts. The clavicle was meshed for FEA. Hereafter, ligaments (conoid, trapezoid and costoclavicular) (Figure 1A), muscles (deltoid, pectoralis major, and trapezius) and joint reaction forces were extracted from the DSEM. These forces were added to the clavicle model. In addition, a gravitational force was also added to the model (Figure 1B). The sternocleidomastoid muscle was not included in the DSEM.

Therefore, this muscle was given a value of 145 Newton for anteflexion and 170 Newton for abduction, based on literature. ${ }^{35,36}$ Thirdly, models of a titanium anteroinferior (Figure 2A) and superior (Figure 2B) plate were made. These models are based on the plates of DePuy Synthes (the LCP Superior Clavicle Plate $3.5 \mathrm{~mm}$, left 8 holes and the VA-LCP Anterior Clavicle Plate 2.7/3.5, 9 holes). The plate was centered on the bone, with an equal amount of locking screws on both sides of the fracture. Screw holes were made in the bone for bicortical fixation. Two simulations for both the plates and the bone (one for abduction and one for anteflexion) were made to determine the von Mises stress, the fracture displacement, and strain. These simulations were done for the clavicle with and without a fracture and for the situation in which the clavicle fracture has been fixated with the superior and anteroinferior positioned plates. 


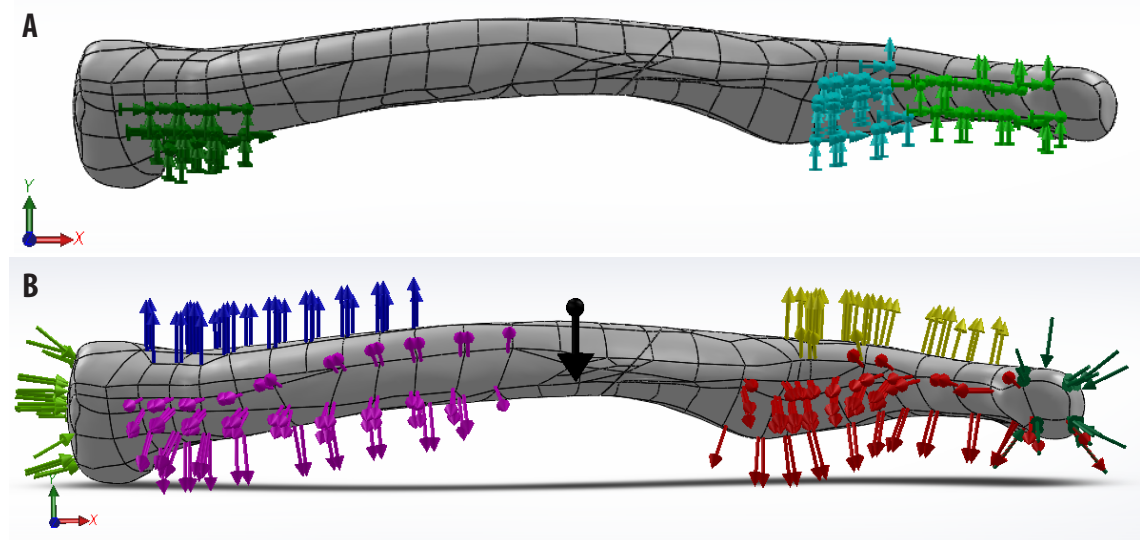

Figure 1.

A) A visualization of the fractured clavicle SolidWorks model with the ligaments (as fixed locations). Dark green: costoclavicular ligament, light blue: conoid ligament, light green: trapezoid ligament. Every point is fixed in the $x-, y$ - and $z$-direction, indicated by three arrows. The disk at the start of the arrow indicates the fixation and the direction of the arrow indicates the direction in which the clavicle is fixed.

B) A visualization of the fractured clavicle SolidWorks model with the forces. Only the conoid ligament is not shown, but this is shown in figure 3a. Light green: sternoclavicular joint reaction force, blue: sternocleidomastoid muscle, purple: pectoralis major muscle, black: gravity, yellow: trapezoid muscle, red: deltoid muscle, dark green: acromioclavicular joint reaction force. The direction of the arrow indicates whether the force pulls or pushes the bone. Note that, the arrows do not indicate the actual direction of the forces, except for the sternocleidomastoid muscle force and the gravity. The gravity has its point of action in the center of mass, which is located at the lowest point of the arrow.
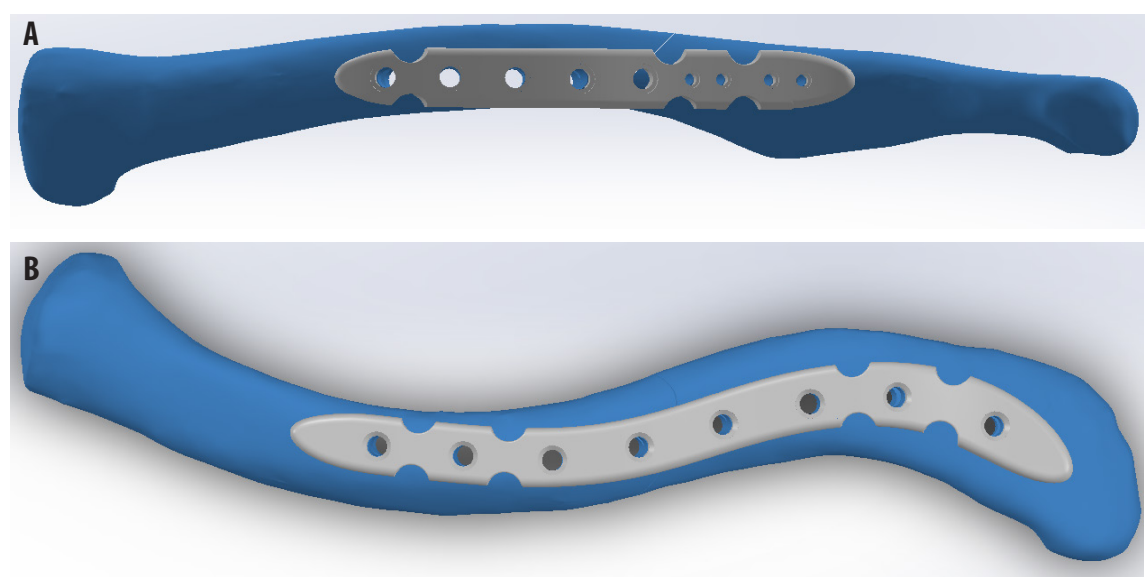

Figure 2.

A) A visualization (frontal view) of the clavicle, with the midshaft fracture and anteroinferior plate fixation. B) A visualization (top view) of the clavicle, with the midshaft fracture and superior plate fixation. 


\section{RESULTS}

Table 1 and 2 and Figures 2-5 in Addendum III show the force values of the DSEM that were used.

Table 1. Force values for anteflexion, used in the finite element model.

\begin{tabular}{lcccccc}
\hline Force direction & SC & AC & L. conoid & Pectoralis major & Deltoid & Trapezoid \\
\hline $\mathrm{X}$ & 68.29 & -106.22 & 10.66 & 16.35 & 34.89 & -16.48 \\
$\mathrm{y}$ & 36.02 & -21.54 & -35.17 & -5.47 & -18.33 & 10.82 \\
$\mathrm{z}$ & 40.81 & -21.22 & 9.89 & -5.65 & -37.39 & 5.66 \\
\hline
\end{tabular}

SC: sternoclavicular joint, AC: acromioclavicular joint. A negative value means that the force is in the opposite direction. All values are in Newton.

Table 2. Force values for abduction, used in the finite element model.

\begin{tabular}{lcccccc}
\hline Force direction & SC & AC & L. conoid & Pectoralis major & Deltoid & Trapezoid \\
\hline$x$ & 39.38 & -114.04 & 12.09 & 30.26 & 45.62 & -16.50 \\
$y$ & 30.28 & -28.76 & -30.83 & 12.56 & 20.10 & 11.46 \\
$z$ & 47.80 & -47.60 & 8.33 & 4.74 & -16.91 & 3.99 \\
\hline
\end{tabular}

SC: sternoclavicular joint, AC: acromioclavicular joint. A negative value means that the force is in the opposite direction. All values are in Newton.

The displacement of the clavicle is visible after the fracture was simulated (Figure 3). The yield strength of cortical bone is $8.000 \times 10^{7} \mathrm{~N} / \mathrm{m}^{2}$. 37,38 The von Mises stress of the bone stays below the yield strength of cortical bone (with a fracture: $1.715 \mathrm{x}$ $10^{7} \mathrm{~N} / \mathrm{m}^{2}$, without a fracture: $1.485 \times 10^{7} \mathrm{~N} / \mathrm{m}^{2}$ ) (Figure 6 in Addendum III). The strain is similar with and without fracture (Figure 7 in Addendum III).

The maximum von Mises stress of both the plate and the bone is higher for the anteroinferior $\left(1.655 \times 10^{7} \mathrm{~N} / \mathrm{m}^{2}\right)$ plate position, compared to the superior (8.036 $\times 10^{6} \mathrm{~N} / \mathrm{m}^{2}$ ) position (Figure 8 in Addendum III). For both plates, the von Mises stress stays below the titanium plate yield strength $\left(9.000 \times 10^{8} \mathrm{~N} / \mathrm{m}^{2}\right.$ for Ti-6Al7Nb). ${ }^{39,40}$ In the operative treatment of midshaft clavicle fractures stable fixation and anatomical repositioning of the fracture is needed (Figure 9 in Addendum III). Secondly, there was a similar strain for both the anteroinferior $\left(5.946 \times 10^{-4}\right)$ and the superior $\left(2.63 \times 10^{-4}\right)$ plate positions (Figure 10 in Addendum III). Therefore, stable fixation is provided by both plates.The distribution of the strain is similar to the distribution of the von Mises stresses (Figure 4). Therefore, the anteroinferior plate can break or deform easier, compared to the superior plate. The results of the simulation during anteflexion (Figures 11-15, 17 and 18 in Addendum III) are similar to the abduction results. 


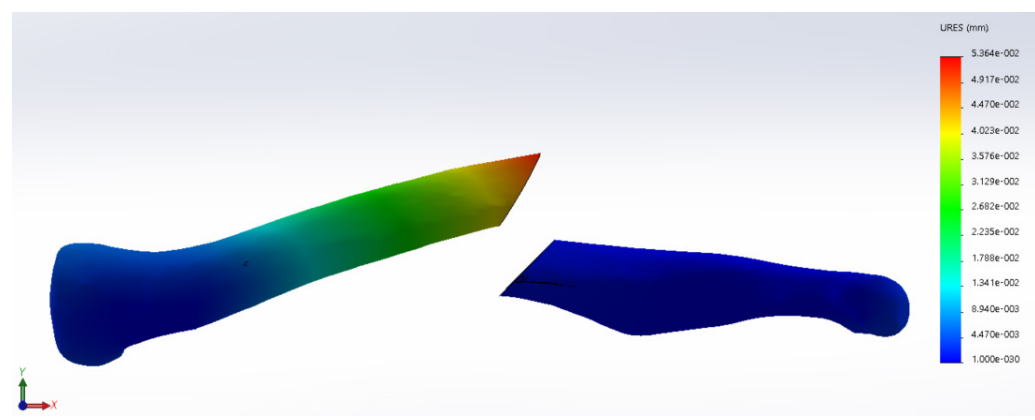

Figure 3. A visualization of the displacement (in $\mathrm{mm}$ ) of the clavicle, with the midshaft fracture, during abduction.

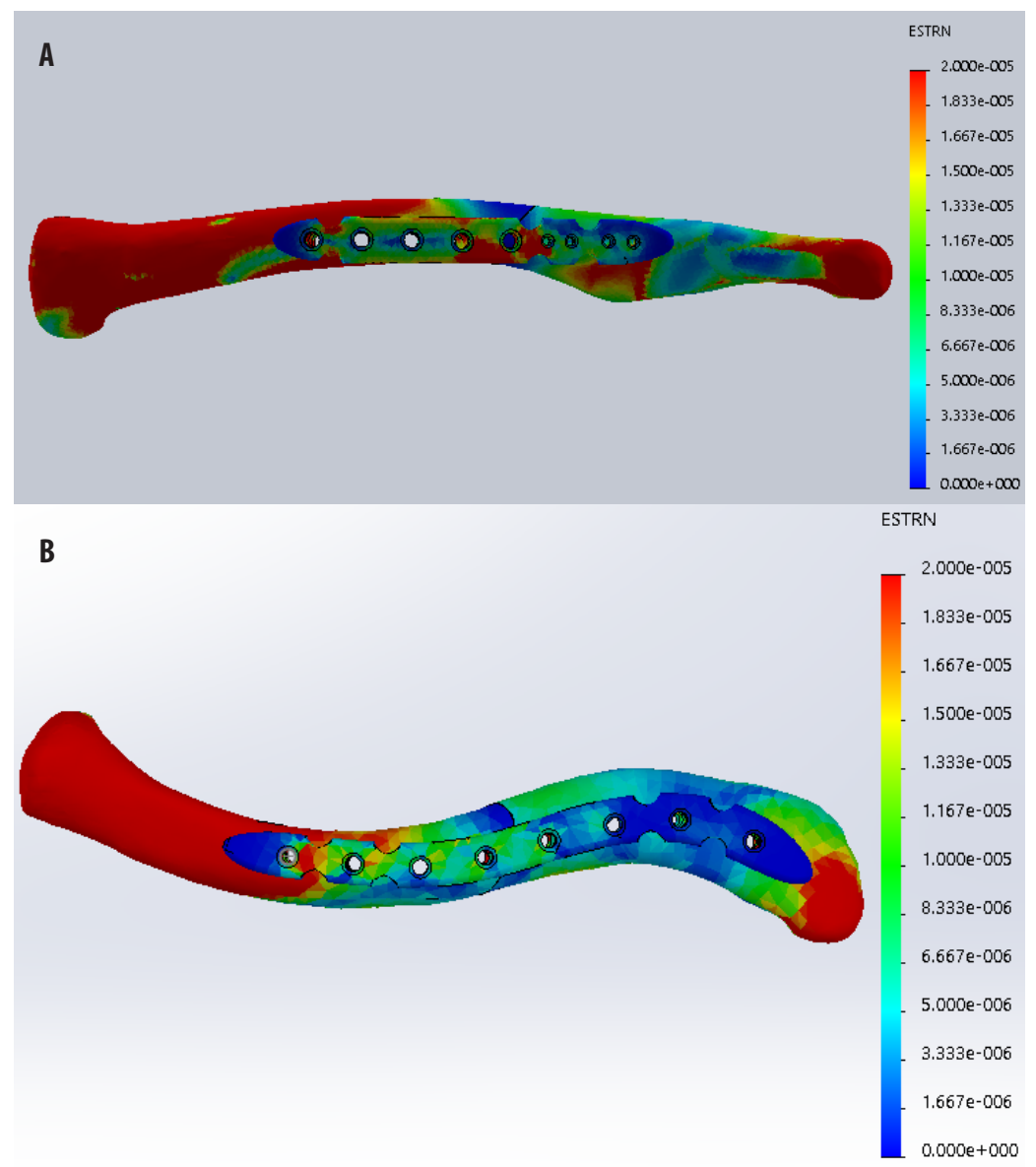

Figure 4.

A) A visualization of the distribution of the strain of the anteroinferior plate fixation, with an adjusted scale, during abduction.

B) A visualization (top view) of the distribution of the strain of the superior plate fixation, with an adjusted scale, during abduction. 


\section{DISCUSSION}

Previous research concerning biomechanical stability after clavicle fracture fixation are mostly based on static tests. This was the first study to construct a dynamic musculoskeletal model, including muscles and ligaments. Herewith using this model to evaluate the extent and direction of the forces acting on the clavicle during physical activity. To eventually determine whether anteroinferior and superior plate osteosynthesis can withstand these forces without permanent deformation or breakage and thus provide stable fixation. Previous biomechanical studies emphysized to quantify the effect of the plate positioning on the fixation strength..$^{20-27,41}$ Unfortunately, there is still no consensus on the optimal position of the plate for fixation of the clavicle fracture. lannotti et al. ${ }^{14}$ showed that superior plating has greater biomechanical stability compared to anteroinferior plating. Taylor et al. ${ }^{37}$ indicated a stiffness differential of 16\% between superior and inferior plating, favoring an inferior plate position. Likewise Robertson et al. ${ }^{31}$ demonstrated that in axial compression or torsion, anteroinferior plates were significantly stiffer than superior plates and therefore considered favorable. However, in failure tests, their results showed that superior plates had a significantly higher bending failure load and stiffness. This result was also documented by Celestre et al. ${ }^{22}$ The incompatibility of these results probably results from the difference in failure test modes. Taylor et al. ${ }^{37}$ used a four-point bending test, whereas Robertson et al. ${ }^{31}$ and Celestre et al. ${ }^{5}$ employed cantilever bending (in which load is applied directly to the lateral end of the clavicle).Contradicting conclusions as a result of differences in testing methods and materials make it hard to conclude whether anteroinferior or superior plate position should be used in the operative treatment of clavicle fractures. Current literature shows advantages for both methods depending on the type of stress being exerted on the clavicle. ${ }^{20,22}$ In general, anteroinferior plating is preferable because it induces deformation modes similar to the intact clavicle and is less likely to fail during normal physiological loading (cantilever bending). 23-27 On the other hand, superior placement of the plate may be recommended for patients with a high risk of shoulder impacts resulting in axial compression. ${ }^{26}$ With the created model and simulations we were able to show the effects of forces on the clavicle. The maximal von Mises stress and strain are located around the ligaments, because the bone is fixed here. When the fracture is fixated, the maximal displacement is lower than without plate fixation in both plate position groups (Figure 3, Figure 9 and 14 in Addendum III). Therefore, stable fixation is provided by both plates. The simulated von Mises stresses stay below the yield strength of both bone and titanium. In the distribution of the von Mises stress and 
the strain, the anteroinferior plate has a larger local maximum. This suggests that the anteroinferior plate may be more prone to deformation or break, compared to the superior plate. Also the local maxima of both the Von Mises stress and the strain of the anteroinferior plate are located at the fracture, in contrast to the local maxima of the superior plate which is located farther away from the fracture site. More research is needed to determine which location of these local maxima results in a lower likelihood of breakage or deformation (Figure 4). The differences in the results between abduction and anteflexion were found to be small. This could be explained by the similarity of forces for both movements. The forces are similar for both movements, except for the pectoralis major and deltoid muscle. The sternocleidomastoid muscle appears to have the largest influence on displacement. Therefore, the displacement is larger in abduction than in anteflexion. We recognize that there are some limitations to this study. Designing a realistic biomechanical test-setup for clavicle fracture fixation is challenging due to the lack of information on clavicular loading in vivo.First of all, the sternocleidomastoid muscle was not included in the DSEM. Therefore, these values were taken from literature. ${ }^{35,36}$ The force of this muscle is large, compared to the other muscles attached to the clavicle and could influence the results. Also, the subclavian muscle was not included in the DSEM and no values were found in the literature. Therefore, it was assumed that this muscle does have a small influence in the model, so it was not included in the analysis. Secondly, the simulations are based on the forces with the largest value. The direction and magnitude of these forces change during movement. Only the largest value for such a force is taken into account, with the corresponding direction. The influence of a smaller force in a different direction is not included in this simulation. This could give a difference in outcome. Moreover, the model is simplified, because only large boxes on the surface of the clavicle could be selected for the locations of the muscles and ligaments. Additionally, the ligaments are fixed and only the cortex is used in the model (Addendum III). The locations of the muscles and ligaments in the model are based on the anatomical positions and not calculated in coordinates. Lastly, only two movements, anteflexion and abduction, were used to be tested in this simulation. Despite the fact that in vivo data about clavicular muscle forces lack, result seem accurate as the magnitude of the forces is similar to that of other musculoskeletal studies. ${ }^{42-45}$ Although none of the existing musculoskeletal models of the shoulder have been validated, they are currently the only tool to provide insight in clavicular load during everyday movements. 


\section{CONCLUSION}

In summary, a musculoskeletal model for clavicle fractures was developed. The superior plating method has a lower von Mises stress and strain, but differences were small in this model. Both plating methods can withstand the forces without permanent deformation or breakage and, therefore, both fixation methods provide stable fixation. Validation of the model is needed, before a definite recommendation about the plate positioning can be made. After validation, the model could assist in a patient-specific recommendation, to determine which plate to use in a patient. 


\section{REFERENCES}

1. Postacchini F, Gumina S, De Santis P, Albo F. Epidemiology of clavicle fractures. J Shoulder Elb Surg. 2002;11(5):452-456. doi:10.1067/mse.2002.126613.

2. Smekal V, Oberladstaetter J, Struve $P$, Krappinger D. Shaft fractures of the clavicle: Current concepts. Arch Orthop Trauma Surg. 2009;129(6):807-815. doi:10.1007/ s00402-008-0775-7.

3. Nordquist A, Petersson C. The incidence of fractures of the clavicle. Clin Orthop Relat Res. 1994;300:127-132.

4. van der Ven DJC, Timmers TK, Flikweert PE, Van ljseldijk ALA, van Olden GDJ. Plate fixation versus conservative treatment of displaced midshaft clavicle fractures: Functional outcome and patients' satisfaction during a mean follow-up of 5 years. Injury. 2015;46(11):2223-2229. doi:10.1016/j.injury.2015.08.004.

5. Mulgrew E, Ravenscroft M. Adult fractures and dislocations of the shoulder and elbow. Surg (United Kingdom). 2013;31(4):162-167. doi:10.1016/j.mpsur.2013.01.018.

6. Robinson CM. Fractures of the clavicle in the adult. J Bone Jt Surg [Br]. 1998;80:476484. doi:10.1302/0301-620X.80B3.8079.

7. Nordqvist A, Petersson CJ. Incidence and causes of shoulder girdle injuries in an urban population. J Shoulder Elb Surg. 1995;4(2):107112. doi:10.1016/S1058-2746(05)80063-1.

8. Stanley D, Trowbridge EA, Norris SH. The mechanism of clavicular fracture: A clinical and biomechanical analysis. J bone Jt Surg [Br]. 1988;70(3):461-464.

9. van Olden GDJ. Claviculafracturen bij wielrenners. Ned Tijdschr voor Traumatol. 2013;21(2):52-57. doi:10.1007/s12506-0130013-y.

10. Robinson CM, Court-Brown CM, McQueen MM, Wakefield AE. Estimating the risk of nonunion following nonoperative treatment of a clavicular fracture. J Bone Jt Surg. 2004;86-A(7):1359-1365.
11. Pecci M, Kreher JB. Clavicle fractures. Am Fam Physician. 2008;77(1):65-70. doi:10.1308/003588408X301190b.

12. Zlowodzki M, Zelle BA, Cole PA, Jeray $K$, Mckee MD. Treatment of acute midshaft clavicle fractures: systematic review of 2144 fractures: on behalf of the EvidenceBased Orthopaedic Trauma Working Group. J Orthop Trauma. 2005;19:504-507. doi:10.1097/01.bot.0000172287.44278.ef.

13. van der Meijden OA, Gaskill TR, Millett PJ. Treatment of clavicle fractures: Current concepts review. J Shoulder Elb Surg. 2012;21(3):423-429. doi:10.1016/j. jse.2011.08.053.

14. Coupe BD, Wimhurst JA, Indar R, Calder DA, Patel AD. A new approach for plate fixation of midshaft clavicular fractures. Inj Int J Car. 2005;36(10):1166-1171. doi:10.1016/j. injury.2005.03.007.

15. Canadian Orthopaedic Trauma Society. Nonoperative treatment compared with plate fixation of displaced midshaft clavicular fractures. A multicenter, randomized clinical trial. J Bone Joint Surg Am. 2007;89(1):1-10. doi:10.2106/JBJS.F.00020.

16. Malik S, Chiampas G, Leonard $H$. Emergent evaluation of injuries to the shoulder, clavicle, and humerus. Emerg Med Clin North Am. 2010;28(4):739-763. doi:10.1016/j.emc.2010.06.006.

17. Robinson CM, Goudie EB, Murray IR, et al. Open reduction and plate fixation versus nonoperative treatment for displaced midshaft clavicular fractures: a multicenter, randomized, controlled trial. J Bone Joint Surg Am. 2013;95(17):1576-1584. doi:10.2106/JBJS.L.00307.

18. Mckee RC, Whelan DB, Frcs C, Schemitsch EH, Mckee MD. Operative versus nonoperative care of displaced midshaft clavicular fractures: a meta-analysis of randomized clinical trials. J Bone Jt Surg - Am Vol. 2012;94A(8):675-684. doi:10.2106/JBJS.J.01364. 
19. Kulshrestha V, Roy T, Audige L. Operative versus nonoperative management of displaced midshaft clavicle fractures: a prospective cohort study. J Orthop Trauma. 2011;25(1):31-38. doi:10.1097/ BOT.0b013e3181d8290e.

20. lannotti MR, Crosby LA, Stafford P, Grayson G, Goulet R. Effects of plate location and selection on the stability of midshaft clavicle osteotomies: A biomechanical study. J Shoulder Elb Surg. 2002;11(5):457462. doi:10.1067/mse.2002.125805.

21. Harnroongroj $T$, Vanadurongwan V. Biomechanical aspects of plating osteosynthesis of transverse clavicular fracture with and without inferior cortical defect. Clin Biomech. 1996;11(5):290-294. doi:10.1016/0268-0033(96)00001-0.

22. CelestreP,Roberston C,Mahar A,Oka R, Meunier M, Schwartz A. Biomechanical evaluation of clavicle fracture plating techniques: does a locking plate provide improved stability? J Orthop Trauma. 2008;22(4):241-247. doi:10.1097/BOT.0b013e31816c7bac.

23. Collinge C, Devinney S, Herscovici D, DiPasquale T, Sanders R. Anterior-inferior plate fixation of middle-third fractures and nonunions of the clavicle. J Orthop Trauma. 2006;20(10):680-686. doi:10.1097/01. bot.0000249434.57571.29.

24. Formaini N, Taylor BC, Backes J, Bramwell TJ. Superior versus anteroinferior plating of clavicle fractures. Orthopedics. 2013;36(7):e898-904. doi:10.3928/0147744720130624-20.

25. Taylor PRP, Day RE, Nicholls RL, Rasmussen J, Yates PJ, Stoffel KK. The comminuted midshaft clavicle fracture: A biomechanical evaluation of plating methods. Clin Biomech. 2011;26(5):491-496. doi:10.1016/j. clinbiomech.2010.12.007.

26. Favre $\mathrm{P}, \mathrm{Kloen} \mathrm{P}$, Helfet $\mathrm{DL}$, Werner $\mathrm{CML}$. Superior versus anteroinferior plating of the clavicle: a finite element study. J Orthop Trauma. 2011;25(11):661-665. doi:10.1097/ BOT.0b013e3182143e06.
27. van Olden GDJ. VA-LCP anterior clavicle plate: the anatomically precontoured fixation system with angular stability for clavicle shaft. Musculoskelet Surg. 2014;98(3):217-223. doi:10.1007/s12306013-0302-z.

28. Bostman O, Manninen M, Pihlajamaki $\mathrm{H}$. Complications of plate fixation in fresh displaced midclavicular fractures. J Trauma Inj Infect Crit Care. 1997;43(5):778-783.

29. van der Helm FCT. A finite element musculoskeletal model of the shoulder mechanism. J Biomech. 1994;27(5):551-569. doi:10.1016/0021-9290(94)90065-5.

30. van der Helm FCT. Analysis of the kinematic and dynamic behavior of the shoulder mechanism. J Biomech. 1994;27(5):527-550. doi:10.1016/0021-9290(94)90064-7.

31. Bolsterlee B, Veeger HEJ, van der Helm FCT. Modelling clavicular and scapular kinematics: From measurement to simulation. Med Biol Eng Comput. 2014;52(3):283-291. doi:10.1007/s11517013-1065-2.

32. Veeger HEJ, van der Helm FCT, van der Woude LHV, Pronk GM, Rozendal RH. Inertia and muscle contraction parameters for musculoskeletal modeling of the shoulder mechanism. J Biomech. 1991;24(7):615-629. doi:10.1016/0021-9290(91)90294-W.

33. Klein Breteler MD, Spoor CW, Van Der Helm FCT. Measuring muscle and joint geometry parameters of a shoulder for modeling purposes. J Biomech. 1999;32(11):11911197. doi:10.1016/S0021-9290(99)00122-0.

34. Nikooyan AA, Veeger HEJ, Chadwick EKJ, Praagman M, Helm FCT van der. Development of a comprehensive musculoskeletal model of the shoulder and elbow. Med Biol Eng Comput. 2011;49(12):1425-1435. doi:10.1007/ s11517-011-0839-7.

35. Moroney SP, Schultz a B, Miller J a. Analysis and measurement of neck loads. J Orthop Res. 1988;6(5):713-720. doi:10.1002/ jor.1100060514. 
36. Toosizadeh N, Haghpanahi M. Generating a finite element model of the cervical spine: Estimating muscle forces and internal loads. Sci Iran. 2011;18(6):1237-1245. doi:10.1016/j. scient.2011.10.002.

37. Duprey S, Bruyere K, Verriest J. Clavicle fracture prediction: Simulation of shoulder lateral impacts with geometrically personalized finite elements models. J Trauma. 2010;68(1):177-182. doi:10.1097/ TA.0b013e318190bf5b.

38. Iwamoto M, Mika K, Yang KH. Development of a finite element model of the human shoulder to investigate the mechanical responses and injuries in side impact. JSME Int J. 2001;44(4):1072-1081.

39. Niinomi M. Mechanical properties of biomedical titanium alloys. Mater Sci Eng. 1998;243:231-236.

40. Materials A. Titanium Alloy Ti-6Al-7Nb. https://www.aircraftmaterials.com/ data/titanium/ti-6al-7nb.html. Accessed December 12, 2017.

41. Robertson C, Celestre P, Mahar A, Schwartz A. Reconstruction plates for stabilization of mid-shaft clavicle fractures: Differences between nonlocked and locked plates in two different positions. J Shoulder Elb Surg. 2009;18(2):204-209. doi:10.1016/j. jse.2008.10.002.
42. Cronskär M. Strength analysis of clavicle fracture fixation devices and fixation techniques using finite element analysis with musculoskeletal force input. Med Biol Eng Comput. 2015;53:759-769. doi:10.1007/ s11517-015-1288-5.

43. Ingram D, Engelhardt C, Farron A, Terrier A, Müllhaupt P. Improving anterior deltoid activity in a musculoskeletal shoulder model - an analysis of the torque-feasible space at the sternoclavicular joint. Comput Methods Biomech Biomed Engin. 2016;19(4):450-463. doi:http://dx.doi.org/10 .1080/10255842.2015.1042465.

44. Karlsson D, Peterson B. Towards a model for force predictions in the human shoulder. J Biomech. 1992;25(2):189-199.

45. Bolsterlee B. Predicting Muscle Forces in the Shoulder by Constraining the Inverse Optimisation with EMG and a Forward Muscle Model.; 2010. 


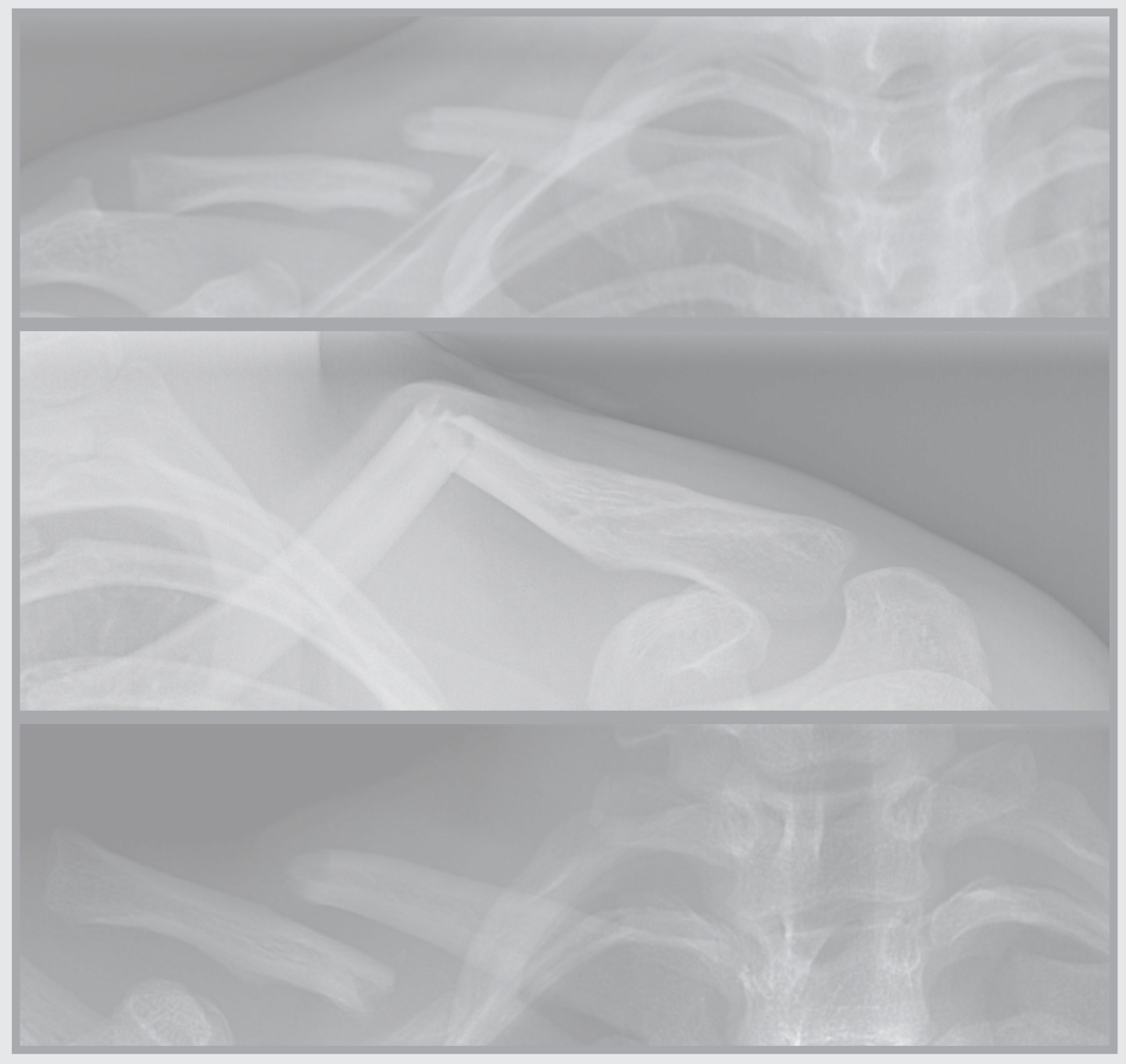




\section{CHAPTER FOUR}

Radiographic shortening is not a good indication for surgical intervention for midshaft clavicle fractures

D.J.C van der Ven, T.K Timmers, R.T.C Welsing, G.D.J van Olden

J Orthop Traumatol Rehabil;2017 


\section{ABSTRACT}

\section{Background}

Whether or not to operate midshaft clavicle fractures is mostly based on the amount of shortening and dislocation seen on the radiograph. Previous studies already suggested that radiographic shortening of midshaft clavicle fractures cannot be adequately determined with an AP view alone. Therefore, before a therapeutic decision can be made based on radiographic examination; the observed fracture characteristics should be evaluated.

\section{Methods}

Between January - and July 2016, 87 patients were prospectively included. When the classification of the fracture was confirmed with a standard AP radiographs, additional radiograph examinations were done; rhomboideus radiograph: a standard AP radiograph in military position. All patients were treated conservatively and followed for 24 weeks. Patients visited the outpatient clinic department after 1,6 , and 24 weeks. The study end-points were investigated (DASH and Constant score) and radiographic combined with physical examinations were done.

\section{Results}

On the standard AP- radiographs in all occasions radiographic shortening was seen. On the additional rhomboideus views the degree of shortening was no longer observable. The mean Constant and DASH score were $88.2 \pm 11.8$ respectively $18.9 \pm 14.4$. and $5.3 \pm 6.8$ respectively $96.2 \pm 5.6$ after 6 and 24 weeks. After conservative treatment nine patients developed a nonunion and were operated and excluded from this study.

\section{Conclusion}

Our results show that the degree of shortening and displacement cannot be adequately determined on standard 2-view radiographic series and that the correlation between permanent clavicle shortening and functional outcome can be questioned. Good functional outcomes were seen after conservative treatment. This indicates that the importance of shortening seen on a radiograph and the degree of permanent shortening in determining functional outcomes remains unclear. 


\section{INTRODUCTION}

The decision to treat closed midshaft clavicle fractures either operatively or nonoperatively remains a topic of debate. There are studies that raised concerns that certain midshaft clavicle fractures treated non-operatively have a higher rate of nonunion or symptomatic mal-union and, therefore, a poorer functional outcome. ${ }^{1,2}$ However, recent research has not shown convincingly that operative treatment is better for these kinds of fractures ${ }^{3-6}$ Plain radiography is the most common way in which clavicle fractures are radiologically assessedRadiographic examination for clavicle fractures includes an anterior-posterior (AP) radiograph and a clavicle radiograph with some horizontal angle $\left(15^{\circ}-45^{\circ}\right)$. The currently described indications for surgical treatment as seen on radiograph examination are: complete displacement and clavicle shortening exceeding $20 \mathrm{~mm}$. Since shortening caused by displacement has been associated with potential shoulder dysfunction ${ }^{3-6}$ Different degrees of shortening leading to an unfortunate outcome are being reported; varying from $15-20 \mathrm{~mm}^{.5-11}$ However, patients' posture due to pain and, therefore, the radiographic angle may influence the displayed degree of shortening and as a consequence thedifference in reported outcome. Nevertheless, an indication for surgical treatment is mostly based on radiologic examination. Previous studies already suggested that the degree of dislocation and shortening of these common clavicle fractures cannot be adequately determined with an AP view alone.12-14 Ideally, before a therapeutic decision can be made; the observed fracture characteristics should be evaluated. Our hypothesis is that the amount of shortening and displacement cannot be adequately determined with a standard radiograph alone. As we believe the change seen on the rhomboideus view is dynamic; clavicle shortening could be reduced in this position.

\section{PATIENTS AND METHODS}

Between January 2013 and October 2016, all consecutive patients presenting at the Emergency Department (ED) of the Meander MC in Amersfoort (the Netherlands), with a new, dislocated midshaft clavicle fracture were prospectively recorded and included in this study. Our hospital serves as a regional Level 2 trauma centre. Our hospital treats an increasing number of emergency department patients of around 40.000 patients. Standard 2-view trauma series of the clavicle at our institution include anterior-posterior (AP) radiograph examination and a clavicle radiographs with some horizontal angle $\left(15^{\circ}-45^{\circ}\right)$. This study was approved by the local medical ethics committee; reference number W15.052. 


\section{Patient selection}

Inclusion criteria were: 1) complete dislocated midshaft clavicle fracture after trauma (no fracture side contact of lateral and medial fragments) according to Robinson classification 2B; 2) age $\geq 18$ years. Exclusion criteria were: 1) fracture in the proximal or distal third of the clavicle; 2) fracture with side contact of lateral and medial fragments; 3 ) pathologic fracture (bony abnormalities at the side of the fracture); 4) open fracture; 5) a significant ipsilateral upper extremity fracture; 6) neurovascular injury of the shoulder region with objective neurological findings on physical examination; 7) a midshaft clavicle fracture more than 14 days old at first hospital visit. When classification of the fracture was confirmed with a standard AP radiograph, additional radiograph examinations were done. These consist of a rhomboideus radiograph: a standard AP radiograph in military position. The military position involves rolling your shoulders back and down. In order to achieve this position, while in pain, all patients received adequate analgesics and wore a special figure-of-eight clavicle brace (Figure 1) The figure-of-eight clavicle brace holds the clavicle in the correct alignment by forcing the shoulders into a retracted position.

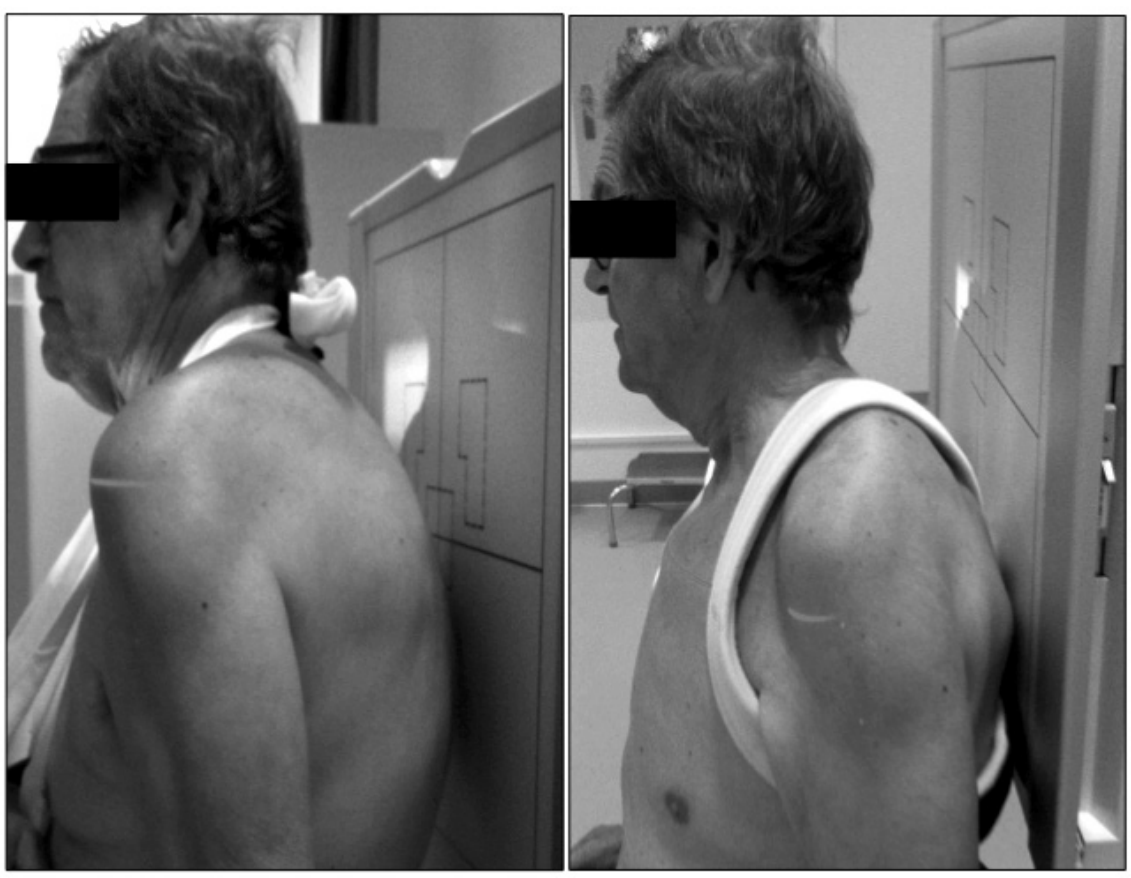

Figure 1. Left: a standard AP radiograph. Right: a rhomboideus radiograph: a standard AP radiograph only in military position wearing a figure-of-eight brace and receiving adequate analgesia. 


\section{End-points}

The primary radiographic outcome parameters were; 1 ) the degree of clavicle shortening; 2) to compare these with an rhomboideus view; The primary clinically outcome parameters were: 1) consolidation of the fracture and the development of nonunion; and 2) functional outcome measured with the DASH Score and Constant Score 3) adverse events.

\section{Union}

Union of the clavicle fracture was defined as complete cortical bridging between lateral and medial fragments. If no callus/bridging between two cortices was present during radiological examination and/or clinical evidence of pain and/or motion at the fracture site at six months this was considered a nonunion.

\section{Functional outcome score}

The Disabilities of Arm, Shoulder and Hand (DASH) Outcome Measure is a validated 30-item, self- report questionnaire. The DASH Outcome Measure consists of two components: the disability/symptom section (30 items) and the optional high performance Sport/Music module (4 items) ${ }^{15}$ The Constant-Murley- score is a validated 14-items questionnaire with a total score of 0-100 and consist of a subjective and objective component. The questionnaire records individual parameters and provides an overall clinical functional assessment. ${ }^{16}$

\section{Adverse events}

Other complications were considered to exist if refracture (i.e. a recurrent fracture of the same clavicle after new trauma) or patients underwent re-surgery for an exostosis.

\section{Follow-up}

After inclusion, all patients were conservatively treated and followed for 24 weeks in total. The figure-of-eight brace was worn for 1 week and it served merely as a reminder for the patients to keep an adequate military position. Hereafter, the patient was seen in the clinic department and physical therapy (rhomboideus training) was prescribed. Rhomboideus training consist of physiotherapy focusing meanly on retraction and mediorotation of the angulus inferior of both scapulae within individual arthrogenic limits. Herewith, the musculus rhomboideii and the musculus serratus posterior are trained. As a result, by retaining an anatomical position of the fracture parts, the amount of shortening due to an imbalance of muscle forces is reduced.Patients visited the clinic department hereinafter with 6 and 24 weeks. On all occasion the study endpoints were investigated and radiographic examinations were done. Patient who developed a nonunion underwent operative fixation using a VA-LCP anterior clavicle plate [17] and were excluded from further follow-up analysis of this study. 


\section{Statistical analysis}

Statistical analysis was performed using SPSS 15.0, Chicago, for Microsoft Windows. Differences in the DASH and the Constant score between the treatment groups were compared with use of the independent t- test. The chi-square test was used for categorical data. Continuous variables were reported as mean \pm SD or median ( $25^{\text {th }}$ and $75^{\text {th }}$ inter quartile ranges) and categorical variables as number and percentages, unless otherwise stated. All tests were two-sided, and the level of significance was set at $\mathrm{p}<0.05$.

\section{RESULTS}

Within the study timeframe, a total of 87 patients were included. Nine patients developed a non-union. These patients underwent surgery and were excluded. A total of 78 patients were included for further analysis.

Baseline characteristics Of the included patients 67 patients were male. The mean age was $42.2 \pm 15.7$ years, in 31 patients the fracture occurred in the clavicle of the dominant arm, and 19 patients were smokers. When inquiring about physical exercise, 20 patients declared that they used to do heavy physical work (Table 1).

Table 1. Baseline characteristics

\begin{tabular}{lc}
\hline $\mathbf{1 .}$ & $\mathbf{n = 8 7}$ \\
\hline Age $^{1}$ & $42.2 \pm 15.7$ \\
Male & 67 \\
Dominant arm & 31 \\
Smoker & 19 \\
Heavy physical work & 20 \\
\hline${ }^{1}$ Mean \pm SD values. &
\end{tabular}

\section{Radiographic evaluation}

On the standard radiographs in all occasions a degree of shortening and displacement was seen (Figure 2A/B). On the additional rhomboideus views the degree of shortening and displacement was no longer observed (Figure 2C). The difference in the position of the patient due to the military position (the figure-ofeight brace and adequate analgesia) changed the amount of shortening seen on the radiographs. 

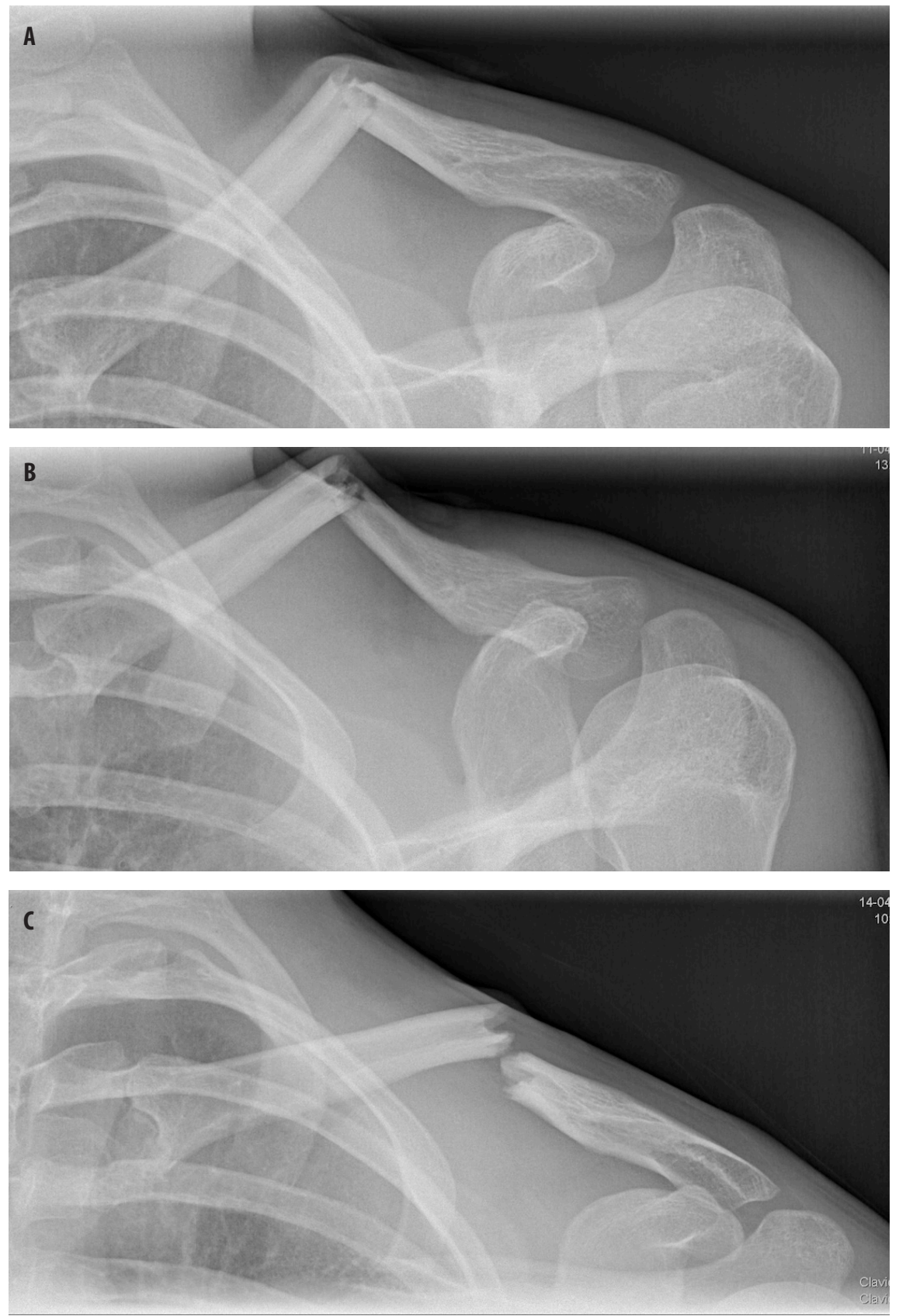

Figure 2. A). Standard 2-view trauma series of the clavicle at our institution include anterior-posterior (AP) radiograph examination and $\mathbf{B})$. Clavicle radiographs with some horizontal angle $\left(15^{\circ}-45^{\circ}\right)$. C). Rhomboideus radiograph 


\section{Clinical outcomes}

\section{Fracture union}

Within these 87 patients fracture union was seen in 78 patients (89.7\%) after 24 weeks without surgery. Nine (10.3\%) patients developed a nonunion. Those patients were operated and excluded from this study. (Table 2A).

\section{Functional outcome}

The DASH and Constant questionnaire was completed in 78 patients (100\%) after 6 weeks. An average DASH score of $18.9 \pm 14.4$ was seen and a Constant score of $88.2 \pm 11.8$ after 6 weeks (Table 2B). After 24 week an average DASH Score of $5.3 \pm 6.8$ and a Constant score of $96.2 \pm 5.6$ was seen. Thirty-three patients (42\%) completed the questionnaires at 24 weeks. (Table $2 \mathrm{C}$ )

\section{Adverse events}

One patient had a refracture after new trauma. Two patients underwent surgery for an exostosis (Table2D).

Table 2. Clinical outcomes

\begin{tabular}{lc}
\hline A & $\mathbf{n}=\mathbf{8 7}$ \\
\hline Fracture union & 78 \\
Nonunion & 9 \\
B $^{1}$ & $18.9 \pm 14.4$ \\
DASH score 6 weeks & $88.2 \pm 11.8$ \\
Constant score 6 weeks & \\
C1,2 & $5.27 \pm 6.79$ \\
DASH score 24 weeks & $96.24 \pm 5.6$ \\
Constant score 24 weeks & \\
D & 2 \\
Adverse events & 1 \\
Refracture & \\
Surgery for a exostosis & \\
\hline
\end{tabular}

${ }^{1}$ Mean \pm SD values. ${ }^{2} .45$ missings (58\%) after 24 weeks 


\section{DISCUSSION}

Shortening caused by dislocation has been associated with potential shoulder dysfunction when treated conservatively ${ }^{5,6}$ Interestingly, different degrees of shortening leading to an unfortunate outcome are being reported; varying from $15-20 \mathrm{~mm}^{5-11}$ The decision to treat midshaft clavicle fractures conservatively or operatively, however, still heavily dependents on radiographic examination and outcome ${ }^{5,6}$ The accuracy of these standard radiographs as a diagnostic instrument can, nonetheless, be questioned. Previous studies showed that shortening could not reliably be assessed on AP and 30-degree caudocephalad radiographs. There was only a moderate to weak inter-observer agreement and minimal intraobserver agreement on the amount of shortening seen on a radiograph.18,19 Jones et al. ${ }^{18}$ found that these values were particularly low in the range of shortening around 1 to $2 \mathrm{~cm}$, which is the most important range when determining the outcome of non-operatively treated fractures. Furthermore, Stegeman et al. ${ }^{19}$ showed that radiologists classified these fractures more reliably than surgeons. Though, when deciding on treatment, $60 \%$ of the evaluators ranked the amount of shortening as the most important criterion: ${ }^{18} \mathrm{AlsO}$, other studies showed that the extent of shortening and dislocation might be misjudged if displayed on standard radiographs.12,13 A study of Sharr et al. ${ }^{13}$ demonstrated the inaccuracy of the commonly used AP 15 cephalic clavicle radiographs. They found a 15\% magnification on the AP 15 cephalic radiographs, with up to $19 \mathrm{~mm}$ of variation on oblique views. An earlier study of Austin et al: ${ }^{12}$ found that the standard 2-view clavicle radiographic $x$-ray underestimates the degree of displacement and shortening. They used of a novel 4-view radiographic series (standard 2 views plus orthogonal views) and concluded that surgeons, with these additional views, were more likely to treat fractures of the clavicle operatively. In order to evaluate the adequacy of the radiographic techniques, we compared the standard 2-view radiographs with a rhomboideus radiograph and found that the amount of shortening seen on a standard radiograph was no longer observable on a rhomboideus radiograph. The intention of the rhomboideus radiograph is not to propose a new diagnostic manner, but to evaluate the accuracy of the standard trauma series. Herewith, address that therapeutic decisions should not solely be based on a radiographical assessment. The combination of the unusual sigmoid shape of the clavicle with the translation of a three-dimensional bone into a twodimensional radiograph makes it difficult to adequately evaluate the classification of the fracture. An amount of shortening occurs in up to $50 \%$ of cases, but the relationship of shortening with an impaired functional outcome remains unclear 
in the literature ${ }^{5,7}$ Nordqvist et al. ${ }^{20}$ found permanent shortening to be common after clavicle fractures but that this had no clinical significance. A study of Nowak et al. ${ }^{21}$ showed that fracture shortening did not predict outcome except for cosmetic defects. And utilizing chest radiographs to compare both clavicles, Rasmussen et al. ${ }^{22}$ found that shortening of greater than $2 \mathrm{~cm}$ was not associated with poorer outcomes. Therefore, although static anatomic changes in the shoulder girdle due to a shortened clavicle were observed. None of the studies found a direct correlation between the extent of clavicle shortening and the degree of objective reduction in shoulder function ${ }^{20-22}$ Therefore, the critical amount of acceptable shortening has not been determined and the value of the standard trauma series can be questioned. A significant amount of research has been done to establish a general consensus on how to treat displaced midshaft clavicle fractures. As these fractures commonly afflict a young, working population were rapid return to function and early union has a high priority. However, we believe operating patients based on radiographic examination alone leads to overtreatment and preventable complications as it remains unclear which characteristics can reliably predict patient-important functional outcomes and union. Treatment should, therefore, be individualized, with consideration of each patient's age, activity level, job description and expectations of treatment.We recognize that there are some limitations to this study. The first limitation is the number of patients who did not complete the DASH and Constant shoulder questionnaires at 24 weeks. Forty-five patients (58\%) were lost to follow-up. This could lead to an underestimation of the complaints present in the patient who were lost to follow-up and fail to detect an effect that is present. However, no differences in demographics were seen. When comparing the patients group that did fill in the questionnaires at 24 weeks compared to those that were lost to follow-up. This indicates that the functional outcome found can be extrapolated for the whole group. Secondly, one of the primary endpoints was the amount of shortening as seen on the standard radiographs and compare it with the rhomboideus radiograph. Despite the clearly difference in radiographic views, we were not able to accurately measure the difference in shortening between both radiographs. The fracture at presentation was diagnosed by a nonstandardized radiographic method; therefore, we weren't able to measure the amount of shortening. The unusual sigmoid shape of the clavicle, difficult patient positioning, variable film distance, and resultant magnification discrepancies all combine reduce an accurate reproduction of the clavicle and therefore, any clavicle length measurements are prone to be incorrect ${ }^{14}$ As a result, we weren't able to establish a reliable association between the initial clavicle shortening and 
the final shortening after union. Nevertheless, this strengthens our hypothesis that the amount of shortening cannot be adequately determined with a standard radiograph alone and cannot be taken into consideration as an important factor in treatment decisions and functional outcome.

\section{CONCLUSION}

In conclusion, our results show that the degree of shortening and displacement cannot be adequately determined on standard 2-view radiographic series and that the correlation between permanent clavicle shortening and functional outcome can be questioned. Good functional outcomes were seen after conservative treatment. This indicates that the importance of shortening seen on a radiograph and the degree of permanent shortening in determining functional outcomes remains unclear. Therefore, the amount of shortening cannot be taken into consideration as an important factor in treatment decisions and functional outcome. Making, that the surgical indications need to be evaluated before therapeutic decisions can be made. 


\section{REFERENCES}

1. Robinson CM, Court-Brown CM, McQueen MM, Wakefield AE. Estimating the risk of nonunion following nonoperative treatment of a clavicular fracture. J Bone Joint Surg Am 2004;86:1359-65.

2. Stegeman SA, de Jong M, Sier CF, Krijnen P, Duijff JW, van Thiel TP et al. Displaced midshaft fractures of the clavicle: nonoperative treatment versus plate fixation (Sleutel-TRIAL). A multicentre randomised controlled trial. BMC Musculoskelet Disord. 2011 Aug 24;12:196. doi: 10.1186/14712474-12-196.

3. McKee RC1, Whelan DB, Schemitsch EH, McKee MD. Operative versus nonoperative care of displaced midshaft clavicular fractures: a meta-analysis of randomized clinical trials. J Bone Joint Surg Am. 2012 Apr 18; 94(8):675-84. doi: 10.2106/JBJS.J.01364.

4. Canadian Orthopaedic Trauma Society. Nonoperative treatment compared with plate fixation of displaced midshaft clavicular fractures. A multicentre randomized clinical trial. J Bone Joint Surg Am 2007, 89:1-10.

5. Eskola A, Vainionpää S, Myllynen P, Pätiälä H, Rokkanen P. Outcome of clavicular fracture in 89 patients. Arch Orthop Trauma Surg 1986, 105:337-338.

6. Hill JM, McGuire MH, Crosby LA. Closed treatment of displaced middle- third fractures of the clavicle gives poor results. J Bone Joint Surg Br 1997, 79:537-539.

7. De Giorgi S, Notarnicola A, Tafuri S, Solarino G, Moretti L, Moretti B. Conservative treatment of fractures of the clavicle. BMC Research Notes. 2011;4:333. doi: 10.1186/1756-0500-4-333.

8. Lazarides S, Zafiropoulos G, Tydfil M. Conservative treatment of fractures at the middle third of the clavicle: the relevance of shortening and clinical outcome. J Shoulder Elbow Surg. 2006;15:191-194.
9. Ledger M, Leeks N, Ackland T, Wang A. Short malunions of the clavicle: an anatomic and functional study. J Shoulder Elbow Surg. 2005;14:349-354

10. Postacchini R, Gumina S, Farsetti $P$ Postacchini F. Long-term results of conservative management of midshaft clavicle fracture. Int Orthop. 2010;34:731736. doi: 10.1007/s00264-009-0850-x. Epub 2009 Aug 10.

11. Thormodsgard TM, Stone K, Ciraulo DL, Camuso MR, Desjardins S. An assessment of patient satisfaction with nonoperative management of clavicular fractures using the disabilities of arm, shoulder and hand outcome measure. J Trauma. 2011;71:11261129. doi: 10.1097/TA.0b013e3182396541.

12. Austin LS, O'Brien MJ, Zmistowski B, Ricchetti ET, Kraeutler MJ, Joshi A, et al. Additional $x$-ray views increase decision to treat clavicular fractures surgically. J Shoulder Elbow Surg. 2012 Oct;21(10):12638. doi: 10.1016/j.jse.2011.08.050.

13. Sharr JR, Mohammed KD. Optimizing the ic technique in clavicular fractures. J Shoulder Elbow Surg 2003;12:170-2. doi:10. 1067/ mse.2003.23

14. Smekal V, Deml C, Irenberger A, Niederwanger C, Lutz M, Blauth $M$ et al. Length determination in mid- shaft clavicle fractures: validation of measurement. J Orthop Trauma. 2005;22:458-462. doi: 10.1097/BOT.0b013e318178d97d.

15. Hudak PL, Amadio PC, Bombardier C. Development of an upper extremity outcome measure: the DASH (disabilities of the arm, shoulder and hand) [corrected]. The Upper Extremity Collaborative Group (UECG). Am J Ind Med 1996, 29:602-608.

16. Constant CR, Murley AH. A clinical method of functional assessment of the shoulder. Clinical orthopaedics and related research. 1987 Jan;(214):160-164 
17. Olden GD,VA-LCP anterior clavicle plate: the anatomically precontoured fixation system with angular stability for clavicle shaft. Musculoskelet Surg. 2014 Dec;98(3):217-23. doi: 10.1007/s12306-013-0302-z. Epub 2013 Oct 27

18. Jones GL, Bishop JY, Lewis B, Pedroza AD; MOON Shoulder Group. Intraobserver and interobserver agreement in the classification and treatment of midshaft clavicle fractures. Am J Sports Med 2014;42: 1176-81. doi: 10.1177/0363546514523926. Epub 2014 Feb 26.

19. Stegeman SA, Fernandes NC, Krijnen P, Schipper IB. Online radiographic survey of midshaft clavicular fractures: no consensus on treatment for displaced fractures. Acta Orthop Belg. 2014 Jun; 80(2):161-5
20. Nordqvist A, Redlund-Johnell I, von Scheele A, Petersson CJ. Shortening of the clavicle after fracture: incidence and clinical significance, a 5-year follow-up of 85 patients. Acta Orthop Scand. 1997;68:349351.

21. Nowak J, Holgersson M, Larsson S. Can we predict long-term sequelae after fractures of the clavicle based on initial findings? A prospective study with nine to ten years follow-up. J Shoulder Elbow Surg. 2004;13:479-486.

22. Rasmussen JV, Jensen SL, Petersen JB, Falstie-Jensen T, Lausten G, Olsen BS. A retrospective study of the association between shortening of the clavicle after fracture and the clinical outcome in 136 patients. Injury. 2011;42:414-417. doi: 10.1016/j.injury.2010.11.061. Epub 2011 Jan 15. 


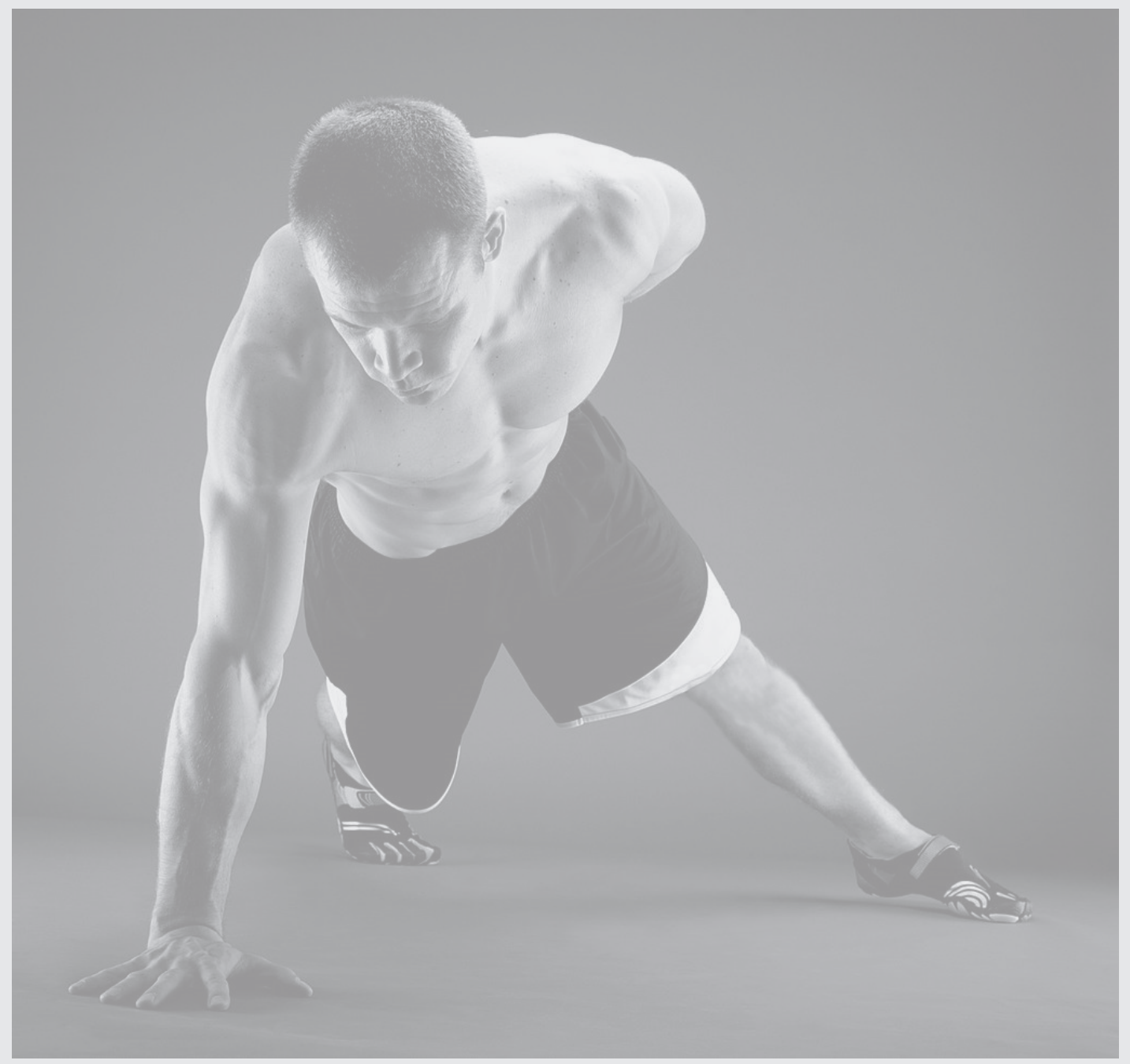




\section{CHAPTER FIVE}

Plate fixation versus conservative treatment of displaced midshaft clavicle

fractures: functional outcome and patients satisfaction during a mean follow-up of 5 years

D.J.C van der Ven, T.K Timmers, P.E Flikweert,

A.L.A van ljseldijk, G.D.J van Olden 


\section{ABSTRACT}

\section{Introduction}

The aim of the present prospective clinical trial was to compare patient-oriented and surgeon-based outcomes after non-operative care with operative treatment of displaced midshaft clavicle fractures.

\section{Patients/Methods}

Between January 2009 and July 2011, 97 consecutive patients presenting with a midshaft clavicle fracture were prospectively recorded and included in this study. The patients were placed in either of the treatment groups on their own prefence. They were then seen in outpatient clinic at two, six and 24 weeks were all endpoints were investigated and motivation of choice of treatment was noted. Study follow-up was continued until Augustus 2014, being the time point that long-term functional outcome was measured through a DASH score by letter.

\section{Results}

97 patients were included in the functional outcome analysis. The mean DASH and

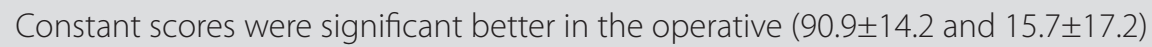
than in the conservative treatment group at six weeks (78.7 \pm 17.0 and $24.8 \pm 16.7)$. There was a significant improvement in the Constant $(95.9 \pm 10.5$ versus $94.5 \pm 5.9)$ and DASH scores $(8.8 \pm 12.0$ versus $7.1 \pm 10.7)$ for both groups at 24 weeks but there was no significant difference in functional scores between the groups. Four patients developed a non-union, one patient in the operative and three patients in the conservative group. Overall complications were significantly higher in the operative group (31\%) compared to the conservative group $(9 \%)(p<0,001)$. There was no significant difference in long-term functional outcome between the two treatment groups $(5.2 \pm 9.8$ versus $2.5 \pm 4.9 p=0,12)$. Patient's satisfaction was higher in the operative than in the conservative group $(p<0,04)$.

\section{Conclusion}

Significant superior outcome scores were seen at six weeks for the operative group. However, at 24 weeks and 5-year follow-up no difference was seen in functional outcome scores for both treatment groups. Therefore, the challenge for the future is to better identify the subgroup of patients who might benefit from primary surgical intervention. 


\section{INTRODUCTION}

Fractures of the clavicle account for 2.6 to $4 \%$ of all fractures. The vast majority (69-82\%) of these fractures are located in the midshaft of the clavicle..$^{1-3}$ These midshaft clavicle fractures are caused by a direct axial compressive force to the shoulder after a sudden stop or fall and occur mostly in young active individuals. The treatment of clavicle fractures is, therefore, aimed at quickly restoring function of the upper extremity and preventing disability. Traditionally, midshaft clavicle fractures have been treated non-operatively, even when substantially displaced. This was based on early reports suggesting that clavicle non-unions are very rare. ${ }^{4,5}$ However, decreased shoulder function due to clavicle shortening after nonoperative fracture management has been reported. ${ }^{6}$

There is, nowadays, a growing trend to treat displaced midshaft clavicle fractures with primary open reduction and plate fixation. Whether such treatment results in improved patient outcomes is debatable. There is limited evidence on the relative effectiveness of different methods of surgical intervention for treating acute fractures of the middle third of the clavicle and no consensus exist yet.? Therefore, the choice of treatment depends mostly upon the experience of the surgeon and is often not patient oriented.

The aim of the present prospective clinical trial was to compare patient-oriented and surgeon-based outcomes after non-operative care with operative treatment of completely displaced midshaft clavicle fractures.

\section{PATIENTS AND METHODS}

Between January 2008 and July 2010, all consecutive patients presenting with a new midshaft clavicle fracture at the emergency department of the Meander Medical Center (MMC), were prospectively recorded and included in this clinical trial. The MMC serves as a regional Level 2 trauma center. Our hospital treats an increasing number of emergency department patients of around 35.000 patients. The study was approved by the local medical ethics committee.

\section{Patient selection}

Inclusion criteria were: 1) a completely displaced midshaft fracture of the clavicle with no cortical contact between the proximal and distal fragment; 2) age between 16 and 70 years.

Exclusion criteria were: 1) fracture in the proximal or distal third of the clavicle; 2) pathological fracture (bony abnormalities at the side of the fracture); 3 ) open fracture; 4) fracture seen more than twenty-one days after the injury; 5) a significant ipsilateral upper extremity fracture. 
Once identified as eligible for the study, patients were seen at the outpatient clinic within 5 days. They received detailed information from one experienced trauma surgeon regarding the advantages and disadvantages of the both operative and nonoperative treatment. After explanation of both therapeutic methods, the patients were placed in either the operative or non-operative group on their own preference.

\section{Outcome measures}

The primary outcome parameters were: 1) fracture union and 2) functional outcome measured using the "Disability of the Arm, Shoulder and Hand" (DASH) questionnaire $^{8}$ and the Constant shoulder questionnaire. ${ }^{9}$

Secondary outcome parameters were: 1) complications; 2) return to work; and 3) motivation choice of treatment.

Long-term outcome parameters were: 1) functional outcome measured using the "Disability of the Arm, Shoulder and Hand" (DASH) questionnaire ${ }^{9}$ and "visual analog scale" VAS ${ }^{10}$ by letter; 2) complications; 3) residual complaints; 4) patients' satisfaction with treatment measured with an additional questionnaire by letter.

\section{Interventions}

Conservative treatment was performed with use of a standard sling for two weeks, only passive movements were allowed. After these two weeks, the patient was seen on the outpatient clinic and a course of physiotherapy for exercise and strengthening was carefully initiated. The full range of active motion was permitted after six weeks, and return to full activities was permitted after three months.

Surgery was performed within three weeks after injury. The procedure of applying the VA-LCP anterior locking compression plate was performed according to standard orthopedic procedures "1. A sling was used during the first two weeks postoperatively. The postoperative exercise protocol was similar to that in the nonoperative group.

\section{Fracture union}

Union of the clavicle fracture was defined as complete cortical bridging between proximal and distal fragments. Symptomatic mal-union was defined as a patient with symptoms severe enough to warrant corrective osteotomy. Non-union was defined as the absence of radiographic union six months or longer after the injury. Patients with nonunion at six months who had symptoms of pain or mobility at the fracture site were offered secondary open reduction and anterior plate fixation ${ }^{11}$. Delayed union was defined as progression to union on three-dimensional CT at one year of follow-up in patients who had not healed by six months. 


\section{Follow-up}

Following enrollment in the study, the patients were seen in outpatient clinic at two, six weeks, and at 6 months. The DASH and Constant shoulder scores were completed, motivation of choice of treatment was noted and radiographs were made.

Study follow-up was continued until May 2014, being the time point that longterm functional outcome was measured through a DASH score and VAS by letter combined with an letter were all adverse events were noted and divided into physical complaints (droopy shoulder, bump and/ or asymmetry, scar, sensitive and / or painful fracture site, hardware irritation, incisional numbness), the need of operative procedure or additional medical treatment and patients' satisfaction with the chosen treatment.

\section{Functional outcome}

The Disabilities of the Arm, Shoulder and Hand (DASH) $)^{8}$ scoring system was developed to assess the level of disability for any patient with any condition affecting the upper limb by covering domains including symptoms, physical function, social function and psychological function. The DASH is scored in two components: the disability/symptom questions (30 items, scored 1-5) and the optional high performance sport/music or work section (4 items, scored 1-5).

The Constant-Murley score ${ }^{9}$ comprises both clinician-assessed physical examination findings and subjective patient-reported assessments. It consists of 14 items, with a total score of 0 -100. The questionnaire consists of two parts: the subjective part measures pain during various activities: pain, activity level sleep affected, recreations/sport limitation, daily living limitations and arm positioning. The objective part is completed by the surgeon and includes the following components: Range of motion, strength of abduction, external rotation and internal rotation. An additional questionnaire was used to assess functional impairment and clinical outcomes including: recovery of former function, such as time to return to previous activities (sport, manual labor), cosmetic appearance and patient satisfaction. The VAS is a self-rated health status using a visual analogue scale (VAS) recording the perception of the participant's current overall health state. The latter is ranged from 0 (the worst imaginable health state) to 100 (the best imaginable state)..$^{10}$

\section{Complications}

Complications were considered to exist if a subsequent surgical procedure was performed, if fixation failed or produced irritationrequiring re-surgery, or if antibiotics were necessary to treat a wound infection. 


\section{Statistical analysis}

Statistical analysis was performed using SPSS 15.0, Chicago, for Microsoft Windows. Differences in the DASH and the Constant score between the treatment groups were compared with use of the independent t-test. The chi-square test was used for categorical data. Continuous variables were reported as mean \pm SD or median ( $25^{\text {th }}$ and $75^{\text {th }}$ inter quartile ranges) and categorical variables as number and percentages, unless otherwise stated. All tests were two-sided, and the level of significance was set at $p<0.05$.

\section{RESULTS}

Between January 2008 and July 2010 a total of 97 patients were included (90 males, mean age $40.6 \pm 14.3$ ). Thirty-nine patients were treated operatively ( $90 \%$ men, mean age $40.8 \pm 12.8$ ) and 58 patients were treated conservatively ( $85.5 \%$ men, mean age $40.5 \pm 15.2)$. The majority of patients had sustained the injury in falls, collision sports, or bicycling/motorcycling accidents. There were no significant differences in the demographic features or injury patterns between the groups (Table 1A).

\section{Functional outcome}

The DASH and Constant questionnaires were completed in 97 patients (100\%) at 6 weeks postoperatively, (Table 1B). Nevertheless, 4 patients (4\%) were excluded due to an incomplete questionnaire. Two patients were excluded due to an incomplete Constant score (2 patients (3\%) in the conservative and 2 patient (5\%) in the operative group. The mean functional scores were significant better in the operative group compared to the conservative treatment group at 6 weeks (20.8 $\pm 19,9$ versus $26.6 \pm 15.5$ ( $p=0,12)$; except for the Symptoms dimension. The Constant score was $90.9 \pm 14.2$ in the operative group versus $78.7 \pm 17.0(p<0,001)$. The DASH score was respectively $15.7 \pm 17.2$ versus $24.8 \pm 16.7(p=0,01)$.

At 24 week 61 patients (63\%) completed the Constant questionnaire. However, only 56 patients (58\%) completed both the Constant and DASH questionnaire. Unfortunately, 15 patients (38\%) in the operative group and 26 patients (45\%) in the conservative group were lost to follow-up (Figure 1). The calculated functional outcome of the DASH and Constant questionnaire is shown in Table 1B/C. There was a significant improvement in the Constant and DASH scores for both groups at 24 weeks. The DASH scores were better (clinically) in de conservative group than in the operative group $(8.8 \pm 12.0$ versus $7.1 \pm 10.7 ; p=0,58)$. The mean Constant score was equal in both groups, $95.9 \pm 10.5$ versus $94.5 \pm 5.9$, respectively ( $p=0,52$ ). Nevertheless, functional outcome was not significant different. 
Table 1A Baseline characteristics of the cohort ( $n=97$ patients) subdivided in an operative and a conservative group.

\begin{tabular}{|c|c|c|c|c|}
\hline & $\begin{array}{l}\text { Overall } \\
\mathrm{N}=97\end{array}$ & $\begin{array}{c}\text { Operative } \\
\mathrm{N}=39\end{array}$ & $\begin{array}{c}\text { Conservative } \\
\qquad \mathrm{N}=58\end{array}$ & p-value ${ }^{2}$ \\
\hline $\mathrm{Age}^{1}$ & $40.6 \pm 14,3$ & $40.8 \pm 12,8$ & $40.5 \pm 15,2$ & 0.91 \\
\hline Male gender (\%) & $84(87)$ & $35(90)$ & $49(85)$ & 0.46 \\
\hline Dominant arm (\%) ${ }^{3}$ & $45(46)$ & 19() & 26() & 0.70 \\
\hline Smoker (\%) & $20(21)$ & $9(23)$ & 11(19) & 0.66 \\
\hline Polytrauma (\%) ${ }^{4}$ & $7(7)$ & $5(12)$ & $2(3)$ & 0.08 \\
\hline \multicolumn{5}{|l|}{ Mechanism of fall (\%) } \\
\hline Fall & $6(6)$ & $1(3)$ & $5(9)$ & 0.59 \\
\hline Sports & $23(24)$ & $8(21)$ & $15(26)$ & \\
\hline Motor-vehicle of motorcycle accident & $24(25)$ & $11(28)$ & $13(22)$ & \\
\hline Bicycling & $37(38)$ & $16(41)$ & $21(36)$ & \\
\hline Skiing & $6(6)$ & $2(5)$ & $4(7)$ & \\
\hline Other $^{5}$ & $1(1)$ & $1(3)$ & $0(0)$ & \\
\hline
\end{tabular}

${ }^{1}$ Mean SD values; ${ }^{2}$ Statistical comparison between the operative and the conservative group; ${ }^{3} 1(1 \%)$ missing; ${ }^{4}$ Concomitant injuries were multiple rib fractures without a pneumothorax in 8 of the patients and a metacarpal fracture in the contralateral hand in one patient, $7(7 \%)$ missings; ${ }^{5}$ Other reason: being robbed in Spain.

Table 1B Constant score and DASH score with the calculated functional outcome score at 6 weeks

\begin{tabular}{|c|c|c|c|c|}
\hline & $\begin{array}{l}\text { Overall } \\
\mathrm{N}=97\end{array}$ & $\begin{array}{c}\text { Operative } \\
\mathrm{N}=39\end{array}$ & $\begin{array}{c}\text { Conservative } \\
\mathrm{N}=58\end{array}$ & p-value ${ }^{3}$ \\
\hline Constant score 6 weeks ${ }^{1}$ & $83.6 \pm 16.9$ & $90.9 \pm 14,2$ & $78.7 \pm 17.0$ & $<0.001$ \\
\hline Subjective component & $30.3 \pm 4.6$ & $31.8 \pm 4,2$ & $29.3 \pm 4.6$ & 0.01 \\
\hline Objective component & $53.7 \pm 13.4$ & $59.5 \pm 10.8$ & $49.8 \pm 13.6$ & $<0.001$ \\
\hline $\begin{array}{l}\text { DASH score } 6 \text { weeks }{ }^{2} \\
\text { Impairments in Dimension: }\end{array}$ & $21.2 \pm 17.4$ & $15.7 \pm 17.2$ & $24.8 \pm 16.7$ & 0.01 \\
\hline Activities & $20.3 \pm 18.4$ & $14.1 \pm 16.8$ & $24,4 \pm 18.2$ & 0.006 \\
\hline Symptoms & $24.3 \pm 17.5$ & $20.8 \pm 19,9$ & $26,6 \pm 15,5$ & 0.12 \\
\hline Sport & $50.9 \pm 40.2$ & $37.5 \pm 39.3$ & $60.3 \pm 38.5$ & 0.02 \\
\hline Work & $24.0 \pm 31.2$ & $12.1 \pm 21.5$ & $32.5 \pm 34.3$ & 0.003 \\
\hline
\end{tabular}

${ }^{1}$ No missings at 6 weeks but 4 patients (4\%) were excluded due to an incomplete questionnaire, 2 patients (3\%) in conservative and 2 patients (5\%) in operative group. ${ }^{2}$ No missings at 6 weeks but $1(2 \%)$ in operative group was excluded due to an incomplete questionnaire. ${ }^{3}$ Statistical comparison between the operative and the conservative group.

Table 1C Constant score and DASH score with the calculated functional outcome score at 24 weeks

\begin{tabular}{lcccc}
\hline & $\begin{array}{c}\text { Overall } \\
\mathbf{N = 9 7}\end{array}$ & $\begin{array}{c}\text { Operative } \\
\mathbf{N = 3 9}\end{array}$ & $\begin{array}{c}\text { Conservative } \\
\mathbf{N = 5 8}\end{array}$ & p-value $^{\mathbf{3}}$ \\
\hline Constant score 24 week & $95.1 \pm 8.3$ & $95.9 \pm 10.5$ & $94.5 \pm 5.9$ & 0.52 \\
Subjective component & $33.2 \pm 3.4$ & $32.9 \pm 4.5$ & $33.5 \pm 2.1$ & 0.57 \\
Objective component & $61.8 \pm 5.8$ & $62.9 \pm 6.1$ & $60.8 \pm 5.2$ & 0.15 \\
DASH score 24 weeks & $7.9 \pm 11.2$ & $8.8 \pm 12.0$ & $7.1 \pm 10.7$ & 0.58 \\
Impairments in Dimension: & & & & \\
$\quad$ Activities & $6.8 \pm 11.3$ & $8.0 \pm 11.8$ & $6.0 \pm 10.9$ & 0.53 \\
$\quad$ Symptoms & $11.8 \pm 13.3$ & $12.9 \pm 14.1$ & $10.9 \pm 12.7$ & 0,58 \\
$\quad$ Sport & $12.5 \pm 18,5$ & $13.1 \pm 21.5$ & $12.0 \pm 16.3$ & 0,84 \\
$\quad$ Work & $8.9 \pm 20.0$ & $13.3 \pm 25.3$ & $4.7 \pm 12.8$ & 0.41 \\
\hline
\end{tabular}

${ }^{1} 36(37 \%)$ missings at 24 week, $11(28 \%)$ in operative group and 25(43\%) in conservative group. ${ }^{2} 41$ (42\%) missings at 24 week, 15(38\%) in operative group and 26 (45\%) in conservative group. ${ }^{3}$ Statistical comparison between the operative and the conservative group. 
Figure 1. Flow chart of the study population

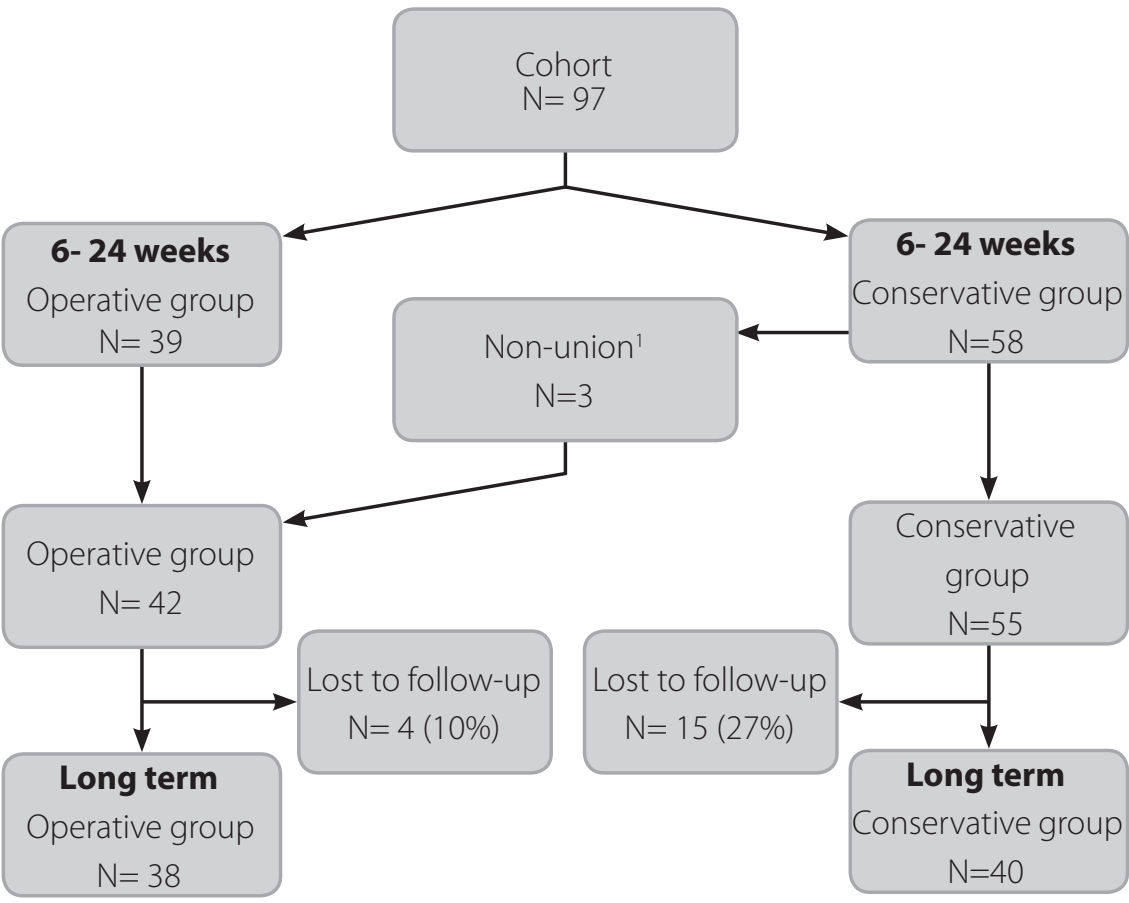

1 Three patients in the conservative treatment group developed a non-union and were in need of an operative intervention. Further follow-up of these patients occurred in the operative treatment group.

\section{Fracture union}

There were 4 patients (4\%) who developed a non-union, 1(3\%) in the operative group and 3 (5\%) in the conservative group requiring plate fixation. After surgery of the non-unions in the conservative group, further long-term follow-up of these 3 patients occurred in the operative group. One patient developed a delayed union in the conservative group (Table 2).

\section{Complications}

Overall complications were significantly higher in the operative group (31\%) compared to the conservative group (9\%) $(p<0,001)$. In the operative group 9 patients (23\%) underwent a second operation within the study follow-up period, one patient (3\%) developed a non-union, four (10\%) patients suffered from hardware irritation requiring removal, and in 3 patients (8\%) there was mechanical failure requiring re-surgery at which 1 patient had a plate fracture twice. Complications in the conservative group were mostly due to non-unions; seen in 3 patients (5\%) in which all patients (100\%) were in need of an intervention (Table 2). 
Table 2. Overall complications

\begin{tabular}{lcccc}
\hline & $\begin{array}{c}\text { Overall } \\
\mathbf{N = 9 7}\end{array}$ & $\begin{array}{c}\text { Operative } \\
\mathbf{N = 3 9}\end{array}$ & $\begin{array}{c}\text { Conservative } \\
\mathbf{N = 5 8}\end{array}$ & p-value $^{1}$ \\
\hline Overall complications (\%) ${ }^{2}$ & $17(18)$ & $12(31)$ & $5(9)$ & $<0.001$ \\
Nonunion (\%) & $4(4)$ & $1(3)$ & $3(5)$ & \\
Delayed union (\%) & $1(1)$ & $0(0)$ & $1(2)$ & \\
Hardware irritation requiring removal (\%) & $4(4)$ & $4(10)$ & $0(0)$ \\
Mechanical failure requiring re-surgery (\%) & $4(4)$ & $4(10)$ & $0(0)$ \\
Other $^{4}$ & $4(4)$ & $3(8)$ & $1(2)$ & \\
\hline
\end{tabular}

1 Statistical comparison between the operative and the conservative group

${ }^{2} 5(8 \%)$ missings in conservative group, no complications in $83(80 \%)$ patients, $30(71 \%)$ patients in operative group en 58 (86\%) in conservative group.

${ }^{3}$ In operative group: 1 patient had 2x plate fracture for which 2x re-surgery

${ }^{4}$ In operative group: 2 patients had reduced sensibility and 1 patient seroma and 1 patient had reduced sensibility in conservative group.

\section{Return to work}

We found a significant difference between both groups with regarding the time to return to work or sports. In the operative group, 13 patients (33\%) had physically heavy work versus 11 (19\%) patients in the conservative group, (Table 3A). In the operative group, patients resumed their work in $2.3 \pm 1.9$ versus $4.1 \pm 3.1$ weeks $(p=0.002)$. Again, a significant difference between the two treatment groups was seen when we differentiated between job descriptions.

\section{Motivation choice of treatment}

Pain (51\%) was most frequently listed as motivation choice of treatment (Table 3B). The patients who chose an operative treatment said to experience more pain than the patients in the conservative group. Job related factors were another frequently occurring motivation choice. Quicker return to work was seen in 26 patients (27\%) to be the reason to prefer an operation. Cosmetic reasons were higher in the operative group (13\% versus 9\%) (Table 3B).

\section{Long-term follow-up}

Functional outcome was measured in $80 \%(n=78)$ of 97 patients alive at the end of our study period with an average follow-up of $5.3 \pm 0.6$ years. The overall outcome in both groups of patients was good after long-term follow-up: DASH score of 3.7 \pm 7.7 and VAS score of $88.6 \pm 14.4$. As shown in Table $4 A$, the overall DASH scores were $2.5 \pm 4.9$ in the conservative group versus $5.2 \pm 9.8$ in the operative group $(p=0.12$ ). 
In the overall group, 67\% suffered from residual physical complaints. A significant higher rate was seen in the operative group compared to the conservative group, $76 \%$ versus $58 \%$ ( $p=0.04$.) A sensitive and/or painful fracture site was the most frequent complaint in both groups of patients (37\% versus 35\%). In the operative group hardware irritation was the second most common complaint (42\%) and in the conservative group a droopy shoulder and a bump and/or asymmetry (20\%), (Table 4B).

Long-term complications were mostly hardware related requiring removal, 10 patients (26\%) in operative group. No long-term complications that occurred after 24 weeks were listed for the conservative group (Table 4C). Patients' satisfaction was higher in the operative compared to the conservative group (84\% versus 64\%, $p=0,04$ ), (Table 4C).

Table 3A. ${ }^{1}$ Work: job description and return to work in weeks.

\begin{tabular}{lcccc}
\hline & $\begin{array}{c}\text { Overall } \\
\mathbf{N}=\mathbf{9 7}\end{array}$ & $\begin{array}{c}\text { Operative } \\
\mathbf{N = 3 9}\end{array}$ & $\begin{array}{c}\text { Nonoperative } \\
\mathbf{N = 5 8}\end{array}$ & p-value $^{2}$ \\
\hline Job description (\%) & & & & \\
Physically demanding job & $24(25)$ & $13(33)$ & $11(19)$ & \\
Physically no demanding job & $62(64)$ & $23(59)$ & $39(67)$ & \\
$\quad$ Retired & $3(3)$ & $1(2)$ & $2(3)$ & \\
$\quad$ Student & $7(7)$ & $2(5)$ & $5(9)$ & \\
Return to work (weeks) $^{3}$ & $3.3 \pm 2,8$ & $2.3 \pm 1.9$ & $4.2 \pm 3.1$ & 0.002 \\
\hline
\end{tabular}

111 missing in non-operative group. ${ }^{2}$ Statistical comparison between the operative and the conservative group. ${ }^{3}$ Mean \pm SD values. ${ }^{4} 20$ missings (21\%), 4 patients (10\%) in the operative and 16 patients (28\%) in de conservative group.

Table 3B. ${ }^{1}$ Motivation choice of treatment.

\begin{tabular}{lccc}
\hline & $\begin{array}{c}\text { Overall } \\
\mathbf{N = 9 7}\end{array}$ & $\begin{array}{c}\text { Operative } \\
\mathbf{N = 3 9}\end{array}$ & $\begin{array}{c}\text { Nonoperative } \\
\mathbf{N = 5 8}\end{array}$ \\
\hline Pain (\%) & $51(53)$ & $16(41)$ & $35(60)$ \\
Quicker return to work (\%) & $26(27)$ & $26(67)$ & $0(0)$ \\
Cosmetic reason (\%) & $10(10)$ & $5(13)$ & $5(9)$ \\
Sports (\%) & $5(5)$ & $5(13)$ & $0(0)$ \\
Physically not demanding job (\%) & $5(5)$ & $0(0)$ & $5(9)$ \\
Prefers an operation/nonoperative treatment (\%) & $18(19)$ & $5(13)$ & $13(22)$ \\
Other (\%) & $18(19)$ & $10(25)$ & $8(14)$ \\
\hline
\end{tabular}

${ }^{1}$ Patients were able to write down multiple motivations. ${ }^{2}$ The nonoperative group: the choice of the doctor/surgeon (4 patients), young age (16 years of age, 2 patients), expects the same result (2 patients), comorbidities (1 patient), good mobility (1 patient).

The operative group: comorbidities (1 patient), dislocation (1 patient), anatomic position (4 patient), skin problem (1 patient), poor previous clavicle fracture healing with nonoperative treatment (1 patient). 
Table 4A. Long term functional outcome calculated with the DASH score and VAS..

\begin{tabular}{|c|c|c|c|c|}
\hline & $\begin{array}{c}\text { Overall } \\
\mathrm{N}=78\end{array}$ & $\begin{array}{c}\text { Operative }^{1} \\
\mathrm{~N}=38\end{array}$ & $\begin{array}{c}\text { Nonoperative } \\
\mathrm{N}=40\end{array}$ & p-value ${ }^{2}$ \\
\hline DASH score ${ }^{3,4}$ & $3.7 \pm 7.7$ & $5.2 \pm 9.8$ & $2.5 \pm 4.9$ & 0.12 \\
\hline \multicolumn{5}{|c|}{ Impairments in Dimension: } \\
\hline Activities $^{3}$ & $2.9 \pm 6,6$ & $4.4 \pm 8.8$ & $1.7 \pm 3,2$ & 0.08 \\
\hline Symptoms ${ }^{3}$ & $8.9 \pm 3.8$ & $9.4 \pm 4.2$ & $8.5 \pm 3.3$ & 0.30 \\
\hline Sport ${ }^{3,5}$ & $4.7 \pm 2.1$ & $5.1 \pm 2.1$ & $4.5 \pm 1.6$ & 0.19 \\
\hline Work ${ }^{3,6}$ & $4.8 \pm 1.9$ & $5.0 \pm 2.7$ & $4.5 \pm 1.4$ & 0.33 \\
\hline VAS $^{3}$ & $88.6 \pm 14.4$ & $86.3 \pm 17.3$ & $90.8 \pm 10.0$ & 0.16 \\
\hline
\end{tabular}

${ }^{1}$ Long- term follow-up of the 3 non-union patients in the conservative group, who were in need of operative intervention was carried out in the operative group.

${ }^{2}$ Statistical comparisons between the operative and the conservative group. ${ }^{3}$ Mean \pm SD values;

${ }^{4}$ Five patients (6\%) were excluded from the DASH scores due to an incomplete questionnaire, 4 patients (10.5\%) in the operative en 1 patient (2.5\%) in the conservative group.

${ }^{5}$ Sport: 11 patients (14\%) didn't practice any sport: 3 (7.5\%) conservative, 7 (18\%) operative group.

${ }^{6}$ Work: 4 patients (5\%) were unemployed and didn't complete the work dimension: 2 (5\%) conservative, 2 (5\%) operative missings.

Table 4B. ${ }^{1}$ Residual physical complaints.

\begin{tabular}{lcccc}
\hline & $\begin{array}{c}\text { Overall } \\
\mathbf{N}=\mathbf{7 8}\end{array}$ & $\begin{array}{c}\text { Operative }^{1} \\
\mathbf{N = 3 8}\end{array}$ & $\begin{array}{c}\text { Nonoperative } \\
\mathbf{N = 4 0}\end{array}$ & p-value $^{2}$ \\
\hline Physical complications $^{2}$ & $52(67)$ & $29(76)$ & $23(58)$ & 0.04 \\
Droopy shoulder $^{1}$ & $13(17)$ & $5(13)$ & $8(20)$ & \\
Bump and/or asymmetry & $11(14)$ & $3(8)$ & $8(20)$ & \\
Scar $^{1}$ & $5(6)$ & $5(13)$ & $0(0)$ \\
Sensitive and/or painful fracture site & $28(35)$ & $14(37)$ & $14(35)$ \\
Hardware irritation and/or1 prominence $^{1}$ & $16(21)$ & $16(42)$ & $0(0)$ & \\
Incisional numbness $^{1}$ & $4(5)$ & $4(11)$ & $0(0)$ & \\
\hline
\end{tabular}

${ }_{1}^{1}$ Patient could suffer from multiple physical complaints. ${ }^{2}$ Statistical comparison between the groups: every complaint was ranked as yes or no, multiple complaints were not counted twice.

Table 4C. Long-term complications and patients satisfactions with choice of treatment.

\begin{tabular}{|c|c|c|c|c|}
\hline & $\begin{array}{c}\text { Overall } \\
\mathrm{N}=78\end{array}$ & $\begin{array}{c}\text { Operative }^{1} \\
\mathrm{~N}=38\end{array}$ & $\begin{array}{c}\text { Nonoperative } \\
\mathrm{N}=40\end{array}$ & p-value ${ }^{2}$ \\
\hline Operative complications (\%) ${ }^{1}$ & $16(21)$ & $16(42)$ & $0(0)$ & \\
\hline Hardware irritation requiring removal (\%) & 10(13) & $10(26)$ & $0(0)$ & \\
\hline Mechanical failure requiring re-surgery (\%) & $6(8)$ & $6(16)$ & $0(0)$ & \\
\hline Patients satisfied with choice (\%) & $57(73)$ & $32(84)$ & 25(64) & 0.04 \\
\hline
\end{tabular}

\footnotetext{
${ }^{1}$ The complications that occurred after 24 weeks;
} 


\section{DISCUSSION}

The purpose of this prospective study was to compare non-operative care with operative treatment of completely displaced midshaft clavicle fractures. Our study shows that operative plate fixation of displaced midshaft clavicle fractures has an early effect on decreasing pain and improving function. This is demonstrated by the significantly improved DASH and Constant scores seen at 6 week after injury. Our findings are consistent with recent studies of Robinson et al. and the Canadian study group ${ }^{12,13}$; they found an early significant benefit from plate fixation and, therefore, concluded that the preferred treatment should be the use of primary plate fixation of displaced fractures in active adults. Our study showed, however, no difference in functional outcome at 24 weeks of follow-up and no clinically important difference in functional outcome at 5 years follow-up for both treatment groups. Our conclusion is comparable to recent $(2012,2013)$ metaanalyses. 15,16 They described that most patients experienced similar functional outcomes regardless of whether they were treated operatively or conservatively, and that there is little evidence that the long-term functional outcome of the operative intervention is significantly superior to non-operative care. ${ }^{15,16} \mathrm{~A}$ lot of research has been done to establish a general consensus on how to treat these types of fractures. Unfortunately, there is much variability in the findings of these studies. ${ }^{6,712-24}$ The traditional opinion in the treatment of displaced midshaft clavicle fractures has been that they rarely require operative stabilization. This was based on: 1) two large studies conducted in the 1960s that reported a higher non-union rate amongst operatively treated patients ${ }^{4,5}$, and 2) studies showing a high level of patient satisfaction after conservative treatment of these fractures. ${ }^{17,18}$ However, several recent prospective studies reported non-union rates of $15-20 \%{ }^{6,14}$ and stated that patients treated non-operatively were more likely to develop a complication than those treated with primary operative repair. $15,19-21$ In our study the overall complication rates were significant lower in the conservative group than in the operative group ( $9 \%$ versus $31 \%, p<0.001$ ). Though, it must be emphasized that the higher overall complication rate is due to operation specific complications (i.e. hardware related), which could not occur in the non-operative treatment group. This is similar to the results of Judd et al.22; they also found a higher complication rate in the operative group and mostly hardware related. Complications more common in the non-operative group were non-union, nevertheless, this was only seen in $5 \%$ in the non-operative group. This is similar to the non-union rates found in the studies of Postacchini et al. ${ }^{23}$ and Robinson et al. ${ }^{24}$; they found an overall prevalence of $5.5 \%$ and $4.5 \%$. However, these numbers are much lower compared 
to the numbers found in recent meta-analyses. This review shows that $15 \%$ of the patients in the non-operative group developed a non-union, compared to the $1 \%$ in the operative group $(p=0,001) \cdot{ }^{15}$ In addition, we found that patients satisfaction was higher in the operative compared to the conservative group $(p=0.04)$, although more complications were seen in the operative group and a higher rate of physical complaints $(p=0.04)$. This could be explained by the fact that this injury commonly afflicts a young, active population in which a rapid return to function and early union has a higher priority than the more traditional outcomes, such as recovery of muscle strength, range of motion, and the avoidance of longterm complications. After all, in our study a significant earlier return to function was seen in the operative group $2.3 \pm 1.9$ versus $4.1 \pm 3.1$ weeks $(p=0.002)$. However, this interpretation may lead to overtreatment, as it remains unclear which patients characteristics can reliably predict patient-important functional outcomes and which factors influence whether a surgical or non-operative approach is more likely to result in a satisfied patient. Treatment should, therefore, be individualized, with consideration of each patient's age, activity level, job description and expectations of treatment.

We recognize that there are some limitations to this study. First of all, patients were not randomized but could choose their own treatment preference. We used the daily practice as starting point for our research protocol. As a consequence, this created a bias in our results, and, thereafter, a weakness in the study. However, our current practice is to counsel patients with use of a shared decision-making process in which the risk factors for non-union with non-operative treatment are balanced with the drawbacks and potential risks of surgery.Another limitation of our study is the number of patients who did not complete the DASH and Constant shoulder questionnaires at 24 weeks. This could lead to an underestimation of the complaints present in the patient who were lost to follow-up and fail to detect an effect that is present.

Up to today, it is still unclear if the indication for operative treatment should be enlarged or that conservative treatment remains the preferred choice. Prognostic indicators that would identify the individuals most at risk for developing a negative outcome would be very helpful in refining operative indications.Therefore, the challenge for the future is to better identify the subgroup of patients who might benefit from primary surgical intervention. 


\section{CONCLUSION}

In conclusion, there is still no consensus in how to treat displaced midshaft clavicle fractures. Our study showed significant superior outcome scores at 6 weeks for the operative group. However, at 24 weeks and 5-year follow-up no difference was seen in functional outcome scores for both treatment groups. Our study also found that, patient's satisfaction was significant higher in the operative group than in the conservative group. Despite the fact that, more complications and a higher rate of physical complaints were seen in the operative group.After these results we believe there is little evidence at present to show that the long-term functional outcome of operative intervention is significantly superior to non-operative care, however, there might be a subgroup of patients who would benefit from primary operative care. 


\section{REFERENCES}

1. Robinson CM. Fractures of the clavicle in the adult. Epidemiology and classification. J Bone Joint Surg Br 1998; 80(3): 476-84.

2. Nordquist A, Petersson C. The incidence of fractures of the clavicle. Clin Orthop Relat Res 1994; 300: 127-32.

3. Postacchini F, Gumina S, De Santis P, Albo F. Epidemiology of clavicle fractures. J Shoulder Elbow Surg. 2002;11(5):452-456.

4. Neer CS. Nonunion of the clavicle. J Am Med Assoc 1960; 172: 1006-1011.

5. Rowe CR. An atlas of anatomy and treatment of midclavicular fractures. Clin Orthop Relat Res. 1968;58:29-42.

6. Hill JM, McGuire MH, Crosby LA: Closed treatment of displaced middle- third fractures of the clavicle gives poor results. J Bone Joint Surg Br 1997, 79:537-539.

7. Rehn CH, Kirkegaard M, Viberg B, Larsen MS. Operative versus nonoperative treatment of displaced midshaft clavicle fractures in adults: a systematic review Eur J Orthop Surg Traumatol. 2013 Dec 10.

8. Hudak P, Amadio PC, Bombardier C, and the Upper Extremity Collaborative Group. Development of an Upper Extremity Outcome Measure: The DASH (Disabilities of the Arm, Shoulder, and Hand). American Journal of Industrial Medicine 1996; 29:602608.

9. Constant C, Murley A. A clinical method of functional assessment of the shoulder. Clin Orthop 1987;214:160-4.

10. Gudex C, Dolan P, Kind P, Williams A. Health state valuations from the general public using the Visual analoge Scale. Qual Life Res 1996; 5: 521-531.

11. Olden GD,VA-LCP anterior clavicle plate: the anatomically precontoured fixation system with angular stability for clavicle shaft. Musculoskelet Surg. 2014 Dec;98(3):217-23.

12. Robinson CM, Goudie EB, Murray IR, Jenkins PJ, Ahktar MA, Read EO, Foster CJ, Clark K,
Brooksbank AJ, Arthur A, Crowther MA, Packham I, Chesser TJ. Open reduction and plate fixation versus nonoperative treatment for displaced midshaft clavicular fractures: a multicenter, randomized, controlled trial.J Bone Joint Surg Am. 2013 Sep 4;95(17):1576-84

13. Canadian Orthopaedic Trauma Society. Nonoperative treatment compared with plate fixation of displaced midshaft clavicular fractures. A multicenter, randomized clinical trial.J Bone Joint Surg Am. 2007 Jan;89(1):1-10.

14. Witzel K. Intramedullary osteosynthesis in fractures of the mid-third of the clavicle in sports traumatology]. Z Orthop Unfall. 2007;145:639-42. German.

15. Mckee RC, Whelan DB, Schemitsch EH, Mckee MD. Operative versus nonoperative care of displaced midshaft clavicular fractures: A meta-analysis of randomized clinical trials.J Bone Joint Surg Am. 2012;94:675-684

16. Lenza M, Buchbinder R, Johnston RV, Belloti JC, Faloppa F. Surgical versus conservative interventions for treating fractures of the middle third of the clavicle. Cochrane Database Syst Rev. 2013 Jun 6;6:CD009363. doi: 10.1002/14651858. CD009363.pub2.

17. Andersen K, Jensen PO, Lauritzen J. Treatment of clavicular fractures, Figure-ofeight bandage versus a simple sling. Acta Orthop Scand.1987;58:71-4

18. Eskola A, Vainionpaa S, Myllynen P, Pataila H, Rokkanen P. Outcome of clavicular fracture in 89 patients. Arch Orthop Trauma Surg. 1986;105:337-8

19. Virtanen KJ, Paavola MP, Remes VM, Pajarinen J, Savolainen V, Bjorkenheim JM. Nonoperative versus operative treatment of midshaft clavicle fractures: a randomized controlled trial. Read at the 75th Annual Meeting of the AAOS; 2010 Mar 9-12; New Orleans, LA. Paper no 331. 
20. Smith CA, Rudd J, Crosby LA. Results of operative versus nonoperative treatment for $100 \%$ displaced midshaft clavicle fractures: a prospective randomized clinical trial. Read at the 16th Annual Open Meeting of the American Shoulder and Elbow Surgeons; 2000 Mar 18; Orlando, FL. Paper no 31.

21. SmekalV, Irenberger A, Struve P, Wambacher M, Krappinger D, Kralinger FS. Elastic stable intramedullary nailing versus nonoperative treatment of displaced midshaft clavicular fractures-a randomized, controlled, clinical trial. J Orthop Trauma. 2009;23:106-12
22. Judd DB, Pallis MP, Smith E, Bottoni CR. Acute operative stabilization versus nonoperative management of clavicle fractures. Am J Orthop (Belle Mead NJ). 2009;38:341

23. Postacchini $R$, Gumina $S$, Farsetti $P$, Postacchini F. Long-term results of conservative management of midshaft clavicle fracture. Int Orthop. 2010;34:731736.

24. Robinson, Court-Brown, McQueen MM et al. Estimating the risk of nonunion following nonoperative treatment of a clavicular fracture. J Bone Joint Surg Am 2004;86:1359-65. 



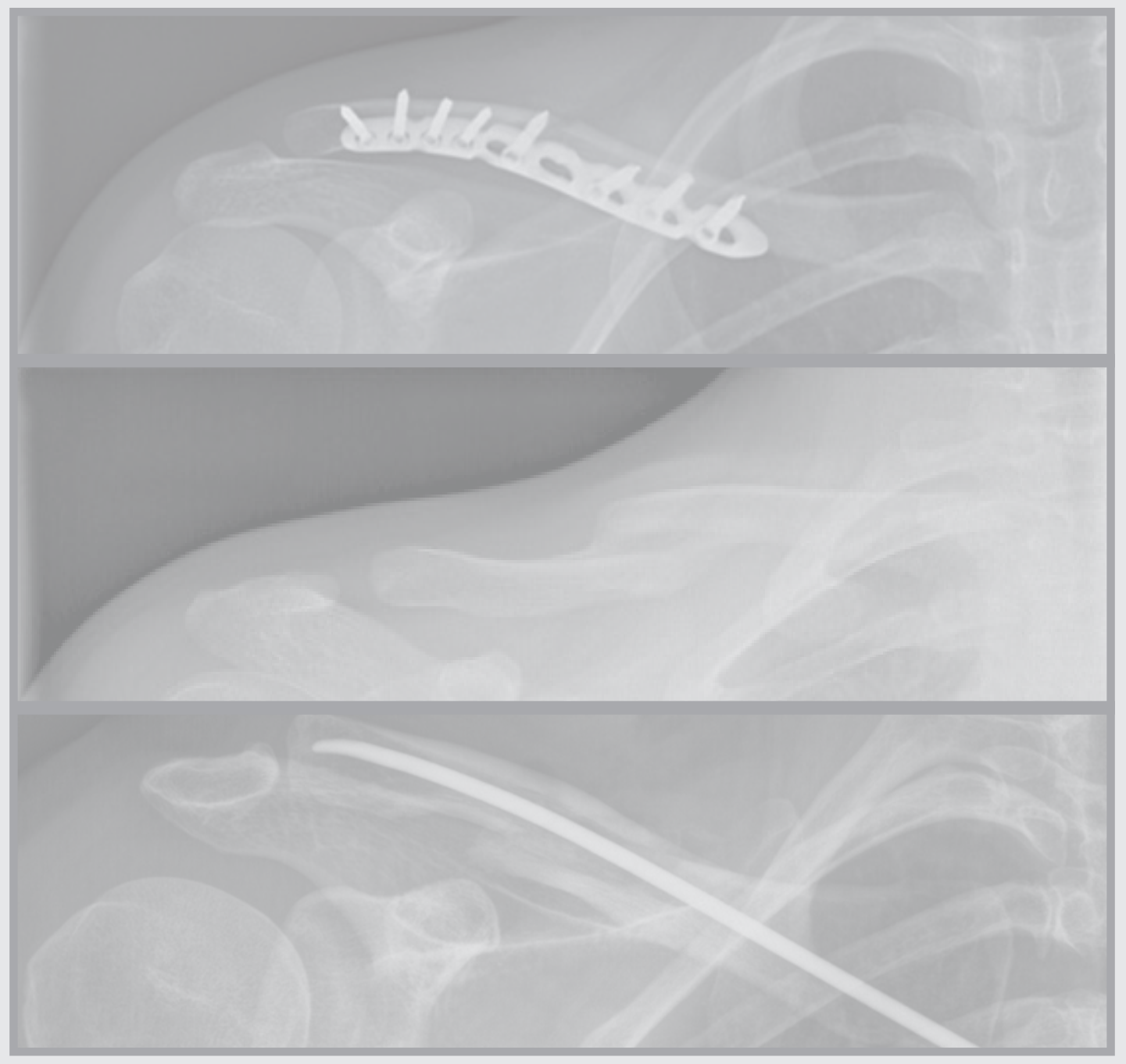




\section{CHAPTER SIX}

Surgical versus conservative treatment of midshaft clavicle fractures in patients aged 16 years and older: a systematic review, meta-analysis and comparison of randomized controlled trials

D.P.J. Smeeing, D.J.C. van der Ven, T.K. Timmers, F Hietbrink,

M van Heijl, M.C. Kruyt, R.H.H. Groenwold, O.A. van der Meijden, F Hietbrink, R.M. Houwert

Am J Sports Med. 2017 Jul;45(8):1937-1945 


\section{ABSTRACT}

\section{Background}

There is no consensus on the choice of treatment of midshaft clavicle fractures. Purpose: The aim of this systematic review and meta-analysis was (1) to compare fracture healing disorders and functional outcome of surgical versus conservative treatment of midshaft clavicle fractures and (2) to compare effect estimates obtained from RCTs and observational studies.Study Design: Systematic review and meta-analysis.

\section{Methods}

The PubMed/MEDLINE, Embase, CENTRAL and CINAHL databases were searched for both randomized controlled trials and observational studies. Using the MINORS instrument all included studies were assessed on their methodological quality. The primary outcome was a nonunion. Effects of surgical versus conservative treatment were estimated using random effects meta-analysis models. Results: A total of 20 studies were included of which 8 were RCTs and 12 observational studies including 1760 patients.

\section{Results}

were similar across the different study designs. Meta-analysis of 19 studies revealed that nonunions were significantly less common after surgical treatment than after conservative treatment (odds ratio (OR) 0.16; 95\% confidence interval (CI) 0.09to0.26). The risk of malunions did not differ between surgical and conservative treatment (OR 0.38; 95\% Cl 0.12to1.19). Both the long term DASH and Constant scores favoured surgical treatment (DASH MD -2.04 (95\%Cl - 3.56to-0.52); Constant MD 3.23 (95\%Cl 1.52 to 4.95$)$ ). No differences were observed regarding revision surgery (OR $0.85 ; 95 \% \mathrm{Cl} 0.42$ to 1.73 ). Including only high quality studies, both the number of malunions and return to work show significant differences in favour of surgical treatment (malunions OR 0.26 (95\% Cl 0.07to0.92); return to work MD -8.64 (95\% Cl -16.22to-1.05)).

\section{Conclusions}

This meta-analysis of high quality studies showed that surgical treatment of MCFs results in less nonunions, less malunions and an accelerated return to work compared to conservative treatment. Meta-analysis of surgical treatments need not be restricted to randomized trials, provided that the included observational studies are of high quality. 


\section{INTRODUCTION}

Clavicle fractures represent $2,6 \%$ to $4 \%$ of all fractures and $35 \%$ to $44 \%$ of those in the shoulder girdle. ${ }^{37 ; 41}$ Midshaft clavicle fractures are among the most common upper extremity injuries managed by orthopedic trauma surgeons. Midshaft fractures account for $69 \%$ of all clavicle fractures of which half are displaced. (44) Most clavicle fractures occur in young men and are caused by falls, sports and roadtraffic accidents. ${ }^{44}$ Open fractures, compromised overlying skin and presence of neurovascular damage require surgical treatment. ${ }^{24}$ However, there is no consensus about the choice of treatment of closed midshaft clavicle fractures (MCFs) without these factors. ${ }^{38 ; 4 ; 50}$ In the past decades, indications for surgical treatment seem to have broadened and operative treatment is increasingly favored, especially by shoulder specialists. ${ }^{7 ; 851}$ However, still half of the surgeons treat their patients conservatively. ${ }^{50}$ Several systematic reviews and meta-analyses have previously been published, with contradicting results. ${ }^{4 ; 3 ; 31}$ All of these studies only included randomized controlled trials (RCTs). ${ }^{29 ; 31 ; 4 ; 58}$ Yet, the holy grail of RCTs has recently been debated. ${ }^{3}$ Observational studies can be included in meta-analyses to increase the sample size and generalizability of findings, provided the quality (i.e., validity) of the observational studies is of the same level as that of the RCTs. Observational studies are very suitable to identify relatively rare outcomes such as infrequent complications. Recent literature shows no difference in effect estimates between RCTs and observational studies. ${ }^{21}$ Therefore, meta-analyses including high-quality observational studies in surgery may be considered complementary to those including RCTs only. ${ }^{1 ; 321}$ The aim of this systematic review and meta-analysis was ${ }^{1}$ to compare fracture healing disorders and functional outcome of surgical versus conservative treatment of midshaft clavicle fractures $a^{2} d^{2}$ to compare effect estimates obtained from RCTs and observational studies.

\section{METHODS}

A published protocol for this review does not exist. No ethical committee approval was necessary for this literature review.

\section{Search strategy and selection criteria}

This review was performed according to the Preferred Reporting Items for Systematic reviews and Meta-Analyses (PRISMA) guidelines and the Quality of Reporting of Meta-analyses standards (QUOROM statement). ${ }^{35 ; 36}$ Published RCTs and observational studies concerning the comparison of surgical and conservative treatment for acute MCFs in patients of 16 years and older were included. Two 
reviewers (D.P.J.S and D.J.C.V) independently conducted an electronic systematic search in PubMed/MEDLINE, Embase, Cochrane Central Register of Controlled Trials (CENTRAL from The Cochrane Library) andCINAHL for articles published up to December 1 $1^{\text {st }}$ 2015. The search syntax is provided in Appendix 1. Duplicate articles were removed. Titles and abstracts of retrieved citations were screened, and potentially suitable studies were read in full by both reviewers. Articles were included if written in English, Dutch, German or French language. Only published data have been included. A minimum follow-up time was not required for inclusion. Letters, comments, abstracts for conferences, case reports, study protocols, reviews, biomechanical studies, animal studies, studies which included patients with (only) floating shoulders, studies describing a surgical technique and non- comparative studies were excluded. In addition, studies were excluded if only the comparison of delayed surgery versus non-surgical treatment was made. No further search restrictions or search filters were applied in the search. Citation tracking and reference screening of the selected studies was performed. Disagreements in the search were resolved by discussion with a third independent reviewer (R.M.H).

\section{Quality assessment}

The methodological quality of all included studies was independently assessed by two reviewers (D.P.J.S and D.J.C.V) using the Methodological Index for NonRandomized Studies (MINORS) ${ }^{46}$ The MINORS is a validated instrument designed to assess the methodological quality and clear reporting of observational surgical studies. ${ }^{46}$ The MINORS is externally validated using RCTs and, therefore, also appropriate to assess the quality of RCTs. ${ }^{46}$ Three other reviewers (T.K.T, O.A.J.M and R.M.H) independently assessed the quality of 7 out of 20 articles to improve unity on the use of the MINORS. The included study published by two of the authors (D.J.C.V. and T.K.T.) was assessed by two other reviewers (D.P.J.S. and R.H.M.).53 Disagreements were resolved by discussion with a third independent reviewer (R.H.M). Details on the quality scoring system are given in Appendix 2.

\section{Data extraction}

The following data were extracted: first author, year of publication, study design, country in which the fracture displacement, type of fractures, mean follow-up, treatment groups, used type of plate or intramedullary fixation material in surgical groups, conservative treatment method, number of patients per group, outcomes including confidence interval (Cl) and/or p-values. Definitions of displacement were used according to the methods section of the included studies. 


\section{Outcome measures}

Fracture healing disorders in this study were nonunions and malunions. Definitions of nonunion and malunion were used according to the methods section of the included studies. The primary outcome parameter was a nonunion. The effectiveness of both the conservative and surgical treatment was evaluated using the following secondary outcome measures: functional scores (DASH and Constant- Murley scores) on both short term ( $<1$ year) and long term ( 1 year), return to work in days, revision surgery and implant removals.11,23 Revision surgery was defined as a second operative fixation in the surgical treatment group and as an operative fixation after initial conservative treatment in the conservative treatment group. Return to work was defined as the number of days needed until work, duty or daily activities could be resumed. For results concerning studies, which used both plate and intramedullary fixation the results of the combination of plate and intramedullary fixation were used. If these results of the whole surgical treatment group were not available, the results of the plate fixation were used which is the most common surgical treatment. ${ }^{13}$

\section{Statistical analysis}

Data management, statistical analyses and graphical representation were performed using Review Manager software (RevMan@ v. 5.3.5) provided by The Cochrane Collaboration. ${ }^{43}$ When means or stand deviations (SD) were not reported in an article, these were calculated - if possible - using the available information. If the range was available for outcome variables the standard deviation was estimated as range divided by $4 .{ }^{21}$ The standard deviation was estimated from the standard error (SE) using the following formula: $\mathrm{SE}=\mathrm{SD} / \sqrt{ } \mathrm{n}$, where $\mathrm{SD}$ indicates the standard deviation and $\mathrm{n}$ is the sample size. The standard error was estimated from the $95 \%$ confidence interval (Cl), by dividing the width of the confidence interval by $2 * 1.96$ $=3.92$. Data were converted into the same units if needed. Outcomes reported by two or more studies were pooled in a meta-analysis. Short term and long term results were analysed separately. The assessment of statistical heterogeneity was done by visual inspection of the forest plots and estimating statistical measures of heterogeneity: Cochran's $Q$ (chi- square test), $I^{2}$, and ${ }^{2}\left(\operatorname{tau}^{2}\right)$. The random effects model was used for meta-analyses. The overall effect Z-test was used to determine significance. A two-sided $p$-value $<0.05$ was considered statistically significant. All analyses were stratified by study design, i.e., cohort studies and RCTs separately. All analyses were then repeated by including all studies (i.e., irrespective of study design). For continuous outcomes, a weighted mean difference (MD) was estimated. The Inverse Variance (IV) statistical method was used to construct a 95\%Cl. A pooled 
odds ratio (OR) was estimated for dichotomous outcomes. The Mantel-Haenszel statistical method was used to construct a $95 \% \mathrm{Cl}$. Zero-event data were handled using different methods. ${ }^{6}$ In the crude method, data of all studies was pooled and analysed without taking clustering of data within studies into account. In the inverse variance method, the log (OR) of each study was weighted by the inverse of the within study variance (also known as fixed effects model). When the inverse variance method was applied with correction, 0.5 was added to each cell of the $2 \times 2$ table of that study, if one (or both) of the treatment arms experienced no events. The same correction was made for the DerSimonian Laird method (also referred to as the random effects model), but in contrast to the inverse variance method, the weighting was based on the inverse of the sum of the within study variance and the between study variance. ${ }^{6}$ If a study had missing data, available case analysis was performed. After the primary analyses, sensitivity analyses on the impact of study quality were performed for the primary outcome. In this sensitivity analysis on high quality, only studies with a MINORS score above 16 (out of a maximum score of 24) were included. Another sensitivity analysis was performed using only low quality studies (MINORS score of 16 or lower). ${ }^{46}$ Potential publication (or reporting) bias was assessed using a funnel plot, showing intervention effect estimates on the primary outcome from individual studies against their standard error. ${ }^{14}$

\section{RESULTS}

\section{Search}

The electronic searches detected 1080 articles. After removing duplicates 563 articles were screened on title and abstract. A total of 22 possible relevant studies from the initial search were assessed on full-text for eligibility and references were checked for suitable related citations. The study of Van der Have et al. was excluded because the study was performed on adolescents. ${ }^{54}$ The study of Smekal et al. was excluded because of overlap in patient population with other studies from their group. ${ }^{47 ; 48} \mathrm{~A}$ total of 132 studies were excluded because these papers did not describe acute MCF or included patients under the age of 16. In total, 20 studies could be included for analysis. ${ }^{2 ; 5 ; ; ; 10 ; 12 ; 16 ; 18 ; 25-~ 28 ; 30 ; 33 ; 34 ; 45 ; 77 ; 52 ; 53 ; 5 ; 57 ~ O f ~ a l l ~ i n c l u d e d ~ s t u d i e s, ~}$ 8 were RCTs and 12 were observational, of which 5 were prospective studies and 7 were retrospective studies. The search results, reasons for exclusion and selection process is summarized in the flowchart in Figure 1. Two studies were excluded because of language and the inclusion of medial and lateral fractures. The search string can be found in Appendix 1. 


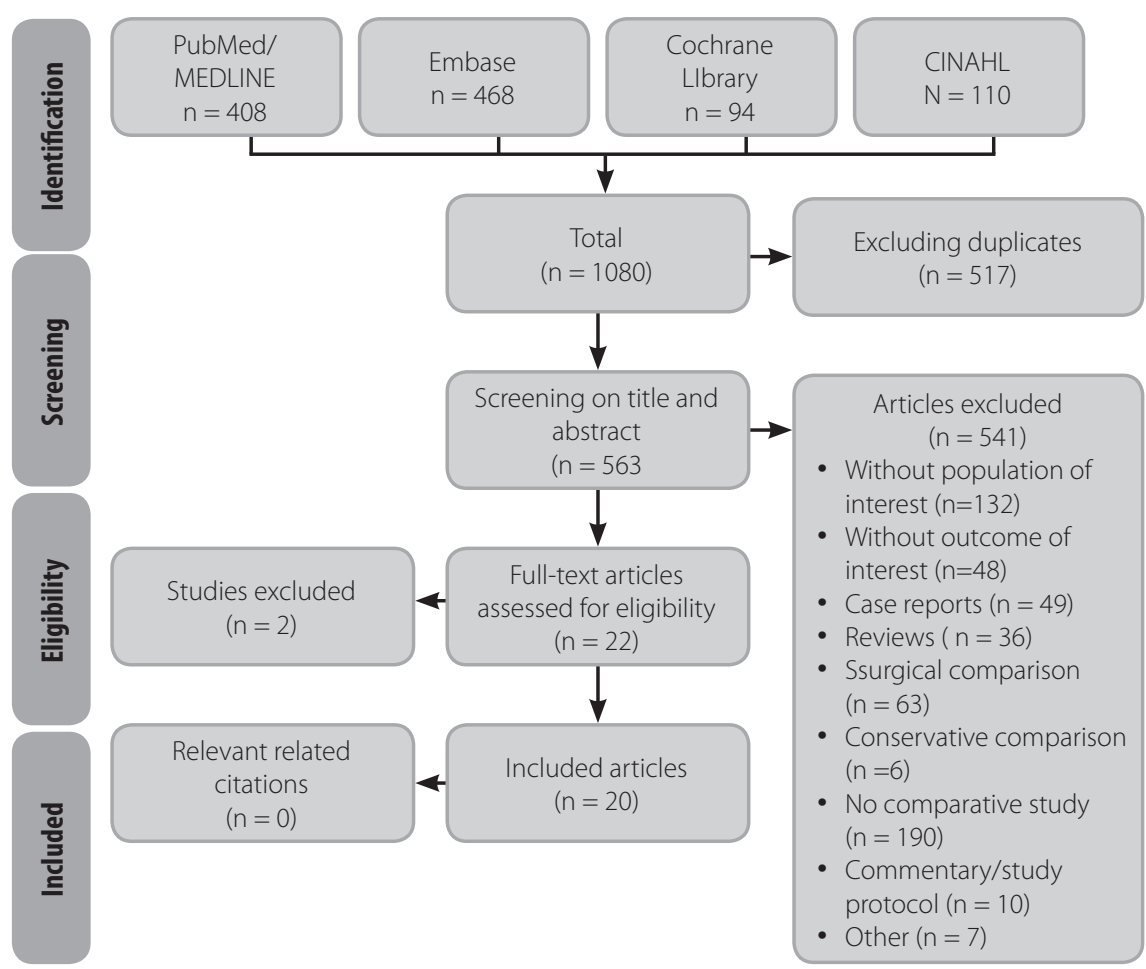

Figure 1. Flowchart of the articles included in a systematic review of MCFs comparing conservative versus surgical treatment

\section{Quality assessment}

Appendix 3 shows the distribution of study quality across the studies. The mean MINORS score was 17.2 ( \pm 3.0$)$ with a range from 11 to 22 . For the RCTs it ranged from 11 to 22 with a mean $( \pm S D)$ of $18.6( \pm 3.5)$ and for the observational studies, it ranged from 11 to 19 with a mean $( \pm S D)$ of $16.2( \pm 2.3)$.

\section{Baseline characteristics}

The characteristics of all included studies, their treatment groups and included type of fractures are described in Appendix 4. Studies did not handle different inor exclusion criteria for their treatment groups. Plate fixation was compared with conservative treatment in 10 (50\%) studies, intramedullary fixation was compared with conservative treatment in 6 (30\%) studies and both plate and intramedullary fixation were compared with conservative treatment in 4 (20\%) studies. A total of 620 patients were treated using plate fixation, 284 patients using intramedullary 
fixation and 856 patients were conservatively treated. The studies included in total 1760 participants (80.2\%men) with a mean age of 35.5 years (range 25 to 46). The number of patients included in a study ranged between 40 and 200. In total, more patients were included in the observational studies (studies $n=12$; patients $n=1068$; mean age $=36.3$ years; mean age range 27.1 to 46 years) compared to the RCTs (studies $n=8 ; n=692$; mean age $=34.0$ years; mean age range 25 to 41 years). The mean age and male/female ratio did not appear to be different across the different study designs.

\section{Fracture healing disorders}

Nineteen (95\%) of the 20 included studies reported the number of nonunions (Appendix 5). 2;5;9;10;2;:18;25-28;30;33;34;45;47;5;;3;55;57 George et al. was excluded because the number of nonunions was not reported. ${ }^{16}$ In the study by Witzel et al. no events occurred in both treatment arms. ${ }^{57}$ Nonunions occurred significantly less after surgical treatment than after conservative treatment with an odds ratio of 0.18 (95\% Cl 0.10 to $0.33 ; \mathrm{p}<0.01$; Figure 2). Surgical treatment resulted in a nonunion in $1.4 \%$ and conservative treatment in $10.5 \%$. The different methods to handle studies in which no event occurred in either (or both) of the treatment arm yielded similar results (data shown in Appendix 6). Thirteen studies (65\%) reported the risk of malunions which showed comparable results between the surgical and conservative treatment arm with an odds ratio of $0.38(95 \% \mathrm{Cl} 0.12$ to $1.19 ; \mathrm{p}=0.10$; Appendix 7). 9:10;18:27:28:30;34;45;47;52;33;55;57 Surgical treatment resulted in a malunion in 6.4\% and conservative treatment in $13.6 \%$.

\section{Functional scores and the return to work}

Both the short-term DASH scores and the short-term Constant-Murley scores showed comparable results between the surgical and conservative treatment arm (Table 1). The long-term results for the DASH scores and the long-term ConstantMurley scores showed significant differences in favour of the surgical treatment arm compared to the conservative treatment arm (DASH MD -2.04; 95\%Cl - 3.56 to -0.52; $\mathrm{p}=0.01$; Appendix 8)(Constant-Murley MD 3.23; 95\%Cl 1.52 to 4.95; $\mathrm{p}<0.01$; Appendix 9). Seven studies (35\%) reported the return to work or daily activities of which in 5 studies a standard deviation was documented or could be estimated. $(2 ; 5 ; 18 ; 28 ; 33 ; 45 ; 53)$ Analysis showed comparable results between the surgical and conservative treatment arm (MD -2.80; $95 \% \mathrm{Cl}-15.03$ to $9.42 ; \mathrm{p}=0.65)$. 


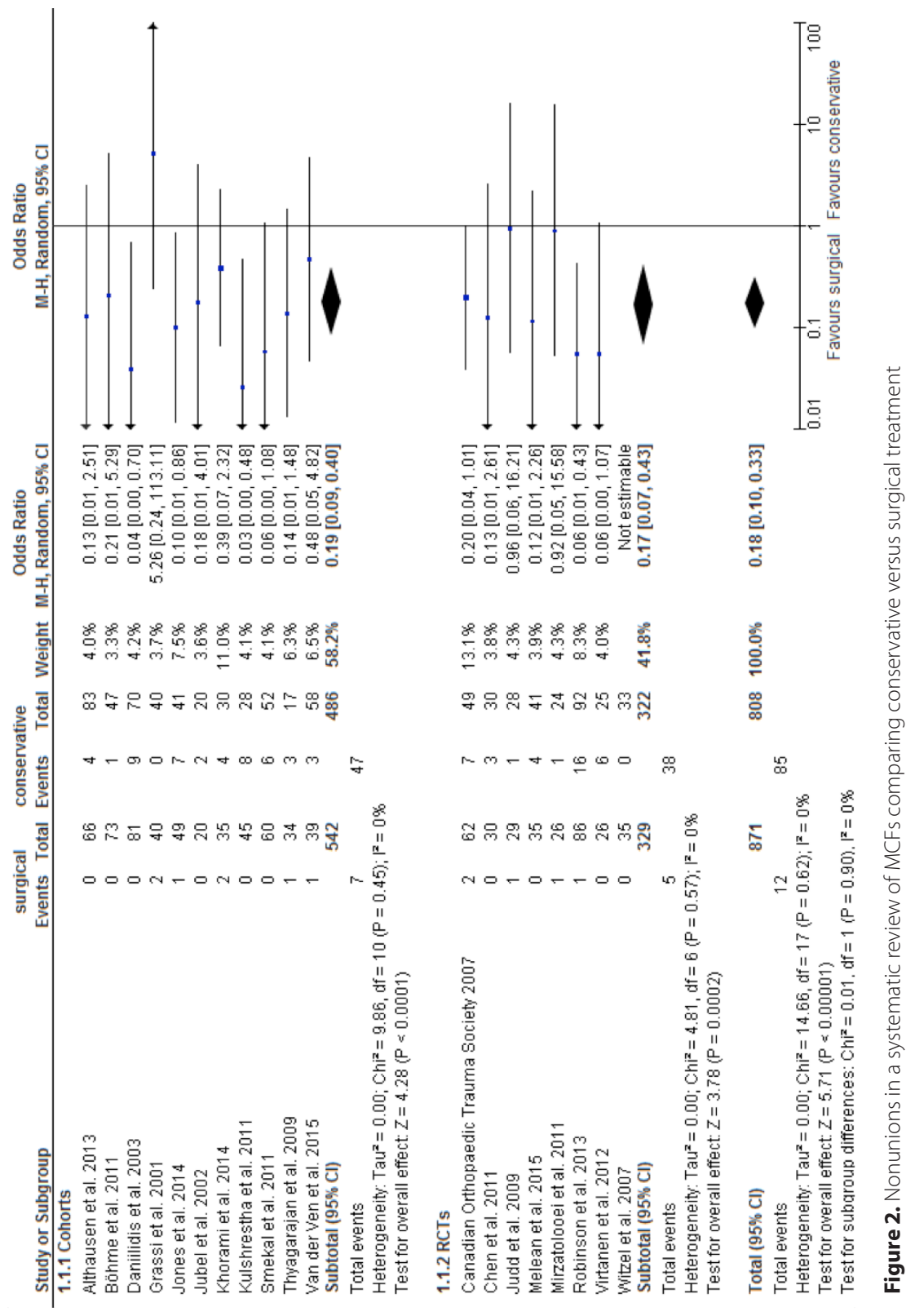




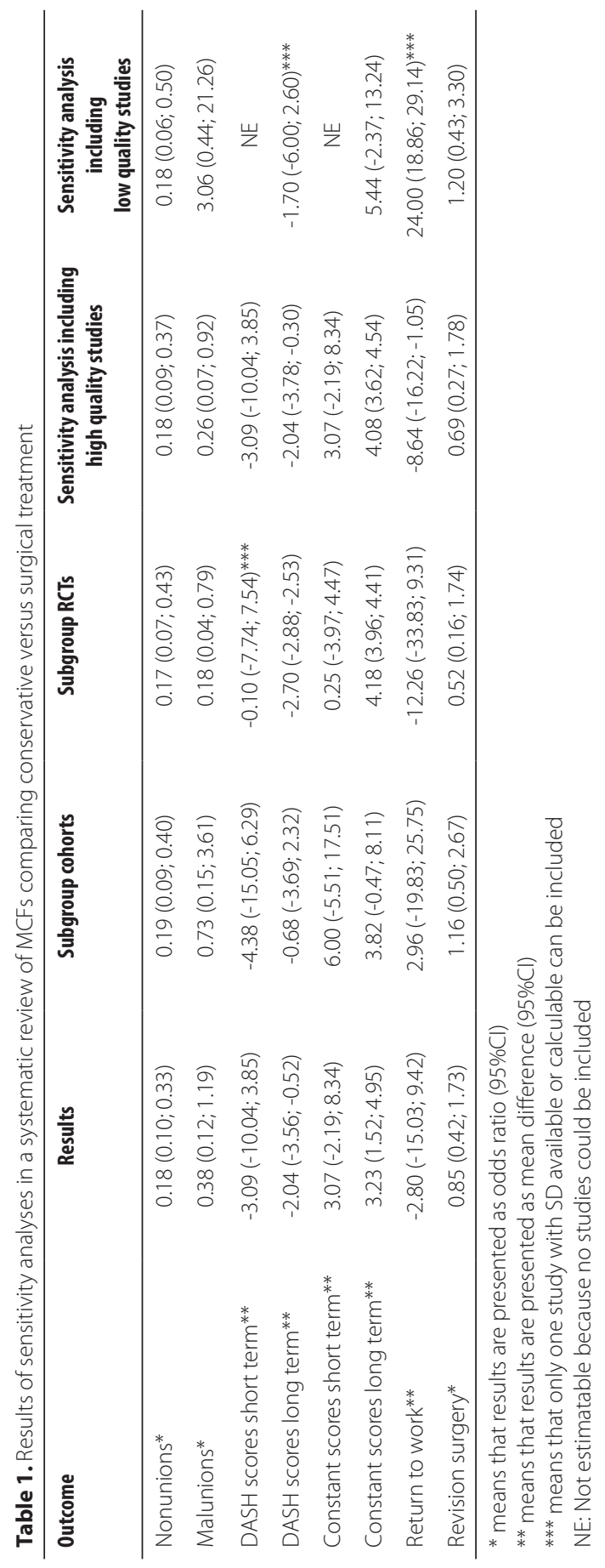




\section{Revision surgery and implant removal}

Eighteen studies (90\%) reported the number of revision surgeries.; 5;:;10;12;18;25;27;28;30;3 3;34;45:47;52;53:55;57 Analysis showed no significant differences between the surgical and conservative treatment group (OR $0.85 ; 95 \% \mathrm{Cl} 0.42$ to $1.73 ; \mathrm{p}=0.65 ;$ Appendix 10). Surgical treatment resulted in revision surgery in $8.2 \%$ and $9.8 \%$ required operative fixation after initial conservative treatment. Implant removal was reported in ten studies (50\%). 9:12;25;27;30;33:45;52;53;57 The mean percentage of implant removal was 35.0\% ranging from $3.7 \%$ to $100 \%$.

\section{Study design analyses}

Results were similar across all included studies, when analyses were stratified by study design as shown in the forest plots (Figure 2 and Appendix 7-10). The subgroups do differ in the significance of the results in three secondary outcomes: malunions, the long term DASH scores and the long term Constant scores. In these outcomes the RCTs showed a significant result compared to the insignificant results of the observational studies. Nevertheless, in all of these studies the outcome did remain in favour of the surgical group.

\section{Sensitivity analysis on quality}

Sensitivity analysis using high quality studies on the primary outcome - nonunions - resulted in an overall OR of 0.14 ( $95 \% \mathrm{Cl} 0.07$ to $0.28 ; \mathrm{p}<0.01$ ) (Table 1). There were no outcomes that changed direction, however, the number of malunions and the days to return to work became significant outcome parameters in favour of the surgical group (Table 1). Sensitivity analysis using low quality studies on the primary outcome resulted in an OR of 0.18 ( $95 \% \mathrm{Cl} 0.06$ to $0.50 ; \mathrm{p}<0.01)$. The other outcomes changed in insignificant results or were not estimatable because no studies could be included. The return to work changed to favourable results for the conservative treatment including only one study.

\section{Assessment of publication bias}

A funnel plot with the odds ratios and standard errors of the studies including nonunions is shown in Figure 3. The funnel plot asymmetry analysis showed relative symmetry, indicating no evidence or a very low risk of existing publication bias in this systematic review and meta-analysis. When excluding the outlier with an OR of 5.26 the appearance of the figure structure stays intact. ${ }^{17}$ 


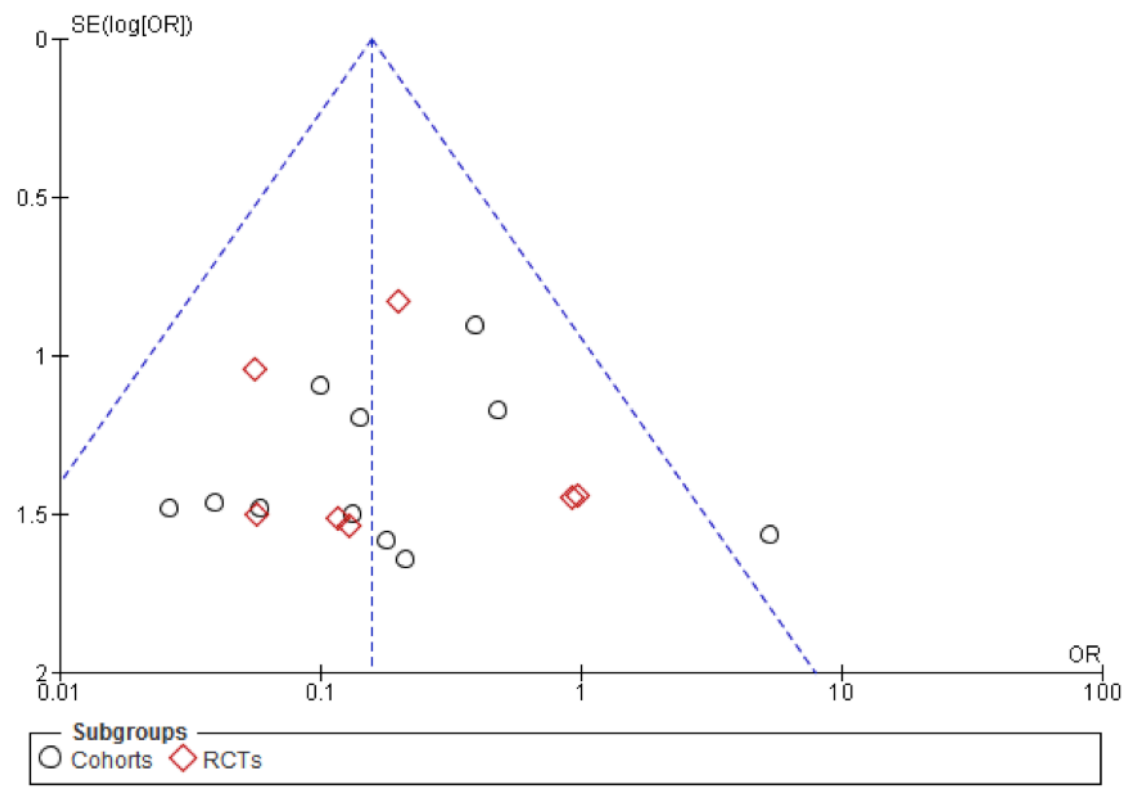

Figure 3. Funnel plot of included studies using the number of non-unions in a systematic review of MCFs comparing conservative versus surgical treatment

\section{DISCUSSION}

Results of this systematic review and meta-analysis including both RCTs and observational studies showed less nonunions for surgical treatment of MCFs compared to conservative treatment. Functional outcomes are statistically significant in favor of surgical treatment, yet these differences seem of little clinical importance. ${ }^{4: 15 ; 18}$ The subgroup analysis of only RCTs and observational studies displayed similar results. In high quality studies less malunions and a faster return to work in favor of the surgical treatment group were observed. Results of functional outcome might be statistically significant, nevertheless, a mean difference of respectively 2 points on the DASH and 3 points on the Constant Murley score are clinically irrelevant. ${ }^{4} 15 ; 18$ For each of these scores, a 10 point difference is deemed clinically relevant. ${ }^{4}: 18$ More nonunions were observed after conservative treatment in this study for all groups. These numbers are in accordance with other systematic reviews and meta-analyses about this topic. ${ }^{28,31,32}$ The earlier return to daily activities after surgical treatment also corresponds with results of another review..$^{19}$ However, in this study Hill et al. ${ }^{19}$ only included 3 studies, whereas our meta-analysis included information of 20 studies. ${ }^{26: 47448}$ In a previous review and meta-analysis, plate and 
intramedullary fixation were compared. No differences were found in terms of function and number of nonunions. Major re-intervention and re-fracture after implant removal occurred more frequently after plate fixation. ${ }^{20}$ One of the most important observations of this study is that high quality observational studies and RCTs provide similar results for this topic (Table 1). By excluding low quality observational studies, malunion and return to work became significant in favor of surgical treatment. Therefore low quality observational studies had enough impact to possibly influence recommendations from this meta- analysis. Obviously, recommendations based on a meta-analysis should be based on the quality of the included studies, not just on their study design. This is the first review that shows an accelerated return to work after operative treatment of midshaft clavicle fractures. As patients with MCFs are generally in the working population with a peak incidence in males younger than 30 years old, this might be an important consideration. ${ }^{44}$ On the other hand, operative treatment of all MCF would substantially increase the cost for society of treating this common injury. Three recent studies about cost-effectiveness of operative treatment emphasize this dilemma. ${ }^{2 ; 3956}$ Walton et al. described the financial impact for society. They found that nonoperative treatment followed by delayed surgery resulted in approximately 11,500 USD cost savings from the perspective of a single health insurance payer. However, costs to the patients are not accounted for in their analysis. ${ }^{56}$ Althausen et al. calculated that operative treatment resulted in approximately 5000 USD cost savings in the perspective of the patient although the initial hospital bill was higher because of surgical charges. ${ }^{2}$ Furthermore, operatively treated patients missed fewer days from work ( 8 vs 35 days) and returned to full duty 25 days sooner than nonoperatively treated patients. Pearson et al. concluded that the cost-effectiveness of operative treatment depended on the durability of functional advantage compared to nonoperative treatment. When functional benefits persisted for more than 9 years, operative treatment had favorable value compared with many accepted health interventions. ${ }^{39}$ However, no comparative studies have yet described the longterm outcome of operative versus nonoperative treatment of MCF. Previously published meta-analyses on this topic only included RCTs for analysis. ${ }^{31: 42 ; 58}$ Currently the value of the different study designs is being discussed. ${ }^{1 ; 3}$ This is the first meta-analysis comparing surgical and conservative treatment of MCF in which data on RCTs and observational studies were combined. Therefore, information of 1760 patients could be included resulting in the largest sample size in a metaanalysis on this topic, which consequently led to an increase in power. Due to this increased power effects may have been detected that would have gone unnoticed 
if only including RCTs. In addition, combining information from both RCTs and observational studies can provide a broader view of the available evidence, possibly leading to results that have better generalizability, which might improve the applicability of recommendations based on systematic reviews. ${ }^{40}$ Because of the often stringent in- and exclusion criteria of RCTs, the generalizability of trial results may be hampered and finding similar effect estimates in observational studies may support the relevance of study results for clinical practice. We note, however, that the baseline characteristics of patients enrolled in the studies included in our meta-analysis did not materially differ across study designs, suggesting results of randomized trials on MCF already have wide applicability. Observational studies inherently have a greater risk of bias due to the non-random allocation of treatment. Therefore, pooling results of studies with a different design is counterintuitive. However, we consider this approach appropriate, since RCTs and observational studies showed similar results and the potential for unmeasured confounding in the observational studies was considered small. This corresponds to an earlier performed meta-analysis including observational studies in which the primary outcome, i.e., re-interventions, showed comparable results between RCTs and observational studies when comparing the plate and intramedullary fixation of clavicle fractures. ${ }^{20}$ The potential for bias in the observational studies included in our meta-analysis appeared to be small (given comparability of measured patient characteristics between treatment arms). Despite a low risk of publication bias in this systematic review and meta-analysis, several factors possibly influencing our results should be mentioned. For example, definitions varied according to the included studies, such as displacement, non- and malunion. Also, time to return to work could be affected by type of occupation. In the current analysis no distinction could be made between laborers and physical demanding occupations from sedentary occupations. Finally, both plate fixation and intramedullary have been included for analysis of'operative treatment'. As a recently published meta- analysis comparing plate and intramedullary fixation found no significant differences regarding functional outcome and the number of nonunions, combining results of functional outcome and non- union of both techniques was justified in our opinion. ${ }^{20}$ Furthermore, results were homogeneous across studies. 


\section{CONCLUSION}

This systematic review and meta-analysis shows that surgical treatment of MCFs results in fewer nonunions, fewer malunions and an accelerated return to work. Functional outcomes are comparable between the groups. RCTs and observational studies showed similar results. Observational studies provide relevant data for metaanalysis as long as the quality of the included studies is taken into account and the results are interpreted in the right clinical context. The results of this meta-analysis favour the surgical treatment of MCFs. However, it should always be kept in mind that patient specific factors should be taken into account. The final decision for a surgical or conservative treatment should be based on shared-decision making. 


\section{REFERENCES}

1. Abraham NS, Byrne CJ, Young JM, Solomon MJ. Meta-analysis of welldesigned nonrandomized comparative studies of surgical procedures is as good as randomized controlled trials. J Clin Epidemiol. 2010;63(3):238-245.

2. Althausen PL, Shannon S, Lu M, O'Mara TJ, Bray TJ. Clinical and financial comparison of operative and nonoperative treatment of displaced clavicle fractures. J Shoulder Elbow Surg. 2013;22(5):608-611.

3. Anglemyer A, Horvath HT, Bero L. Healthcare outcomes assessed with observational study designs compared with those assessed in randomized trials. Cochrane Database Syst Rev. 2014;4:MR000034.

4. Ban I, Branner U, Holck K, Krasheninnikoff M, Troelsen A. Clavicle fractures may be conservatively treated with acceptable results: a systematic review. Dan Med J. 2012;59(7):A4457.

5. Bohme J, Bonk A, Bacher GO, Wilharm A, Hoffmann $\mathrm{R}$, Josten $\mathrm{C}$. [Current treatment concepts for mid-shaft fractures of the clavicle: results of a prospective multicentre study]. Z Orthop Unfall. 2011;149(1):68-76.

6. Bradburn MJ, Deeks JJ, Berlin JA, Russell LA. Much ado about nothing: a comparison of the performance of meta-analytical methods with rare events. Stat Med. 2007;26(1):53-77.

7. Bravman JT, Vidal AF. Midshaft clavicle fractures: are surgical indications changing? Orthopedics. 2009;32(12):909-913.

8. Brin YS, Palmanovich E, Dolev E, Nyska M, Kish BJ. Displaced mid- shaft clavicular fractures: is conservative treatment still preferred? Isr Med Assoc J. 2014;16(12):748-752.

9. Canadian Orthopaedic Trauma Society. Nonoperative treatment compared with plate fixation of displaced midshaft clavicular frac- tures: a multicenter, randomized clinical trial. J Bone Joint Surg Am. 2007;89(1):1-10.
10. Chen QY, Kou DQ, Cheng XJ, et al. Intramedullary nailing of clavicu- lar midshaft fractures in adults using titanium elastic nail. Chin J Trau- matol. 2011;14(5):269-276.

11. Constant $\mathrm{CR}$, Murley $\mathrm{AH}$. A clinical method of functional assessment of the shoulder. Clin Orthop Relat Res. 1987;214:160-164.

12. Daniilidis K, Raschke MJ, Vogt $B$, et al. Comparison between conser- vative and surgical treatment of midshaft clavicle fractures: outcome of 151 cases. Technol Health Care. 2013;21(2):143-147.

13. Duan X, Zhong G, Cen S, Huang F, Xiang $Z$. Plating versus intrame- dullary pin or conservative treatment for midshaft fracture of clavicle: a meta-analysis of randomized controlled trials. J Shoulder Elbow Surg. 2011;20(6):1008-1015.

14. Egger M, Davey SG, Schneider M, Minder C. Bias in meta-analysis detected by a simple, graphical test. BMJ. 1997;315(7109):629634.

15. Evaniew $\mathrm{N}$, Simunovic $\mathrm{N}$, McKee MD, Schemitsch E. Cochrane in $\operatorname{CORR}(R)$ : surgical versus conservative interventions for treating fractures of the middle third of the clavicle. Clin Orthop Relat Res. 2014;472(9):2579-2585.

16. George DM, McKay BP, Jaarsma RL. The long-term outcome of displaced mid-third clavicle fractures on scapular and shoulder function: variations between immediate surgery, delayed surgery, and nonsur- gical management. J Shoulder Elbow Surg. 2015;24(5):669-676.

17. Grassi FA, Tajana MS, D’Angelo F. Management of midclavicular fractures: comparison between nonoperative treatment and open intrame- dullary fixation in 80 patients. J Trauma. 2001;50(6):1096-1100. 
18. Gummesson C, Atroshi I, Ekdahl C. The Disabilities of the Arm, Shoulder and Hand (DASH) outcome questionnaire: longitudinal con- struct validity and measuring self-rated health change after surgery. BMC Musculoskelet Disord. 2003;4:11.

19. Hill CE. Is intramedullary nailing more effective than non-operative treatment in adults with displaced middle-third clavicle fractures? J Orthop Traumatol. 2014;15(3):155-164.

20. Houwert RM, Smeeing DP, Ahmed Ali U, Hietbrink F, Kruyt MC, Van der Meijden OA. Plate fixation or intramedullary fixation for midshaft clavicle fractures: a systematic review and meta-analysis of random-ized controlled trials and observational studies. J Shoulder Elbow Surg. 2016;25(7):11951203.

21. Hozo SP, Djulbegovic B, Hozo I. Estimating the mean and variance from the median, range, and the size of a sample. BMC Med Res Methodol. 2005;5:13.

22. Hudak PL, Amadio PC, Bombardier C. Development of an upper extremity outcome measure: the DASH (Disabilities of the Arm, shoulder and Hand) [corrected]. The Upper Extremity Collaborative Group (UECG). Am J Ind Med. 1996;29(6):602-608.

23. Hughes PJ, Bolton-Maggs B. Fractures of the clavicle in adults. Curr Orthop. 2002;16(2):133-138.

24. Jones LD, Grammatopoulos G, Kambouroglou G. Titanium elastic nails, open reduction internal fixation and nonoperative manage- ment for middle third clavicle fractures: a comparative study. Eur J Orthop Surg Traumatol. 2014;24(3):323-329.

25. Jubel A, Andermahr J, Faymonville C, Binnebosel M, Prokop A, Rehm KE. [Reconstruction of shoulder-girdle symmetry after midcla- vicular fractures: stable, elastic intramedullary pinning versus ruck- sack bandage]. Chirurg. 2002;73(10):978-981.
26. Judd DB, Pallis MP, Smith E, Bottoni CR. Acute operative stabiliza- tion versus nonoperative management of clavicle fractures. Am J Orthop (Belle Mead NJ). 2009;38(7):341-345.

27. Khorami M, Fakour M, Mokarrami H, Arti HR, Nasab AM, Shahrivar F. The comparison of results of treatment of midshaft clavicle fracture between operative treatment with plate and non-operative treatment. Arch Bone Joint Surg. 2014;2(3):210-214.

28. Kong L, Zhang Y, Shen Y. Operative versus nonoperative treatment for displaced midshaft clavicular fractures: a meta-analysis of ran- domized clinical trials. Arch Orthop Trauma Surg. 2014;134(11): 1493-1500.

29. Kulshrestha V, Roy T, Audige L. Operative versus nonoperative man- agement of displaced midshaft clavicle fractures: a prospective cohort study. J Orthop Trauma. 2011;25(1):31-38.

30. Lenza M, Buchbinder R, Johnston RV, Belloti JC, Faloppa F. Surgical versus conservative interventions for treating fractures of the middle third of the clavicle. Cochrane Database Syst Rev. 2013;6:CD009363.

31. Liu GQ, Zhao L, Li L, Wang LM, Zhang JH. A meta-analysis of com- parison between operative and nonoperative treatment on the mid- shaft clavicle fractures. Life Sci J. 2014;11(8):810-816.

32. Mckee MD. Clavicle fractures in 2010: sling/swathe or open reduc- tion and internal fixation? Orthop Clin North Am. 2010;41(2):225-231.

33. Melean PA, Zuniga A, Marsalli M, et al. Surgical treatment of dis- placed middle-third clavicular fractures: a prospective, randomized trial in a working compensation population. J Shoulder Elbow Surg. 2015;24(4):587-592.

34. Mirzatolooei F. Comparison between operative and nonoperative treatment methods in the management of comminuted fractures of the clavicle. Acta Orthop Traumatol Turc. 2011:45(1):34-40. 
35. Moher D, Cook DJ, Eastwood S, Olkin I, Rennie D, Stroup DF. Improving the quality of reports of meta-analyses of randomised con- trolled trials: the QUOROM statement. Quality of Reporting of Meta- analyses. Lancet. 1999;354(9193):1896-1900.

36. Moher D, Liberati A, Tetzlaff J, Altman DG. Preferred reporting items for systematic reviews and meta-analyses: the PRISMA statement. BMJ. 2009;339:b2535.

37. Nordqvist A, Petersson C. The incidence of fractures of the clavicle. Clin Orthop Relat Res. 1994;300:127-132.

38. O'Brien MJ, Savoie FH III. Clavicular fractures. Curr Orthop Pract. 2010;21(5):429-434.

39. Pearson AM, Tosteson AN, Koval KJ, et al. Is surgery for displaced, midshaft clavicle fractures in adults cost-effective? Results based on a multicenter randomized, controlled trial. J Orthop Trauma. 2010;24(7):426-433.

40. Peinemann F, Tushabe DA, Kleijnen J. Using multipletypes ofstudies insystematic reviews of health care interventions: a systematic review. PLoS One. 2013;8(12):e85035.

41. Postacchini F, Gumina S, De SP, Albo F. Epidemiology of clavicle fractures. J Shoulder Elbow Surg. 2002;11(5):452-456.

42. Rehn CH, Kirkegaard M, Viberg B, Larsen MS. Operative versus non- operative treatment of displaced midshaft clavicle fractures in adults: a systematic review. Eur J Orthop Surg Traumatol. 2014;24(7):1047- 1053.

43. Review Manager (RevMan) [computer program]. Version 5.3. Copen- hagen: The Nordic Cochrane Centre, Cochrane Collaboration; 2014.

44. Robinson CM. Fractures of the clavicle in the adult: epidemiology and classification. J Bone Joint Surg Br. 1998;80(3):476-484.

45. 45. Robinson CM, Goudie EB, Murray IR, et al. Open reduction and plate fixation versus nonoperative treatment for displaced midshaft clavic-ular fractures: a multicenter, randomized, controlled trial. J Bone Joint Surg Am. 2013;95(17):1576-1584.
46. Slim K, Nini E, Forestier D, Kwiatkowski F, Panis Y, Chipponi J. Methodological Index for Non-Randomized Studies (MINORS): develop- ment and validation of a new instrument. ANZ J Surg. 2003;73(9): 712-716.

47. Smekal $V$, Irenberger A, Attal RE, Oberladstaetter J, Krappinger D, Kralinger F. Elastic stable intramedullary nailing is best for mid-shaft clavicular fractures without comminution: results in 60 patients. Injury. 2011;42(4):324-329.

48. Smekal V, Irenberger A, Struve P, Wambacher M, Krappinger D, Kra- linger FS. Elastic stable intramedullary nailing versus nonoperative treatment of displaced midshaft clavicular fractures: a randomized, controlled, clinical trial. J Orthop Trauma. 2009;23(2):106-112.

49. Stegeman $S A$, de Jong $M$, Sier $C F$, et al. Displaced midshaft frac- tures of the clavicle: non-operative treatment versus plate fixation (Sleutel-TRIAL). A multicentre randomised controlled trial. BMC Musculoskelet Disord. 2011;12:196.

50. Stegeman SA, Fernandes NC, Krijnen P, Schipper IB. Online radio- graphic survey of midshaft clavicular fractures: no consensus on treat- ment for displaced fractures. Acta Orthop Belg. 2014;80(1):82-87.

51. Stegeman SA, Roeloffs CW, van den Bremer J, Krijnen P, Schipper IB. The relationship between trauma mechanism, fracture type, and treatment of midshaft clavicular fractures. Eur J Emerg Med. 2013;20(4):268272.

52. Thyagarajan S, Day M, Dent C, Williams R, Evans R. Treatment of mid-shaft clavicle fractures: a comparative study. Int J Shoulder Surg. 2009;3(2):23-27.

53. van der Ven DJC, Timmers TK, Flikweert $P E$, Van ljseldijk $A L$, van Olden GD. Plate fixation versus conservative treatment of dis- placed midshaft clavicle fractures: functional outcome and patients' satisfaction during a mean follow-up of 5 years. Injury. 2015;46(11):2223-2229. 
54. Vander Have KL, Perdue AM, Caird MS, Farley FA. Operative versus nonoperative treatment of midshaft clavicle fractures in adolescents. J Pediatr Orthop. 2010;30(4):307-312.

55. Virtanen KJ, Remes V, Pajarinen J, Savolainen V, Bjorkenheim JM, Paavola M. Sling compared with plate osteosynthesis for treatment of displaced midshaft clavicular fractures: a randomized clinical trial. J Bone Joint Surg Am. 2012;94(17):1546-1553.

56. Walton B, Meijer K, Melancon K. A cost analysis of internal fixation versus nonoperative treatment in adult midshaft clavicle fractures using multiple randomized controlled trials. J Orthop Trauma. 2015; 29(4):173-180.
57. Witzel K. [Intramedullary osteosynthesis in fractures of the mid-third of the clavicle in sports traumatology]. Z Orthop Unfall. 2007; 145(5):639-642.

58. $\mathrm{Xu} \mathrm{J,} \mathrm{Xu} \mathrm{L,} \mathrm{Xu} \mathrm{W,} \mathrm{Gu} \mathrm{Y,} \mathrm{Xu} \mathrm{J.} \mathrm{Operative}$ versus nonoperative treat- ment in the management of midshaft clavicular fractures: a meta- analysis of randomized controlled trials. J Shoulder Elbow Surg. 2014;23(2):173-181. 


\section{Appendix 1}

\section{Search strings}

\section{Searchstring PubMed/MEDLINE $(n=408)$}

(clavicle[MeSH Terms] OR clavicle[Title/Abstract] OR clavicula[Title/Abstract] OR claviculae[Title/Abstract] OR clavicular[Title/Abstract] OR collarbone[Title/ Abstract] OR collar bone[Title/Abstract]) AND

(Fractures, bone[MeSH Terms] OR fracture[Title/Abstract] OR fractured[Title/ Abstract] OR fractures[Title/Abstract]) AND

(midshaft[Title/Abstract] OR mid shaft[Title/Abstract] OR midclavicular[Title/ Abstract] OR mid clavicular[Title/Abstract] OR midclavicle[Title/Abstract] OR mid clavicle[Title/Abstract] OR middle third[Title/Abstract] OR mid third[Title/Abstract]) AND

(surgery[subheading] OR Fracture Healing[MeSHTerms] OR Fracture Fixation[MeSH Terms] OR Surgical Procedures, Operative[MeSH Terms] OR Physical Therapy Modalities[MeSH Terms] OR orthopedics[MeSH Terms] OR orthopedics[Title/ Abstract] OR orthopaedics[Title/Abstract] OR surgery[Title/Abstract] OR surgical[Title/Abstract] OR operative[Title/Abstract] OR operation[Title/Abstract] OR conservative[Title/Abstract] OR conventional[Title/Abstract] OR nonoperative[Title/Abstract] OR nonoperative[Title/Abstract] OR sling[Title/Abstract] OR figure-of-eight bandage[Title/Abstract])

\section{Searchstring Embase $(n=468)$}

('clavicle'/exp OR clavicle:ti,ab OR clavicula:ti,ab OR claviculae:ti,ab OR clavicular:ti,ab OR collarbone:ti,ab OR'collar bone':ti,ab) AND

('fracture'/exp OR fracture:ti,ab OR fractured:ti,ab OR fractures:ti,ab) AND (midshaft:ti,ab OR 'mid shaft':ti,ab OR midclavicular:ti,ab OR 'mid clavicular':ti,ab OR midclavicle:ti,ab OR 'mid clavicle':ti,ab OR 'middle third':ti,ab OR 'mid third':ti,ab) AND

('surgery'/exp OR surgery:ti,ab OR surgical:ti,ab OR operative:ti,ab OR operation:ti,ab OR 'conservative treatment'/exp OR 'conservative treatment':ti,ab OR conservative:ti,ab OR conventional:ti,ab OR 'non-operative':ti,ab OR nonoperative:ti,ab) 


\section{Searchstring CENTRAL (The Cochrane Library) $(n=94)$}

(clavicle AND fracture)

\section{Searchstring CINAHL $(n=110)$}

(clavicle OR clavicula OR claviculae OR clavicular OR collarbone OR collar bone) AND

(fracture OR fractured OR fractures) AND

(midshaft OR mid shaft OR midclavicular OR mid clavicular OR midclavicle OR mid clavicle OR middle third OR mid third) AND

(surgery OR surgical OR operative OR operation OR conservative OR conventional OR non-operative OR nonoperative) 


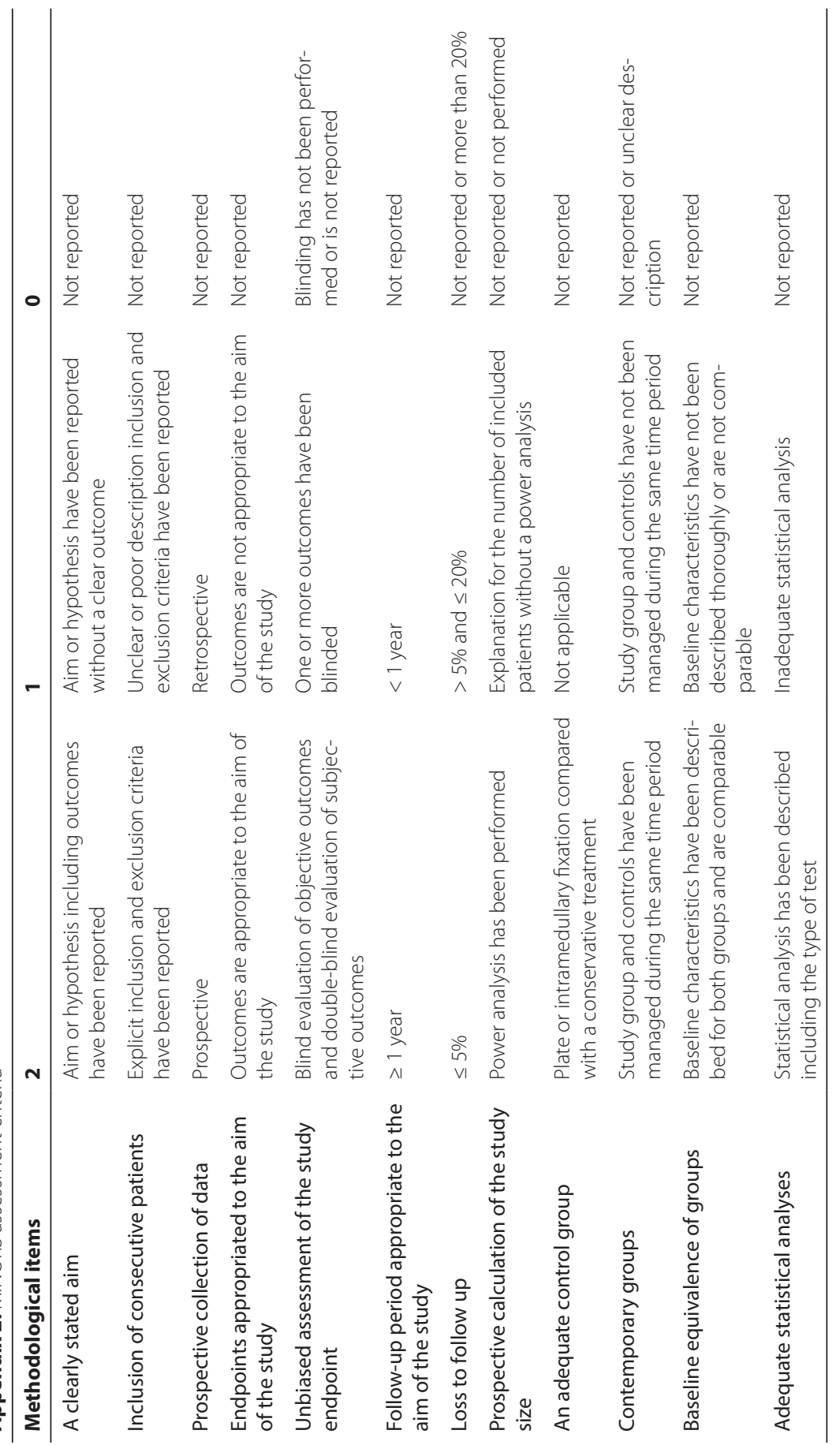




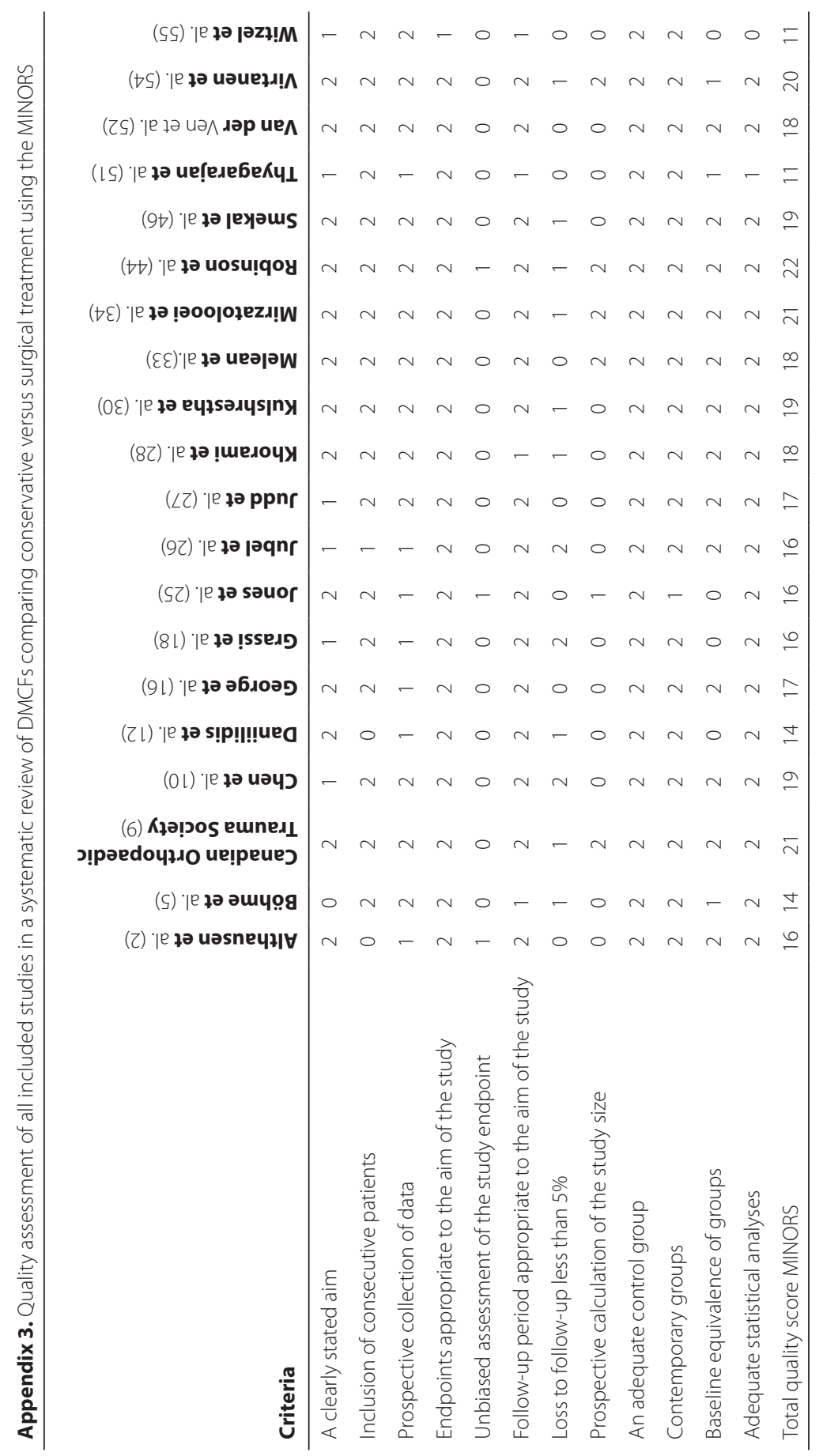


Part 3 - Treatment

Appendix 4. Baseline characteristics of included studies in a systematic review of DMCFs comparing conservative versus surgical treatment

\begin{tabular}{|c|c|c|c|c|}
\hline Study & Year & $\begin{array}{l}\text { Study } \\
\text { design }\end{array}$ & Country & Fracture type(s) \\
\hline Althausen et al. (2) & 2013 & $\mathrm{RC}$ & USA & $\begin{array}{l}\text { No further classification } \\
\text { applied }\end{array}$ \\
\hline Böhme et al. ${ }^{(5)}$ & 2011 & PC & Germany & $\begin{array}{c}\text { Using a modified AO } \\
\text { Classification; } \\
\text { Type A, B and C fractures }\end{array}$ \\
\hline Canadian Orthopaedic Trauma Society ${ }^{(9)}$ & 2007 & $\mathrm{RCT}$ & Canada & $\begin{array}{l}\text { No further classification } \\
\text { applied }\end{array}$ \\
\hline Chen et al. ${ }^{(10)}$ & 2011 & $\mathrm{RCT}$ & China & $\begin{array}{c}\text { Simple, wedge and com- } \\
\text { minuted fractures accord- } \\
\text { ing to the AO classification } \\
\text { system }\end{array}$ \\
\hline Daniilidis et al. ${ }^{(12)}$ & 2003 & $\mathrm{RC}$ & Germany & $\begin{array}{l}\text { No further classification } \\
\text { applied }\end{array}$ \\
\hline George et al. ${ }^{(16)}$ & 2015 & $\mathrm{RC}$ & Australia & Edinburgh type 2B1 \\
\hline Grassi et al. ${ }^{(18)}$ & 2001 & $\mathrm{RC}$ & Italy & $\begin{array}{c}\text { Simple, with a butterfly } \\
\text { fragment and commi- } \\
\text { nuted }\end{array}$ \\
\hline Jones et al. ${ }^{(25)}$ & 2014 & $\mathrm{RC}$ & UK & Allman type 1 fractures \\
\hline Jubel et al. ${ }^{(26)}$ & 2002 & $\mathrm{RC}$ & Germany & $\begin{array}{l}\text { No further classification } \\
\text { applied }\end{array}$ \\
\hline Judd et al. ${ }^{(27)}$ & 2009 & $\mathrm{RCT}$ & USA & $\begin{array}{l}\text { No further classification } \\
\text { applied }\end{array}$ \\
\hline Khorami et al. ${ }^{(28)}$ & 2014 & $P C$ & Iran & Robinson 2A2, 2B1, $2 \mathrm{~B} 2$ \\
\hline
\end{tabular}




\begin{tabular}{|c|c|c|c|c|}
\hline $\begin{array}{l}\text { Follow-up } \\
\text { (months) }\end{array}$ & Groups & $\begin{array}{l}\text { Number } \\
\text { of patients }\end{array}$ & $\begin{array}{l}\text { Age (years) } \\
( \pm \mathrm{SD})\end{array}$ & $\begin{array}{l}\text { Male/ } \\
\text { Female }\end{array}$ \\
\hline \multirow[t]{2}{*}{32} & Surgical - superior locking plate & 66 & 40.3 & $47 / 19$ \\
\hline & Conservative & 83 & 41.7 & $65 / 18$ \\
\hline \multirow[t]{3}{*}{8} & $\begin{array}{l}\text { Surgical fixation - DCP or LCDCP or } \\
\text { reconstruction plate }\end{array}$ & 53 & \multirow{3}{*}{$\begin{array}{c}\text { total: } \\
\text { men: } 35 \\
\text { (range 18-69) } \\
\text { women: } 41 \text { (range } \\
\text { 22-69) }\end{array}$} & \multirow[t]{3}{*}{$\begin{array}{l}\text { total: } \\
\text { 95/25 }\end{array}$} \\
\hline & Surgical fixation - pin & 20 & & \\
\hline & $\begin{array}{l}\text { Conservative - figure-of-eight- } \\
\text { bandage }\end{array}$ & 47 & & \\
\hline \multirow[t]{2}{*}{12} & $\begin{array}{l}\text { Surgical - LCDCP or reconstruction } \\
\text { plate or precontoured plate or } \\
\text { other plate }\end{array}$ & 62 & 33.5 & $53 / 9$ \\
\hline & Conservative - sling & 49 & 33.5 & $34 / 15$ \\
\hline \multirow[t]{2}{*}{15} & Surgical - TEN & 30 & $39.0( \pm 11.9)$ & $16 / 14$ \\
\hline & Conservative - sling & 30 & $38.4( \pm 13.3)$ & $16 / 14$ \\
\hline \multirow[t]{3}{*}{15} & Surgical - LCP & 73 & 40.3 & $64 / 17$ \\
\hline & Surgical - TEN & 8 & 27.1 & \\
\hline & $\begin{array}{l}\text { Conservative - figure-of-eight- } \\
\text { bandage }\end{array}$ & 70 & 40.8 & $51 / 19$ \\
\hline \multirow[t]{2}{*}{62} & Surgical - plate & 20 & 36 (range 18-63) & $13 / 7$ \\
\hline & Conservative & 20 & 46 (range 22-78) & $16 / 4$ \\
\hline \multirow[t]{2}{*}{64} & Surgical - intramedullary pin & 40 & $\begin{array}{c}30.2 \\
\text { (range 15-62) }\end{array}$ & $31 / 9$ \\
\hline & $\begin{array}{l}\text { Conservative - figure-of-eight- } \\
\text { bandage }\end{array}$ & 40 & $\begin{array}{c}37.2 \\
\text { (range 15-70) }\end{array}$ & $35 / 5$ \\
\hline \multirow[t]{3}{*}{30} & Surgical - plate & 24 & total: $27.1( \pm 8)$ & total: $76 / 14$ \\
\hline & Surgical - TEN & 25 & & \\
\hline & Conservative & 41 & & \\
\hline \multirow[t]{2}{*}{36} & Surgical - TEN & 20 & $37( \pm 16)$ & $16 / 4$ \\
\hline & Conservative & 20 & $36( \pm 15)$ & $17 / 3$ \\
\hline \multirow[t]{2}{*}{12} & Surgical - modified Hagie pin & 29 & $\begin{array}{c}28 \\
\text { (range 19-40) }\end{array}$ & $27 / 2$ \\
\hline & Conservative - sling & 28 & $\begin{array}{c}25 \\
\text { (range 17-41) }\end{array}$ & $25 / 3$ \\
\hline \multirow[t]{2}{*}{6} & Surgical - $3.5 \mathrm{~mm}$ plate & 35 & $31( \pm 9.5)$ & $25 / 10$ \\
\hline & $\begin{array}{l}\text { Conservative - figure-of-eight- } \\
\text { bandage }\end{array}$ & 30 & $30( \pm 13.0)$ & $23 / 7$ \\
\hline
\end{tabular}


Part 3 - Treatment

Appendix 4. Continued

\begin{tabular}{|c|c|c|c|c|}
\hline Study & Year & $\begin{array}{l}\text { Study } \\
\text { design }\end{array}$ & Country & Fracture type(s) \\
\hline Kulshrestha et al. ${ }^{\left({ }^{30}\right)}$ & 2011 & $P C$ & India & Robinson 2B1, 2B2 \\
\hline Melean et al. ${ }^{(33)}$ & 2015 & $\mathrm{RCT}$ & Chile & Robinson 2B1, $2 \mathrm{~B} 2$ \\
\hline Mirzatolooei et al. ${ }^{(34)}$ & 2011 & $\mathrm{RCT}$ & Iran & $\begin{array}{l}\text { No further classification } \\
\text { applied }\end{array}$ \\
\hline Robinson et al. ${ }^{(44)}$ & 2013 & $\mathrm{RCT}$ & UK & Edinburgh type $2 \mathrm{~B}$ \\
\hline Smekal et al. ${ }^{(46)}$ & 2011 & PC & Austria & $\begin{array}{c}15 B 1,15 B 2,15 B 3, \text { accord- } \\
\text { ing to the } A O \text { classification } \\
\text { system }\end{array}$ \\
\hline Thyagarajan et al. ${ }^{(51)}$ & 2009 & $\mathrm{RC}$ & UK & $\begin{array}{l}\text { No further classification } \\
\text { applied }\end{array}$ \\
\hline Van der Ven et al. ${ }^{(52)}$ & 2015 & PC & The Netherlands & $\begin{array}{l}\text { No further classification } \\
\text { applied }\end{array}$ \\
\hline Virtanen et al. ${ }^{(54)}$ & 2012 & $\mathrm{RCT}$ & Finland & $\begin{array}{c}\text { 15B1, } 15 B 2, \text { according } \\
\text { to the AO classification } \\
\text { system }\end{array}$ \\
\hline Witzel et al. (55) & 2007 & $\mathrm{RCT}$ & Germany & $\begin{array}{l}\text { No further classification } \\
\text { applied }\end{array}$ \\
\hline
\end{tabular}

SD indicates standard deviation; NR indicates not reported; PC indicates a prospective cohort study; $\mathrm{RC}$ indicates a retrospective cohort study; $\mathrm{RCT}$ indicates a randomized controlled trial; $\mathrm{LCDCP}=$ low contact dynamic compression plate; $\mathrm{DCP}=$ dynamic compression plate; TEN = titanium elastic nail; $L C P=$ locking compression plate; $C l=$ confidence interval. 


\begin{tabular}{|c|c|c|c|c|}
\hline $\begin{array}{l}\text { Follow-up } \\
\text { (months) }\end{array}$ & Groups & $\begin{array}{l}\text { Number } \\
\text { of patients }\end{array}$ & Age (years) ( $\pm S D)$ & $\begin{array}{l}\text { Male/ } \\
\text { Female }\end{array}$ \\
\hline \multirow[t]{2}{*}{18} & $\begin{array}{l}\text { Surgical - contoured reconstruction } \\
\text { plate }\end{array}$ & 45 & $32.0( \pm 6.2)$ & $43 / 2$ \\
\hline & Conservative - sling & 28 & $32.8( \pm 4.6)$ & $24 / 4$ \\
\hline \multirow[t]{2}{*}{12} & Surgical - 3.5mm LCP & 34 & $38.1( \pm 13)$ & NR \\
\hline & Conservative - sling & 42 & $37.2( \pm 11.2)$ & NR \\
\hline \multirow[t]{2}{*}{12} & $\begin{array}{l}\text { Surgical-3.5mm reconstruction } \\
\text { plate }\end{array}$ & 29 & 36.0 & $20 / 6$ \\
\hline & Conservative - sling & 31 & 35.3 & $21 / 3$ \\
\hline \multirow[t]{2}{*}{12} & Surgical - LCP & 95 & $32.3(95 \% \mathrm{Cl} 30.1-34.5)$ & $83 / 12$ \\
\hline & Conservative - collar and cuff & 105 & $32.5(95 \% \mathrm{Cl} 30.1-34.9)$ & $92 / 13$ \\
\hline \multirow[t]{2}{*}{24} & Surgical - TEN & 60 & $36.8( \pm 12.6)$ & $54 / 6$ \\
\hline & Conservative - sling & 52 & $38.0( \pm 14.8)$ & $44 / 8$ \\
\hline \multirow[t]{3}{*}{6} & Surgical - LCDCP & 17 & $\begin{array}{c}32.1 \\
\text { (range 17-46) }\end{array}$ & $15 / 2$ \\
\hline & Surgical - Rockwood pin & 17 & $\begin{array}{l}28 \\
\text { (range 15-56) }\end{array}$ & $16 / 1$ \\
\hline & Conservative - sling & 17 & $\begin{array}{l}34.5 \\
\text { (range 17-64) }\end{array}$ & $12 / 5$ \\
\hline \multirow[t]{2}{*}{60} & Surgical - LCP & 39 & $40.8( \pm 12.8)$ & $35 / 4$ \\
\hline & Conservative - sling & 58 & $40.5( \pm 15.2)$ & $49 / 9$ \\
\hline \multirow[t]{2}{*}{12} & $\begin{array}{c}\text { Surgical-3.5mm reconstruction } \\
\text { plate }\end{array}$ & 28 & $41( \pm 10.8)$ & $24 / 4$ \\
\hline & Conservative - sling & 32 & $33( \pm 12.0)$ & $28 / 4$ \\
\hline \multirow[t]{2}{*}{19} & Surgical - Prévot pin & 35 & 34.2 (range 19-72) & $22 / 13$ \\
\hline & $\begin{array}{c}\text { Conservative - figure-of-eight- } \\
\text { bandage }\end{array}$ & 33 & $\begin{array}{c}\text { NR } \\
\text { total: } 35.4 \text { (range 18-72) }\end{array}$ & $23 / 10$ \\
\hline
\end{tabular}


Appendix 5. Study outcomes and results in a systematic review of DMCFs comparing conservative versus surgical treatment

\begin{tabular}{|c|c|c|c|c|c|c|}
\hline \multirow[t]{3}{*}{ Study } & \multicolumn{2}{|c|}{ Nonunion } & \multicolumn{4}{|c|}{$\begin{array}{c}\text { Functional scores } \\
\text { short term (<1 year) }\end{array}$} \\
\hline & \multirow{2}{*}{\multicolumn{2}{|c|}{ 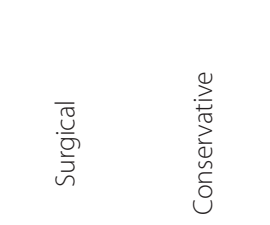 }} & \multicolumn{2}{|c|}{ DASH scores } & \multicolumn{2}{|c|}{ Constant score } \\
\hline & & & 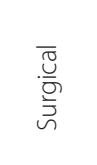 & 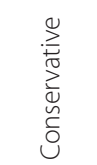 & 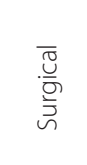 & 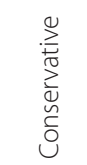 \\
\hline Althausen et al. (2) & 0 & $\begin{array}{c}4 / 83 \\
(4.8 \%)\end{array}$ & NR & NR & NR & NR \\
\hline Böhme et al. (5) & 0 & $\begin{array}{c}1 / 47 \\
(2,1 \%)\end{array}$ & NR & NR & $\begin{array}{l}88.2^{*} \\
94.0^{* *}\end{array}$ & 83.6 \\
\hline Canadian Orthopaedic Trauma Society (9) & $\begin{array}{c}2 / 62 \\
(3.2 \%)\end{array}$ & $\begin{array}{c}7 / 49 \\
(14.3 \%)\end{array}$ & 21 & 40 & 80 & 69 \\
\hline Chen et al.(10) & 0 & $3 / 30(10 \%)$ & NR & NR & NR & NR \\
\hline Daniilidis et al. (12) & $0^{* * *}$ & $\begin{array}{c}9 / 70 \\
(12.9 \%)\end{array}$ & NR & NR & NR & NR \\
\hline George et al. (16) & NR & NR & NR & NR & NR & NR \\
\hline Grassi et al. (18) & $\begin{array}{l}2 / 40 \\
(5 \%)\end{array}$ & 0 & NR & NR & NR & NR \\
\hline Jones et al. (25) & $\begin{array}{c}1 / 24 \\
(4.7 \%)^{*} \\
0 / 25^{* *} \\
1 / 49 \\
(2.0 \%)^{* * *}\end{array}$ & $\begin{array}{c}7 / 41 \\
(17.1 \%)\end{array}$ & NR & NR & NR & NR \\
\hline Jubel et al. (26) & 0 & $\begin{array}{l}2 / 20 \\
(10 \%)\end{array}$ & NR & NR & NR & NR \\
\hline Judd et al. (27) & $\begin{array}{c}1 / 29 \\
(3.5 \%)\end{array}$ & $\begin{array}{c}1 / 28 \\
(3.6 \%)\end{array}$ & NR & NR & NR & NR \\
\hline Khorami et al. (28) & $\begin{array}{l}2 / 35 \\
(5.7 \%)\end{array}$ & $\begin{array}{c}4 / 30 \\
(13.3 \%)\end{array}$ & $\begin{array}{c}24.6 \\
\text { (range } \\
0-88 \text { ) }\end{array}$ & $\begin{array}{c}22.7 \\
\text { (range } \\
0-87 \text { ) }\end{array}$ & $\begin{array}{l}20.97 \\
( \pm 5.7)\end{array}$ & $\begin{array}{c}20.53 \\
( \pm 7.04)\end{array}$ \\
\hline Kulshrestha et al. (30) & 0 & $\begin{array}{c}8 / 28 \\
(28.6 \%)\end{array}$ & NR & NR & 90 & 78 \\
\hline
\end{tabular}




\begin{tabular}{|c|c|c|c|c|c|c|c|c|c|c|}
\hline \multicolumn{4}{|c|}{$\begin{array}{c}\text { Functional scores } \\
\text { long term ( } \geq \text { 1year) }\end{array}$} & \multicolumn{2}{|c|}{ malunion } & \multicolumn{2}{|c|}{ Return to work in days } & \multicolumn{2}{|c|}{ Revision surgery } & \multirow{3}{*}{ 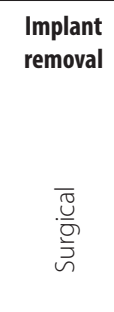 } \\
\hline \multicolumn{2}{|c|}{ DASH scores } & \multicolumn{2}{|c|}{ Constant score } & \multirow[b]{2}{*}{ 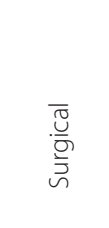 } & \multirow[b]{2}{*}{ 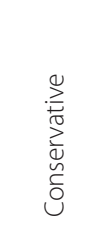 } & \multirow[b]{2}{*}{$\begin{array}{l}\overline{\widetilde{0}} \\
\stackrel{\bar{n}}{\bar{n}}\end{array}$} & \multirow[b]{2}{*}{ 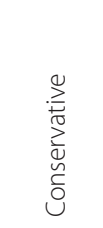 } & \multirow[b]{2}{*}{ 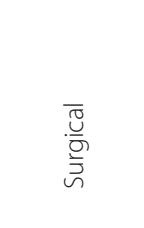 } & \multirow[b]{2}{*}{ 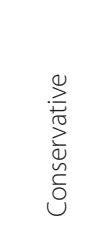 } & \\
\hline $\begin{array}{l}\overline{0} \\
\stackrel{\bar{v}}{5} \\
\bar{n}\end{array}$ & 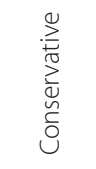 & 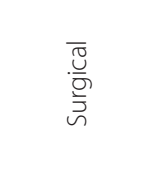 & 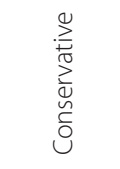 & & & & & & & \\
\hline NR & NR & NR & NR & NR & NR & 35.9 & 61.1 & $\begin{array}{l}3 / 66 \\
(4.5 \%)\end{array}$ & 0 & NR \\
\hline NR & NR & $\begin{array}{c}94.4^{*} \\
96.7^{* *} \\
\text { (8 months) }\end{array}$ & $\begin{array}{c}90.3 \text { (8 } \\
\text { months) }\end{array}$ & NR & NR & 34 & 36 & $\begin{array}{c}4 / 53 \\
(7.5 \%)^{*} \\
1 / 20(5 \%)^{* *}\end{array}$ & $\begin{array}{l}1 / 47 \\
(2.1 \%)\end{array}$ & NR \\
\hline 5 & 14 & 96 & 90 & 0 & $\begin{array}{c}9 / 49 \\
(18.4 \%)\end{array}$ & NR & NR & $\begin{array}{c}3 / 62 \\
(4.8 \%)\end{array}$ & $\begin{array}{c}16 / 49 \\
(32.7 \%)\end{array}$ & $\begin{array}{l}5 / 62 \\
(8.1 \%)\end{array}$ \\
\hline $\begin{array}{c}2.74 \\
( \pm 3.6)\end{array}$ & $\begin{array}{c}7.91 \\
( \pm 12.6)\end{array}$ & $\begin{array}{c}97.0 \\
( \pm 4.2)\end{array}$ & $\begin{array}{c}94.0 \\
( \pm 5.4)\end{array}$ & 0 & $\begin{array}{l}2 / 30 \\
(6.7 \%)\end{array}$ & $N R$ & NR & $\begin{array}{l}1 / 30 \\
(3.3 \%)\end{array}$ & $\begin{array}{c}5 / 30 \\
(16.7 \%)\end{array}$ & NR \\
\hline $7.3^{* * *}$ & 11.1 & $\begin{array}{c}91.7 \\
(\text { SE: 1.1) }\end{array}$ & $\begin{array}{c}88.1 \\
\text { (SE: } 1.4)\end{array}$ & NR & NR & NR & NR & $\begin{array}{c}9 / 81 \\
(11.1 \%)^{* * *}\end{array}$ & $\begin{array}{c}9 / 70 \\
(12.9 \%)\end{array}$ & $\begin{array}{c}3 / 81 \\
(3.7 \%)^{* * *}\end{array}$ \\
\hline $\begin{array}{c}10.13 \\
( \pm 15.7)\end{array}$ & $\begin{array}{l}11.22 \\
( \pm 18.8)\end{array}$ & NR & NR & NR & NR & NR & NR & NR & NR & NR \\
\hline NR & NR & $\begin{array}{l}82.9 \\
\text { (range } \\
63-95 \text { ) }\end{array}$ & $\begin{array}{c}84.4 \\
\text { (range } \\
52-95 \text { ) }\end{array}$ & $\begin{array}{l}2 / 40 \\
(5 \%)\end{array}$ & 0 & $\begin{array}{c}40.7 \\
\text { (range } \\
20-60 \text { ) }\end{array}$ & $\begin{array}{c}16.7 \\
\text { (range } \\
7-60)\end{array}$ & $\begin{array}{l}1 / 40 \\
(2.5 \%)\end{array}$ & 0 & NR \\
\hline $\begin{array}{c}10 \\
( \pm 15)^{*} \\
1.7 \\
( \pm 2.9)^{* *} \\
5.9 \\
( \pm 11.5)^{* * *}\end{array}$ & $\begin{array}{c}7.6 \\
( \pm 9.3)\end{array}$ & NR & NR & NR & NR & NR & NR & $\begin{array}{c}N R^{*} \\
1 / 25^{* *} \\
N R^{* * *}\end{array}$ & $\begin{array}{l}1 / 41 \\
(2.4 \%)\end{array}$ & $\begin{array}{c}10 / 25 \\
(40 \%)^{* *}\end{array}$ \\
\hline$N R$ & NR & $97( \pm 4)$ & $78( \pm 23)$ & NR & NR & NR & NR & NR & NR & NR \\
\hline NR & NR & NR & NR & $\begin{array}{c}1 / 29 \\
(3.5 \%)\end{array}$ & 0 & NR & NR & $\begin{array}{c}7 / 29 \\
(24.1 \%)\end{array}$ & $\begin{array}{c}1 / 28 \\
(3.6 \%)\end{array}$ & $\begin{array}{l}29 / 29 \\
(100 \%)\end{array}$ \\
\hline NR & NR & NR & NR & $\begin{array}{l}18 / 35 \\
(51.4 \%)\end{array}$ & $\begin{array}{c}7 / 30 \\
(23.3 \%)\end{array}$ & $\begin{array}{c}59.5 \\
( \pm 13.3)\end{array}$ & $\begin{array}{c}61.6 \\
( \pm 13.3)\end{array}$ & $3 / 35(8.6 \%)$ & $\begin{array}{c}4 / 30 \\
(13.3 \%)\end{array}$ & NR \\
\hline NR & NR & 94 & 84 & $\begin{array}{c}2 / 45 \\
(4.4 \%)\end{array}$ & $\begin{array}{l}10 / 28 \\
(35.7 \%)\end{array}$ & NR & NR & $\begin{array}{c}2 / 45 \\
(4.4 \%)\end{array}$ & $\begin{array}{c}8 / 28 \\
(28.6 \%)\end{array}$ & $\begin{array}{l}4 / 45 \\
(8.9 \%)\end{array}$ \\
\hline
\end{tabular}


Appendix 5. Continued

\begin{tabular}{|c|c|c|c|c|c|c|}
\hline \multirow[t]{3}{*}{ Study } & \multicolumn{2}{|c|}{ Nonunion } & \multicolumn{4}{|c|}{$\begin{array}{l}\text { Functional scores } \\
\text { short term (<1 year) }\end{array}$} \\
\hline & \multirow{2}{*}{\multicolumn{2}{|c|}{ 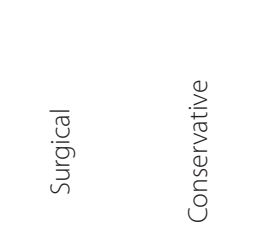 }} & \multicolumn{2}{|c|}{ DASH scores } & \multicolumn{2}{|c|}{ Constant score } \\
\hline & & & 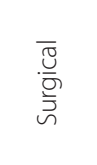 & 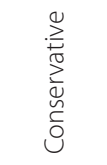 & $\begin{array}{l}\overline{\frac{U}{0}} \\
\frac{\bar{\sigma}}{J} \\
\sim\end{array}$ & 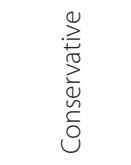 \\
\hline Melean et al.(33) & 0 & $\begin{array}{l}4 / 41 \\
(9.6 \%)\end{array}$ & NR & NR & $\begin{array}{c}76 \text { (range } \\
48-93) \\
\text { (3 months) }\end{array}$ & $\begin{array}{c}74 \\
\text { (range } \\
31-95) \\
\text { (3 months) }\end{array}$ \\
\hline Mirzatolooei et al. (34) & $\begin{array}{c}1 / 26 \\
(3.8 \%)\end{array}$ & $\begin{array}{c}1 / 24 \\
(4.2 \%)\end{array}$ & NR & NR & NR & NR \\
\hline Robinson et al. (44) & $\begin{array}{c}1 / 86 \\
(1.2 \%)\end{array}$ & $16 / 92(17.4 \%)$ & 22 & 28 & 70 & 67 \\
\hline $\begin{array}{l}\text { Smekal et al. (46) } \\
2011\end{array}$ & 0 & $\begin{array}{c}6 / 52 \\
(11.5 \%)\end{array}$ & NR & NR & NR & NR \\
\hline Thyagarajan et al. (51) & $\begin{array}{c}1 / 17 \\
(5.9 \%)^{*} \\
0 / 17^{* *} \\
1 / 34 \\
(2.9 \%)^{* * *}\end{array}$ & $\begin{array}{c}3 / 17 \\
(17.6 \%)\end{array}$ & NR & NR & $\begin{array}{c}97.8 \\
( \pm 2.5)^{*} \\
93.7 \\
( \pm 4.4)^{* *} \\
\mathrm{NR}^{* * *}\end{array}$ & $\begin{array}{c}89.0 \\
( \pm 16.0)\end{array}$ \\
\hline Van der Ven et al. (52) & $\begin{array}{c}1 / 39 \\
(2.6 \%)\end{array}$ & $3 / 58(5.2 \%)$ & $\begin{array}{c}15.7 \\
( \pm 17.2)\end{array}$ & $\begin{array}{c}24.8 \\
( \pm 16.7)\end{array}$ & $90.9( \pm 14.2)$ & $\begin{array}{c}78.7 \\
( \pm 17.0)\end{array}$ \\
\hline Virtanen et al. (54) & 0 & $\begin{array}{l}6 / 25 \\
(24 \%)\end{array}$ & $\begin{array}{c}14.2 \\
( \pm 13.4)\end{array}$ & $\begin{array}{c}14.3 \\
( \pm 14.4)\end{array}$ & $78.7( \pm 10.9)$ & $\begin{array}{c}80.0 \\
( \pm 10.2)\end{array}$ \\
\hline Witzel et al. (55) & 0 & 0 & NR & NR & NR & NR \\
\hline
\end{tabular}




\begin{tabular}{|c|c|c|c|c|c|c|c|c|c|c|}
\hline \multicolumn{4}{|c|}{$\begin{array}{l}\text { Functional scores } \\
\text { long term ( } \geq \text { 1year) }\end{array}$} & \multicolumn{2}{|c|}{ malunion } & \multicolumn{2}{|c|}{ Return to work in days } & \multicolumn{2}{|c|}{ Revision surgery } & \multirow{3}{*}{$\begin{array}{l}\text { Implant } \\
\text { removal } \\
\overline{\bar{ত}} \\
\overline{ত ্ ড}\end{array}$} \\
\hline \multicolumn{2}{|c|}{ DASH scores } & \multicolumn{2}{|c|}{ Constant score } & \multirow[b]{2}{*}{$\begin{array}{l}\overline{\frac{\pi}{\pi}} \\
\bar{\Xi}\end{array}$} & \multirow[b]{2}{*}{ 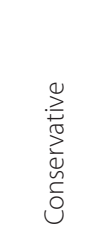 } & \multirow[b]{2}{*}{ 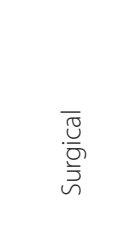 } & \multirow[b]{2}{*}{ 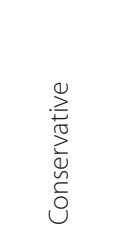 } & \multirow[b]{2}{*}{ 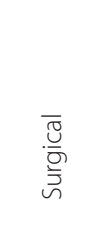 } & \multirow[b]{2}{*}{ 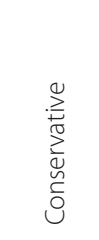 } & \\
\hline $\begin{array}{l}\overline{\bar{U}} \\
\bar{\Xi} \\
\backsim\end{array}$ & 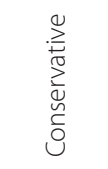 & 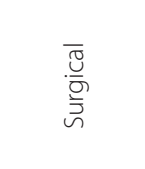 & 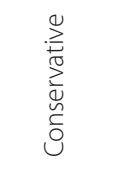 & & & & & & & \\
\hline NR & NR & $\begin{array}{c}93 \\
\text { (range } \\
91-95)\end{array}$ & $\begin{array}{c}87 \\
\text { (range } \\
79-95)\end{array}$ & NR & NR & $\begin{array}{c}88.2 \\
( \pm 24.3)\end{array}$ & $\begin{array}{l}112.5 \\
( \pm 33.5)\end{array}$ & 0 & $\begin{array}{c}4 / 41 \\
(9.8 \%)\end{array}$ & $\begin{array}{c}4 / 35 \\
(11.4 \%)\end{array}$ \\
\hline 8.6 & 21.3 & 89.8 & 78.8 & $\begin{array}{c}4 / 26 \\
(15.4 \%)\end{array}$ & $\begin{array}{c}19 / 24 \\
(79,2 \%)\end{array}$ & NR & NR & $\begin{array}{l}3 / 26 \\
(11.5 \%)\end{array}$ & $\begin{array}{c}1 / 24 \\
(4.2 \%)\end{array}$ & NR \\
\hline $\begin{array}{c}3.4 \\
\text { (R1.9-4.9) }\end{array}$ & $\begin{array}{c}6.1(\mathrm{R} 4.1 \\
-8.1)\end{array}$ & $\begin{array}{c}92 \\
(\mathrm{R} 90.0-94.0)\end{array}$ & $\begin{array}{c}87.8 \\
R 85.2-90.3)\end{array}$ & 0 & $\begin{array}{c}8 / 92 \\
(8.7 \%)\end{array}$ & $\begin{array}{c}22.0 \\
(95 \% \mathrm{Cl} \\
15.1-28.9)\end{array}$ & $\begin{array}{c}24.2(95 \% \\
\text { Cl 16.9- } \\
31.5)\end{array}$ & $\begin{array}{c}5 / 86 \\
(5.8 \%)\end{array}$ & $\begin{array}{c}13 / 92 \\
(14.1 \%)\end{array}$ & $\begin{array}{l}10 / 86 \\
(11.6 \%)\end{array}$ \\
\hline $\begin{array}{c}0.5 \\
( \pm 1.8)\end{array}$ & $\begin{array}{c}3.1 \\
( \pm 7.4)\end{array}$ & $\begin{array}{l}98.0 \\
( \pm 3.6)\end{array}$ & $\begin{array}{c}95.1 \\
( \pm 7.0)\end{array}$ & $\begin{array}{l}2 / 60 \\
(3.3 \%)\end{array}$ & $\begin{array}{c}9 / 52 \\
(17.3 \%)\end{array}$ & NR & NR & $\begin{array}{l}12 / 60 \\
(20 \%)\end{array}$ & $\begin{array}{c}6 / 52 \\
(11.5 \%)\end{array}$ & NR \\
\hline NR & NR & NR & NR & $\begin{array}{c}2 / 17 \\
(11.8 \%)^{*} \\
0 / 17^{* *} \\
2 / 34 \\
(5.9 \%)^{* * *}\end{array}$ & $\begin{array}{c}1 / 17 \\
(5.9 \%)\end{array}$ & NR & NR & $\begin{array}{c}2 / 17 \\
(11.8 \%)^{*} \\
0^{* *} \\
2 / 34 \\
(5.9 \%)^{* * *}\end{array}$ & $\begin{array}{c}4 / 17 \\
(23.5 \%)\end{array}$ & $\begin{array}{c}2 / 17 \\
(11.8 \%)^{*} \\
17 / 17 \\
(100 \%)^{* *} \\
19 / 34 \\
(55.9 \%)^{* * *}\end{array}$ \\
\hline $\begin{array}{c}5.2 \\
( \pm 9.8)\end{array}$ & $\begin{array}{c}2.5 \\
( \pm 4.9)\end{array}$ & NR & NR & 0 & $\begin{array}{l}1 / 58 \\
(1.7 \%)\end{array}$ & $\begin{array}{c}16.1 \\
( \pm 13.3)\end{array}$ & $\begin{array}{c}29.4 \\
( \pm 21.7)\end{array}$ & $\begin{array}{c}9 / 39 \\
(23.1 \%)\end{array}$ & $\begin{array}{l}3 / 58 \\
(5.2 \%)\end{array}$ & $4 / 39(10.3 \%)$ \\
\hline $\begin{array}{c}5.0 \\
( \pm 6.4)\end{array}$ & $\begin{array}{c}8.0 \\
( \pm 13.3)\end{array}$ & $87.3( \pm 6.5)$ & $\begin{array}{l}85.2 \\
( \pm 9.5)\end{array}$ & $\begin{array}{c}3 / 26 \\
(11.5 \%)\end{array}$ & $\begin{array}{l}3 / 25 \\
(12 \%)\end{array}$ & NR & $N R$ & $\begin{array}{l}1 / 26 \\
(3.8 \%)\end{array}$ & $\begin{array}{l}1 / 25 \\
(4 \%)\end{array}$ & NR \\
\hline NR & NR & NR & NR & 0 & 0 & NR & NR & 0 & 0 & $\begin{array}{l}35 / 35 \\
(100 \%)\end{array}$ \\
\hline
\end{tabular}


Part 3 - Treatment

Appendix 6. Impact of different methods to handle zero-event data in the meta-analysis of conservative vs surgical treatment of DMCF and nonunions.

\begin{tabular}{lcc}
\hline & Observational studies & Randomised trials \\
\hline Method & Pooled $\mathrm{OR}(95 \% \mathrm{Cl})$ & Pooled $\mathrm{OR}(95 \% \mathrm{Cl})$ \\
Crude & $0.11(0.04 ; 0.25)$ & $0.11(0.04 ; 0.29)$ \\
Inverse variance - no correction & $0.20(0.06 ; 0.65)$ & $0.22(0.08 ; 0.64)$ \\
Inverse variance - with correction & $0.17(0.07 ; 0.38)$ & $0.17(0.07 ; 0.43)$ \\
DerSimonian Laird with correction & $0.16(0.05 ; 0.55)$ & $0.18(0.05 ; 0.67)$ \\
Peto & $0.12(0.06 ; 0.23)$ & $0.15(0.07 ; 0.30)$ \\
\hline
\end{tabular}




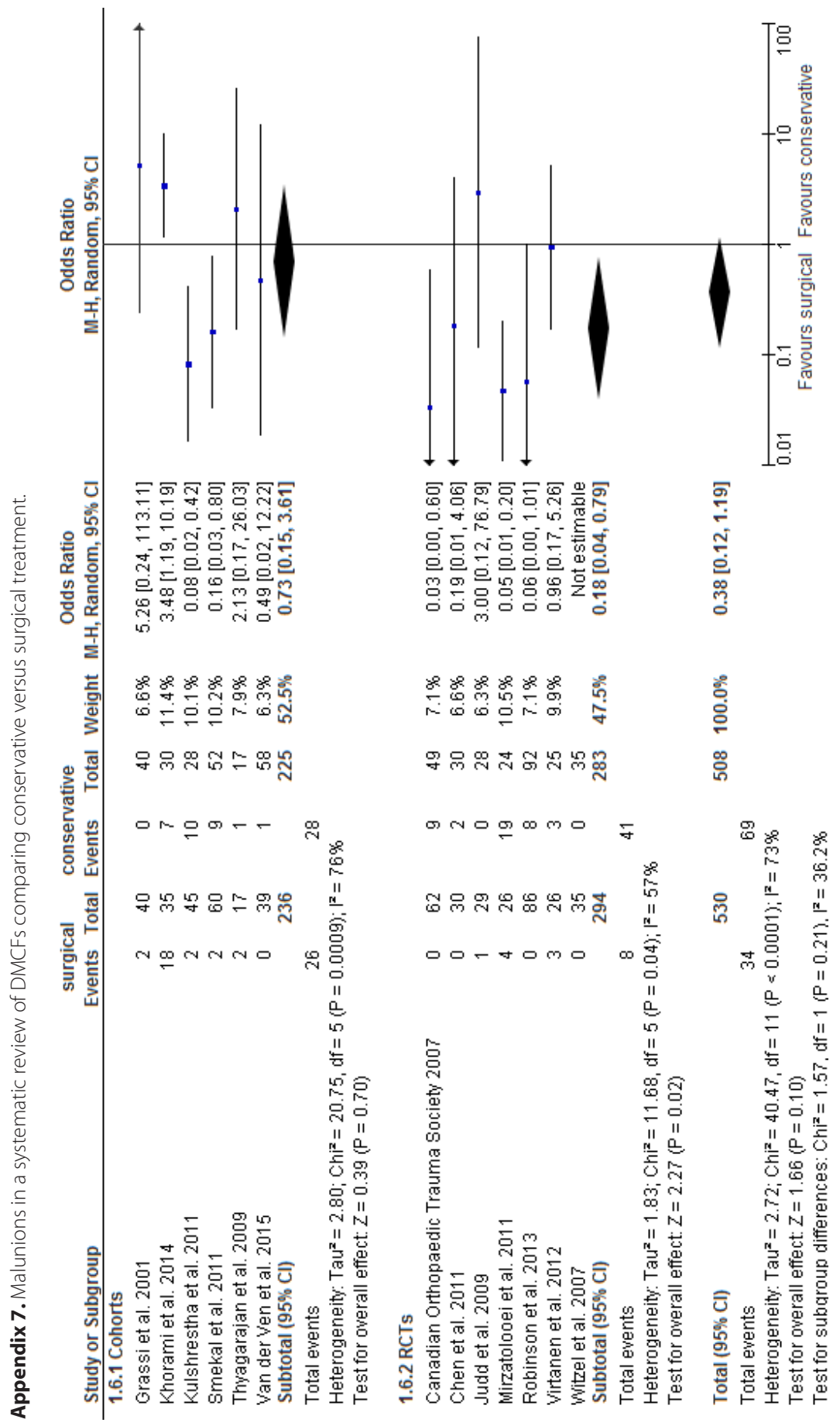




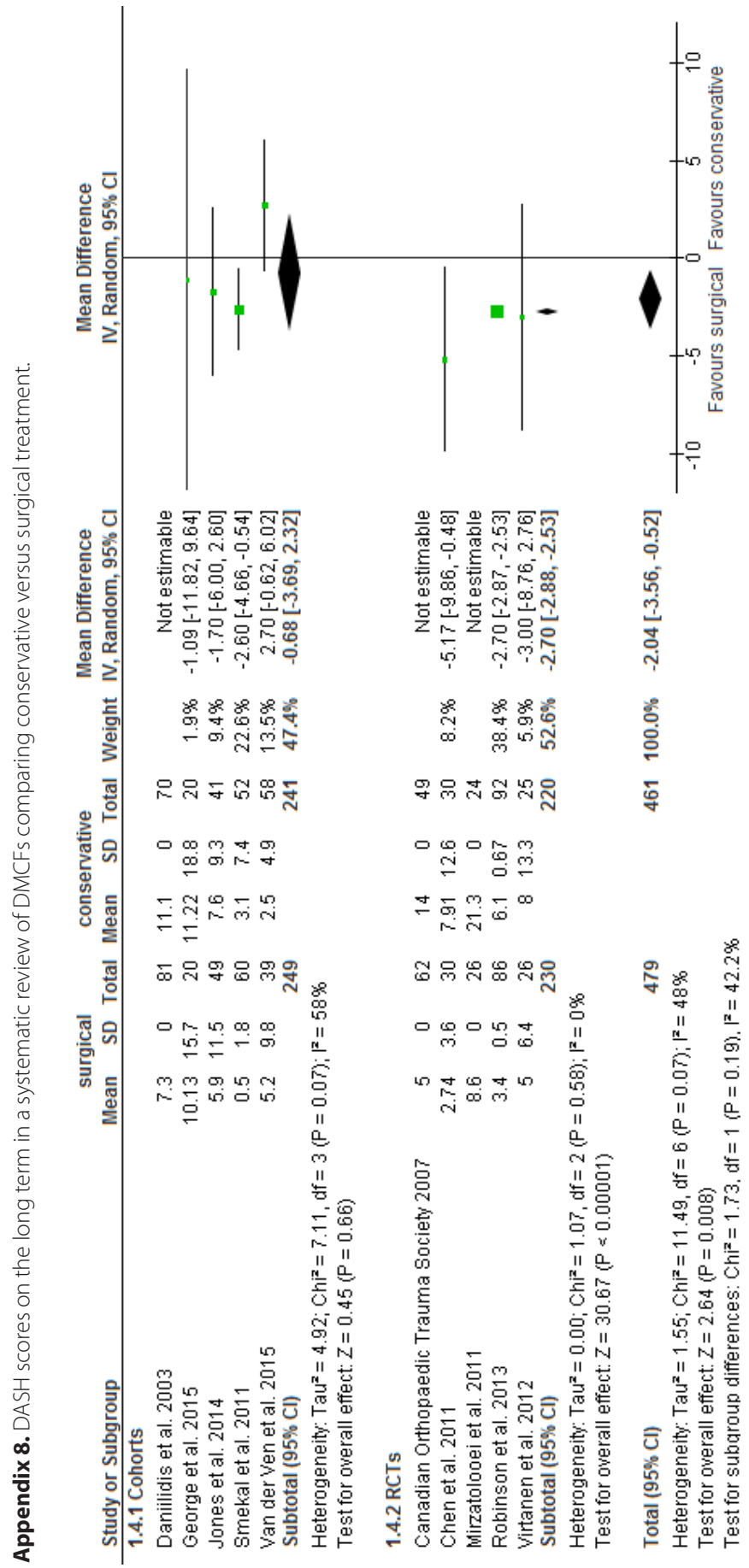




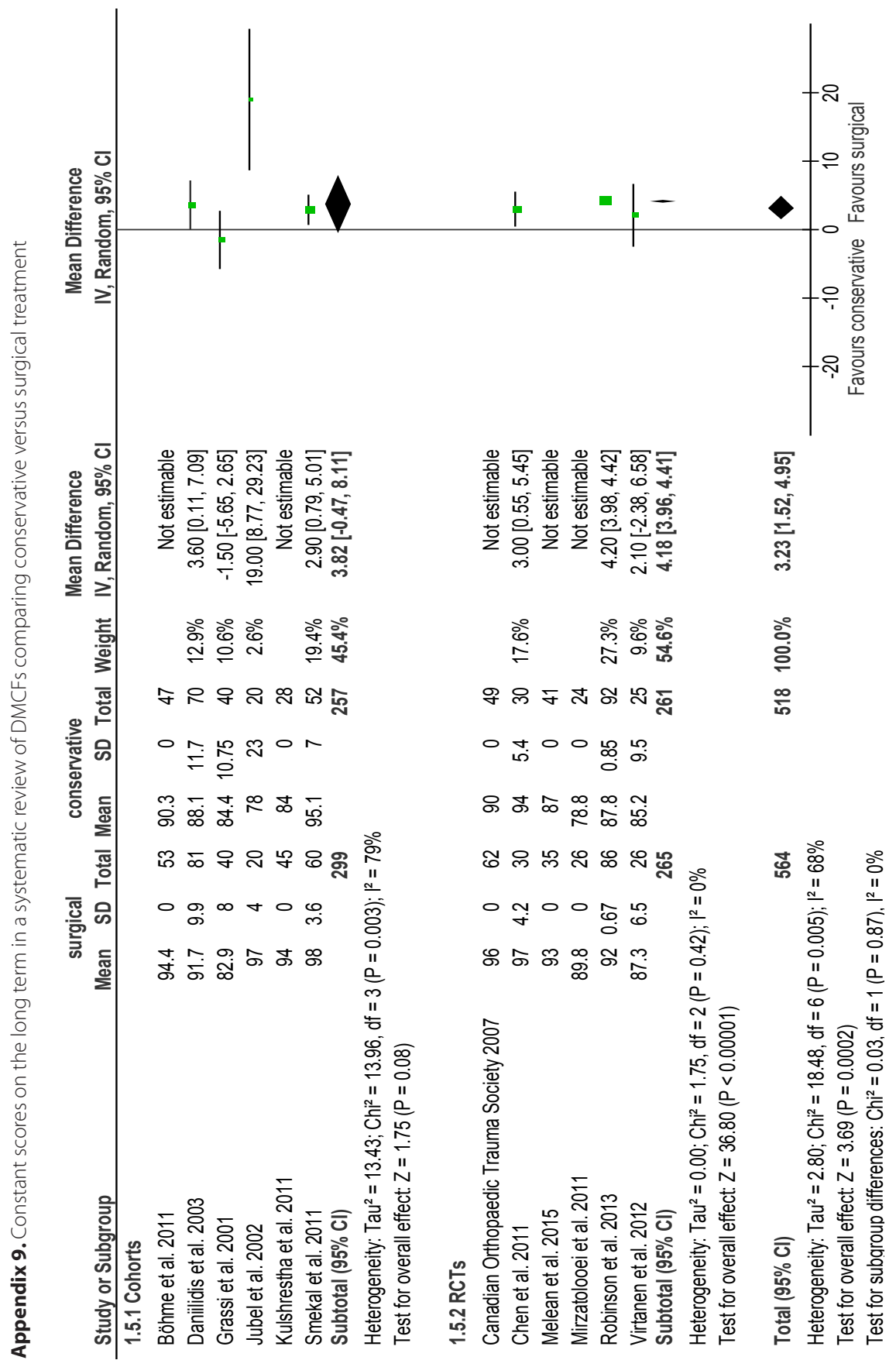




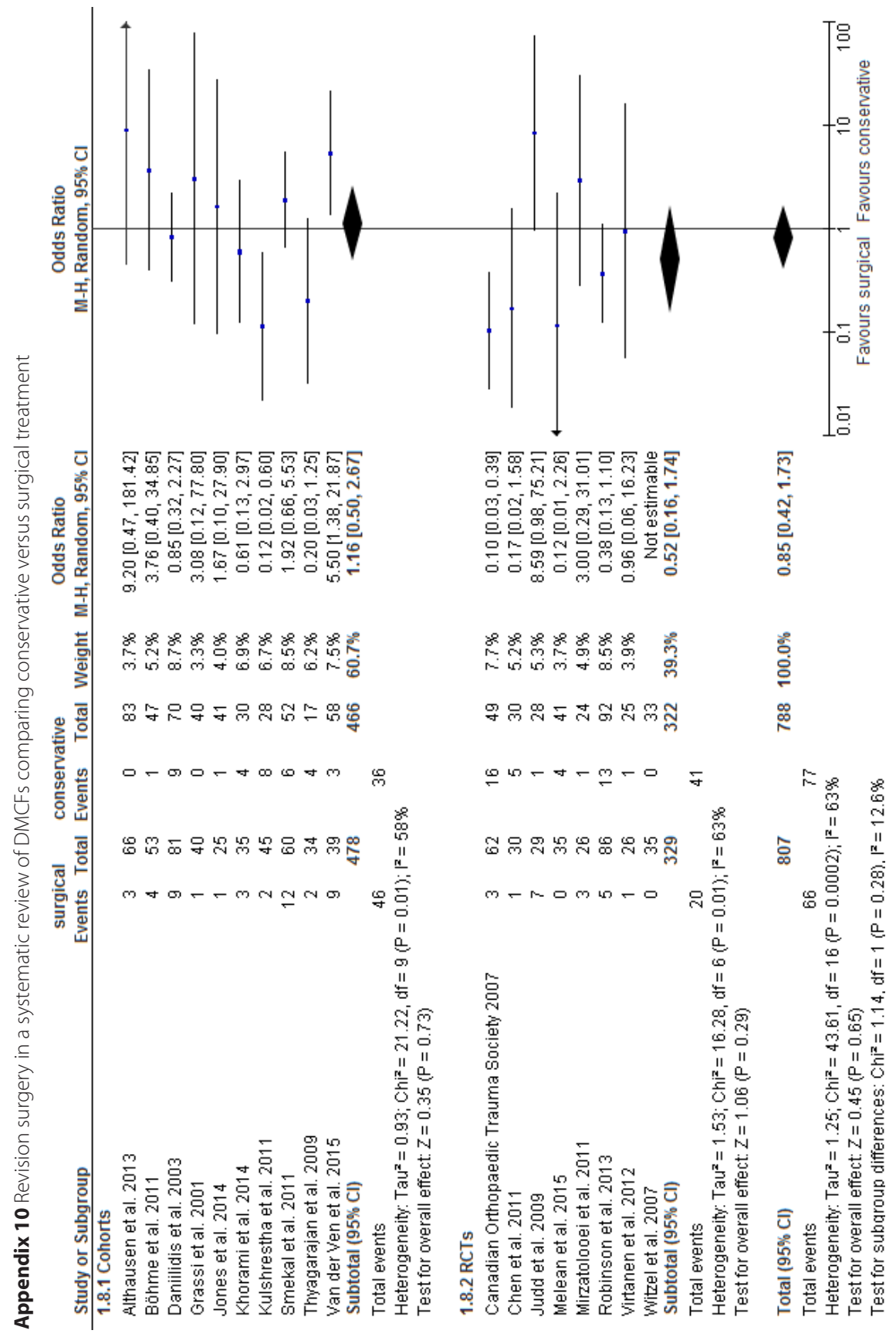





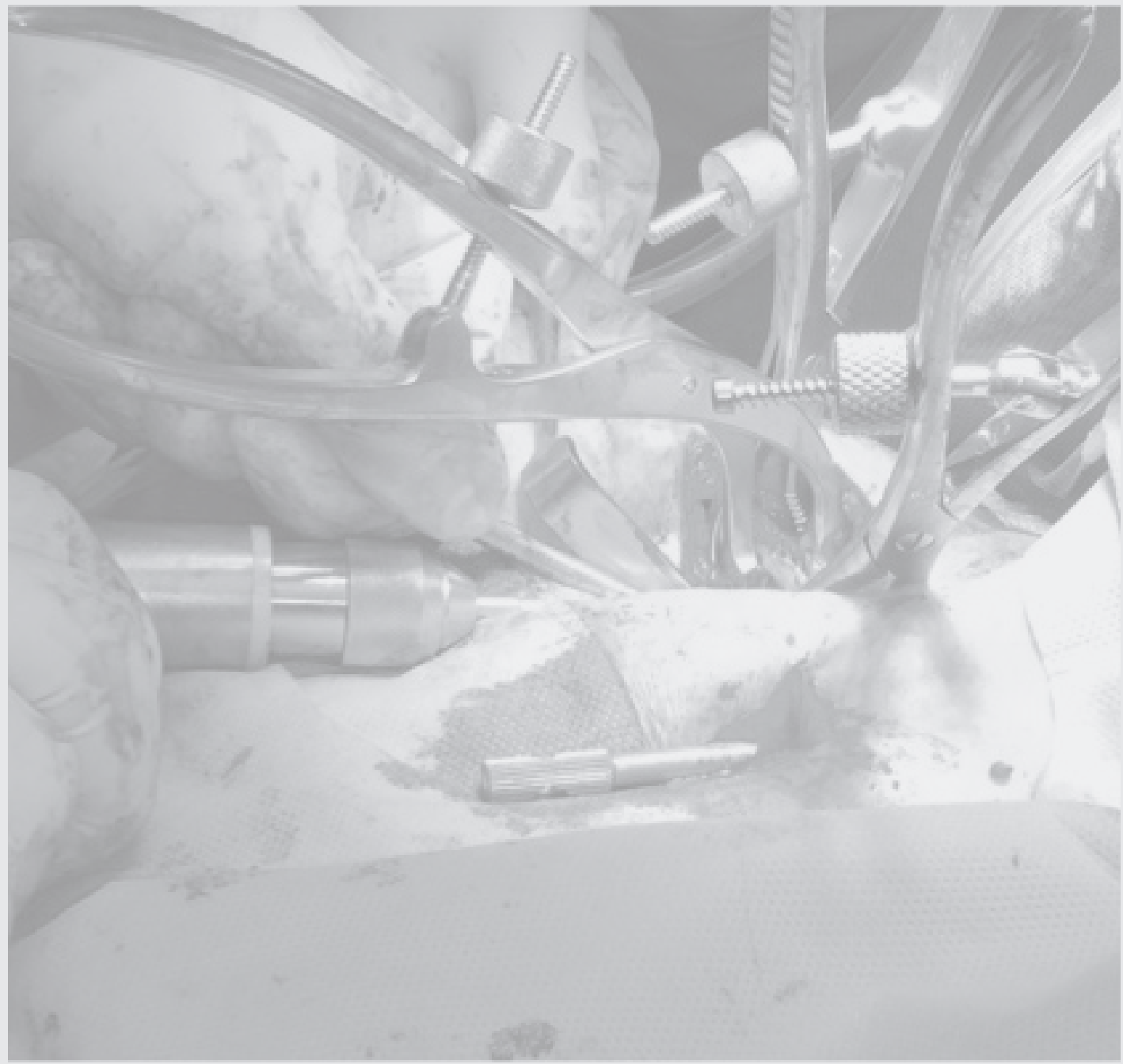




\section{CHAPTER SEVEN}

Mini-invasive plate osteosynthesis (MIPO)
using VA-LCP Anterior Clavicle Plate

D.J.C. van der Ven, T.K. Timmers, G.D.J. van Olden, I.A.M.J. Broeders

Submitted 


\section{ABSTRACT}

\section{Introduction}

The main advantage of the minimally invasive plate osteosynthesis (MIPO) technique is the reduction of soft tissue disruption and preservation of blood supply to the fracture area. MIPO of clavicular fractures is not commonly used because it is a technically demanding procedure for indirect reduction, and the proximity of neurovascular structures have to be considered.

\section{Patients/methods}

Between 2014-2016 the MIPO technique was applied in the operative treatment of patients with middle-third fractures of the clavicle at the Meander Medical Centre. A cohort of patients operated between 2011-2013 with the conventional operation technique was used as a control group. Patients were seen at 6 and 24 weeks. The Constant shoulder and DASH questionnaires were completed at 6 weeks and scar evaluating by POSASv2.0 were performed.

\section{Results}

The study cohort included a total of 82 patients. The mean Constant scores and DASH were; $93.0 \pm 10.4$ and $7.8 \pm 8.4$ for the MIPO group and $92.7 \pm 10.1$ and $8.8 \pm 6.3$ for the conventional group. Complication rates were 5 versus $7 \%$. Overall POSAS value was significant better in the MIPO group; $2.0 \pm 0.9$ versus $3.1 \pm 2.4, p=0.04$.

\section{Conclusion}

Minimal invasive anterior-inferior plating (MIPO) with the VA-LCP anterior clavicle plate appears to be an effective method of treating clavicle fractures. Excellent functional outcomes scores and low complication rates were seen in both the open plating and minimal invasive plate osteosynthesis treatment group. However, the MIPOtechnique resulted in a better overall cosmetic appearance. 


\section{INTRODUCTION}

Clavicle fractures are common in adults, with middle-third fractures account for $80 \%$ of the cases, and are caused by a direct axial compressive force to the shoulder after a sudden stop or fall. ${ }^{1-3}$ This injury commonly afflicts the young and active population. An increase in clavicle fractures is seen due to an increase in sports and physical activity. Midshaft clavicle fractures have traditionally been treated nonoperatively, even when substantially displaced. ${ }^{4}$ Recent meta-analyses confirm that the majority of the fractures heal without sequelae. ${ }^{5}$ However, several factors have been reported in the literature to be associated with potential shoulder dysfunction, including: severity of displacement, degree of comminution, and greater than $2 \mathrm{~cm}$ of shortening. ${ }^{5,6-8}$ Therefore, there is a trend to treat displaced midshaft clavicle fractures operatively. The standard surgical techniques carried out are open reduction and internal plate fixation or intramedullary fixation. ${ }^{6,9-15}$. Although a recent review showed no difference either in functional outcome or complications after plate fixation or intramedullary fixation ${ }^{9}$, short-term results favor plate fixation. ${ }^{16}$ Nevertheless, there are several complications described after plate fixation, such as deep infection, non-union, implant failure, re-fracture after implant removal, and poor cosmetic appearance ${ }^{17-19}$ The main advantage of the minimally invasive plate osteosynthesis (MIPO) technique is reduction of soft tissue disruption and preservation of blood supply to the fracture, which might enhance the healing process and reduce postoperative complications. It is a technically demanding procedure for indirect reduction, and the proximity of neurovascular structures have to be considered. As a consequence, there are only a few studies available evaluating the MIPO technique ${ }^{20-28}$ and comparative data are seldom reported. 29,30 $^{2}$ The primary aim of our study was to report the short-term clinical outcomes following MIPO of displaced midshaft clavicle fractures. Our secondary aim was to compare these results with those from a historical series of patients treated by an ORIF approach at the same institution. We hypothesized that both methods are safe, but that the MIPO technique will have a better cosmetic result.

\section{PATIENTS AND METHODS}

In 2014 the MIPO technique was introduced in Meander Medical Centre and since then used in the operative treatment patients with middle-third clavicle fractures. MIPO was not performed until 2014. With the introduction of the MIPO technique, the open technique was completely abandoned from 2014 onwards. Our hospital serves as a regional Level 2 trauma centre and treats around 35.000 trauma patients annually. The study was approved by the local medical ethics committee; reference number W15.052. 


\section{Patient selection}

Inclusion criteria were: 1) a completely displaced midshaft fracture of the clavicle with no cortical contact between the proximal and distal fragment; 2) fractures in the middle third of the clavicle, i.e. a fracture amenable to plate fixation with a minimum of four screws in each proximal and distal fragment; 3 ) the age between 16 and 70 years; Exclusion criteria were: 1) pathologic fractures 2) open fractures; 3) a significant ipsilateral upper extremity fracture; The patients in the MIPO group were prospectively included between 2014-2016. These patients were operated using the minimally invasive technique with the VA-LCP Anterior Clavicle Plate (DePuySynthes). ${ }^{15}$ The historical series consists of consecutive patients operated between 2011-2013 in the Meander Medical Centre; before the introduction of the MIPO technique. These patients were operated with the conventional open technique using the same VA-LCP Anterior Clavicle Plate. All included patients were operated by the same surgeon.

\section{Outcome measures}

The primary outcome parameters after minimal invasive plate osteosynthesis were: 1) fracture union; 2) functional outcome measured using the "Disability of the Arm, Shoulder and Hand" (DASH) questionnaire ${ }^{31}$, and the Constant shoulder questionnaire ${ }^{32}$; 4) scar evaluation using the Patient Scale of the POSAS (Patient and Observer Scar Assesment Scale) ${ }^{33}$; and, 6) complications. The secondary outcome was: to compare these results with a similar historical cohort; patients operated through the conventional surgical technique in our hospital.

\section{Functional outcome}

The Disabilities of Arm, Shoulder and Hand (DASH) Outcome Measure is a validated 30-item, self- report questionnaire. The DASH Outcome Measure consists of two components: the disability/symptom section (30 items) and the optional high performance Sport/Music module (4 items). ${ }^{31}$ The Constant-Murley- score is a validated 14-items questionnaire with a total score of 0-100 and consist of a subjective and objective component. The questionnaire records individual parameters and provides an overall clinical functional assessment. ${ }^{32}$

\section{Scar evaluation}

The POSASv2.0 is a questionnaire validated for linear scars. It contain six items that are scored numerically on a ten-step scale. The scales complement each other and they can be used separately. ${ }^{33}$

\section{Adverse event $\underline{s}$}

Complications scored were superficial wound infection requiring antibiotics, re- 
intervention for deep wound infection, re-fracture (i.e. a recurrent fracture of the same clavicle after plate removal), hardware failure (i.e. plate loosing, axial pull-out of the screws or plate breakage) and non-union (i.e. if no callus/bridging between two cortices was present during radiological examination and/or clinical evidence of pain and/or motion at the fracture site at six months). Plate irritation is considered discomfort coexisting with the treatment rather than a complication. It is often treated by surgical implant removal of the hardware.

\section{Surgical technique}

The patient is positioned in a beach-chair, semi-sitting position on a radiolucent operating table. After pre-operative planning, a gentle curvilinear lateral incision of $3 \mathrm{~cm}$ directly on top of the fracture is made parallel to the skin cleavage lines. The platysma is carefully divided to expose the clavicle periosteum at the deltotrapezial fascia. Blunt dissection is performed from the lateral window medially using a periosteal elevator. The periosteum is minimally dissected to expose the fracture. Bone fragments are not detached from the periosteum in order to preserve vascularization. It is critical not to strip any comminuted fragments. Normal length, axis angulation, and rotation are restored. An appropriate plate length is selected for the fracture (Figure 1). In all cases, the VA-LCP (DePuySynthes) anterior clavicle plate is used, with different lengths varying from 7 to 12 holes. Due to varying patient anatomy, the plate may not be anatomically perfect and slight plate bending may be necessary for an optimum fit. The plate is inserted from the lateral access and crossed the fracture area to the medial clavicle (Figure 2). After plate insertion, alignment of the clavicle, and the position of the plate in correspondence of the acromioclavicular joint is checked using an image intensifier. A medial incision of $0.5 \mathrm{~cm}$ is made at the medial screw hole (Figure 3). Fixation starts with the most medial screw at the desired angle, desired depth, and bicortical. The plate position should not oversize the superior cortex. After the first medial screw the lateral screws can be fixated. The most medial 3 holes are approached by the medial incision. Reduction, plate position and screw fixation are repetitively checked with an image intensifier. ${ }^{34}$ 


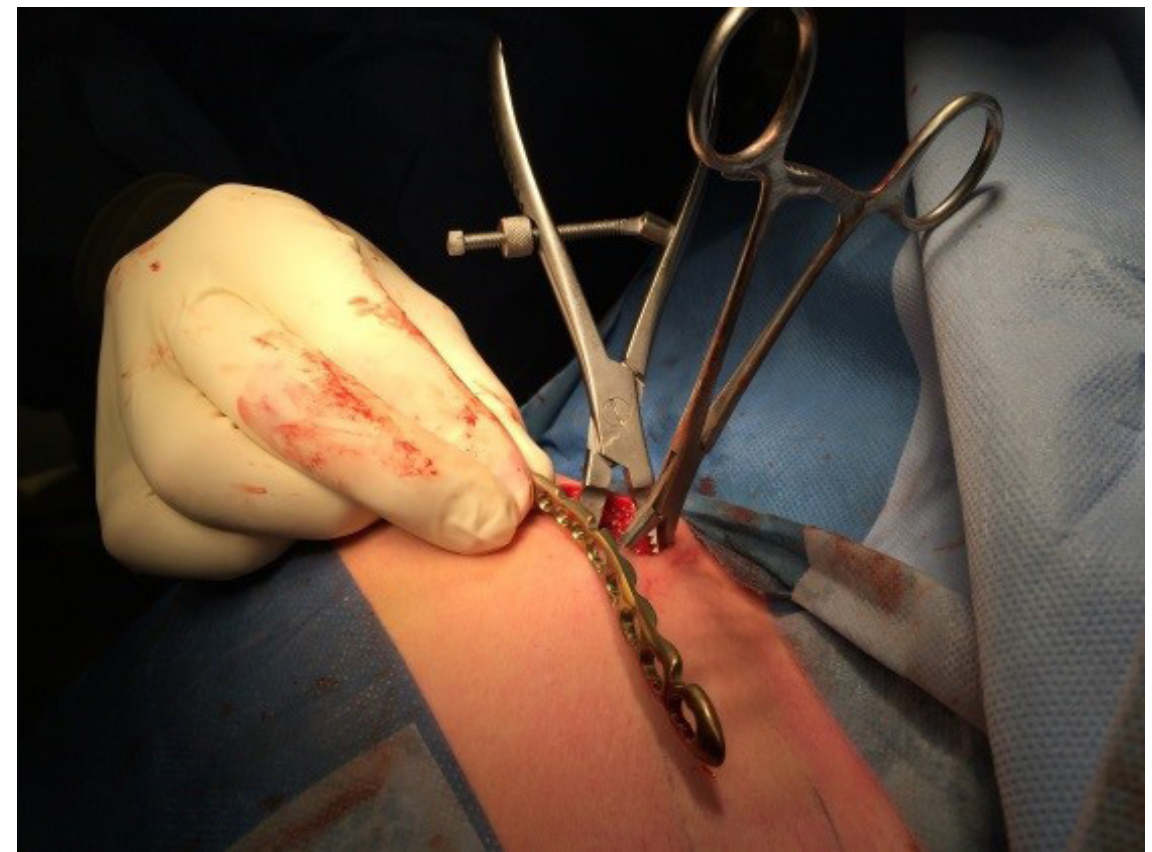

Figure 1. An appropriate VA-LCP anterior clavicle plate was selected and contoured to fit the anterior surface.
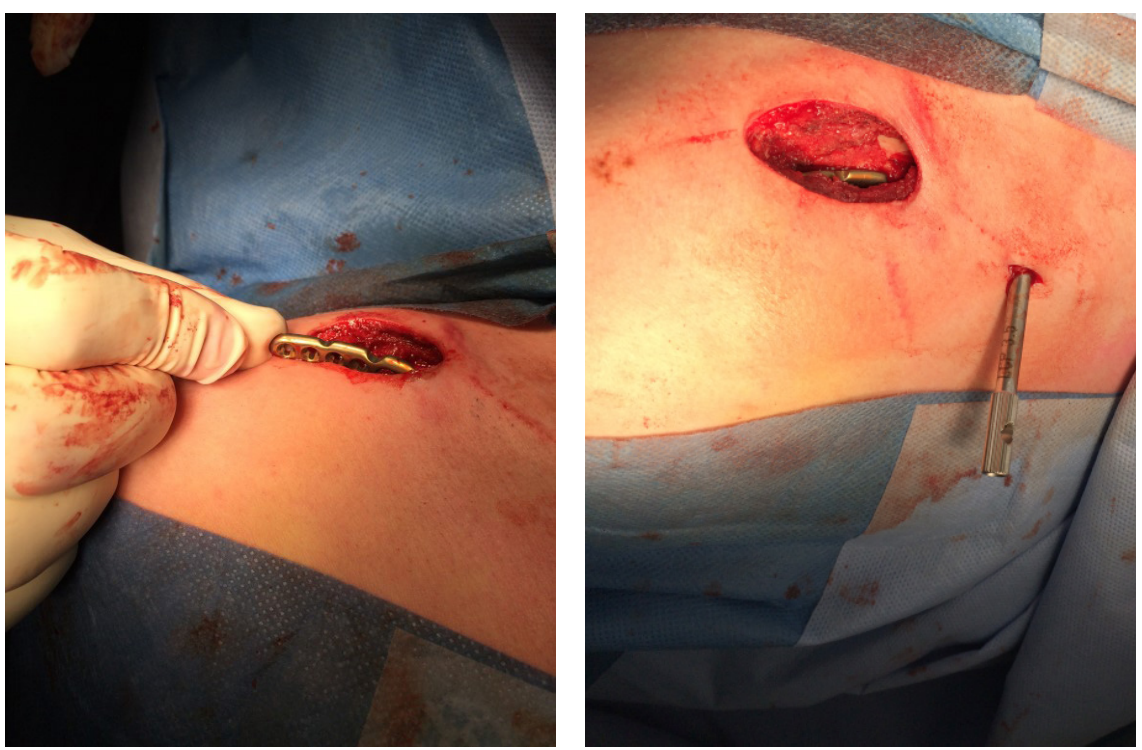

Figure 2. Introduction of the VA-LCP anterior plate from lateral to medial underneath the pectoralis

Figure 3. Medial and lateral Incisions in operation. major muscle. 


\section{Follow-up}

After one week all patients were seen in the outpatient clinic and physical therapy (rhomboideus training) was prescribed. Patients were then seen at 6 and 24 weeks. At 6 weeks the DASH and Constant shoulder questionnaires were completed and radiographs were made. Fracture consolidation was evaluated through clinical examination and standardised radiological analysis (an anterior-posterior AP view and a radiograph with some horizontal angle $15^{\circ}-45^{\circ}$ ).

For the MIPO group at 24 weeks, the POSASv2.0 patient scales were completed. Patients'satisfaction and all adverse events were also noted (i.e. complications, and plate irritation requiring subsequent removal).

When the wound was adequately healed and the scar was settled after tissue regeneration the POSASV2.0 patient scale and the additional questionnaire were sent by letter for the patients in the conventional operation historical control group. All patients requiring re-surgery (i.e. implant removal, mechanical failure, re-fracture or deep wound infection) were excluded for the POSASv2.0 questionnaire.

\section{Statistical analysis}

Statistical analysis was performed using SPSS 15.0, Chicago, for Microsoft Windows. Differences in the DASH and the Constant score between the treatment groups were compared with use of the independent t-test. The chi-square test was used for categorical data. Continuous variables were reported as mean \pm SD or median $\left(25^{\text {th }}\right.$ and $75^{\text {th }}$ inter quartile ranges) and categorical variables as number and percentages, unless otherwise stated. All tests were two-sided, and the level of significance was set at $\mathrm{p}<0.05$.

\section{RESULTS}

After selection based on the described in- and exclusion criteria, the study cohort included a total of 82 patients; 40 in the MIPO group and 42 in the conventional group. Further demographic data are shown in Table 1. The clinical evaluation gave a mean Constant Score and a mean DASH score at six week of $93.0 \pm 10.4$ and $7.8 \pm 8.4$ for the MIPO group and $92.7 \pm 10.1$ and $8.8 \pm 6.3$ for the conventional group. No significant difference was seen between the groups according to functional outcome scores, $\mathrm{p}=0.90$ and $\mathrm{p}=0.56$ (Table $2 \mathrm{~A}$ ).

Patients' satisfactions showed no significant difference as a high rate of satisfaction about the treatment was seen in both groups (38/34 versus $37 / 34$ patients, $p=0.51$, $p=0.93$ ) (Table 2B). 
Table 1. Baseline characteristics.

\begin{tabular}{lcccc}
\hline & $\begin{array}{c}\text { Overall } \\
\mathbf{N = 8 2}\end{array}$ & $\begin{array}{c}\text { MIP0 } \\
\mathbf{N = 4 0}\end{array}$ & $\begin{array}{c}\text { Conventional } \\
\mathbf{N = 4 2}\end{array}$ & p-value $^{2}$ \\
\hline Age $^{1}$ & $39.1 \pm 15.0$ & $37,6 \pm 16.1$ & $40,7 \pm 13.8$ & 0.34 \\
Male gender & 65 & 31 & 34 & 0.41 \\
Dominant arm & & 22 & 20 & 0.50 \\
Smoker $^{4}$ & 42 & 4 & 7 & 0.13 \\
Physical demanding job $^{5}$ & 11 & 21 & 17 & 0.39 \\
\hline
\end{tabular}

${ }^{1}$ Mean \pm SD values; ${ }^{2}$ : Statistical comparison between the MIPO and the conventional operation group. ${ }^{3} 2$ missings in MIPO group ${ }^{4} 10$ missings conventional group ${ }^{5} 2$ missings in conventional group.

Table 2A. DASH and Constant score at 6 en 24 weeks.

\begin{tabular}{lcccc}
\hline & 0verall & MIP0 & Conventional & p-value $^{2}$ \\
& $\mathbf{N}=\mathbf{8 2}$ & $\mathbf{N}=\mathbf{4 0}$ & $\mathbf{N}=\mathbf{4 2}$ & \\
\hline${\text { Constant score } 6 \text { weeks }^{1}}^{\text {DASH score 6 weeks }}$ & $92,9 \pm 10.2$ & $93.0 \pm 10.4$ & $92.7 \pm 10.1$ & 0.90 \\
\hline
\end{tabular}

Table 2B. Patients' satisfaction

\begin{tabular}{lcccc}
\hline & $\begin{array}{c}\text { Overall } \\
\mathbf{N}=\mathbf{8 2}\end{array}$ & $\begin{array}{c}\text { MIP0 } \\
\mathbf{N}=\mathbf{4 0}\end{array}$ & $\begin{array}{c}\text { Conventional } \\
\mathbf{N}=\mathbf{4 2}\end{array}$ & p-value $^{2}$ \\
\hline Patients' satisfaction & & & \\
Therapy & & & 34 & 0.51 \\
Cosmetic aspect & $72(88)$ & 38 & 34 & 0.93 \\
\hline
\end{tabular}

B) ${ }^{1}$ Mean \pm SD values; ${ }^{2}$ Statistical comparison between the operative and the MIPO and the conventional operation group; ${ }^{3}$ One missing in the MIPO group; ${ }^{4} 7$ missings; ${ }^{5}$ in the conventional group and 2 in the MIPO group.

There were 5 complications seen in the MIPO group, two patients had a re-fracture, two patients mechanical failure (i.e. one patient underwent re-surgery because screws were to long and one patient after plate breakage), and one patient developed a deep wound infection requiring re-surgery. Fracture union occurred in all patients after operative plate fixation in both treatment groups.Seven complications seen in the conventional group were three re-fractures after plate removal, one superficial wound infection, one deep wound infection requiring resurgery and two mechanical failures (i.e. one plate loosing and one screw and AC joint), Table $3 A$. 
Seven patients in the MIPO group and 14 patients in the conventional group underwent re-surgery. These patients were excluded for the scar evaluation. The patient scale for evaluating the scar postoperative only showed a significant higher score in the overall scar assessment for the conventional operation group. Therefore, a more unsightly appearance of the scar was seen in this operation group. (2.0 \pm 0.9 versus $3.1 \pm 2.4, p=0.04$, Table 4). Overall postoperative appearance of the scar after the minimal invasive surgical technique is shown in Figure 4.

Table 3A. Complications.

\begin{tabular}{lcccc}
\hline & $\begin{array}{c}\text { 0verall } \\
\mathbf{N = 8 2}\end{array}$ & $\begin{array}{c}\text { MIP0 } \\
\mathbf{N = 4 0}\end{array}$ & $\begin{array}{c}\text { Conventional }_{\mathbf{N}=\mathbf{4 2}} \\
\text { p-value }^{\mathbf{1}}\end{array}$ \\
\hline Overall complications & 12 & 5 & 7 & 0.53 \\
Re-fracture & 5 & 2 & 3 & \\
Mechanical failure & 4 & 2 & 2 & \\
Superficial wound infection & 1 & 0 & 1 & \\
Deep wound infection & 2 & 1 & 1 & \\
\hline
\end{tabular}

Table 3B. Hardware related complications.

\begin{tabular}{lcccc}
\hline & $\begin{array}{c}\text { Overall } \\
\mathbf{N = 8 2}\end{array}$ & $\begin{array}{c}\text { MIP0 } \\
\mathbf{N =}=\mathbf{4 0}\end{array}$ & $\begin{array}{c}\text { Conventional } \\
\mathbf{N = 4 2}\end{array}$ & p-value \\
\hline Hardware irritation requiring removal $^{2}$ & 15 & 4 & 11 & 0.05 \\
Re-surgery $^{1}$ & 21 & 7 & 14 & 0.08 \\
\hline
\end{tabular}

A) ${ }^{1}$ Statistical comparison between the MIPO and the conventional operation group;

B) ${ }^{1}$ All causes for re-surgery: plate irritation requiring removal, re-fracture (two patient did not undergo re-surgery after re-fracture in the MIPO group), infection, and hardware failure.

Table 4. Patient scale ${ }^{2}$ of the POSAS.

\begin{tabular}{lcccc}
\hline & $\begin{array}{c}\text { Overall } \\
\mathbf{N}=\mathbf{6 1}\end{array}$ & $\begin{array}{c}\text { MIP0 } \\
\mathbf{N}=\mathbf{3 4}\end{array}$ & $\begin{array}{c}\text { Conventional } \\
\mathbf{N = 2 7}\end{array}$ & p-value $^{\mathbf{1}}$ \\
\hline Painfull & $1.7 \pm 1.4$ & $1.5 \pm 0.9$ & $2.2 \pm 1.9$ & 0.11 \\
Itchy & $1.6 \pm 1.3$ & $1.5 \pm 0.9$ & $1.8 \pm 1.8$ & 0.54 \\
Colour & $3.5 \pm 2.1$ & $3.7 \pm 1.8$ & $3.2 \pm 2.6$ & 0.46 \\
Stiffness & $3.0 \pm 2.0$ & $2.8 \pm 1.8$ & $3.3 \pm 2.2$ & 0.40 \\
Thickness & $2.6 \pm 1.7$ & $2.6 \pm 1.5$ & $2.6 \pm 2.1$ & 0.98 \\
Irregular & $2.5 \pm 1.5$ & $2.5 \pm 1.3$ & $2.6 \pm 1.9$ & 0.96 \\
Overall value & $2.5 \pm 1.7$ & $2.0 \pm 0.9$ & $3.1 \pm 2.4$ & 0.04 \\
\hline
\end{tabular}

${ }^{1}$ Statistical comparison between the MIPO and the conventional operation group; ${ }^{2} 11$ missings; 4 in the conventional group and 7 in the MIPO group. The observer scale was not included in this study 


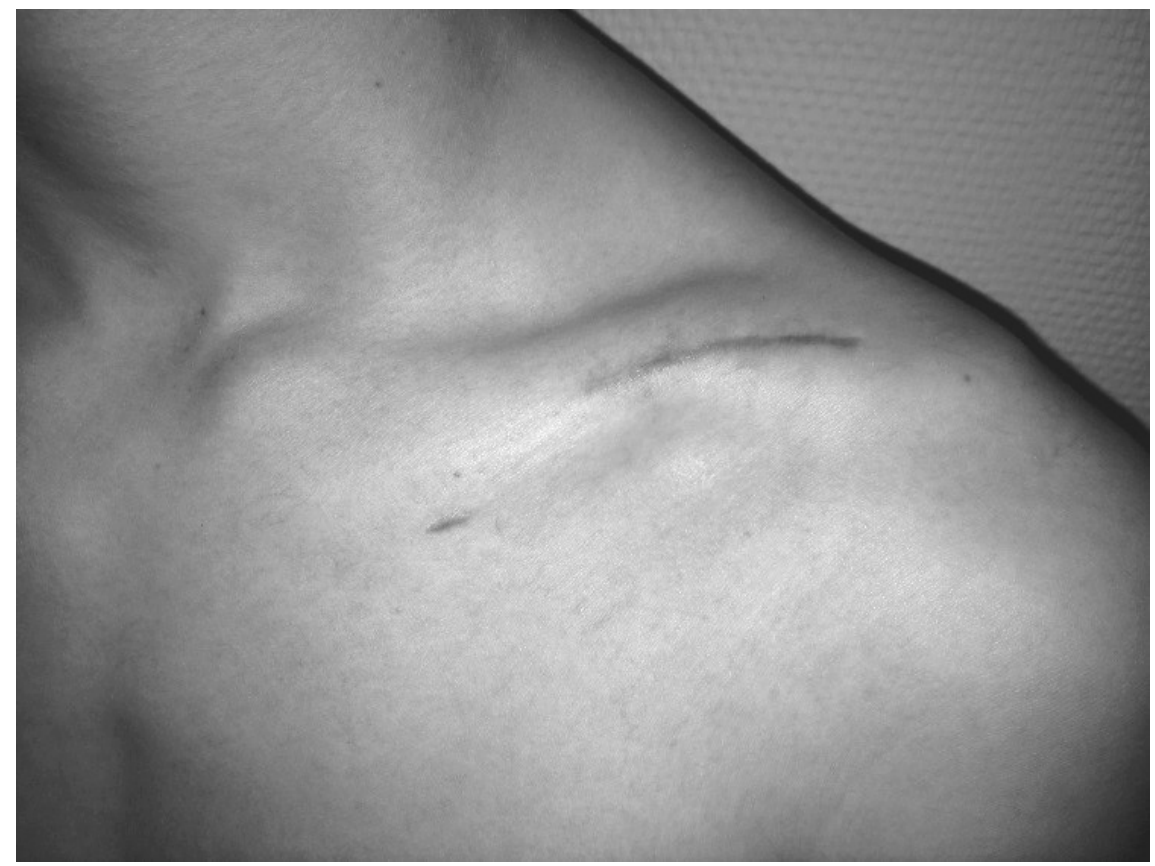

Figure 4. Postoperative scar.

\section{DISCUSSION}

The goal of surgical treatment is the anatomic reduction with reconstruction of clavicular length and alignment of the shoulder girdle. Although various operative treatments for clavicular midshaft fractures have been reported, the gold standard is open reduction and plate fixation. ${ }^{35,36}$ One major disadvantage is the large incision,which leads to soft tissue disruption. Plate osteosynthesis is associated with several complications, such as deep infection, non-union, implant failure, and re-fracture after implant removal.. ${ }^{17-19}$ Extensive periosteal stripping of the fracture site may partly cause these complications. The minimally invasive plate osteosynthesis (MIPO) technique was developed to enhance bone healing by preserving the periosteal blood supply of the fracture.Plate fixation with the MIPO technique can minimize soft tissue dissection, therefore promoting bony union, reducing soft tissue complications ${ }^{20-28}$, and leading to a smaller surgical scar compared with conventional open reduction and internal fixation. 29,30 With the enhancement of the concept minimally invasive and the development of locking 
technology, the minimally invasive plateosteosynthesis has been gradually applied in the treatment of clavicle fractures.Previous studies reported good clinical and radiological outcomes after MIPO with superior or anterior-inferior plating.Zang et al. ${ }^{26}$ demonstrated that the MIPO procedure for midshaft clavicular fractures, which uses superior anatomic locking plates, can be a reproducible and safe procedure. Sohn et al..$^{23}$ reported 15 cases of acute displaced midshaft clavicular fractures treated with MIPO using anterior-inferior plating. They found satisfactory clinical outcomes without serious complications after surgery. Overall, recent studies found that the minimal invasive technique is a safe, effective and practical procedure with a rapid recovery, high union rates, low complication rates, favourable cosmetic outcomes, and excellent functional results. These authors stated that it could be an alternative to the conventional operative methods..$^{20-28}$ Our results confirm these previous outcomes as we found good functional scores with union in all cases, and low complications rates. Only a few studies compare the effectiveness and safety of a conventional plating technique and a minimal invasive technique both using a clavicle plate. ${ }^{29,30}$ Our study showed good functional outcome scores and low complication rates comparing both treatment groups. However, the MIPO technique resulted in a better cosmetic appearance. One of the known advantages of MIPO is a less visible scar in comparison with the conventional plate fixation technique.The comparative study of Jiang et al. ${ }^{29}$ confirms this. They found that, although functional outcomes (Constant and DASH) were not different between the two groups, overall satisfaction was higher in the MIPO group; resulting in a lower rate of dysesthesia, hypertrophic scarring, and a better cosmetic than the conventional open reduction.

Also, a recent study of Sohn et al. ${ }^{30}$ stated that both open plating and MIPO are equally effective and safe treatment methods. Nevertheless, precaution should be taken during MIPO surgery using an anterior locking plate. Blunt dissection using a periosteal elevator from the lateral window to the medial window should be performed carefully because of the proximity of the neurovascular bundle that crosses the path of the blunt dissection. ${ }^{34}$ We always start medial. After that, most lateral screws can be fitted in the correct position. On the medial side it is important to ensure that the plate does not extend past the bone. This can be checked by hand. This position will result in irritation and could be an indication for osteosythesis removal after consolidation. We recognize that there are some limitations to this study. First of all, since the technique was only introduced in 2014 the follow-up period was relatively short and late complications (i.e. refracture after removal) or complaints (i.e. hardware irritation and subsequent removal) could not 
be evaluated sufficiently. However, functional outcome and most complications (i.e. infection, nonunion) occur within the follow-up period. Secondly, cosmetic appearance was not evaluated at the same moment in the follow-up period. However, it was done for all patients after 24 weeks. All scars are healed by then and do not change dramatically in appearance.

\section{CONCLUSION}

Minimal invasive anterior-inferior plating (MIPO) with the VA-LCP anterior clavicle plate appears to be a safe and effective method for treating clavicle fractures. Excellent short-term functional outcomes scores and low complication rates were seen in both the open plating and the MIPO treatment group. However, the MIPOtechnique resulted in a better overall cosmetic appearance. 


\section{REFERENCES}

1. Robinson CM. Fractures of the clavicle in the adult. Epidemiology and classification. J Bone Joint Surg Br 1998; 80(3): 476-84.

2. Nordquist A, Petersson C. The incidence of fractures of the clavicle. Clin Orthop Relat Res 1994; 300: 127-32.

3. Postacchini F, Gumina S, De Santis P, Albo F. Epidemiology of clavicle fractures. J Shoulder Elbow Surg. 2002;11(5):452-456.

4. Neer CS. Nonunion of the clavicle. J Am Med Assoc 1960; 172: 1006-1011.

5. Mckee RC, Whelan DB, Schemitsch EH, Mckee MD. Operative versus nonoperative care of displaced midshaft clavicular fractures: a meta-analysis of randomized clinical trials. J Bone Joint Surg Am. 2012;94:675-84.

6. Hill JM, McGuire MH, Crosby LA. Closed treatment of displaced middle-third fractures of the clavicle gives poor results. J Bone Joint Surg Br. 1997;79:537-9.

7. Matis N. Effects of clavicle shortening after clavicle fracture. Unfallchirurg. 1999;275:314-5.

8. Nowak J, Holgersson M, Larsson S. Can we predict long-term sequelae after fractures of the clavicle based on initial findings? A prospective study with nine to ten years follow-up. J Shoulder Elbow Surg. 2004;13:479-486.

9. Houwert RM, Wijdicks FJ, Steins Bisschop C, Verleisdonk EJ, Kruyt M. Plate fixation versus intramedullary fixation for displaced midshaft clavicle fractures: a systematic review. Int Orthop. 2012;36:579-85.

10. Chu CM, Wang SJ, Lin LC. Fixation of midthird clavicular fractures with knows pins: 78 patients followed for 2-7 years. Acta Orthop Scand. 2002 Apr;73(2):134-9.

11. Chuang TY, Ho WP, Hsieh PH, Lee PC, Chen $\mathrm{CH}$, Chen YJ. Closed reduction and internal fixation for acute midshaft clavicular fractures using cannulated screws.J Trauma. 2006 Jun;60(6):1315-20; discussion 1320-1.
12. Shen WJ, Liu TJ, Shen YS. Plate fixation of fresh displaced midshaft clavicle fractures. Injury. 1999 Sep;30(7):497-500.

13. Robinson CM, Court-Brown CM, McQueen MM, Wakefield AE. Estimating the risk of nonunion following nonoperative treatment of a clavicular fracture. J Bone Joint Surg Am 2004;86:1359-65.

14. SmekalV, Irenberger A, Struve P, Wambacher M, Krappinger D, Kralinger FS. Elastic stable intramedullary nailing versus nonoperative treatment of displaced midshaft clavicular fractures-a randomized, controlled, clinical trial. J Orthop Trauma. 2009;23:106-12

15. Olden GD,VA-LCP anterior clavicle plate: the anatomically precontoured fixation system with angular stability for clavicle shaft. Musculoskelet Surg. 2014 Dec;98(3):217-23.

16. van der Meijden OA, Houwert RM, Hulsmans M, Wijdicks FJ, Dijkgraaf MG, Meylaerts SA, et al. Operative treatment of dislocated midshaft clavicular fractures: plate or intramedullary nail fixation? A randomized controlled trial. J Bone Joint Surg Am. 2015 Apr 15;97(8):613-9. doi: 10.2106/JBJS.N.00449.

17. Bostman $\mathrm{O}$, Manninen $\mathrm{M}$, Pihlajamaki $\mathrm{H}$. Complications of plate fixation in fresh displaced midclavicular fractures. J Trauma. 1997;43:778-783.

18. Der Tavitian J, Davison JN, Dias JJ.Clavicular fracture non-union surgical outcome and complications. Injury. 2002 Mar;33(2):13543. Review.

19. Duncan SF, Sperling JW, Steinmann S. Infection after clavicle fractures. Clin Orthop Relat Res. 2005 Oct;439:74-8.

20. Jung G.H., Park C.M., Kim J.D: Biologic fixation through bridge plating for comminuted shaft fracture of the clavicle: technical aspects and prospective clinical experience with a minimum of 12-month follow-up. Clin Orthop Surg 2013; 5: pp. 327-333 
21. Lee H.J., Oh C.W., Oh J.K., Yoon J.P., Kim J.W., Na S.B., et al: Percutaneous plating for comminuted midshaft fractures of the clavicle: a surgical technique to aid the reduction with nail assistance. Injury 2013; 44: pp. 465-470

22. Sohn H.S., Kim B.Y., and Shin S.J.: A surgical technique for minimally invasive plate osteosynthesis of clavicular midshaft fractures. J Orthop Trauma 2013; 27: pp. e92-e96

23. Sohn H.S., Shin S.J., and Kim B.Y.: Minimally invasive plate osteosynthesis using anterior-inferior plating of clavicular midshaft fractures. Arch Orthop Trauma Surg 2011; 132: pp. 239-244

24. Tieyi $Y$, Minimal invasive plating for fresh displaced midshaft fractures of the clavicle. Orthopedics. 2014 Oct;37(10):679-83. doi: 10.3928/01477447-20140924-05.

25. Wang X, Wang Z, Xia S, Beigang F. Minimal invasive in the treatment of clavicle middle part fractures with locking reconstruction plate. Int J Surg. 2014;12(7):654-8. doi: 10.1016/j.ijsu.2014.05.001

26. Zhang $Y, X u$ J, Zhang $C$, Sun Y. Minimally invasive plate osteosynthesis for midshaft clavicular fractures using superior anatomic plating. J Shoulder Elbow Surg. 2016 Jan;25(1):e7-12. doi: 10.1016/j.jse.2015.06.024.

27. Al-Sadek TA, Niklev D, Al-Sadek A:Midshaft Clavicular Fractures - Osteosynthesis with Minimally Invasive Technique.Open Access Maced J Med Sci. 2016 Dec 15;4(4):6-649. doi: 10.3889/oamjms.2016.136.

28. Zhang T, Chen W, Sun J, Zhang Q, Zhang Y.Minimally invasive plate osteosynthesis technique for displaced midshaft clavicular fracture using the clavicle reductor.Int Orthop. 2017 Jan 12. doi: 10.1007/s00264016-3392-z

29. Jiang $H_{\text {., }}$ and Qu W.: Operative treatment of clavicle midshaft fractures using a locking compression plate: comparison between mini-invasive plate osteosynthesis (MIPPO) technique and conventional open reduction. Orthop Traumatol Surg Res 2012; 98: pp. 666-671

30. Sohn HS, Kim WJ, Shon MS. Comparison between open plating versus minimally invasive plate osteosynthesis for acute displaced clavicular shaft fractures. Injury. 2015 Aug;46(8):1577-84. doi: 10.1016/j. injury.2015.05.038. Epub 2015 May 22.PMID: 26077663

31. Hudak PL, Amadio PC, Bombardier C: Development of an upper extremity outcome measure: the DASH (disabilities of the arm, shoulder and hand) corrected. The Upper Extremity Collaborative Group (UECG). Am J Ind Med 1996, 29:602-608.

32. Constant $\mathrm{CR}$, Murley $\mathrm{AH}$. A clinical method of functional assessment of the shoulder. Clinical orthopaedics and related research. 1987 Jan;(214):160-164

33. Van de Kar AL, Corion LU, Smeulders MJ, Draaijers $L$, van der Horst CM, van Zuijlen PP. Reliable and feasible evaluation of linear scars by the Patient and Observer Scar Assessment Scale. Plast Reconstr Surg. 2005;116:514-522

34. Van Olden GDJ. Mini-invasive plate osteosynthesis (MIPO) using VA-LCP anteriorclavicle plate. https://www. youtube.com/watch?v=oeF4IcL6Teo. Retrieved January, 2017

35. Zlowodzki M, Zelle BA, Cole PA, JerayK, McKee MD; Evidence-Based Orthopaedic Trauma Working Group. Treatment of acute midshaft fractures: systemic review of 2144 fractures. J Orthop Trauma. 2005; 19:504-507.

36. Canadian Orthopaedic Trauma Society. Nonoperative treatment compared with plate fixation of displaced midshaft clavicular fractures. A multicentre, randomized clinical trial. J Bone Joint Surg Am. 2007 Jan;89(1):1-10.

37. Sinha A, Edwin J, Sreeharsha B, Bhalaik V, Brownson P. A radiological study to define safe zones for drilling during plating of clavicle fractures. J Bone Joint Surg Br. 2011;93:1247-52. 
38. Taylor PR, Day RE, Nicholls RL, Rasmussen J, Yates PJ, Stoffel KK. The comminuted midshaft clavicle fracture: a biomechanical evaluation of plating methods. Clin Biomech (Bristol, Avon). 2011; 26:491-6.

39. Celestre P, Roberston C, Mahar A, Oka R, Meunier M, Schwartz A. Biomechanical evaluation of clavicle fracture plating techniques: does a locking plate provide improved stability? J Orthop Trauma. 2008;22:241-247.

40. Robertson C, Celestre P, Mahar A, Schwartz A. Reconstruction plates for stabilization of mid-shaft clavicle fractures: differences between nonlocked and locked plates in two different positions. J Shoulder Elbow Surg. 2009 Mar-Apr;18(2):204-9. doi: 10.1016/j.jse.2008.10.002. Epub 2008 Dec 25.
41. Haidukewych GJ. Innovations in locking plate technology. J Am Acad Orthop Surg 2004;12:205-12.

42. Perren SM. Evolution and rationale of locked internal fixator technology. Introductory remarks. Injury 2001;32(Suppl.2):B3—9. 


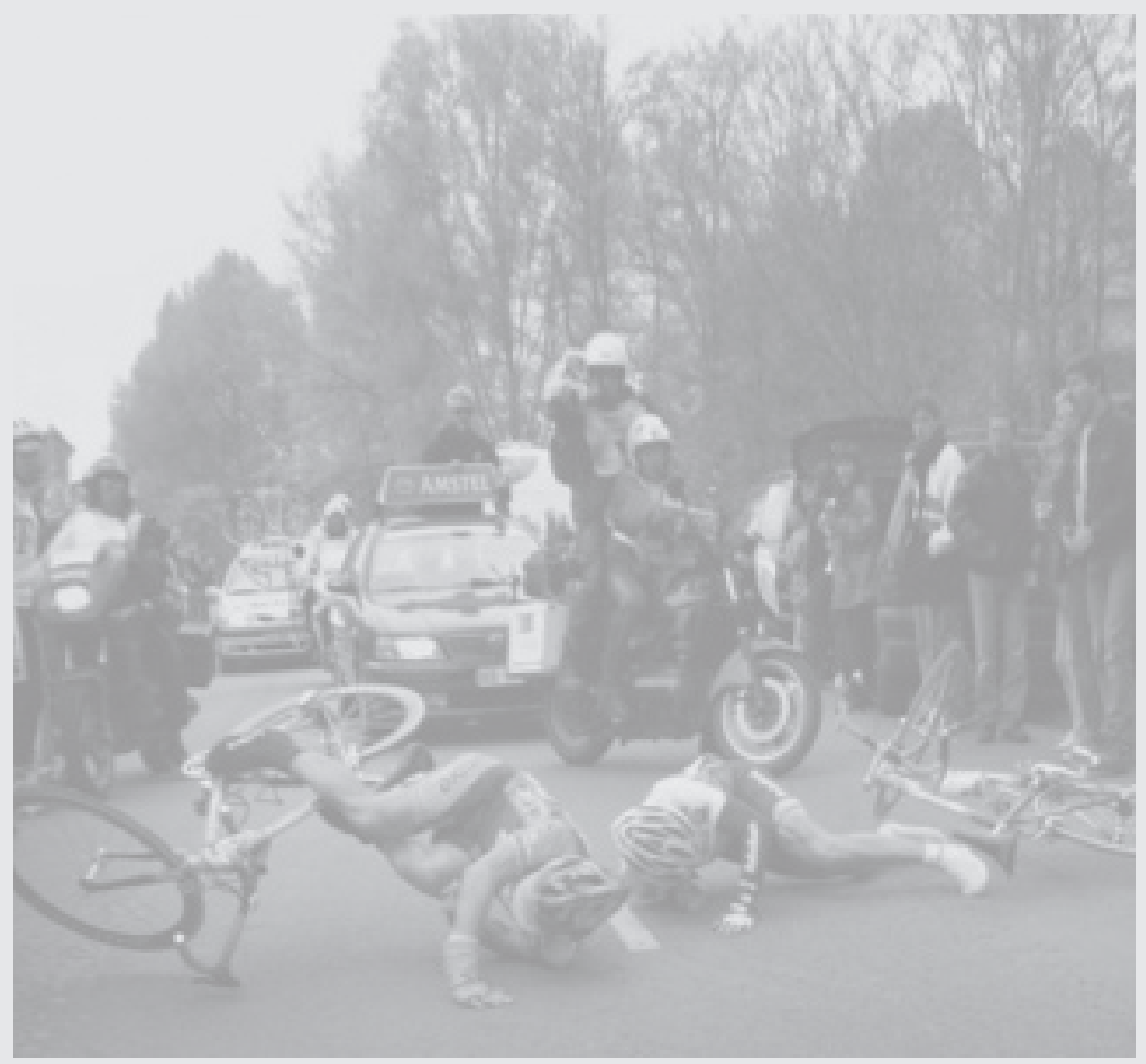




\section{CHAPTER EIGHT}

\section{Displaced clavicle fractures in cyclists: return to athletic activity after anteroinferior plate fixation}




\section{ABSTRACT}

\section{Background}

One of the most commonly observed injuries in cycling is fracture of the clavicle. Nevertheless, there is limited literature available on clinical outcomes after plate fixation of clavicle fractures in cyclists, rehabilitation protocols and the time to return to sports. Purpose: The aim of this study was to evaluate the functional outcome, complications, return to athletic activity at short-term follow-up after surgical repair.

\section{Study Design}

Case Series

\section{Methods}

Between January 2008 and October 2014, all professional and recreational cyclists presenting with a new clavicle fracture at the emergency department, were prospectively recorded. All patients had an anteroinferior plate fixation; VA-LCP (DePuySynthes). Patients were seen at 2, 6, and 24 weeks at the outpatient clinic to gather DASH and Constant shoulder questionnaires and radiographs were made. Cyclists were allowed to resume outside training one week after surgery.

\section{Results}

10 professional cyclists and 15 recreational cyclists were included. All (25/25) patients returned to cycling after plate fixation. Mean Constant Scores and mean DASH scores of $96.8 \pm 4.1$ and $5.1 \pm 5.5$ at six weeks and $99.1 \pm 1.5$ and $2.9 \pm 4.6$ at 24 weeks were measured. There were 3 complications; One patient developed a nonunion, there was one wound infection requiring antibiotics, and in one patient a re-fracture occurred.

\section{Conclusion}

Plate fixation for cyclists with displaced clavicle fractures was successful in terms of fast return to previous level of athletic activity. It is a valuable and safe option for athletes in cycling. 


\section{INTRODUCTION}

Clavicle fractures are mostly due to sports activities (45.3\%). Sports-related fractures most commonly result from bicycling (16\%), followed by football (12\%), and soccer (6\%). 6,22 The vast majority (80\%) of these fractures are located in the midshaft of the clavicle. ${ }^{14,16,19}$ Presently, there is no consensus in the optimal treatment of clavicle fractures. Surgical repair appears to deliver superior shortterm outcome ${ }^{11}$; nevertheless, there is little evidence at present to show that the long-term functional outcome of operative intervention is also better. ${ }^{18}$ The current indication for surgical treatment is displacement with clavicle shortening exceeding $20 \mathrm{~mm}$ because this is associated with potential shoulder dysfunction.,7 Several complications are described after plate fixation such as deep infection, nonunion, implant failure, and re-fracture after implant removal2,4 The most common complications after conservative treatment are mal-union and non-union. ${ }^{13,20}$ Midshaft clavicle fractures are caused by a direct axial compressive force to the shoulder after a sudden stop or fall. This makes athletes, particularly cyclists, prone to this injury. ${ }^{21}$ The risk of recurrent shoulder contact during the recovery after a clavicle fracture causes difficulties to return to athletic activity. For professional cyclists, a long recuperation is likely to result in considerable training delay and consequently delay in future competition. The treatment in athletes should be aimed at rapid restoration of function of the upper extremity; therefore, operative fixation is preferred, but objective information on clinical outcomes after operative treatment of clavicle fractures in athletes, rehabilitation protocols, and time to return to athletic activity is hard to find. 12,17,23 The aim of this study was to evaluate the functional outcome, complications, return to athletic activity (i.e. cycling) after plate fixation. Our hypothesis is that that an early return to cycling is achievable with surgical fixation and an adequate rehabilitation protocol.

\section{PATIENTS AND METHOD}

Between January 2008 and October 2014, all professional and recreational cyclists presenting with a new clavicle fracture at the emergency department, were prospectively recorded. Standard 2-view trauma radiograph series of the clavicle at our institution include anterior-posterior (AP) radiograph examination and clavicle radiographs with a $\left(15^{\circ}-45^{\circ}\right)$ horizontal angle (Figure 1$)$. The study was approved by the local medical ethics committee, reference number W15.052 


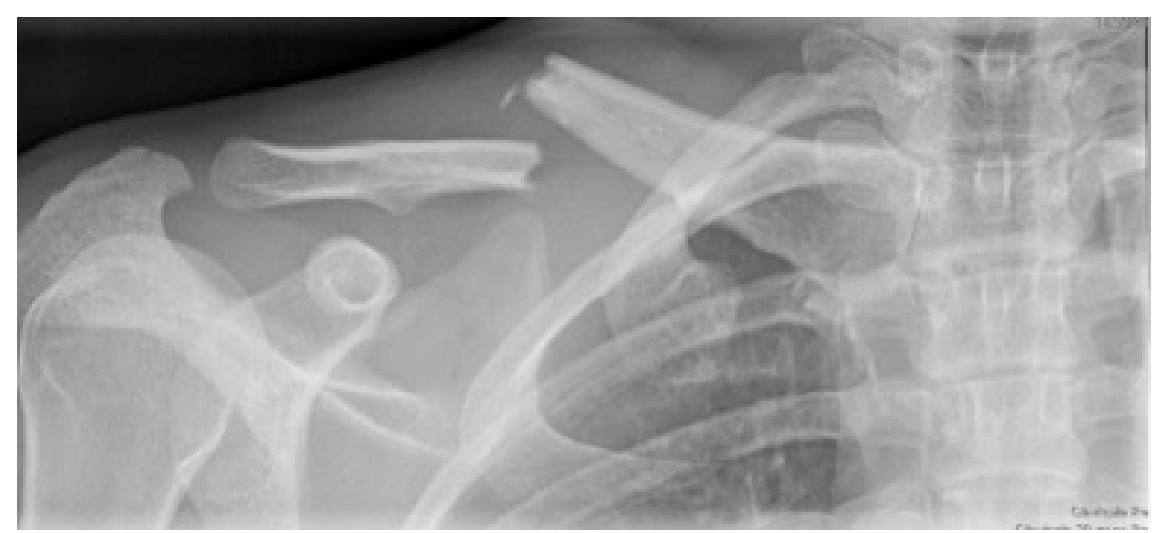

Figure 1. Radiograph after trauma.

\section{Patient selection and endpoints}

Inclusion criteria were: 1) a completely displaced fracture of the clavicle with no cortical contact between the proximal and distal fragment; 2) a fracture in the medial, midshaft, or lateral third of the clavicle; 3) cyclists; patient sport level was divided into competitive sport (i.e. professional cyclists); regular sport with competition and practice $>2$ times per week and noncompetitive sports (i.e. recreational cyclists); regular sport without competition <2 times per week; and 4) functional indication: in all cases there was an intention to rapid return to athletic activity (i.e. cycling) postoperatively.

Exclusion criteria were: 1) open fracture; 2) a significant ipsilateral upper extremity fracture; and 3) plate fixation of non-unions after initial conservative treatment. The primary outcome parameters were: return to athletic activity (i.e. cycling), fracture union, and functional outcome measured using the "Disability of the Arm, Shoulder and Hand" (DASH) questionnaire ${ }^{8}$ and the Constant shoulder questionnaire ${ }^{3}$. Secondary outcome parameter was: complications.

\section{Intervention}

Surgery was performed within three weeks after injury. All patients were operated with the same technique by the same surgeon. A Variable Angle Locking compression plate (VA-LCP) anterior plate (DePuySynthes) was placed according to standard orthopaedic procedures. The fracture was rigidly fixated on the anteroinferior aspect of the clavicle. Plates with different number of holes (varying form 7-11 holes) and different amount of screws were used; with placement of at least four bi-cortical screws on the lateral side of the fracture and three screws on the medial side to reduce the possibility of re-fracture after new trauma (Figure 2). ${ }^{15}$. 


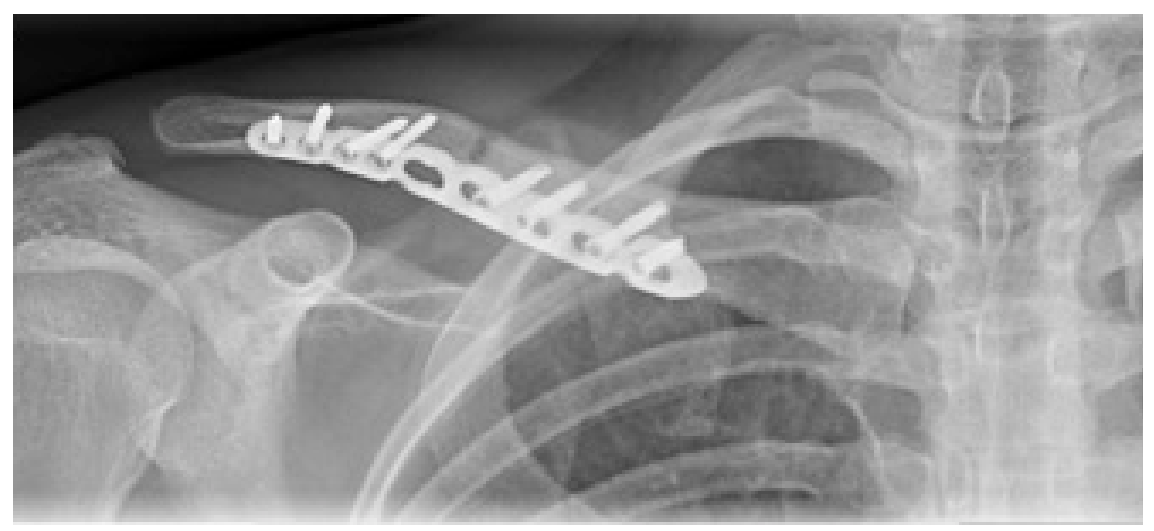

Figure 2. Postoperative radiograph

\section{Postoperative rehabilitation protocol}

The postoperative exercise protocol consists of wearing a sling for a maximum of one week. Hereafter, the patient was seen in the outpatient clinic department and physical therapy (rhomboideus training) was prescribed. Rhomboideus training consisted of physiotherapy focusing mainly on retraction and mediorotation of the angulus inferior of both scapulae within individual arthrogenic limits. Herewith, the musculus rhomboideii and the musculus serratus posterior are trained. In order to prevent a scapula alata, training needs to focus on the musculus serratus anterior. On the second postoperative day exercises on the home trainer started for professional cyclists. They were allowed to resume outside training the following week. At two weeks after surgery patients were allowed to extend the physical strain and full range of active motion was permitted. This requires mobility of the surrounding joint and shoulder girdle: the sternoclavicular (SC) joint the acromioclavicular (AC) joint, first and second rib, glenohumeral joint, and cervical and cervical thoracic junction. After consolidation of the fracture these joints needed to be mobilised or manipulated. Cyclists were allowed to return to competition at three weeks after surgery.

\section{Follow-up}

Patients were seen at 2, 6, and 24 weeks at the outpatient clinic department, on all occasions the study endpoints were investigated; the DASH and Constant shoulder questionnaires were completed and radiographs were made. Fracture consolidation was evaluated through clinical examination with pain and/or motion at the fracture site and through standardized radiological analysis (an anteriorposterior [AP] view and a radiograph with a $\left(15^{\circ}-45^{\circ}\right)$ horizontal angle), Figure 3 . 


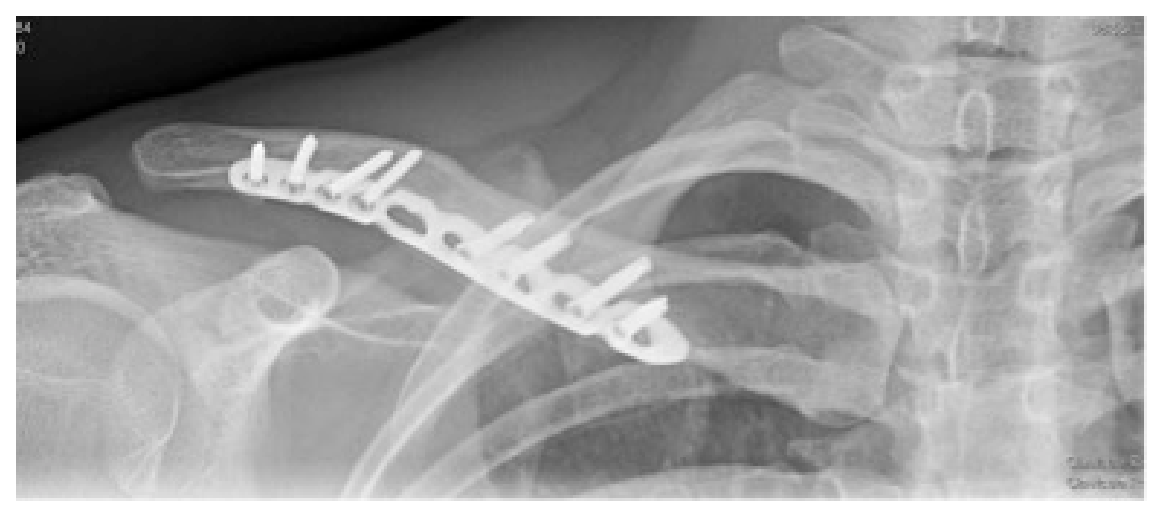

Figure 3. Radiograph after 24 weeks: consolidation

\section{Functional outcome}

The Disabilities of Arm, Shoulder and Hand (DASH) Outcome Measure is a validated 30-item, self- report questionnaire. The DASH Outcome Measure consists of two components: the disability/symptom section (30 items) and the optional high performance Sport/Music module (4 items). ${ }^{8}$ The Constant-Murley- score is a validated 14-items questionnaire with a total score of 0-100 and consist of a subjective and objective component. The questionnaire records individual parameters and provides an overall clinical functional assessment. ${ }^{3]}$

\section{Complications}

Complications were considered to exist when wound infection required antibiotics, when re-intervention was performed for infection, re-fracture (i.e. a recurrent fracture of the same clavicle after plate removal), hardware failure (i.e. plate loosing or plate breakage), or non-union. Non-union was defined as the absence of radiographic union six months or longer after the injury. When patients suffered from plate irritation requiring subsequent removal of the implant material, this was not considered a complication. However we did not recommend the cyclist to remove the plate, as athletes are considered a high risk for a new trauma.

\section{Statistical analysis}

Statistical analysis was performed using SPSS 15.0, Chicago, for Microsoft Windows. Continuous variables were reported as mean \pm SD or median $\left(25^{\text {th }}\right.$ and $75^{\text {th }}$ inter quartile ranges) and categorical variables as number and percentages, unless otherwise stated. We preformed a retrospective analysis of prospectively collected data. 


\section{RESULTS}

The study cohort included a total of 25 patients: 10 professional cyclists and 15

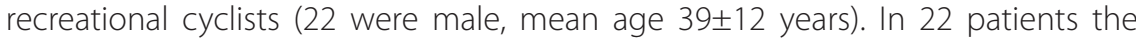
fracture occurred in the mid-third of the clavicle. Further demographic data are shown in Table 1.

Table 1. Baseline characteristics of the case series ( $n=$ patients) subdivided in a competitive and recreational group.

\begin{tabular}{lccc}
\hline $\mathbf{1}$ & $\begin{array}{c}\mathbf{0} \text { (verall } \\
\mathbf{n = 2 5}\end{array}$ & $\begin{array}{c}\text { Competitive } \\
\mathbf{n = 1 0}\end{array}$ & $\begin{array}{c}\text { Recreational } \\
\mathbf{n = 1 5}\end{array}$ \\
\hline Age & $39 \pm 12$ & $32 \pm 11$ & $45 \pm 11$ \\
Male gender & 22 & 8 & 14 \\
Dominant arm & 15 & 6 & 9 \\
Smoker & 0 & 0 & 0 \\
Fracture location & 22 & 8 & 14 \\
Midshaft & 3 & 2 & 1 \\
Lateral & & & \\
Mechanisms of injury & 21 & 10 & 11 \\
Cycling & 4 & 0 & 4 \\
Mountain bike & & & \\
\hline
\end{tabular}

${ }^{1}$ Mean \pm SD values; ${ }^{2}$ Four missing in the recreational group.

The clinical evaluation gave a mean Constant Score and a mean DASH score of $96.8 \pm 4.1$ and $5.1 \pm 5.5$ at six weeks and $99.1 \pm 1.5$ and $2.9 \pm 4.6$ at 24 weeks (Table 2A). All patients returned to athletic activity(i.e. cycling) after fixation of their fracture. The mean time to return to full athletic activity was 10 days in the professional cyclists with return to competition after 3 weeks (Table 2B). In recreational cyclist an average return to athletic level was seen after 2- 6 weeks postoperative.

A complication was seen in three patients. One patient developed a non-union, there was one wound infection requiring antibiotics, and in one patient a refracture occurred. There was no hardware failure requiring re-surgery seen during the postoperative period (Table 2C). 
Table 2A. ${ }^{1}$ DASH and constant score at 6 en 24 weeks.

\begin{tabular}{|c|c|c|c|}
\hline & $\begin{array}{c}\text { Overall } \\
n=25\end{array}$ & $\begin{array}{c}\text { Competitive } \\
n=10\end{array}$ & $\begin{array}{c}\text { Recreational } \\
n=15\end{array}$ \\
\hline Constant score 6 weeks² & $96.8 \pm 4.1$ & $97.9 \pm 4.0$ & $96.3 \pm 4.2$ \\
\hline Constant score 24 week $^{3}$ & $99.1 \pm 1.5$ & $99.4 \pm 1.3$ & $98.9 \pm 1.5$ \\
\hline DASH score 6 weeks ${ }^{2}$ & $5.1 \pm 5.5$ & $3.0 \pm 3.4$ & $6.5 \pm 6.3$ \\
\hline DASH score 24 weeks ${ }^{3}$ & $2.9 \pm 4.6$ & $1.1 \pm 2.2$ & $4.0 \pm 5.5$ \\
\hline
\end{tabular}

${ }^{1}$ Mean \pm SD values; ${ }^{2}$ after 6 weeks four Constant score missing and five DASH score missing

${ }^{3}$ after 24 weeks two Constant score and DASH score missing

Table 2B. Return to athletic activity: cycling.

\begin{tabular}{lccc}
\hline & $\begin{array}{c}\text { 0verall } \\
\mathbf{n = 2 5}\end{array}$ & $\begin{array}{c}\text { Competitive } \\
\mathbf{n = 1 0}\end{array}$ & $\begin{array}{c}\text { Recreational } \\
\mathbf{n = 1 5}\end{array}$ \\
\hline Return to athletic activity & & & \\
Competitive (days) & 10 & & \\
Recreational (weeks) & $2-6$ & & \\
\hline
\end{tabular}

Table 2C. Overall complications.

\begin{tabular}{lccc}
\hline & $\begin{array}{c}\text { Overall } \\
\mathbf{n = 2 5}\end{array}$ & $\begin{array}{c}\text { Competitive } \\
\mathbf{n = 1 0}\end{array}$ & $\begin{array}{c}\text { Recreational } \\
\mathbf{n = 1 5}\end{array}$ \\
\hline Overall complications & 3 & 1 & 2 \\
Nonunion & 1 & 0 & 1 \\
Hardware failure requiring removal & 0 & 0 & 0 \\
Re-fracture & 1 & 0 & 1 \\
Wound infection & 1 & 1 & 0 \\
Hardware irritation requiring removal & 4 & 0 & 4 \\
\hline
\end{tabular}

\section{DISCUSSION}

We found that after plate fixation of displaced midshaft clavicle fracture an early return to cycling is possible with an adequate rehabilitation protocol. This confirms out hypothesis.

For high performance and professional athletes, a quick consolidation of the fracture is of major importance. Return to athletic activity after conservative treatment is limited by time to union, shoulder range of motion, and strength; therefore, their training is delayed and competitions are missed because of the time required for the fracture to heal. In case of surgical treatment, the arm can be lifted above the horizon immediately after surgery and may be used in activities of daily living because of quick pain relief. This gives physically active patients, as a result of fracture stabilisation, the benefit of early return to training and competition. Although clinical advantages within the first 6 weeks of plate fixation compared 
with conservative treatment were published before ${ }^{11}$, there is a lack of evidence in professional athletes. Only a few studies evaluate return to athletic activity after clavicle fracture, in which good functional outcomes were seen and all athletes returned to their previous athletic activity. ${ }^{12,17}$ This is similar to our results, as all of our study-patients (25/25) resumed athletic activity. These findings are of major importance because it affects a young and active patient population, making early union and return to function a priority in their treatment. However, previous studies had some limitations. Their study population was not homogenous but consist of a various number of athletic disciplines and included different plate fixation techniques. Also, variable postoperative rehabilitation protocols were used resulting in a wide range of return to athletic activities.

In a retrospective case series of 30 patients by Meisterling et al. ${ }^{12}$, patients returned to sport after operative treatment with a mean time 83 days (range 13-277). Patients began rehabilitation immediately after surgery, however, return to sports was only permitted after fracture union had occurred, full shoulder range of motion had been achieved, and strength was near $100 \%$. This time-interval to return to athletic activity was also seen in a recent study of Rossi et al. (mean of 68 days; range 5-180 days)..$^{17}$ In this group, full range of motion and functional training was prohibited for 8 weeks after surgery. Nevertheless, in both studies patients who did not follow the protocol and returned to athletic activity earlier (within 6 weeks) then the protocol prohibited. These patients did not show more complications. ${ }^{12,17}$ The authors did not anticipate on these results allowing the patients to resume athletic activity earlier. Rehabilitation protocol were maintained nonetheless as they do not believe to have sufficient evidence to allow early return to athletic activities. ${ }^{17}$

All professional cyclists in our study started on the home trainer on the second day after surgery and resumed their training programs within one week. These cyclists resumed athletic activity two weeks postoperatively and returned to competition after three weeks due to an early postoperative rehabilitation protocol and guidance. Confidence and comfort about the clavicle is an important factor in returning to athletic activity. Therefore, resuming training and cycling is a significant part of the postoperative rehabilitation protocol. For example, a cyclist of the Dutch professional cycling team fell three weeks before the Olympics and sustained a midshaft clavicle fracture. She was operated and could eventually participate in the Olympics where she played an essential part in the team's effort to win a Gold Medal These results are consistent with the study of Jubel et al. ${ }^{10}$ in which surgical treatment for mid-third clavicle fractures in 12 top-performance athletes was evaluated. They resumed training an average of 5.9 days after surgery and returned to competition at an average of 16.8 days. However, they evaluated 
intramedullary fixation only. Two of the most common surgical fixation methods include plates and screws, and intramedullary stabilisation. Although a recent review showed no difference in functional outcome after plate fixation or intramedullary fixation [9], short-term results favor plate fixation. ${ }^{24}$ Also, high rates of implantedrelated pain, implant removal, and implant migration after intramedullary fixation are described'. Therefore, plate fixation is the preferred treatment in this hospital. Verborgt et al. ${ }^{23}$ evaluated 39 semi-professional athletes after plate fixation with an average return to athletic activity of 45 days, union in $90 \%$ after 12 weeks and a good functional outcome. These findings are similar to our results in the subgroup analysis of recreational athletes with an average return to athletic activity of 6 weeks and good functional outcome scores; Constant score $96.3 \pm 4.2$ versus 88 points (Verborgt cohort). Verborgt et al. stated, therefore, that rigid plate fixation of middle-third clavicle fractures gives good results in the semi-professional athlete; however, at the expense of a significant risk for complications. Complications reported in their study were: 18\% wound infections, 5\% re-fractures, and $75 \%$ transient neurological complications. This is in contrast with the results of our study, in which a overall complication rate (3/25 patients) with a low re-fracture rate (1 patient) was seen. The most import risk after removal of the plate is refracture following recurrent trauma. The plate is, therefore, not removed before one year and most preferable, in athletes or patients with high risk of recurrent trauma, not removed at all; Namely, in this patient population high force and tension is being subjected to the clavicle, due to extensive training and high risk of recurrent trauma after return to training and competition.

We recognize that there are limitations. This study included lateral fractures as well, making the group less homogeneous to compare. However, these lateral fractures occurred in the most proximal 1/3 part and were operated with the same technique using a VA-LCP anterior locking compression plate. Secondly, because we choose a specific patient group for this study, only 25 patients were included.

\section{CONCLUSION}

Plate fixation for professional and recreational cyclists with displaced clavicle fractures was successful in terms of return to previous level of athletic activity, and having excellent clinical results. Our study demonstrated that plate fixation followed by an early postoperative rehabilitation protocol allows professional cyclists to resume athletic activity after two weeks and return to competition after three weeks. This gives high performance cyclists the benefit of early return to training and competition. It is a valuable and safe option for surgeons treating athletes.- 


\section{REFERENCES}

1. Andrade-Silva FB, Kojima KE, Joeris A, et al. J Bone Joint Surg Am. 2015 Apr 15;97(8):6206. doi: 10.2106/JBJS.N.00497.

2. Bostman $\mathrm{O}$, Manninen $\mathrm{M}$, Pihlajamaki $\mathrm{H}$. Complications of plate fixation in fresh displaced midclavicular fractures. J Trauma. 1997;43:778-783.

3. Constant C, Murley A. A clinical method of functional assessment of the shoulder. Clin Orthop 1987;214:160-4.

4. Duncan SF, Sperling JW, Steinmann S. Infection after clavicle fractures. Clin Orthop Relat Res. 2005 Oct;439:74-8.

5. Eskola A, Vainionpaa S, Myllynen P, et al. Outcome of clavicular fracture in 89 patients. Arch Orthop Trauma Surg 1986, 105:337-338.

6. Goldberg AS, Moroz L, Smith A, et al. Injury surveillance in young athletes: a clinician's guide to sports injury literature. Sports Med. 2007;37:265-278

7. Hill JM, McGuire MH, Crosby LA: Closed treatment of displaced middle- third fractures of the clavicle gives poor results. J Bone Joint Surg Br 1997, 79:537-539.

8. Hudak P, Amadio PC, Bombardier C, and the Upper Extremity Collaborative Group. Development of an Upper Extremity Outcome Measure: The DASH (Disabilities of the Arm, Shoulder, and Hand). American Journal of Industrial Medicine 1996; 29:602608.

9. Houwert RM, Wijdicks FJ, Steins Bisschop $C$, et al. Plate fixation versus intramedullary fixation for displaced mid-shaft clavicle fractures: a systematic review. Int Orthop. 2012;36:579-85.

10. Jubel A, Andemahr J, Bergmann $\mathrm{H}$, et al. Elastic stable intramedullary nailing of midclavicular fractures in athletes. $\mathrm{Br} J$ Sports Med. 2003;37(6):480-483.

11. McKee RC, Whelan DB, Schemitsch EH, et al. Operative versus nonoperative care of displaced midshaft clavicular fractures: A meta-analysis of randomized clinical trials.J Bone Joint Surg Am. 2012;94:675-684.

12. Meisterling SW, Cain EL, Fleisig GS, et al. Return to athletic activity after plate fixation of displaced midshaft clavicle fractures. Am J Sports Med. 2013 Nov;41(11):2632-6. doi: 10.1177/0363546513501494. Epub 2013 Aug 27.

13. Neer CS. Nonunion of the clavicle. J Am Med Assoc 1960; 172: 1006-1011.

14. Nordqvist A, Petersson C. The incidence of fractures of the clavicle. Clin Orthop Relat Res 1994; 300: 127-32.

15. Olden GD,VA-LCP anterior clavicle plate: the anatomically precontoured fixation system with angular stability for clavicle shaft. Musculoskelet Surg. 2014 Dec;98(3):217-23.

16. Postacchini F, Gumina S, De Santis P, et al. Epidemiology of clavicle fractures. J Shoulder Elbow Surg. 2002 SepOct;11(5):452-6.

17. Ranalletta M, Rossi LA, Piuzzi NS, et al. Return to sports after plate fixation of displaced midshaft clavicular fractures in athletes. Am J Sports Med. 2015 Mar;43(3):565-9. doi: 10.1177/0363546514559913. Epub 2014 Dec 9.PMID:25492034.

18. Rehn $\mathrm{CH}$, Kirkegaard $\mathrm{M}$, Viberg $\mathrm{B}$, et al. Operative versus nonoperative treatment of displaced midshaft clavicle fractures in adults: a systematic review Eur J Orthop Surg Traumatol. 2013 Dec 10.

19. Robinson CM. Fractures of the clavicle in the adult. Epidemiology and classification. J Bone Joint Surg Br 1998; 80(3): 476-84.

20. Rowe CR. An atlas of anatomy and treatment of midclavicular fractures. Clin Orthop Relat Res. 1968;58: 29-42.

21. Stanley D, Trowbridge EA, Norris SH. The mechanism of clavicle fracture: a clinical and biomechanical analysis. J Bone Joint Surg Br. 1988;70:461-464. 
Part 3 - Treatment

22. Van Tassel D, Owens BD, Pointer $L$, et al. Incidence of clavicle fractures in sports: analysis of the NEISS Database.Int J Sports Med. 2014 Jan;35(1):83-6. doi: 10.1055/s0033-1345127. Epub 2013 Jun 14.

23. Verborgt $\mathrm{O}$, Pittoors K, Van Glabbeek F, et al. Plate fixation of middle-third fractures of the clavicle in the -professional athlete. Acta Orthop Belg. 2005;71:17-21.
24. Wijdicks FJ, Houwert $M$, Dijkgraaf $M$, et al. Complications after plate fixation and elastic stable intramedullary nailing of dislocated midshaft clavicle fractures: a retrospective comparison. Int Orthop. 2012 Oct;36(10):2139-45. doi: 10.1007/s00264012-1615-5. Epub 2012 Jul 31. 



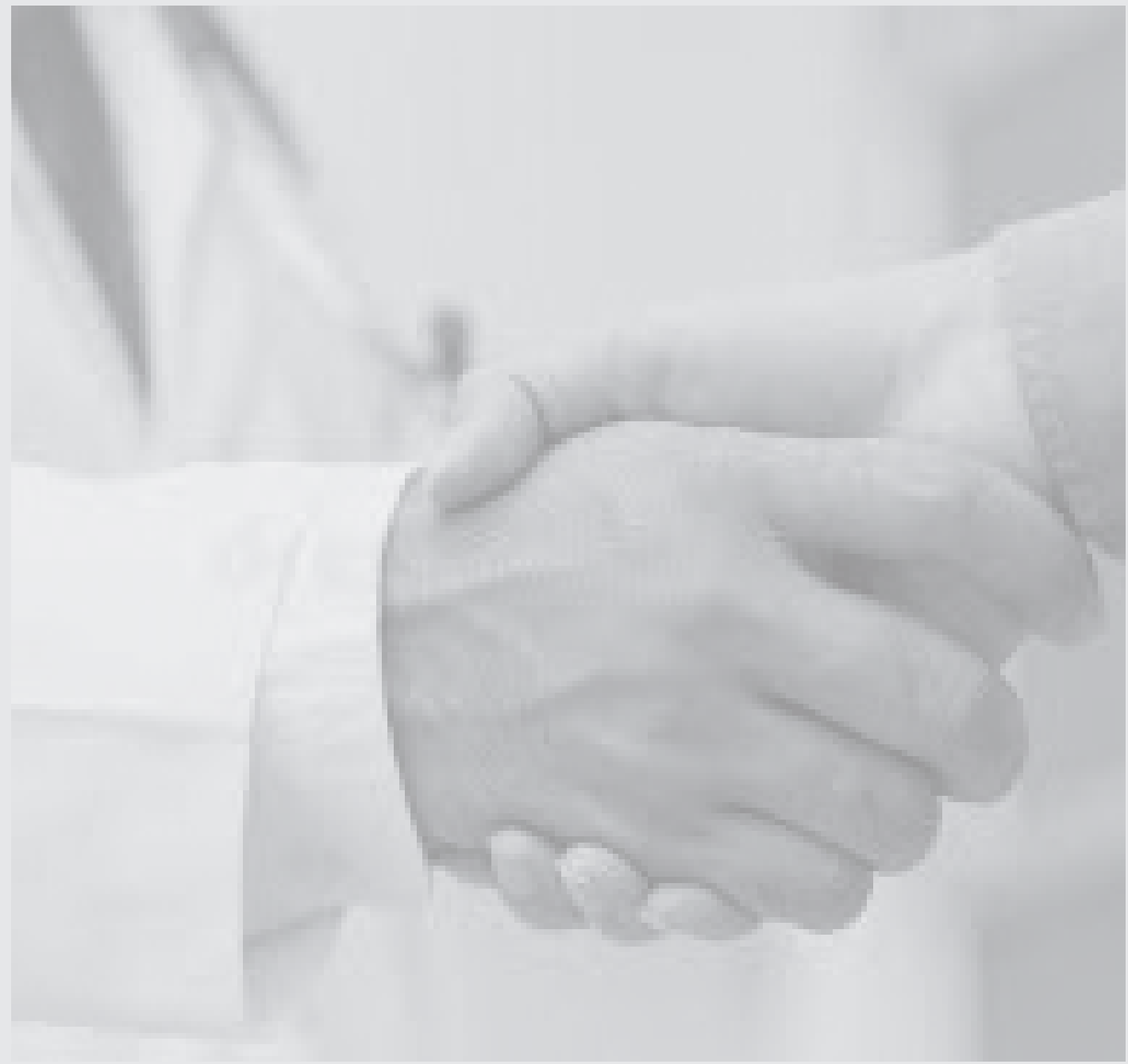




\section{CHAPTER NINE}

General discussion and future perspectives 


\section{General summary}

Throughout history different theories are conducted in the search for the optimal treatment of midshaft clavicle fractures. Clavicle fracture healing includes a complex interaction of biological, biomechanical and clinical aspects. In an attempt to capture fracture characteristics and use these as the fundamental basis for therapy, radiological examination has an important diagnostic and "therapeutic" value. In the search for the optimal treatment strategy, different aspects of clavicle management are evaluated. These concepts are needed to make a next step in clavicle fracture management with a renewed treatment strategy.

The most important impasses in current literature are the indications for operative fixation, optimal plate location and the differences in outcome in studies on fracture healing and complications rates (i.e. nonunion, delayed union, malunion, implant related irritation and infection). These differences in study results come from the fact that observational and comparative studies do not use uniform definitions. In Chapter two, we give an overview of currently used definitions in clavicle fracture management. We differentiate between the most discussed aspects; operation indication criteria, fracture healing disorders, implant related irritation and infection. The first line and quote of Voltaire of this chapter, captures the essence of it all: "If you want to converse with me, first define your terms." This systematic review showed that there exist a wide variety of definitions for disorders of clavicle fracture healing, adverse events or functional outcome. With this review, we want to step away from fixating on rates and outcomes that cannot be compared. As a consequence, influencing the timing of possible (secondary) interventions.

For a better understanding of the current deficits, you have to go back to the basics. That laid the ground works for Chapter three where we developed a musculoskeletal model. Anatomically the clavicle acts as a strut to enable motion of the arm and, is subjected to both tensile and compressive loads. It deflects with torsion or twisting because of the three-dimensional s-shaped structure'; therefore, the clavicle rotates in 3 planes: elevation-depression, protraction-retraction, and axial rotation of the clavicle. This makes the clavicle bone and the forces acting on it a complex interplay of factors.

When a clavicle fractures, indirect bone healing is initiated. This includes the formation of callus, which is generally enhanced by motion and inhibited by rigid fixation. With operative fixation you remove the fracture hematoma and direct fracture healing occurs. Direct fracture healing occurs only when there 
is anatomic reduction of the fracture fragments by rigid internal fixation and decreased intrafragmentary strains. Any deficit expressed at any point of the healing cycle alters the physiological sequence of fracture healing and predisposes to complications. An existing musculoskeletal model, the Delft Shoulder and Elbow Model, was used to calculate all forces on the clavicle during rehabilitation. A clavicle finite element model with a midshaft fracture was made and all muscles, ligaments, and gravitational forces were added to the finite element model.This model was firstly used to give more insight in the forces acting on the clavicle during rehabilitation. Secondly, extrapolating these data into the clinical practice and towards optimal plate positioning. We found that the simulated Von Mises stress of the bone stays below the yield strength of cortical bone. The von Mises stress is higher for anteroinferior plate fixation. The displacement and the strain are similar for anteroinferior and superior plate fixation. This indicates that both plates provide stable fixation.

As mentioned above, one of the concerns in clavicle management are the operation indication criteria. They include complete displacement and clavicle shortening exceeding $20 \mathrm{~mm}$. These are a result of the imbalance of muscle forces and gravity; the medial fragment of the clavicle displaces posterior-superiorly and the lateral fragment anterior-inferiorly causing displacement. This shift causes a mal-aligned fracture with a superimposition of the two fragments, which results in the shortening of the clavicle. ${ }^{3}$ The current described operation criteria are mostly based on radiographic examination alone. These radiographic aspects are used because shortening caused by displacement has been associated with potential shoulder dysfunction in previous studies. ${ }^{4}$ Different degrees of shortening leading to an unfortunate outcome are being reported; varying from $15-20 \mathrm{~mm}^{5-7}$ After we reviewed the anatomy and biomechanical aspects of the clavicle it seemed challenging that, fracture characteristics of a three dimension curved shaped bone with a complex attachment of muscles and ligaments, is seen correctly on a twodimensional series. This theory is further outlined in the next two chapters. The study in Chapter four was a way to engage a discussion about the current operation indications. There are previous studies that question the diagnostic value of radiographic assessment with a two dimensional $x$-ray. ${ }^{8-10}$ However, these studies attempted to adjust the current diagnostic tool or develop a more adequate one. We wanted to abandon the idea that, the choice to operate, depends mostly on radiographic examination alone. Radiographs are an excellent way to diagnose a clavicle fracture. However, it cannot adequately show all fracture aspects 
adequately enough to make a well-considered decision as it is too much subjected to change. We showed that the position of a patient has a great influence on the fracture characteristics seen on the radiograph. Therefore, that the degree of shortening and displacement cannot be adequately determined on standard 2-view radiographic series.

In our clinical study in Chapter five we compared both treatment options. In a cohort study of 97 patients, we treated 58 patients conservatively and 39 patients underwent anteroinferior plate fixation. We found that the functional outcome (i.e. mean DASH and Constant scores) were significant better in the operative than in the conservative treatment group at six weeks. At 24 week there was a significant improvement in the Constant and DASH scores for both groups but there was no significant difference in functional scores between the groups. Overall complications were significantly higher in the operative group (31\%) compared to the conservative group (9\%) ( $p<0.001)$. Four patients developed a non-union, one patient in the operative and three patients in the conservative group. Regarding the long-term functional outcome, no significant difference was seen $(5.2 \pm 9.8$ versus $2.5 \pm 4.9 p=0.12$ ). Interestingly, patient's satisfaction was higher in the operative than in the conservative group $(p<0.04)$. Our study was one of first to include patients' satisfaction in the results. The current literature still mostly focuses on complications such as nonunion, hardware irritation and infection. In a systematic review and meta-analysis (Chapter six) we reviewed the outcomes in literature. We found that showed that surgical treatment of MCFs results in fewer nonunions, fewer malunions, and an accelerated return to work compared with nonsurgical treatment. Functional outcomes were statistically significant in favor of surgical treatment, but these differences seem of little clinical importance. ${ }^{11-13}$ Functional outcomes might be statistically significant; nevertheless, an MD of 2 points on the DASH score and 3 points on the Constant-Murley score are clinically irrelevant. ${ }^{11-13}$ For each of these scores, a 10-point difference is deemed clinically relevant.11,13

During the past decades, various surgical interventions with several fixation methods have been developed for the treatment of displaced clavicle fractures. These interventions are constantly being improved in order to provide more effective fracture treatment. The standard surgical techniques carried out are open reduction and internal plate fixation or intramedullary fixation. ${ }^{14-18}$ Although a recent review showed no difference either in functional outcome or complications after plate fixation or intramedullary fixation ${ }^{14}$, short-term results favor plate fixation. ${ }^{18}$ 
In Chapter seven we describe a new operation technique using a minimal invasive plate osteosynthese. Plate fixation with the MIPO technique can minimize soft tissue dissection, therefore promoting bony union, reducing soft tissue complications, ${ }^{19-23}$ and leading to a smaller surgical scar compared with conventional open reduction and internal fixation. ${ }^{24}$ Excellent outcomes were seen after the follow-up of 40 patients treated with the MIPO technique Furthermore, we compared MIPO technique with a similar group of patients treated with the conventional "open" fixation technique. We found both techniques are safe and effective methods. The added value for the MIPO technique lies in a better cosmetic appearance. For young patients cosmetic appearance can be an important factor in patients' satisfaction. The incidence of clavicle fractures is highest in this group of young patients, mostly active men. The trauma mechanism consists of an axial compression to the shoulder and is seen during sports or motor vehicle accidents. ${ }^{7}$ Cyclists are prone to this kind of injury. In Chapter eight a postoperative rehabilitation protocol, functional outcome and complications for cyclists was outlined. For this group of patients operative intervention is a must, because quick consolidation of the fracture is of major importance. Conservative treatment limits time to union, shoulder range of motion, and strength.

\section{Future perspectives}

Compared to Hippocrates' treatment strategy, great progress was made in the search for the optimal treatment of displaced clavicle fractures. Numerous articles are written to compare different treatment options, plate locations and develop innovative operation techniques to reduce complications and optimize functional outcomes. Nonetheless, still no consensus is reached and no uniform clavicle management is being practiced. In this thesis factors that contribute to this were identified. The focus on radiological operation criteria, various definitions used in clavicle management and lack of patient important outcomes and satisfaction in currents studies.

\section{Shared decision making}

In healthcare more and more treatment strategies are based on shared decision making. Shared decision making (SDM) has been defined as: 'an approach where clinicians and patients share the best available evidence when faced with the task of making decisions, and where patients are supported to consider options, to achieve informed preferences".25 The principles reflect the ideas of current society. Nowadays, autonomy and self-participation becomes more and more important for patients. Excluding patients from their own treatment is outdated Getting 
patients involved helps in the rehabilitation and patients' satisfaction after trauma. SDM is supported by evidence from 86 randomized trials showing knowledge gain by patients, more confidence in decisions, more active patient involvement, and, in many situations, informed patients elect for more conservative treatment options. ${ }^{26}$ To achieve this, patients have to be involved through gaining high quality information. In order to inform patient adequately, there is great potential in creating uniform definitions in clavicle management. It seems impossible to create treatment strategies, interpret studies results and inform patients based upon different ideas of healing disorders and complications. Therefore, we want to propose and create new uniform definitions based on available evidence on fracture healing.Conservative treatment of displaced clavicle fractures can be a good choice for individual patients. However, patients have to be, informed, empowered to understand and act upon crucial information when making a decision.Overall research only shows a benefit for operative treatment for clavicle fractures in the first few weeks. Long-term functional outcomes do not differ clinically between the conservative and operative treatment groups. With conservative treatment indirect bone healing occurs. Indirect bone healing can be divided into four stages. Starting with inflammation, the formation of soft and hard callus and eventually remodeling of the former fracture parts. ${ }^{27}$ With remodeling an amount of shortening occurs. There is a lot of discussion in literature about the influence of shortening on functional outcome. We further outlined this in Addendum 1. For this we attempted to measure the shortening as seen on the first radiograph after trauma and radiograph after 24 weeks. All radiographs had to be adjusted to be able to compare and measure the amount of shortening. All radiographs showed an amount of shortening after trauma. Throughout the process of fracture healing first an extension of the clavicle compared to trauma was seen and eventually after remodeling of the fracture parts an amount of shortening was observed. However, although these fractures heal with an amount shortening, excellent functional outcome scores were seen.

Patients place different importance on the outcomes associated with various options and have other preferences about the processes and paths that lead to these outcomes. If patients are not informed, they will be unable to assess ' what it is important to them', and so establish informed preferences. A patient that depends on quickly regaining function because of sports or work has other expectations and is likely to choose a different treatment option than a patient who is not.We have to abandon basic principles such as, radiological operation indication criteria and stop focusing on what fracture characteristic should be operated.Instead, focus 
should be on what patient should be operated based upon patients' satisfaction, expectations of functional outcome, shared decision making and individualisation of treatment.

\section{Individualization of treatment}

It remains a challenge in the current daily practice whether to choose an operation or treat a patient conservatively with a sling or a figure-of-eight brace. Therefore, the recommendation in treatment of clavicular fractures should be individualized, with a prerequisite discussion of the known potential risks and benefits of both operative and non-operative management. The option of surgical treatment may be offered to patients within the premise of a reduction in the relative risk of nonunion and symptomatic mal-union and an earlier return to work or sport.

Various surgical interventions with several fixation methods have been developed for the treatment of displaced clavicle fractures. A range of implants is available on the market for internal fixation, divided into plate/ screw configurations and intramedullary devices. The use of dynamic compression plates (DCP), locking plates (LP) and reconstruction plates has all been reported in the literature. ${ }^{28}$ These interventions are constantly being improved in order to provide more effective fracture treatment. Still, complications (i.e. infections, implant breakage, refracture, nonunion and implant related irritation) after plate fixation are seen. Implant related irritation is a profound complication leading to removal of the plate and herewith a second intervention. ${ }^{28}$ This causes a lot of discussion in current literature regarding the optimal plate fixation. Two locations are used: anterior and superior plate fixation. Numerous biomechanical studies were conducted to give more insight in the optimal positioning of the plate. For both locations benefits and disadvantages were found. Both plating methods can withstand the forces without permanent deformation or breakage and, therefore, provide a stable fixation. Research demonstrates that plate position was not significantly associated with implant-related irritation. ${ }^{29,30}$ In a recent study, almost an equal percentage of implant removals was seen in both groups because of implant irritation (36\% versus 37\%). ${ }^{30}$ No difference in reoperation rates between plate types or location could be detected. ${ }^{29,30}$ With intramedullary devices the complication of hardware related irritation could be avoided. A recent review showed no difference either in functional outcome or complications after plate fixation or intramedullary fixation. However, plate fixation has a faster recovery period. ${ }^{31,32}$

Further steps toward individualization can be achieved by adjusting the clavicle plate for every patient. As explained before, the standard clavicle series cannot be 
used to accurately assess all the components of fracture, including shortening, angulation, rotation, and shoulder-girdle changes.Although not indicated in all routine cases, advanced imaging such as computed tomography (CT), which allows reconstructions of the clavicle in three dimensions, may overcome this barrier. Furthermore, measurement of the true total clavicle length is more accurate in these images. ${ }^{28}$ Currently a next step is made through 3D printing of the clavicle based on computed tomography. The real-size 3D-printed uninjured clavicle model is utilized as a template to select the plate, which best fits the model. A locking reconstruction plate can be molded to fit on the clavicle. However, it is preferable not to bend or mold the plate but to select an anatomically contoured locking plate. As bending or molding the plate may reduce fatigue strength of the plate, which has the potential for plate breakage. ${ }^{33} 3 \mathrm{D}$ models can be invaluable for a precise preoperative plan as the plate can be attached to the 3D-printed fracture model prior to surgery. This allows the surgeon to select the correct screw holes to use or to perform a surgery on the 3D model prior to the real fracture surgery. The disadvantage of this technique is that considerable time and cost are required from the acquisition of the $\mathrm{CT}$ data to manufacturing and receiving the real-size 3D-printed model. 33,34

The future in 3D modelling is an anatomically correct precountoured clavicle plate adjusted for an individual patient. Preparing an accurate prebent plate is difficult because of the complex shape and individual differences of the clavicle. However, the use and popularity of 3D printing in industry is growing at an exponential rate. This growth can be associated with lower printing costs and subsequently greater accessibility to printing technologies in the future. Until now technologies is not far enough to be able to generate $100 \%$ precontoured plates adjusted to an individual patient. Nevertheless, precountoured plates that are $95 \%$ of a near anatomical fit for the common patient are at the moment second best. This can be seen as a big step toward eventually customizing the clavicle plate for every patient.

\section{Conclusion}

Treatment for displaced midshaft clavicle fractures shows overall excellent functional outcomes scores. To improve patients' satisfaction and prevent unnecesarry complications and (secondary) interventions, optimal treatments strategies should be advised. Focus should be on patients' satisfaction and adequately inform patients on the optimal treatment strategy based upon individual expectations. To achieve this uniform defintions on fractures healing and complications should exist, radiological examination as operations indication 
criteria should be abandoned and patient should be more involved in the decision for a treatment option. The optimal treatment stragery should be based upon and adjusted for every individual patient rather than trying to create an overall optimal treatment for displaced midshaft clavicle fractures. 


\section{REFERENCES}

1. Boresi AP, Schmidt RJ, Sidebottom OM. Deflection of curved beams. Advanced mechanics of materials. New York: Wiley \& Sons; 1993. p. 385-91.

2. Rozalia Dimitriou, Eleftherios Tsiridis, Peter V. Giannoudis Current concepts of molecular aspects of bone healing. Injury. 2005 Dec; 36(12): 1392-404. Epub 2005 Aug 15.

3. De Giorgi S, Notarnicola A, Tafuri S, Solarino G, Moretti L, Moretti B. Conservative treatment of fractures of the clavicle. BMC Research Notes. 2011;4:333. doi:10.1186/1756-05004-333. Hill JM, McGuire MH, Crosby LA. Closed treatment of displaced middle- third fractures of the clavicle gives poor results. J Bone Joint Surg Br 1997, 79:537-539.

4. Eskola A, Vainionpää S, Myllynen P, Pätiälä H, Rokkanen P. Outcome of clavicular fracture in 89 patients. Arch Orthop Trauma Surg 1986, 105:337-338.

5. Lazarides S, Zafiropoulos G, Tydfil M. Conservative treatment of fractures at the middle third of the clavicle: the relevance of shortening and clinical outcome. J Shoulder Elbow Surg. 2006;15:191-194.

6. Postacchini R, GuminaS, Farsetti P Postacchini F. Long-term results of conservative management of midshaft clavicle fracture. Int Orthop. 2010;34:731-736. doi: 10.1007/ s00264-009-0850-x. Epub 2009 Aug 10

7. Austin LS, O'Brien MJ, Zmistowski B, Ricchetti ET, Kraeutler MJ, Joshi A, et al. Additional $x$-ray views increase decision to treat clavicular fractures surgically. J Shoulder Elbow Surg. 2012 Oct;21(10):12638. doi: 10.1016/j.jse.2011.08.050.

8. Sharr JR, Mohammed KD. Optimizing the ic technique in clavicular fractures. J Shoulder Elbow Surg 2003;12:170-2. doi:10. 1067/ mse.2003.23

9. Smekal $V$, Deml C, Irenberger A, Niederwanger $C$, Lutz $M$, Blauth $M$ et al. Length determination in mid- shaft clavicle fractures: validation of measurement. J Orthop Trauma. 2005;22:458-462. doi:
10. Houwert RM, Wijdicks FJ, Steins Bisschop C, Verleisdonk EJ, Kruyt M. Plate fixation versus intramedullary fixation for displaced midshaft clavicle fractures: a systematic review. Int Orthop. 2012;36:579-85.

11. Ban I, Branner U, Holck K, Krasheninnikoff M, Troelsen A. Clavicle fractures may be conservatively treated with acceptable results: a systematic review. Dan Med J. 2012;59(7):A4457.

12. Evaniew $N$, Simunovic $N$, Mckee MD, Schemitsch E. Cochrane in $\operatorname{CORR}(R)$ : surgical versus conservative interventions for treating frac- tures of the middle third of the clavicle. Clin Orthop Relat Res. 2014;472(9):2579-2585.

13. Gummesson C, Atroshi I, Ekdahl C. The Disabilities of the Arm, Shoulder and Hand (DASH) outcome questionnaire: longitudinal con- struct validity and measuring selfrated health change after surgery. BMC Musculoskelet Disord. 2003;4:11.

14. Chu CM, Wang SJ, Lin LC. Fixation of midthird clavicular fractures with knows pins: 78 patients followed for 2-7 years. Acta Orthop Scand. 2002 Apr;73(2):134-9.

15. Chuang TY, Ho WP, Hsieh PH, Lee PC, Chen $\mathrm{CH}$, Chen YJ. Closed reduction and internal fixation for acute midshaft clavicular fractures using cannulated screws.J Trauma. 2006 Jun;60(6):1315-20; discussion 1320-1.

16. Olden GD,VA-LCP anterior clavicle plate: the anatomically precontoured fixation system with angular stability for clavicle shaft. Musculoskelet Surg. 2014 Dec;98(3):217-23.

17. van der Meijden OA, Houwert RM, Hulsmans M, Wijdicks FJ, Dijkgraaf MG, Meylaerts SA, et al. Operative treatment of dislocated midshaft clavicular fractures: plate or intramedullary nail fixation? A randomized controlled trial. J Bone Joint Surg Am. 2015 Apr 15;97(8):613-9. doi: 10.2106/JBJS.N.00449. 
18. Lee H.J., Oh C.W., Oh J.K., Yoon J.P., Kim J.W., Na S.B., et al: Percutaneous plating for comminuted midshaft fractures of the clavicle: a surgical technique to aid the reduction with nail assistance. Injury 2013; 44: pp. 465-470

19. Tieyi $Y$, Minimal invasive plating for fresh displaced midshaft fractures of the clavicle. Orthopedics. 2014 Oct;37(10):679-83. doi: 10.3928/01477447-20140924-05.

20. Wang X, Wang Z, Xia S, Beigang F. Minimal invasive in the treatment of clavicle middle part fractures with locking reconstruction plate. Int J Surg. 2014;12(7):654-8. doi: 10.1016/j.ijsu.2014.05.001

21. Zhang $Y, X u$ J, Zhang $C$, Sun Y. Minimally invasive plate osteosynthesis for midshaft clavicular fractures using superior anatomic plating. J Shoulder Elbow Surg. 2016 Jan;25(1):e7-12. doi: 10.1016/j. jse.2015.06.024.

22. Al-Sadek TA, Niklev D, Al-Sadek A.:Midshaft Clavicular Fractures - Osteosynthesis with Minimally Invasive Technique.Open Access Maced J Med Sci. 2016 Dec 15;4(4):6-649. doi: 10.3889/oamjms.2016.136.

23. Zhang T, Chen W, Sun J, Zhang Q, Zhang Y.Minimally invasive plate osteosynthesis technique for displaced midshaft clavicular fracture using the clavicle reductor.Int Orthop. 2017 Jan 12. doi: 10.1007/s00264016-3392-z.

24. Jiang $H_{\text {., }}$ and Qu W.: Operative treatment of clavicle midshaft fractures using a locking compression plate: comparison between mini-invasive plate osteosynthesis (MIPPO) technique and conventional open reduction. Orthop Traumatol Surg Res 2012; 98: pp. 666-671

25. Elwyn G, Coulter A, Laitner S, Walker E, Watson P, Thomson R. Implementing shared decision making in the NHS. BMJ. 2010;341:c5146. doi: 10.1136/bmj.c5146.
26. Stacey D, Bennett C, Barry M, Col N, Eden K, Holmes-Rovner, M Llewellyn-Thomas, H Lyddiatt A, et al. Decision aids for people facing health treatment or screening decisions. Cochrane Database of Systematic Reviews. 2011;as well as(10):CD001431.

27. Giannoudis PV, Thomas A. EinhornDavid Marsh Fracture healing: The diamond concept. Injury. 2007 Sep;38 Suppl 4:S3-6.

28. Hosalkar HS, Parikh G, Bittersohl B Surgical fixation of displaced clavicle fracture in adolescents: a review of literature. Orthop Rev (Pavia). 2013 Oct 2;5(3):e29. doi: 10.4081/ or.2013.e29. Review. PMID:24191189

29. Ashman BD, Slobogean GP, Stone TB, Viskontas DG, Moola FO, Perey BH, Boyer DS, McCormack RG.Reoperation following open reduction and plate fixation of displaced mid-shaft clavicle fractures. Injury. 2014 Oct;45(10):1549-53. doi: 10.1016/j.injury.2014.04.032. Epub 2014 Apr 28.PMID: 24893919

30. Hulsmans $M H J$, van Heijl M, Frima $H$, van der Meijden OAJ, van den Berg HR, van der Veen AH, Gunning AC, Houwert RM, Verleisdonk EJMM. Predicting suitability of intramedullary fixation for displaced midshaft clavicle fractures. Eur J Trauma Emerg Surg. 2017 Oct 9. doi: 10.1007/ s00068-017-0848-9. PMID: 28993839

31. van der Meijden OA, Houwert RM, Hulsmans M, Wijdicks FJ, Dijkgraaf MG, Meylaerts SA, et al. Operative treatment of dislocated midshaft clavicular fractures: plate or intramedullary nail fixation? A randomized controlled trial. J Bone Joint Surg Am. 2015 Apr 15;97(8):613-9. doi: 10.2106/JBJS.N.00449.

32. Fuglesang HFS, Flugsrud GB, Randsborg $\mathrm{PH}$, Oord $\mathrm{P}$, Benth JŠ, Utvåg SE. Plate fixation $<$ i $>$ versus $</ i>$ intramedullary nailing of completely displaced midshaft fractures of the clavicle: a prospective randomised controlled trial. Bone Joint J. 2017 Aug;99-B(8):1095-1101. doi: 10.1302/0301-620X.99B8.BJJ-2016-1318.R1. 
33. Kim HN, Liu XN, Noh KC.Use of a real-size 3D-printed model as a preoperative and intraoperative tool for minimally invasive plating of comminuted midshaft clavicle fractures. J Orthop Surg Res. 2015 Jun 10;10:91. doi: 10.1186/s13018-015-0233-5. PMID: 26054648
34. Jeong HS, Park KJ, Kil KM, Chong S, Eun $\mathrm{HJ}$, Lee TS, Lee JP.Minimally invasive plate osteosynthesis using 3D printing or shaft fractures of clavicles: technical note.Arch Orthop Trauma Surg. 2014 Nov;134(11):1551-5. doi: 10.1007/s00402014-2075-8. Epub 2014 Aug 28.PMID: 25164764 



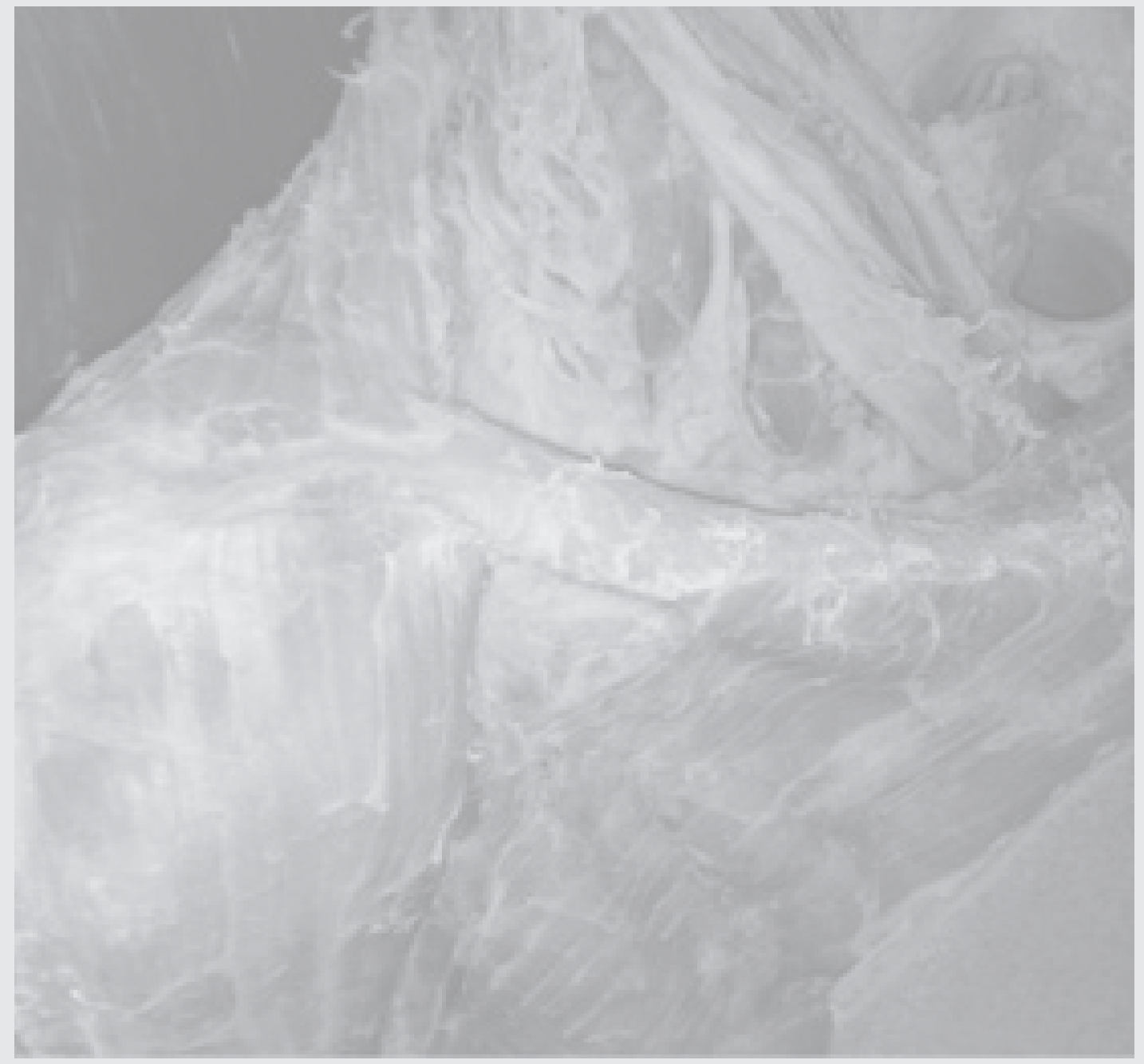




\section{CHAPTER TEN}

Nederlandse samenvatting 


\section{Anatomie}

De clavicula, oftewel het sleutelbeen, is een S-vormig bot en vormt de enige benige verbinding tussen het schoudergewricht en het borstbeen(sternum). Het sleutelbeen wordt omgeven door aantal spieren. De musculus trapezius, musculus deltoideus, musculus sternocleidomastoideus en musculus pectoralis major (Figuur 1). Tussen sternum en sleutelbeen zit het sternoclaviculaire gewricht (SCgewricht), tussen schouderblad (scapula) en borstbeen het acromioclaviculaire gewricht (AC-gewricht). Ook zijn er ligamenten, een bindweefsel band om een gewricht, die het sleutelbeen omgeven. Het ligament tussen het coracoid (deel van het schouderblad) en het sleutelbeen heet het coracoclaviculaire ligament. Het ligament tussen coracoid en het acromion heet het caracoacromiale ligament. Het sleutelbeen heeft een belangrijke rol in het stabiliseren van het schoudergewricht. Wanneer de continuïteit van het bot is onderbroken (fractuur) heeft dit direct weerslag op het functioneren van de arm.

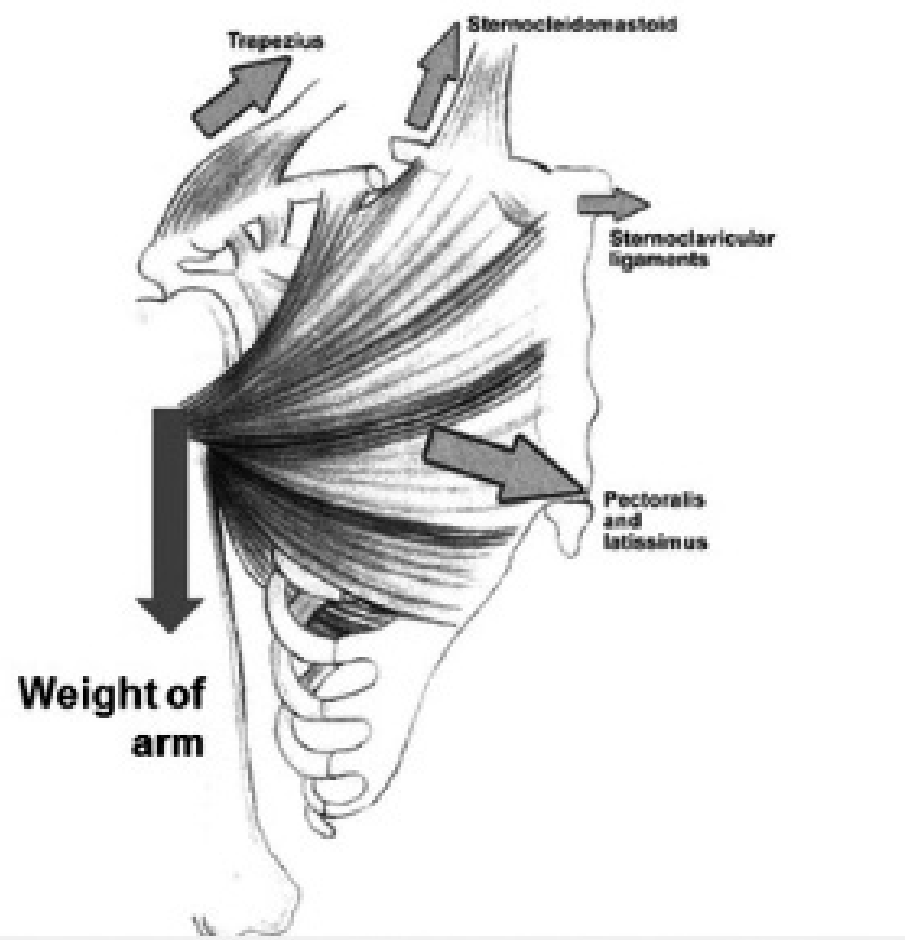

Figuur 1. 


\section{Classificatie}

Er zijn verschillende classificatie systemen ontwikkeld om de breuken in het sleutelbeen in te delen. Grofweg wordt de breuk ingedeeld naar de locatie. Mediale (binnenste 1/3e deel) breuken, lateraal (buitenste 1/3e deel) breuken en midschacht breuken (middelste 1/3e deel) (Figuur 2). Midschacht sleutelbeen breuk komt het meest voor in $80 \%$ van de gevallen. ${ }^{1,2}$ Daarnaast wordt er onderscheid gemaakt of de breuk uit meerdere botdelen bestaat (comminutief) en of deze botdelen wel of niet verplaatst zijn (dislocatie). De indeling en behandeling van de breuk is per locatie verschillend. In de literatuur is het duidelijk dat niet gedisloceerde breuken conservatief behandeld worden. In dit proefschrift worden dan ook alleen gedisloceerde midschacht sleutelbeenbreuken besproken. Door middel van röntgenfoto's wordt de diagnose gesteld en geclassificeerd. Er worden twee röntgenfoto's vervaardigd: één voor achterwaartse richting (anteroposterieure c.q. AP richting) en één in 15-45 graden.

\section{Classificatie volgens Robinson}

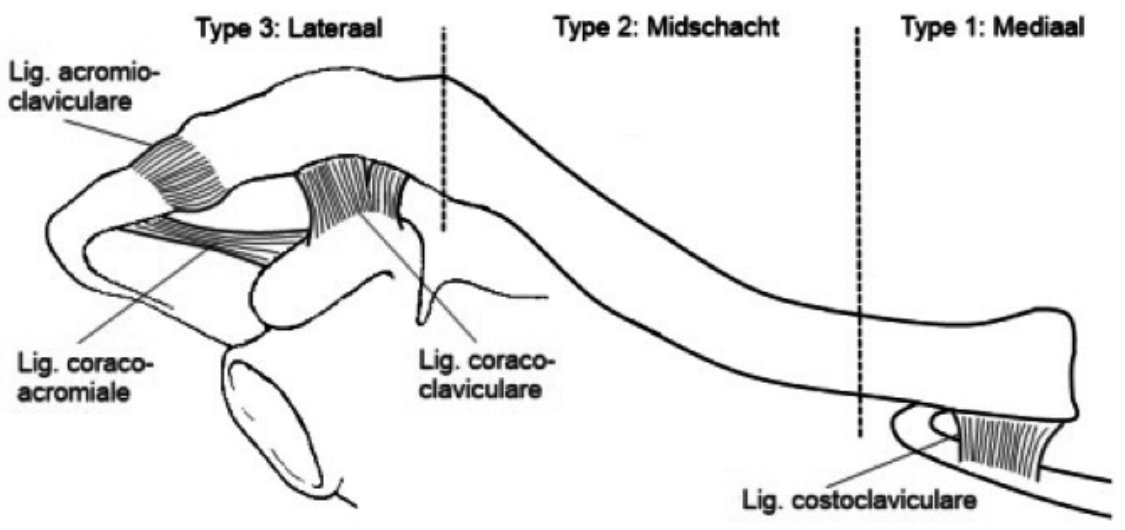

Figuur 2

\section{Trauma}

Bij jongere patiënten bestaat het ongevalsmechanisme meestal uit een val op de uitgestrekte hand of een val op de schouder, bijvoorbeeld bij fietsen, paardrijden, skiën en motorrijden. ${ }^{1,3}$ Bij ouderen betreft het dikwijls een val door bijvoorbeeld struikelen en ontstaat vaker een laterale (in het buitenste 1/3 deel) fractuur.' De incidentie van claviculafracturen bedraagt 29-64 per 100.000 personen per jaar. Meestal betreft het jonge mannen.1-4 Wielrenners vormen daardoor een grote patiëntengroep. 


\section{Behandeling}

In de behandeling van sleutelbeen breuken kan gekozen worden voor conservatieve behandeling (zonder te opereren) of een operatie.

\section{Conservatieve behandeling}

Conservatieve behandeling bestaat uit het dragen van een sling of figure-of-eight brace gedurende de eerste week. De nabehandeling bestaat in de eerste week vooral uit uitleg over de anatomie, herstel proces en houdingstherapie. Na een breuk van het sleutelbeen dreigt een versterking van de protractiestand (naar voren) van het schouderblad en kyfotische houding (kromming van de wervelkolom) door pijnontwijkend gedrag. Hiermee is er tevens een grotere kans op een verkorting van het sleutelbeen na botgenezing. De adviezen bestaan dan ook uit het aanleren van de beide schouderbladen naar achter en naar binnen te bewegen binnen de grenzen van de individuele patiënt. Denk daarbij aan een militaire houding. Eventueel kan gebruik worden gemaakt van feedback met een tape op de rug of een spiegel. De verantwoordelijke musculatuur zijn de musculi rhomboideii en serratus posterior. Om een scapula alata (afstaand schouderblad) tegen te gaan moet er aandacht uitgaan naar training van musculus serratus anterior. Rekken van musculus pectoralis minor komt in een later stadium. De oefentherapie is binnen de pijngrens. Na 2 weken kan gestart worden met opbouwen van de belastbaarheid. ${ }^{5}$ Met conservatieve behandeling treedt secundaire botgenezing op. Dit houdt in dat de genezing verloopt in opeenvolgende stappen, op dezelfde manier als wondgenezing. Direct na het ontstaan van de breuk vormt zich een groot hematoom. Na een paar dagen ontstaat zacht granulatieweefsel ofwel zacht callus in het wondgebied. Na een week verandert het zachte callus langzaam in benig callus en vindt er bot remodellering plaats. Bij secundaire botgenezing is de fixatie niet rigide, zoals bij primaire botgenezing, maar dynamisch. Hierdoor wordt het lichaam gestimuleerd extra botweefsel aan te maken. ${ }^{6}$

\section{Operatieve behandeling}

Door het weghalen van het fractuur hematoom tijdens een operatie krijg je primaire botgenezing. Dit type botgenezing vereist een rigide fixatie en anatomische repositie van de breuk waarbij geen callus gevormd wordt. Primaire botgenezing treedt op indien de breuk is gefixeerd met osteosynthese materiaal (zoals platen of pennen). De breuk delen liggen perfect gereponeerd tegen elkaar aan. Er ontstaat direct een goede verbinding tussen de fragmenten door de uitgroei van Haverskanalen van het ene fragment naar het andere. ${ }^{6}$ 
De huidige indicaties om te opereren zijn: bedreigde huid, het niet vastgroeien van het bot na conservatieve behandeling (nonunion), verkorting van $>2 \mathrm{~cm}$ en schachtbreedte dislocatie. Er zijn meerdere technieken om te opereren. Er kan gekozen worden voor een pen of een plaat.

Meest gebruikte operatie techniek is middels een plaat. Er kan voor 2 posities gekozen worden voor de plaat; bovenop het sleutelbeen (superior) of meer naar voren en beneden (anteroinferior). De nabehandeling na een operatie staat vrijwel gelijk aan die van conservatieve behandeling. ${ }^{5}$

\section{Complicaties}

De meest voorkomende complicaties na conservatieve behandeling betreffen complicaties met betrekking tot de botgenezing. Nonunion wordt gedefinieerd als het niet vastgroeien van de breuk binnen 6 maanden gediagnostiseerd middels röntgenfoto. Dit kan symptomatisch zijn wat betekent dat patiënten er klachten van hebben of verminderde functie van het schoudergewricht. Ook kunnen patiënten hierbij geen klachten ervaren wat dan een asymptomatische nonunion genoemd wordt. Hier wordt niet altijd onderscheid in gemaakt. Delayed union: pijn of beweging ter plaatse van de breuk in combinatie met afwezigheid van botgenezing op de röntgenfoto na 3 maanden. Malunion: pijn, zwakte of functionele klachten van de schoudergordel in combinatie met genezing van de breuk in een verkorte gedraaide of verplaatst positie gezien op een röntgenfoto of een CT-scan.

De complicaties die gezien worden na een operatie zijn: wondinfectie, nonunion, breken of uitbreken van de plaat, een tweede breuk. Een tweede breuk ontstaat als patiënt opnieuw valt meestal nadat de plaat verwijderd is.

De functionele klachten worden middels vragenlijsten uitgevraagd. De meest gebruikte vragenlijsten zijn de DASH (Disability of the Arm, Shoulder and Hand) en de Constant score. ${ }^{7,8}$

\section{Hoofdstukken}

\section{Hoofdstuk 1 - Introductie}

Clavicula oftewel sleutelbeen komt voort uit het Latijnse clavicula wat "kleine sleutel" betekent. Dit refereert naar de anatomische structuur van het sleutelbeen. Het bot beweegt langs zijn as als een sleutel en heeft het dezelfde vorm als de sleutel van een Romeins deurslot Daarnaast is het sleutelbeen de enige benige verbinding tussen borstkast en schouder en verwijst dit naar de "sleutel" connectie van het borstbeen met het schouder gewricht. 


\section{Deel 1 -De beginselen van sleutelbeen breuken}

Door de spieren die aanhechten aan de het sleutelbeen is deze onderhevig aan bepaald krachten. Het middelste $1 / 3^{e}$ deel van het bot heeft een vrije rand waarbij geen spieren aanhechten. De combinatie van de krachten van de spieren die aanhechten en de s-vorm van het sleutelbeen zorgt ervoor dat meeste breuken in het middelste $1 / 3^{e}$ deel voorkomen. Als de clavicula breekt zorgt de trekkracht van de spieren die aanhechten dat er een bepaalde verkorting en verplaatsing (dislocatie) van de twee botdelen ontstaat. Door de spieren wordt het binnenste (mediale) botdeel naar boven en buitenste (laterale) botdeel naar beneden getrokken (Figuur 1).

\section{Hoofdstuk 2}

In dit hoofdstuk worden de definities die gebruikt worden bij sleutelbeen breuken in de literatuur tegen het licht gehouden. De definities betreffende de verschillende complicaties: botgenezing (o.a. nonunion, delayed union en malunion), wondinfectie, klachten van de pen of de plaat en functionele uitkomsten. Deze review liet zien dat vergelijkende studies in de huidige literatuur verschillende definities gebruiken. Hierdoor is het niet mogelijk om resultaten te vergelijken en daar (behandel) consequenties aan te verbinden. Er dienen dan ook uniforme definities te komen in de literatuur zodat de uitkomsten van studies adequaat met elkaar vergeleken kunnen worden.

\section{Hoofdstuk 3}

Een computermodel is ontwikkeld waarbij alle spieren en ligamenten zijn geïntegreerd die aanhechten op het sleutelbeen. Bewegingen in het schoudergewricht zijn complex door de hoeveelheid aan spieren en ligamenten die erop aanhechten. De grote en de richting van de krachten die inwerken op het sleutelbeen zijn nog niet geheel duidelijk. Een bestaand model; het Delft Shoulder Model werd gebruikt om de krachten te berekenen die inwerken op het sleutelbeen tijdens verschillende bewegingen. Dit model wordt uiteindelijk geëxtrapoleerd naar de praktijk. Hierdoor komt er meer inzicht naar de krachten die inwerken op het sleutelbeen en de plaat tijdens het revalidatie proces. Zoals eerder beschreven gaat plaat fixatie gepaard met primaire botgenezing en is dus rigide fixatie nodig voor optimale omstandigheden voor botgenezing. Dit model liet zien dat beide posities van de plaat zorgen voor rigide en stabiele fixatie. 


\section{Deel 2 - Beeldvorming}

In dit deel gaan we verder in op röntgen diagnostiek en de operatie indicatie die daarmee verbonden zijn.

\section{Hoofdstuk 4}

Röntgenfoto's worden gebruikt als diagnosticum voor sleutelbeen breuken. Echter wordt ook de beslissing om te opereren gebaseerd op een röntgenfoto. Namelijk als er $>2 \mathrm{~cm}$ verkorting gezien wordt of een schachtbreedte verplaatsing. In de literatuur is er al veel discussie of dit wel adequaat gemeten kan worden op een röntgenfoto. Een breuk van een sleutelbeen is namelijk dynamische en 3D terwijl een foto 2D statisch is. Dit onderzoek liet zien dat conventionele röntgenfoto's niet adequaat genoeg alle breuk delen in beeld brengen en dat de positie verandering van de patiënt zorgt voor verandering in karakteristieken van de breuk. Hierdoor is het moeilijk om een röntgenfoto te gebruiken in de beslissing voor een operatie.

\section{Deel 3 - Behandeling}

In het laatste deel van het proefschrift worden de verschillende behandeling opties besproken en geëvalueerd.

\section{Hoofdstuk 5}

We vergeleken de twee behandeling opties met elkaar. In een groep van 97 patiënten werden 58 patiënten conservatief behandeld en 39 patiënten geopereerd middels met een plaat. Deze studie liet zien dat de functionele uitkomsten (DASH en Constant score) significant beter waren in de operatieve groep in vergelijking met de conservatieve groep na 6 weken. Echter na 24 weken was er geen verschil meer te zien. Complicaties waren hoger in de operatieve groep (31\%) in vergelijking met de conservatieve groep (9\%) ( $p<0.001)$. De patiënt tevredenheid was hoger in de operatieve groep. Dit onderzoek was een van de eerste die ook patiënt tevredenheid includeerde in de resultaten. Veel onderzoeken focussen voornamelijk nog op complicaties als primaire uitkomst.

\section{Hoofdstuk 6}

Een meta-analyse van de literatuur liet zien dat de operatieve behandeling van midschacht sleutelbeenbreuken resulteert in minder nonunions, minder malunions en sneller terugkeer naar werk in vergelijking met conservatieve behandeling. Functionele uitkomen waren beter voor operatieve behandeling. Echter zonder klinische relevantie. 


\section{Hoofdstuk 7}

Hier wordt een nieuwe operatie techniek beschreven. Het betreft een minimaal invasieve behandeling (MIPO) middels anteroinferior plaat fixatie. Minimaal invasieve chirurgie houdt in dat een kleinere incisie gemaakt wordt. Het doel is dat er zo min mogelijk schade gemaakt wordt aan de zachte weefsels zoals spieren. Daarnaast om de bloedvoorziening zoveel mogelijk intact te houden. Patiënten die middels MIPO werden behandeld werden vergeleken met een groep die via een conventionele open techniek werden behandeld. Beide technieken bleken veilig en effectief. De MIPO techniek resulteerde in een betere cosmetische uitkomst. Vooral voor jonge patiënten kan cosmetiek een belangrijke factor spelen in patiënt tevredenheid. De volledig operatie is ook te bekijken via deze link; https://youtu. be/oeF4lcL6Teo

\section{Hoofdstuk 8}

In dit laatste hoofdstuk wordt een subgroep patiënten beschreven betreffende wielrenners. Voor deze jonge actieve patiënt populatie is het belangrijk om snel terug te keren naar hun sportlevel van voor het trauma. Tien professionele en 15 amateur wielrenners werden geïncludeerd. Een professionele wielrenner gaat direct op de rollerbank (hometrainer). Voor beide is een sling voor maximaal 1 week. Meestal wordt de pijn na 10 dagen minder en kan de patiënt toenemend belasten. Alleen de kracht is na 6 weken nog wat minder, maar de bewegingen zijn bijna ongestoord. Na operatieve behandeling kan een wielrenner na 1 week weer buiten fietsen. ${ }^{5}$ Een professionele wielrenner zit na 10 dagen weer op zijn oude sportlevel. Een amateur wielrenner na 2-6 weken.

\section{Conclusies}

De behandeling van gedisloceerde midschacht sleutelbeen breuken laten in het algemeen uitstekende functionele uitkomsten zien. Om patiënt tevredenheid, (onnodige) complicaties en (secundaire) interventies te voorkomen dienen optimale behandel strategieën gekozen te worden. De focus zal daarbij moeten liggen op de individuele patiënt. Waarbij een patiënt adequate uitleg dient te krijgen over de behandel opties en rekening dient te worden gehouden met de verwachtingen van een patiënt betreffende een behandeling. Shared decision making wordt steeds belangrijker geacht. Daarbij wordt de patiënt betrokken in de keuze voor een behandeling. Om patiënten goed voor te kunnen lichten dienen uniforme definities wat betref botgenezing en complicaties te bestaan. Daarnaast dienen fractuur karakteristieken gezien op een röntgenfoto als operatie indicatie 
verlaten te worden. De optimale operatie strategie dient gebaseerd te worden op en aangepast voor elke individuele patiënt in plaats van streven naar een algemene optimale behandeling voor gedisloceerde midschacht sleutelbeen breuken. 


\section{Referenties}

1. Robinson CM. Fractures of the clavicle in

5. www.sleutelbeen.info the adult. Epidemiology and classification. J Bone Joint Surg Br. 1998;80:476-484 Medline. doi:10.1302/0301-620X.80B3.8079

2. Nordqvist A, Petersson C. The incidence of fractures of the clavicle. Clin Orthop Relat Res. 1994;300:127-32 Medline.

3. Zlowodzki M, Zelle BA, Cole PA, Jeray $K$, Mckee MD. Treatment of acute midshaft clavicle fractures: systematic review of 2144 fractures: on behalf of the Evidence-Based Orthopaedic Trauma Working Group. J Orthop Trauma. 2005;19:504-7 Medline. doi:10.1097/01.bot.0000172287.44278.ef

4. Mckee MD. Clavicle fractures in 2010: sling/swathe or open reduction and internal fixation? Orthop Clin North Am. 2010;41:225-31 Medline. doi:10.1016/j. ocl.2009.12.005

6. Dimitriou R1, Tsiridis E, Giannoudis PV. Current concepts of molecular aspects of bone healing. Injury. 2005 Dec;36(12):1392404. Epub 2005 Aug 15.

7. Hudak P, Amadio PC, Bombardier C, the Upper Extremity Collaborative Group. Development of an Upper Extremity Outcome Measure: The DASH (Disabilities of the Arm, Shoulder, and Hand). Am J Indust Med 1996;29:602-8.

8. Constant C, Murley A. A clinical method of functional assessment of the shoulder. Clin Orthop 1987;214:160-4. 




\section{CHAPTER ELEVEN}

Review committee List of publications Acknowledgement

Curriculum vitae 



\section{Prof dr. J.N. Kok (chairman)}

Faculty of Electrical engineering, Mathematics and Computer Science

University of Twente

Enschede, the Netherlands

\section{Prof. dr. D.M. Brouwer}

Faculty of Engineering Technology

University of Twente

Enschede, the Netherlands

\section{Prof. dr. I.R.S Stramigioli}

Department of Robotics and Mechatronics

University of Twente

Enschede, the Netherlands

\section{Prof. dr. A. B. van Vugt}

Department of trauma surgery

Medisch Spectrum Twente

Enschede, the Netherlands

\section{Prof. dr. M.H.J. Verhofstad}

Department of trauma surgery

University Rotterdam

Rotterdam, the Netherlands

\section{Dr. E.J.M.M. Verleisdonk}

Department of trauma surgery

Diakonessenhuis

Utrecht, the Netherlands

Prof. dr. F.G.J. Backx

Department of sports medicine and rehabilitation

University of Utrecht

Utrecht, the Netherlands 



\section{CHAPTER ELEVEN}

Review committee List of publications Acknowledgement

Curriculum vitae 

Timmers TK, van der Ven DJC de Vries LS, van Olden GDJ. Functional outcome after tibial plateau fracture osteosynthesis: a mean follow-up of 6 years. Knee. 2014 Dec;21(6):1210-5. doi: 10.1016/j.knee.2014.09.011.

van der Ven DJC JC, Timmers TK, Flikweert PE, Van ljseldijk AL, van Olden GD. Plate fixation versus conservative treatment of displaced midshaft clavicle fractures: Functional outcome and patients' satisfaction during a mean follow-up of 5 years. Injury. 2015 Nov;46(11):2223-9. doi: 10.1016/j.injury.2015.08.004.

Smeeing DPJ, van der Ven DJC, Hietbrink F, Timmers TK, van Heijl M, Kruyt MC, Groenwold RHH, van der Meijden OAJ, Houwert RM. Surgical Versus Nonsurgical Treatment for Midshaft Clavicle Fractures in Patients Aged 16 Years and Older: A Systematic Review, Meta-analysis, and Comparison of Randomized Controlled Trials and Observational Studies. Am J Sports Med. 2017 Jul;45(8):1937-1945. doi: $10.1177 / 0363546516673615$

Kruithof RN, Formijne Jonkers HA, van der Ven DJC, van Olden GDJ, Timmers TK. Functional and quality of life outcome after non-operatively managed proximal humeral fractures. J Orthop Traumatol. 2017 Dec;18(4):423-430. doi: 10.1007/ s10195-017-0468-5.

van der Ven DJC, T.K. Timmers., R.T.C Welsing, GDJ Olden G.D.J. van Radiographic shortening is not a good indication for surgical intervention for midshaft clavicle fractures. J Orthop Traumatol. 2017

van der Ven DJC, Timmers TK, Broeders IAMJ, van Olden GDJ.Displaced Clavicle Fractures in Cyclists: Return to Athletic Activity After Anteroinferior Plate Fixation. Clin J Sport Med. 2017 Dec 1. doi: 10.1097/ JSM.0552 



\title{
CHAPTER ELEVEN
}

\author{
Review committee \\ List of publications \\ Acknowledgments (Dankwoord) \\ Curriculum vitae
}


In de afgelopen jaren heb ik me naast de kliniek toegelegd op dit proefschrift. Er zijn veel mensen geweest die hebben bijgedragen aan alle studies die beschreven zijn in dit proefschrift. Een aantal personen wil ik hiervoor expliciet bedanken.

Allereerst gaat mijn dank uit naar mijn promotor en copromotoren.

Geachte professor dr. Broeders, beste Ivo. Met onderwerp gericht op de traumachirurgie had ik van te voren nooit kunnen bedenken dat ik een van jouw promovenda zou worden. Toch heb jij mij die kans gegeven en daar ben ik je heel dankbaar voor. Jouw kritische en rechtlijnige visie op onderzoek heb ik altijd heel erg gewaardeerd. Je achtergrond bij een Technische Universiteit had ook zeker zijn voordelen. Dit heeft mooi onderzoek opgeleverd met een meer technische invalshoek.

In de chaos van het Meander was jij, als ik je te pakken kreeg, een baken van rust. In die momenten wist je altijd gelijk de vinger op de zere plek te leggen.

Bedankt voor alles.

Dr. van Olden, beste Ger. Als sportarts van de wielerploeg ben jij een ware expert geworden op het gebied van clavicula fracturen. Aangezien wielrenners nogal eens willen vallen en daarbij hun sleutelbeen breken. Door het hele land komen bekende en minder bekende Nederlanders naar het Meander om door jou geopereerd te worden. Het was altijd inspirerend om te zien hoe je mee denkt met je patiënt wat betreft de behandeling. Als geen andere weet je ook dat je met je tijd mee moet gaan en heb je je eigen site gemaakt over clavicula fracturen en post je filmpjes over operaties op youtube. Met een beetje hulp van je zoon dan wel. Als begeleider heb je vaak een nuchtere blik op dingen en wist je altijd weer door middel van je connecties veel voor elkaar te krijgen ten behoeve van mijn onderzoek. Maar ook daarbuiten heb ik genoten van jou: in je kerstmannen pak tijdens je verjaardag, je vele foto's tijdens je avonturen met de wielerploeg, aan het schitteren op de piano of op je zeilboot in Friesland. Heel erg bedankt voor de afgelopen jaren. Ik heb een fantastische tijd gehad.

Dr. Timmers, beste Tim. Tim Timmers chirurgggie galmt het door de gangen van het ziekenhuis. Als derde jaars coassistent bij de Heelkunde werd ik destijds aan jou gekoppeld. Jij toen nog eerste jaars AIOS in het UMCU. Daar heb je mij geïntroduceerd in de wondere wereld van de chirurgie en vervolgens 6 weken lang op sleeptouw mee genomen. Daarna heb je me kennis laten maken met de wondere wereld (en soms wat mindere wondere wereld) van het onderzoek. 
Altijd had je weer nieuwe ideeën voor mooie studies, was je beschikbaar voor advies maar had je ook een (bijna altijd) zeer gewaardeerde kritisch noot. Ik ken niemand die meer dedicated is dan jij wat betreft onderzoek en de Heelkunde. Daarnaast heb jij mij altijd het vertrouwen gegeven dat het ging lukken. In al die jaren zijn we goed op elkaar ingespeeld geraakt en kon ik al aan de aanhef van de e-mail herkennen of het positief of kritisch ging worden. Schoonheid was veelal positief, meisje dan werd het belerend en bij beste Denise. Tjah.. dan werd het kritisch.

Nooit meer zal ik een begeleider treffen die zelfs tijdens de nachtelijke flesvoeding van zijn dochtertjes tijd maakt om e-mails te beantwoorden. Ik ben heel dankbaar voor je begeleiding en wat heb ik veel van jou mogen leren in de afgelopen jaren. Deel 1 is gelukt, nu gaat de gaat de stoomtrein door voor deel 2. Om in jouw woorden te eindigen. Hulde!

Geachte leden van de beoordelingscommissie: prof dr. Brouwer, prof dr. Stramigioli, prof. dr. van Vugt, prof dr. Verhofstad, dr. Verleisdonk, prof. dr. Backx.

Hartelijk dank voor uw interesse, tijd en energie die $u$ in mij en de beoordeling van dit proefschrift hebt willen steken en daarnaast plaats te willen nemen in de oppositie. In het bijzonder wil ik prof. dr. Kok hartelijk danken voor het voorzitten van de promotie.

Geachte professor dr. Leenen. Bedankt voor de mogelijkheden die u mij geboden heeft in de tijd dat mijn proefschrift gemaakt werd.

Beste Marijn, als een ware pater familias leid jij samen met Falco Hietbrink de onderzoeksgroep in het UMCU. Het was fantastisch om te zien met wat voor plezier en enthousiasme jij je toelegt op onderzoek. Altijd was jij bereid om mee te denken of kwam je weer met een fantastisch plan. Na dit proefschrift zullen we dan ook verder gaan met de onderzoeksplannen. Ook buiten onderzoek heb je mij altijd gesteund, waarvoor heel veel dank.

Beste mede- onderzoeker, Diederick Smeeing, Died. Wat heb ik altijd genoten van onze onderzoek meetings. Denk dat ik in die tijd nog nooit zoveel lunch tentjes in Utrecht heb gezien. Jouw nuchtere en praktisch aanpak in het onderzoek en schrijven van onze artikelen samen heb ik altijd zeer erg gewaardeerd. Je bent een topper!! 
Beste Anne Meester, Niels Schurink en Hans Pieter Snels. Als technisch geneeskunde studenten zijn jullie heel erg waardevol geweest voor de technische stukken van dit onderzoek. Zonder jullie technische kijk op onderzoek was dit niet gelukt. Heel erg bedankt.

Onderzoeksgroep Meander. Behalve Hendrike en Fem. Rob, Sander, Tim, Paul en niet te vergeten natuurlijk Jan. De disco hitje en het foute uurtje op onze boxen in "onze onderzoeksruimte" maakt het allemaal dragelijk. Wat heb ik met jullie gelachen en genoten van onze (vaak net te lange) koffie pauzes. Ondanks dat we niet veel bij elkaar gezeten hebben door ons afwisselende werk in de kliniek, konden we altijd bij elkaar terecht.

Geachte prof. dr. Slump. Bedankt voor de goede ideeën en oplossingen voor de technische stukken en de samenwerking in de begeleiding van de technische geneeskunde studenten.

Dr. van der Meijden, beste Olivier. Op de valreep nog samen aan een mooi artikel mogen werken. Dank je goede ideeën en kritische noot. Kijk uit naar onze verdere samenwerking in de toekomst. Die uiteindelijke definities moeten er natuurlijk wel komen.

Dr. Welsing, beste Roy. Dank voor je medewerking en je inclusies vanaf de spoed eisende hulp.

Chirurgen Meander Medisch Centrum. Allen bedankt voor de begeleiding en interesse de afgelopen 3 jaar. Ik heb een fantastische tijd gehad en veel van jullie mogen leren. Met speciale dank aan dr. Esther Consten. Jouw begeleiding en steun in de laatste periode bij de Heelkunde in het Meander was zeer waardevol.

Beste secretaresses van het Meander, Henriette en Marja dank jullie wel voor het meedenken, ontvangen en ordenen van de brieven en rekening houden met. Etiketten printen blijkt soms toch moeilijker dan gedacht.

Beste Anja, jij ook natuurlijk bedankt voor het meedenken en je vaak praktische oplossingen.

Intensivisten Meander Medisch Centrum. Erik, Bert, Ton, Hinke, Oscar, Laura en Bianca. Bedankt dat er ruimte was om in de rustige uurtjes (na eerst wat zelfstudie over beademing natuurlijk) iets aan onderzoek te doen. Wat hebben jullie een 
fantastisch team!

Assistentengroep Meander. Wat hadden we een heerlijke groep mensen bij elkaar. Georganiseerde chaos met alleen maar hoogtepunten. Dank, dank, dank.

Allerbeste huisgenootjes, liefste Churchill queens, dushi's: Marko, myrth, ka en ook nog beetje flo en bettie! Wat had ik zonder jullie gemoeten. Ondanks de verhalen waar jullie vaak maar de helft van begrepen, wilde jullie altijd alles horen. Dan scheelt het nog met onderzoek dat er geen bloed in voorkomt dus dan konden jullie het beter aan. Ons huis was echt een heerlijke plek om thuis te komen en soms verplaatsten we die gewoon even naar Curaçao. Ook in de weekend dagjes in de coffee company hebben we altijd gelachen. En als je er niet om kan lachen. tjah dan puf je het maar even weg. Dank jullie wel.

Flipjes, lieve clubgenootjes. Dirk, Flo, Sas, Lot, Flora, Neel, Bettie, Veer, Bakkie, Jojo, Renaat, Marjo, Maar, Lin en Na. Ondanks dat het vooral niet teveel over Geneeskunde moest gaan tijdens clubeten was er altijd ruimte en enthousiasme over promotie verhalen en perikelen. Ik heb jullie lef(fe) altijd zeer gewaardeerd. Dank jullie wel voor het luisterend oor.

Liefste oud-huisgenootjes. Ammie en smartie. Lau, aso en accie in de lauwerecht. Zowel op de Lauwe Tosti als in de Begoniastraat heb ik een top tijd gehad. Tijdens mijn studie tijd begonnen mijn eerste stappen in het onderzoek. Waar kun je dan beter terecht dan in je huisje. Bedankt meiden voor jullie steun, adviezen en de nodige kritische noot.

Beste Sluiters, lieve commissiegenootjes. Eigenlijk hebben jullie geen toevoeging gehad aan dit proefschrift. Maar hebben jullie vooral voor de welkome afleiding gezorgd. Waarvoor dank.

Beste paranimf, beste Hendrike Bolkenstein, lieve dirkie, liefste vriendinnetje. Als iemand een bedankje verdiend dan ben jij het wel. Sinds dag 1 van Geneeskunde zijn wij onafscheidelijk geweest en hebben we in de afgelopen jaren al heel wat mee gemaakt. Als ik er even doorheen zat dan bood jij altijd een luisterend oor. Het is heerlijk om iemand in je leven te hebben waarbij je aan 1 blik genoeg hebt, iemand die hetzelfde denkt en vaak hetzelfde eruit flapt zonder altijd na te denken. 
Het kon dan ook eigenlijk niet anders dat wij ook samen in het Meander terecht kwamen. Een aantal maanden hebben we samen zitten shinen aan het onderzoek. De dag begon in de auto keihard mee zingend met de backstreet boys. De toon was dan weer gezet. $(\mathrm{L}$

Beste paranimf, beste Femke Amelung, lieve femmie. Als mede onderzoeker en mede assistent hadden we altijd maar een half woord nodig. Tussen de kliniek door op je vrije dag aan het onderzoek was voor ons beide geen uitzondering. Het was fijn om in hetzelfde schuitje te zitten. Daarnaast hebben we samen een fantastisch assistententijd gehad. Zowel bij de chirurgie als op de IC. Wat waren we altijd een top team (die CVL zat er in record tijd in!). Behalve je wetenschappelijke skills was ik ook altijd onder de indruk van je festival skills en verkleed outfits. Wat waren we mooie bruidjes. Dankjewel voor alles!!!

Lief broertje, rickiiee Ik voel me altijd je grote wijze zus. Maar voor jou zal ik toch altijd je kleine zusje blijven. Ik weet dat je er altijd voor me bent, ben trots op je en blij met jou als broertje. Gelukkig dat je toch nog op tijd terug bent uit Zuid-Amerika. Het was niet compleet geweest zonder jou.

Je moet alleen nog even oefenen voor het promotiefeest anders is het geen "geluk" meer.

Lieve mama en papa. Voor jullie natuurlijk ook een speciaal dankwoord. Jullie hebben mij altijd onvoorwaardelijk gesteund in alle keuzes die ik gemaakt heb. In elke stap van mijn leven zijn jullie intens betrokken geweest. Jullie kleine meisje naar Utrecht zien verhuizen was niet altijd makkelijk (hè mama). Maar zonder jullie support de afgelopen jaren was het niet gelukt!! 



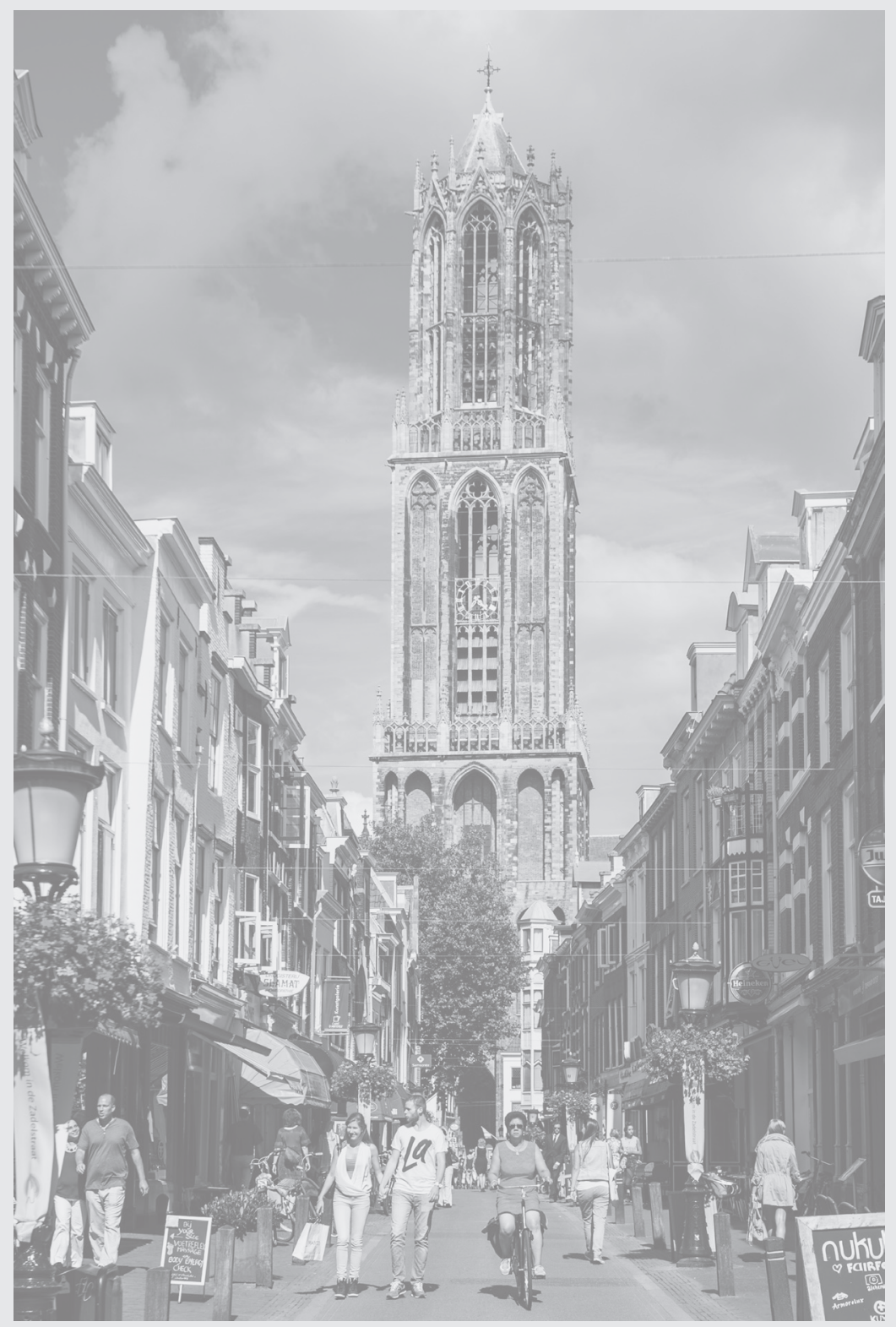




\section{CHAPTER ELEVEN}

Review committee List of publications Acknowledgement Curriculum vitae 

Denise Josephina Christina van der Ven was born on July 11th 1990 in Maastricht, the Netherlands. In 2008, she graduated from the Gymnasium at Sint Maartens College in Maastricht. She was admitted tot Utrecht University medical school in 2008.

For an elective internship, she worked for three months at the Andersen Medical Centre - Mt Elgon Orchards in Kenia. Her interest in surgery emerged during her junior internships. After participating in a project on tibia plateau fractures under supervision of Dr. TKTimmers and Dr. GDJ van olden, she joined the research group of the Meander Medical Centre. During an elective internship at the department of trauma surgery, Denise worked on a project on clavicle fractures with Dr. TK Timmers en Dr GDJ van Olden, which became the topic of this thesis.

Eventually, she started her PhD research project under the supervision of Prof. Dr. I.A.M.J Broeders, Dr. TK Timmers and Dr. GDJ van olden at the Meander Medical Centre. The following years, she also joined the research group of the University Medical Centre Utrecht and worked on projects under de supervision of Dr. R.M. Houwert.

After graduating from medical school in 2015, she worked as a surgical resident not in training in the Meander Medical Centre's general surgery department Amersfoort. After that she worked for 9 months at the Intensive Care department until the end of 2017. Besides the full-time function of surgical intern she continued working at her $\mathrm{PhD}$ research.

Recently, she is working with Broeder de Vries Dutch Medical Services to provide global medical guidance. At the end of 2018, she will continue her work as a surgical resident. 



\section{ADDENDUM ONE}

Conservative treatment of displaced midshaft clavicular fractures: the measurement of shortening and its implications. 


\section{ABSTRACT}

\section{Background}

Treatment of midshaft clavicle fractures is mostly based on the amount of shortening and dislocation seen on radiographic examination. The aim of this study was to investigate the length of the fractured clavicle after consolidation and during the remodeling fase. We evaluated the accuracy of the standard trauma series and the utility of shortening as an operation indication.

\section{Methods}

Between October 2013 - and December 201649 patients were prospectively included. All patients were treated conservatively and visited the outpatient clinic department after 6 and 24 weeks. On all occasions the standard AP radiographs and the DASH and Constant scores were collected. After scoring and adapting all images, the technical measurements were done.

\section{Results}

The median length of the clavicles after trauma was $27,16 \mathrm{~cm}$, and after 4 weeks $28,51 \mathrm{~cm}$. An average DASH score of 19,6 \pm 14,4 was seen and a Constant Score of $87,7 \pm 10,6$ after 6 weeks.

\section{Conclusion}

Midshaft clavicular fractures tend to heal with an amount of shortening, which increases in length after 6 weeks of trauma. This does not appear to influence functional outcome of the shoulder. The level of adaptations needed for adequate measuring indicates the inaccuracy of radiographs to reliably determine the degree of shortening. 


\section{INTRODUCTION}

Clavicle fractures account for 2.6 to $4 \%$ of all fractures with the majority (69-82\%) located in the midshaft. About $80 \%$ is displaced. ${ }^{25}$ This injury occurs most often in a young active population and is the result of a direct axial compressive force, caused by falls, sports or road-traffic accidents. ${ }^{27}$ There is no consensus in the treatment of displaced midshaft clavicular fractures. ${ }^{23,27,29}$ Traditionally, these fractures were treated conservatively, with provision of a sling, collar and cuff or figure-of-eight bandage during the initial phase and early mobilization (after one week) as the pain decreases.,21 This was based upon earlier studies that the majority of the fractures heal without sequelae. However, recent studies show a higher rate of nonunion and mal-union after conservative treatment than previously thought. The currently described indications for surgical treatment as seen on radiograph examination are: complete displacement and clavicle shortening exceeding $20 \mathrm{~mm}$. Because shortening caused by dislocation has been associated with shoulder dysfunction and poorer functional outcome. 3,5,6,9,13,18 Several randomized controlled trials (RCTs) have been conducted to determine whether displaced midshaft clavicle fractures should be treated operatively, to optimize union rates and functional outcome. ${ }^{3,5,21}$ However, research has not shown convincingly that operative treatment is better for these kinds of fractures. ${ }^{27}$ These same studies show that the indications for surgical treatment are mostly based on radiograph examination alone. Previous studies have already emphasized that dislocation and shortening of fractures of the clavicle cannot be adequately determined with an AP view alone. 10,18,22,24,28 Therefore, indication for surgical treatment are still not set. Our hypothesis is that 1) all displaced midshaft clavicle fractures heal with an amount of shortening after conservative treatment. 2) the amount of shortening after consolidation has no clinically important influence on functional outcome. 3) shortening measured on routine radiographic examination alone cannot be used as an indication for operative treatment. The objective of this study we want to observe and measure the length of the fractured clavicle after consolidation and during the remodeling fase with the use of technical measurements. Herewith evaluate the accuracy of the standard trauma series and the utility of shortening as an operation indication.

\section{PATIENTS AND METHODS}

Between October 2013 and December 2016 all patients with a new, dislocated midshaft clavicle fracture presented at the Emergency Department of the Meander Medical Centre (MMC) in Amersfoort were prospectively recorded and included 
in this study. This study was approved by the local medical ethics committee; reference number W15.052.

\section{Patient selection}

Inclusion criteria were: 1) complete dislocated midshaft clavicle fracture with no cortical contact between the medial and lateral fragment; 2) age $\leq 65$ years. Exclusion criteria were: 1 ) pathologic fracture (bony abnormalities at the side of the fracture); 2) open fracture; 3) a significant ipsilateral upper extremity fracture; 4) neurovascular injury of the shoulder region with objective neurological findings on physical examination; 5) a midshaft clavicle fracture more than 14 days old at first hospital visit.

\section{Outcome measures}

The primary outcome measures were: 1) shortening of the clavicle after consolidation and 2) functional outcome measured using the DASH Score and Constant Score.

\section{Shortening}

Shortening was defined as the measured decrease in length of the clavicle seen on an anterior-posterior radiograph. As a result of the imbalance of muscle forces and gravity, the medial fragment of the clavicle displaces posterior-superiorly and the lateral fragment anterior-inferiorly. This shift causes a mal-aligned fracture with a superimposition of the two fragments, which results in the shortening of the clavicle. ${ }^{5}$ Details of measurement techniques are described in following paragraphs.

\section{Functional outcome score}

The Disabilities of Arm, Shoulder and Hand (DASH) Outcome Measure is a validated self- report questionnaire of 30 items, which consists of two components: the disability/symptom section and the optional high performance Sport/Music module. ${ }^{10}$ The Constant-Murley-score is a validated questionnaire of 14 items with a subjective and objective component. ${ }^{4}$ A lower DASH-score indicates less disability, while a lower Constant-Murley-score indicates worse function of the shoulder.

\section{Follow-up}

All patients were conservatively treated, with a figure-of-eight brace. After one week all patients were seen in the outpatient clinic and physical therapy (rhomboideus training) was prescribed. Patients were then seen at 6 and 24 weeks, on all occasion the study end-points were investigated. At 6 weeks the DASH and Constant shoulder questionnaires were completed and radiographs were made. Fracture consolidation was evaluated through clinical examination and standardised radiological analysis. 
Patients with no radiographic follow-up or who underwent operative fixation after nonunion were excluded from this analysis and therefore loss to follow-up.

\section{Radiographic protocol}

The standard trauma series include an anterior-posterior radiograph and a clavicle radiograph with horizontal angle $\left(15-45^{\circ}\right)$. These series are made by different radiology technologists. After evaluation with the radiologist we found that the current protocol allows for a lot of variation in rotation, resolution and dimension.

\section{Technical drawings and measurements}

Each patient's imaging was accessed using the picture archiving and communication system of the MMC hospital; MCS Easy Care for Windows, 2016. In order to be able to perform these technical measurements we attempted to reduce the variation (i.e. in rotation and dimension) and improve the possibility to compare different images. To ensure the quality of measuring, a scoring system was used to evaluate the suitability of the images. Each image was scored (from 0 to 5 points) on resolution, perspective and the visibility of both ends of the clavicle. Images with a score of 0 were excluded from measurement.

First, all images were anonymized and transferred to Microsoft Office Powerpoint, 2013. Secondly, for every patient reference points were identified. Reference points were defined as anatomic structures visible on every image of one patient. For most of the radiographs new reference points had to be identified, because not all anatomic structures were equally visible on every image The reference structures were marked with a colored line, which was attached to the image by grouping them. By rescaling these lines on every image, the scale of each image was adjusted. At least two reference points per patient were necessary in order to get a comparable scale. Continuously, the images were aligned using extra vertical lines as a coordination-tool. Finally, the length of each clavicle, measured lengthwise from the sternal to the acromial end, was recorded. To ensure equality of the measurements, one set of figures was used for all images (Figure 1).

To define shortening, we used the derivative of the extension of the clavicle during follow-up. The difference in length measured present at trauma and after 4, respectively 16 weeks was calculated. This result was used in relation to the "new" length in order to obtain a proportional value. Afterwards, shortening was defined as a positive $\triangle$.

$\Delta$ length 4 weeks $=(($ length after 4 weeks-length at trauma)/length after 4 weeks $)$ $\Delta$ length 16 weeks $=(($ length after 16 weeks-length at trauma)/length after 16 weeks) 


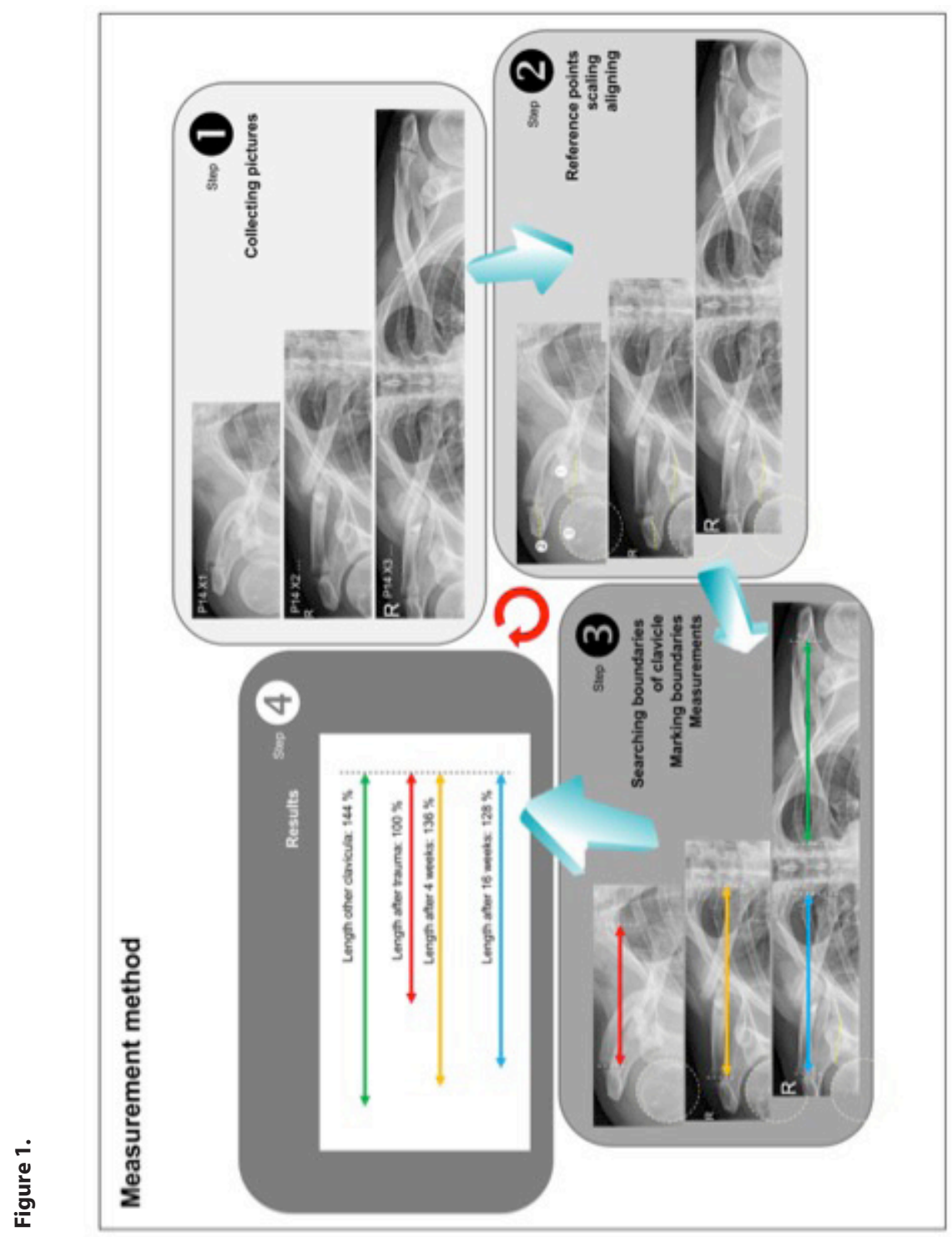


All measurements were performed by two researchers. Both checked each other's results to improve the reliability and reproducibility. The intention of our technical drawings was not to propose a new measuring matter, but to evaluate the current directive.

\section{Statistical analysis}

Statistical analysis was performed using Statistical Package for the Social Sciences (SPSS) software, Chicago for Microsoft Windows. Differences in the DASH- and the Constant-Murley-score between the treatment groups were compared with use of the independent t- test. Continuous variables were reported as mean \pm SD or median ( $25^{\text {th }}$ and $75^{\text {th }}$ inter quartile ranges) and categorical variables as number and percentages, unless otherwise stated. All tests were two-sided, and the level of significance was set at $\mathrm{p}<0.05$

\section{RESULTS}

Within the study timeframe, a total of 71 patients were included for follow-up. 22 patients were excluded by further selection.

In 10 patients the period of follow-up was too short (set at a minimum of 28 and 112 days after trauma), in 8 patients the quality of the images was insufficient to measure, one patient suffered a new trauma causing refracture during follow-up and one had a previous clavicle fracture on the ipsilateral side. Two patients were loss to follow-up. A total of 49 patients were included for further analysis.

\section{Baseline characteristics}

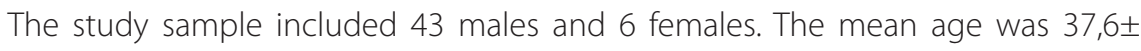
13,6 years. 11 patients were smokers. The fracture occurred in the clavicle of the dominant arm in 20 patients, and 35 of the fractures were comminutive. (Table 1)

\section{Radiographic evaluation}

The median length of the clavicles after trauma was $27,16 \mathrm{~cm}$, and after 4 weeks $28,51 \mathrm{~cm}$. In 27 patients the length after 16 weeks was measured, with a median of $27,42 \mathrm{~cm}$. (Figure 2)

In 33 patients $(67,3 \%)$ extension of the clavicle compared to trauma was seen after 4 weeks, with a mean " $\triangle$-length" of 0,02 $\pm 0,07$. After 16 weeks a mean " $\triangle$-length" of $0,48 \pm 0,509$ was calculated in 13 patients $(48,1 \%)$. Of the remaining patients reduction or constant length of the clavicle was seen during follow-up. 
Table 1. Baseline characteristics $(N=49)$

\begin{tabular}{lcl}
\hline Age & $37,6 \pm 13,6$ & \\
Male & 43 & $87,8 \%$ \\
Dominant arm & 20 & $40,8 \%$ \\
Comminutive fracture & 35 & $71,4 \%$ \\
Smoker & 11 & $22,4 \%$ \\
\hline
\end{tabular}

\section{Functional outcome}

The DASH and Constant-Murley questionnaire was completed in 49 patients (100\%) after 6 weeks. An average DASH score of 19,6 14,4 was seen and a Constant Score of 87,7 $\pm 10,6$ after 6 weeks. (Table 2) After 24 weeks 23 (47\%) DASH and Constant questionnaires were completed, with average scores of respectively 4,04 $\pm 3,8$ and $96,9 \pm 3,4$.

Table 2. Functional outcomes

\begin{tabular}{lcc} 
& $\mathbf{6}$ weeks $\mathbf{( N = 4 9 )}$ & $\mathbf{2 4}$ weeks $\mathbf{( N = 2 3 )}$ \\
DASH-score & $19,6 \pm 14,4$ & $4,04 \pm 3,8$ \\
Constant-Murley-score & $87,7 \pm 10,6$ & $96,9 \pm 3,4$ \\
\hline
\end{tabular}

\section{DISCUSSION}

The purpose of this study was to evaluate the accuracy of the standard trauma series and herewith the utility of shortening as an operation indication. We hypothesized that shortening as measured on current radiographic examination alone cannot be used as an indication for operative treatment and that there is no clinically important influence of shortening after conservative treatment on functional outcome. Nowadays, the decision on how to treat midshaft clavicle fractures still heavily depends on radiographic examination. ${ }^{6,9}$ The accuracy of these standard radiographs as a diagnostic instrument can, nonetheless, be questioned. Several previous studies have shown that standard plain unilateral radiographs are insufficient to reliably determine the degree of shortening of clavicle fractures. ${ }^{18,22,24}$ In some studies different techniques of imaging were used to evaluate the adequacy of the current standard trauma series. Both Harris et al. and Austin et al. ${ }^{2,4}$ used extra orthogonal views, of which they suggested the information relative to the amount 
of shortening, fracture displacement and comminution was improved. As a result, the two studies found an improvement in their understanding of these injuries and increase in operative treatment. Van der Ven et al. ${ }^{28}$ compared a standardized clavicle series with a rhomboideus radiograph: a standard AP radiograph in military position. These patients wore a special figure-of-eight clavicle brace to hold the clavicle in the correct alignment. On these additional views earlier observed shortening was no longer seen. All these studies confirmed our hypothesis that the current examination is not sufficient to determine shortening and subsequently use as an indication for operative treatment. Not only the accuracy of radiographic examination, but also the degree of shortening leading to an unfortunate outcome remains a topic of debate; varying from $15-20 \mathrm{~mm}$ in literature. $5,6,9,19$ Besides, these absolute values of shortening do not take into account the variations in clavicle length present in the population. ${ }^{5}$ Di Giorgi et al. ${ }^{5}$ redefined shortening as a proportional value rather than an absolute length. They calculated the percentage of shortening value as compared to the contralateral, uninjured clavicle. Their results demonstrate that shortening of more than 9,7\% is predictive of poor clinical results and problematic malunion., ${ }^{5,18}$ In our study we also used a proportional value for shortening (" $\triangle$-length"), as well as the absolute measurement of length. We calculated the length present at trauma in relation to follow-up-measurements, and, if available, compared to the contralateral, uninjured clavicle. In these 9 contralateral sides the median length was $29,89 \mathrm{~cm}$, in comparison to a median of $27,42 \mathrm{~cm} 16$ weeks after trauma at the injured clavicle. Shortening at trauma occurred in 8 of these 9 patients.

Another, subject that is under discussion in literature is the relationship of shortening on functional outcome. ${ }^{5,6,26}$ Some studies have found an association of shortening caused by dislocation and potential shoulder dysfunction 6,9,12. However, no direct correlation between the extent of shortening and the reduction in shoulder function has been found. 16,17,26 Interestingly, other studies have demonstrated no or small influence on the functional outcome., 16,17,20,26 Which is in accordance with the DASH and Constant Murley scores of our study population. Based on the above, we believe current treatment strategies should be reviewed and adjusted. In order to choose the optimal treatment, all fracture characteristics (i.e. fracture location, direction, displacement, shortening, comminution, and healing) should be considered. Operative treatment can not be confidently undertaken without having all this relevant information. ${ }^{8}$ However, we believe these characteristics should no longer be the overriding factor, as they cannot be adequately evaluated on current radiographic examination. Therefore, the recommendation of treatment of fractured clavicles should be made on a case-by-case, individualized basis with a 
prerequisite discussion of the known potential risks and benefits of both operative and non-operative management. The option of surgical treatment may be offered to patients within the premise of a reduction in the relative risk of nonunion and symptomatic mal-union and an earlier return to work or sport.

We recognize that there are some limitations to this study. First of all, the study sample was relatively small. Nevertheless, by handling strict exclusion criteria, we have created a homogeneous group of both patients and images. Another limitation of this study was the quality of the radiographs. Due to a wide variation in rotation, scale, resolution and dimension, a reliable comparison of radiological analysis of different points of follow-up or between different patients was difficult. This variation also influenced the reproducibility of our technical measurements. New reference points had to be identified, while not all anatomic structures were equally visible on every image. However, this wide variation and need for adaptation emphasizes the necessity of the evaluation of the accuracy of the standard trauma series. And therefore, shows the benefit of this study. By scoring all images we reduced this variation as much as possible. In the absence of most images of the contralateral clavicle, we have used the derivative of extension of the injured clavicle after trauma to define shortening. It is debatable whether this gives a distorted view. Hereby, the opposite effect cannot be excluded in calculating correlations. In this case the correlation between extension during follow-up and functional outcome would be calculated.

Furthermore, there were a substantial number of patients who did not return for follow-up at 24 weeks. This disabled us to compare the outcomes between 6 and 24 weeks. The loss to follow-up is frequently higher after non-operative treatment, because these patients have less commitment to return. ${ }^{27,29}$

Finally, concerning follow-up; we, unfortunately did not had a uniformly strict time schedule for clinical examination. Hereby, there is a wide variation of time in between radiographs and functional scores of different patients. This makes the comparison of these outcomes less powerful. Nonetheless, the latter points are part of the daily clinic and therefore not insurmountable. 


\section{CONCLUSION}

Our study showed that displaced midshaft clavicular fractures tend to heal with an amount of shortening, which increases in length after 6 weeks of trauma. Nevertheless, this does not appear to influence functional outcome of the shoulder. We believe that the level of adaptations needed for adequate measuring shows the inaccuracy of radiographs to reliably determine the degree of shortening. Therefore, we cannot support the current tendency towards operation indications based on radiographic examination alone. Treatment should be based on shared decisionmaking, with consideration of each patient's activity level and expectations. 


\section{REFERENCES}

1. Asadollahi S, Hau RC, Page RS, Richardson M. Complications associated with operative fixation of acute midshaft clavicle fractures. Injury, Int. J. Care Injured 2016;1248-1252. doi:10.1016/j.injury.2016.02.005

2. Austin LS, O'Brien MJ, Zmistowski B, Richetti ET, Kraeutler MJ, Joshi A et al. Additional $x$-ray views increase decision to treat clavicular fractures surgically. J Shoulder Elbow Surg. 2012 Oct;21(10):1263-8. doi:101016/j.jse.2011.08.050

3. Canadian Orthopaedic Trauma Society. Nonoperative treatment compared with plate fixation of displaced midshaft clavicular fractures. A multicentre randomized clinical trial. J Bone Joint Surg Am 2007, 89:1-10. doi:10.2106/JBJS.F.00020

4. Constant $\mathrm{CR}$, Murley $\mathrm{AH}$. A clinical method of functional assessment of the shoulder. Clinical orthopaedics and related research. 1987 Jan;(214):160-164

5. De Giorgi S, Notarnicola A, Tafuri S, Solarino G, Moretti L, Moretti B. Conservative treatment of fractures of the clavicle. BMC Research Notes. 2011;4:333. doi:10.1186/1756-0500-4-333.

6. Eskola A, Vainionpää S, Myllynen P, Pätiälä H, Rokkanen P. Outcome of clavicular fracture in 89 patients. Arch Orthop Trauma Surg 1986, 105:337-338.

7. Figueiredo et al. Correlation of the degree of clavicle shortening after non-surgical treatment of midshaft fractures with upper limb function. BMC Musculoskeletal Disorders 2015;16:151. doi:10.1186/s12891-015-0585-3

8. Harris JD, Latshaw JC. Improved clinical utility in clavicle fracture decision-making with true orthogonal radiographs. Int J Shoulder Surg. 2012 Oct;6(4):130-4. doi: 10.4103/0973-6042.106227.

9. Hill JM, McGuire MH, Crosby LA. Closed treatment of displaced middle- third fractures of the clavicle gives poor results. J Bone Joint Surg Br 1997; 79:537-539
10. Hudak PL, Amadio PC, Bombardier C. Development of an upper extremity outcome measure: the DASH (disabilities of the arm, shoulder and hand) [corrected]. The Upper Extremity Collaborative Group (UECG). Am J Ind Med 1996; 29:602-608.

11. Jones GL, Bishop JY, Lewis B, Pedroza AD; MOON Shoulder Group. Intraobserver and interobserver agreement in the classification and treatment of midshaft clavicle fractures. AM J Sports Med 2014;42: 1176-81. doi: 10.1177/0363546514523926. Epub 2014 Feb 26.

12. Lazarides S, Zafiropoulos G, Tydfil M. Conservative treatment of fractures at the middle third of the clavicle: the relevance of shortening and clinical outcome. J Shoulder Elbow Surg. 2006;15:191-194. doi: 10.1016/j. jse.2005.08.007

13. McKee RC1, Whelan DB, Schemitsch EH, McKee MD. Operative versus nonoperative care of displaced midshaft clavicular fractures: a meta-analysis of randomized clinical trials. J Bone Joint Surg Am. 2012 Apr 18; 94(8):675-84. doi: 10.2106/JBJS.J.01364.

14. Mc Knight B, Heckmann N, Hill JR, Pannel WC, Mostofi A, Omid R, Hatch GF. Surgical management of midshaft clavicle nonunions is associated with a higher rate of short-term complications compared with acute fractures. J Shoulder Elbow Surg (2016)25, 1412-1417. doi:10.1016/j. jse.2016.01.028

15. Murray IR, Foster CJ, Eros A, Robinson CM. Risk factors for nonunion after nonoperative treatment of displaced midshaft fractures of the clavicle. J Bone Joint Surg Am 2013;95:1153-8. doi: 10.2106/JBJS.K.01275

16. Nordqvist A, von Scheele A, Petersson CJ. Shortening of the clavicle after fracture: incidence and clinical significance, a 5-year follow-up of 85 patients. Acta Orthop Scand. 1997;68:349-351. 
17. Nowak J, Holgersson M, Larsson S. Can we predict long-term sequelae after fractures of the clavicle based on initial findings? A prospective study with nine to ten years follow-up. J Shoulder Elbow Surg. 2004;13:479-486. doi:10.1016/ S1058274604000436

18. Omid R, Kidd C, Yi A, Villacis D, White E. Measurement of clavicle fracture shortening using computed tomography and chest radiography. Clin Orthop Surg 2016;8:367372. doi:10.4055/cios.2016.8.4.367

19. Postacchini R, Gumina S, Farsetti P. Longterm results of conservative management of midshaft clavicle fracture. Int Orthop. 2010;34:731-736. doi: 10.1007/s00264-0090850-x. Epub 2009 Aug 10.

20. Rasmussen JV, Jensen SL, Petersen JB, Falstie-Jensen T, Lausten G, Olsen BS. A retrospective study of the association between shortening of the clavicle after fracture and the clinical outcome in 136 patients. Injury. 2011;42:414-417. doi: 10.1016/j.injury.2010.11.061. Epub 2011 Jan 15.

21. Robinson CM, Court-Brown CM, McQueen MM, Wakefield AE. Estimating the risk of nonunion following nonoperative treatment of a clavicular fracture. J Bone Joint Surg Am 2004;86:1359-65. PMID:15252081

22. Sharr JR, Mohammed KD. Optimizing the radiographic technique in clavicular fractures. J Shoulder Elbow Surg 2003;12:170-2. doi:10. 1067/mse.2003.23

23. Smeeing DPJ, van der Ven DJC, Hietbrink F, Timmers TK, van Heijl M, Kruyt MC, Groenwold $\mathrm{RHH}$, van der Meijden OAJ, Houwert RM. Surgical versus nonsurgical treatment for midshaft clavicle fractures in patients aged 16 years and older. A systematic review, meta-analysis, and comparison of randomized controlled trials and observational studies. The American Journal of Sports Medicine. doi:10.1177/0363546516673615
24. Smekal $V$, Deml C. Irenberger $A$, Niederwanger C, Lutz M, Blauth $M$ et al. Length determination in mid-shaft clavicle fractures: validation of measurement. J Orthop Trauma. 2005;22:458-462. doi:10.1097/BOT.0b013e318178d97d.

25. Stegeman SA, de Jong M, Sier CF, Krijnen P, Duijff JW, van Thiel TP et al. Displaced midshaft fractures of the clavicle: nonoperative treatment versus plate fixation (Sleutel-TRIAL). A multicentre randomised controlled trial. BMC Musculoskelet Disord. 2011 Aug 24;12:196. doi: 10.1186/14712474-12-196.

26. Stegeman SA, de Witte PB, Boonstra $S$, de Groot JH, Nagels J, Krijnen P, Schipper IB. Posttraumatic midshaft clavicular shortening does not result in relevant functional outcome changes. Observations in 32 healed, nonoperatively treated fractures. Acta Ortopedica 2015;86 (5): 545552

27. Van der Ven Denise JC, et al. Plate fixation versus conservative treatment of displaced midshaft clavicle fractures \pm Functional outcomes and patients' satisfaction during a mean follow/up of 5 years. Injury 2015. doi: 10.1016/j.injury.2015.08.004

28. Van der Ven DJC, Timmers TK, Welsing RTC, van Olden GDJ. Radiographic examination alone is not a good indication for surgical intervention of displace midshaft clavicle fractures. Journal of Orthopedics, Traumatology and Rehabilitation. Manuscript pre-publication.

29. Woltz S, Stegeman SA, Krijnen P, van Dijkman BA, van Thiel TPH et al. Plate fixation compared with nonoperative treatment for displaced midshaft 



\section{ADDENDUM TWO}

Biomechanical testing of anterior and superior plate positioning in midshaft clavicle fractures based on a finite elements model 


\section{INTRODUCTION}

Clavicle fractures are mostly caused by a direct axial compressive force to the shoulder. Eighty percent of the fractures is located in the middle third of the clavicle. These midshaft fractures have traditionally been treated nonoperatively. However, recent literature shows higher incidence of nonunion after conservative treatment than previously described. Subsequently, the trend to treat these fractures surgically is rising. ${ }^{4-10}$ The currently described surgical techniques are intramedullary nails, or open reduction and internal plate fixation. ${ }^{23}$ Both intramedullary and plate fixation are considered safe. They have similar complication risks. Plate fixation is the preferred technique, if the surgeon is skilled in this technique and has a better patient recovery rate. ${ }^{11-13,28-30}$ Operative treatment, with removal of the fracture hematoma, leads to direct fracture healing. Direct fracture healing only occurs when there is an anatomic reduction of the fracture fragments, a rigid internal fixation and a decreased intrafragmentary strain. ${ }^{19}$

Any deficit expressed at the healing cycle alters the physiological sequence of fracture healing. These deficits predispose to complications. Nonunion, implant failure and re-fracture after necessary implant removal still occurs after plate fixation. Therefore, in order to enable the physiological process of fracture healing to progress to union, well-timed and well-aimed interventions are needed. Particularly with hard-to-heal fractures, such as displaced midshaft clavicle fractures. ${ }^{26,27,1,6,18}$ In plate fixation two locations are used, the superior and the anterior location at the clavicle. Both locations appear to be safe in the treatment of displaced midshaft clavicle fractures. The major benefit of anteroinferior plating is that it avoids the most superficial, superior aspect of the clavicle and is hypothesized to reduce complaints associated with implant prominence. ${ }^{15,16}$ In addition, the clavicle has a larger anteroinferior to posterior position; therefore longer screws can be used. However, some biomechanical studies found a higher fracture rigidity and stiffness in the superior position. ${ }^{14,17}$ Overall, there is no conclusive evidence on better rigidity and strain and there is no consensus in clinical evidence for both plate locations mostly due to limited knowledge on the load (direction and amplitude of forces) on the clavicle during and after rehabilitation. 12,13,15-17 In the previous study of van der Ven et al. a three dimensional model is made considering the loads on the clavicle and plates. ${ }^{34}$ The goal of this study is to execute a biomechanical experiment to test the forces on this model of plates and simulated clavicle 


\section{METHODS}

\section{Clavicle forces}

The previous study of van der Ven et al. ${ }^{34}$ created a finite element model of a clavicle, anterior and superior plate. Musculoskeletal modeling and finite element analysis (FEA) were used to determine the effects of activities of daily life on the clavicle. Also, plate stresses were determined for both superior and anteroinferior plate fixation. In this model the forces of seven influences of the clavicle have been simulated for two motions of the arm. The forces of the Pectoralis major, Trapezoid, Deltoid muscles, conoid ligament and acromioclavicular and sternoclavicular joint are described in the Delft shoulder and elbow model. Next to these forces, the influence of the sternocleidomastoid muscle, based upon values of the literature, was used. ${ }^{20-22,34}$

\section{Net force calculation}

The forces of the anatomical structures were simplified unto one force for the experiment. The FEA model has 21 degrees of freedom (df), one df for every force in three directions. To translate these df into a biomechanical model the amount of df need to be reduced. The forces and directions have been recalculated into four net forces: one net force for the lateral part of the clavicle, one net force for the medial part of the clavicle. The lateral and medial force vector is calculated for the abduction and anteflexion of the arm. The conoid ligament, the acromioclavicular joint and the trapezoid and deltoid muscle forces in three directions were combined into the lateral net force. The sternocleidomastoid and pectoralis major muscle and the sternoclavicular joint in three directions were combined into the medial net force. First the net forces of the three directions were calculated by the following equation: $F_{r}=F_{1}+F_{2}+F_{3}+\cdots$ The three net forces, in $x, y$ and $z$ direction were added up into one force amplitude. These net forces in the three directions were used to calculate the resulting net force at the medial and lateral part by the following equation: Magnitude $=\sqrt{2+y^{2}+z^{2}}$.24 The initial force distribution and the simplified net forces are visualized in appendix $A$.

\section{Plate fixation}

Eight midshaft VariAx clavicle locking plates were available for the experiment. Four superior and four anterior plates with eight holes of 3.5 millimeters for the left clavicle were used (Stryker, Michigan). The plates were fixed with three screws on each side of the fracture. The middle screws on the lateral and medial side were 3.5 
millimeters tapping titanium cortical screws. The other four screws were locking screws varying in length (Stryker, Michigan). Al screws were fixated bicortical. Screw fixation in both cortices gives better rigidity and strain to the clavicle.11, 13, 14 The length of the screws used to fixate the plate per clavicle can be seen in Table 1. The plates were fixed on a clavicle Sawbone using a bench vice and repositioning clamps. The Sawbones were 17 centimeters long and had a left orientation. Next, ten Sawbones were identically prepared with a fracture in the mid-shaft area. An oblique fracture was made using an electric rail cutting precision saw (Forest Drapery hardware group, Netherlands) in an angle of 45 degrees. The fracture is made at eight centimeters from the lateral side at the mid shaft of the Sawbone. ${ }^{25}$

\section{Mechanical tests}

Table 1. the forces in clavicle in three directions and the net force for the two motions at the medial and lateral part of the clavicle in Newton:

\begin{tabular}{lcc}
\hline Motion & Location / Direction & Force (N) \\
\hline Abduction & Medial x & 69.64 \\
Medial y & Medial z & 212.84 \\
Abduction & Medial total & 52.54 \\
& Lateral x & 230.02 \\
Anteflexion & Lateral y & -72.83 \\
& Lateral z & -28.03 \\
& Lateral total & -52.19 \\
Anteflexion & Medial x & 93.88 \\
& Medial y & 84.64 \\
& Medial z & 175.55 \\
& Medial total & 35.16 \\
& Lateral x & 198.04 \\
\hline
\end{tabular}


To set up the mechanical tests a prototype of the plates has been made and assembled to a Sawbone for primary validation of the test setting. A schematic overview of the setting can be seen in Figure 1A. For the experiment the Sawbones were put at the medial side in a small cup filled with two-component epoxy adhesive (araldite 2011 epoxy adhesive, Switzerland). The repaired Sawbones were tested in a setting, which can be seen in Figure 1B. The epoxy adhesive cube is fixed in a clamp of two brass plates. At the lateral side of the clavicle a dyneema wire of three millimeters with PES mantle T-3790 (Royal DSM N.V., Netherlands) was connected using a double round turn and two half hitch knots. The other side of the wire was connected to the middle part of a lever by a clove hitch knot. The

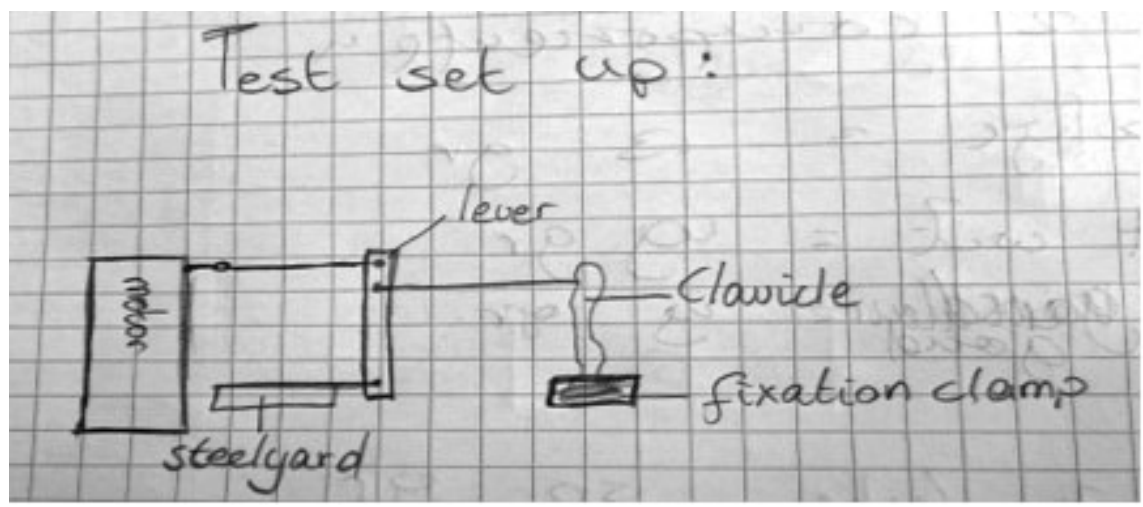

Figure 1A. The schematic set up of the experiment.

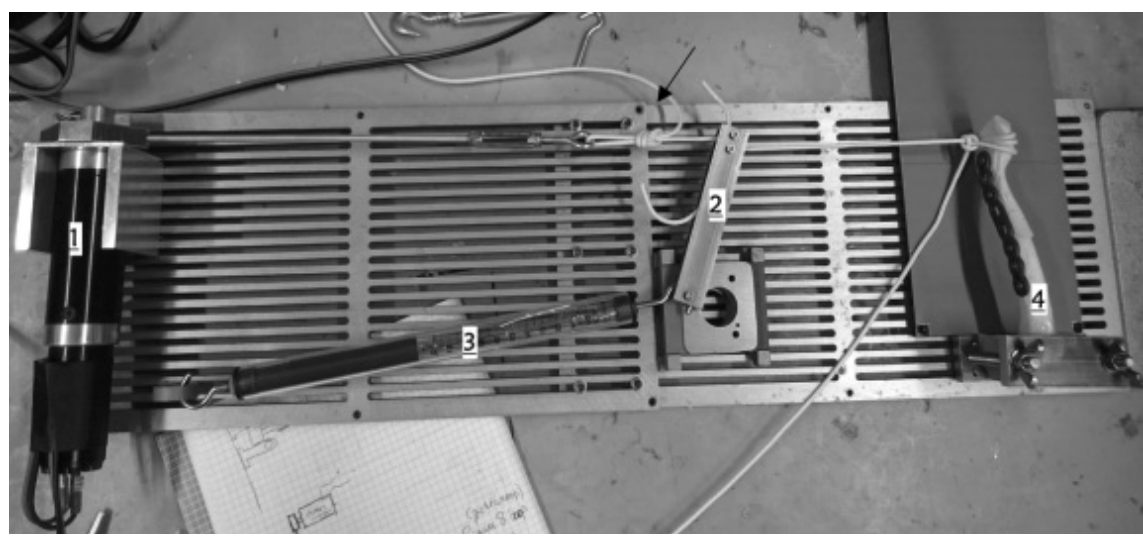

Figure 1B. The test setting for the repaired sawbones. 1 is the motor used for the repetitive eccentric movement, 2 is the lever used for the display for force, 3 is the steelyard and 4 is the clavicle assemble. At the arrow the connection to the motor and the lever can be seen. This is the figure eight loop knot. 
closest part of the lever was connected by a wire to a metal eye. At the lever side the wire was connected via a clove hitch and at the metal eye a figure eight loop knot was used.

The metal eye was connected to an eccentric moving bearing around the axis of a Maxon DC motor as can be seen in Figure 2 (Maxon motor, Switzerland).

At the other side of the lever a steelyard was used to display the forces working on the clavicle by the motor movement. This can be seen in Figure 1A/B. The distance ratio between the connections in the lever are 1:10. Therefore the force in the steelyard will be ten times smaller. The motor was placed in the most left position. The clavicle was then placed in the clamp and the wires spanned. The connection part left to the figure eight loop knot (Figure 1A/B at the black arrow) has a left and right screw thread therefore it can be used to put more load on the clavicle. The load on the clavicle was increased to the intended forces. The motor then starts and makes 2500 eccentric motions to simulate arm movement. 2500 is the equivalent to the motions of an arm during revalidation and the year after implantation.

To measure the displacement at the clavicle fracture gap and the plates the test

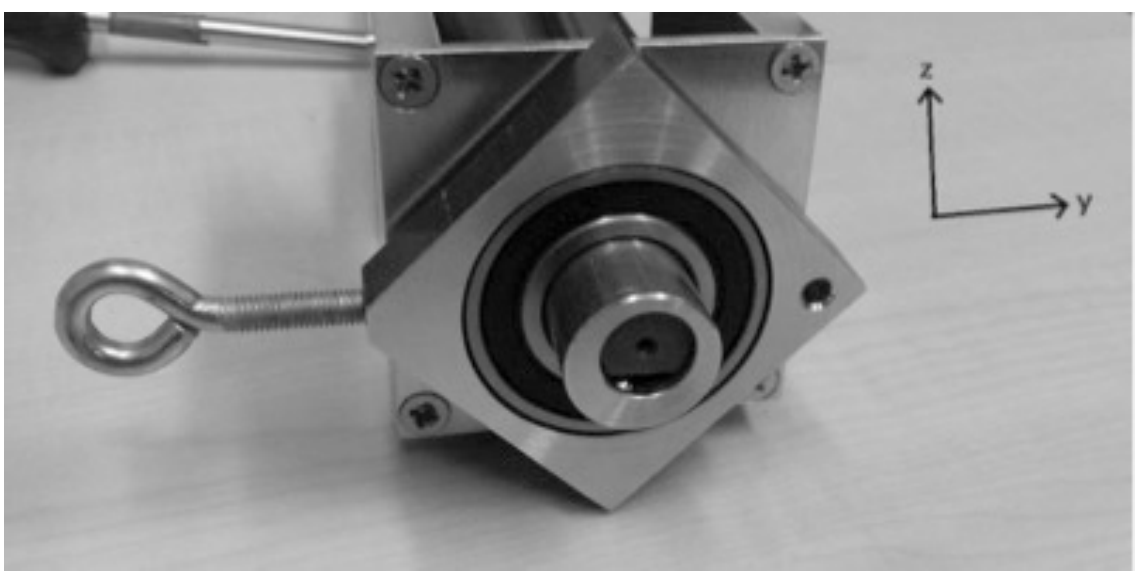

Figure 2. The axis of the motor is surrounded by a brass ring. The brass ring inner circle midpoint is placed $2 \mathrm{~mm}$ of the centre of the motor axis. The ring is imbedded in a bearing. The bearing is glued in to a brass block with a stainless steel eye. 
setting was built in front of a grey plane. In this grey plane a line was placed. At the far side of this grey plane a camera was placed fifty centimeters from the clavicle. This camera records the experiment. The movie is recorded by Matlab and was exported into Matlab data. The images were digitally subtracted in Matlab 2017a, so the displacement of the Sawbone and plate will be visible in the resulting image.

\section{RESULTS}

The calculated forces are denoted in Table 1. The sum of the forces in the $x, y$ and $z$ direction are denoted for abduction and anteflexion. These sum of forces are calculated to a net force for the medial and lateral part of the clavicle for abduction and anteflexion. The net force is given as the total force in Table 1. These net forces are put together for one load amplitude on the clavicle to use in the clamp. In Table 2 the net force used for the experiment is denoted. The three directions are calculated into one net force.

In Figure $3 A / B$ the starting position of the experiment is visualized of both plate

Table 2. The net forces of the motions are denoted in the three directions and the final amplitude of the net force.

\begin{tabular}{lcc}
\hline Motion & Direction & Net force $(\mathbf{N})$ \\
\hline Abduction & $x$ & $-3,19$ \\
& $y$ & 184,81 \\
Anteflexion & $z$ & 0,35 \\
& Totaal & 184,84 \\
& $x$ & 7,49 \\
& $y$ & 111,33 \\
& $z$ & $-7,9$ \\
\hline
\end{tabular}

positions. The total length of the plate is visible. The clavicle is fixed in two component epoxy adhesive. Every clavicle is placed in $50 \mathrm{~g}$ of the premixed adhesive. During the increase of the load on the clavicle the Sawbone breaks. In the case of the prototype plate the clavicle broke at 20-30N. The Sawbone with the superior and anterior plates broke around 30N. The fracture of the Sawbone was at the most medial screw of the structure. 


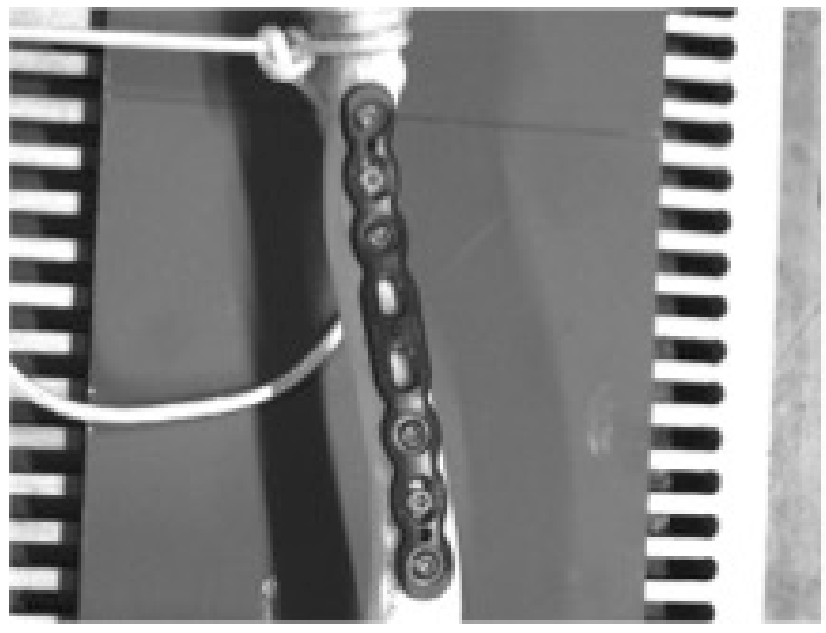

Figure $\mathbf{3 A}$. is the starting position for the anterior plate

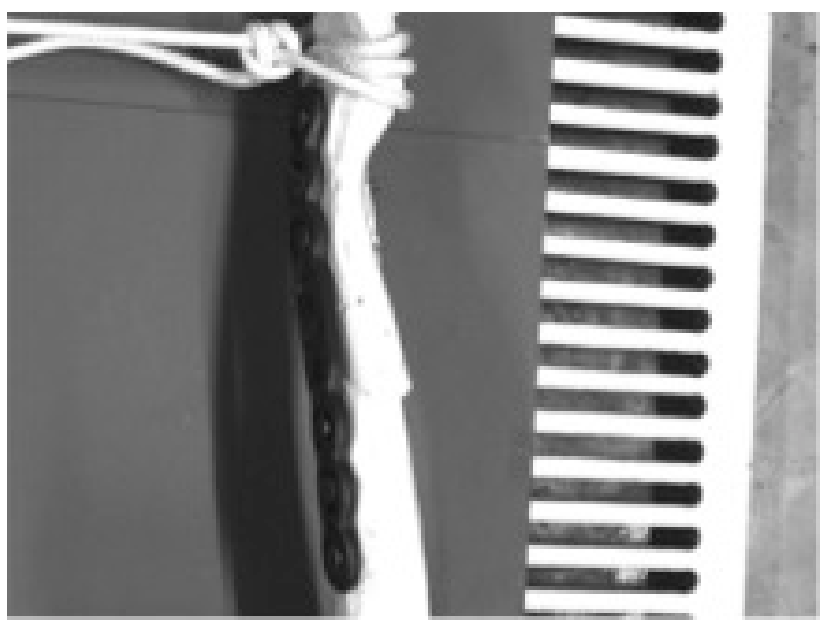

Figure $\mathbf{3 B}$. is the starting position of the superior plate.

\section{DISCUSSION}

Higher risks to non-union in mid shaft clavicle factures increase the choice to treat surgically. Debate on the benefits of the anterior and superior plate position raise the question which one has the best properties. With a biomechanical experiment the rigidity is tested to obtain knowledge on the best position for the plate. 
The plates were fixated to solid foam Sawbones. The material of the Sawbones was not sufficient for the purpose of the experiment. ${ }^{32}$ The plastic had not enough rigidity. The material should at least be able to withstand a load of $250 \mathrm{~N}$. The solid foam Sawbone was assumed as a strong enough clavicle simulation.

The other materials used for the experiment will influence the outcome as well. The stainless steel grid used as surface for the setup and the brass used for the lever will deform by the forces applied. The ultimate tensile strength of brass and stainless steel are over the $500 \mathrm{~N}$ per square millimeter. Therefore the deformation will be very small. ${ }^{33}$ The dyneema wire (Royal DSM N.V., Netherlands) can bear up to 300 kilograms and has a low strain. In this case the deformation will have a larger impact. The knots in the dyneema wire will become tighter after a load is placed to the setting. The tighter the knot becomes the ends of the knots become longer. Thus the wire will become longer if the knots tighten. To work the setting with the prototype used for validation the knots would tighten and most of the variation will already be taken care of.

In the test setting the motor has an eccentric motion of 4 millimeters. The center of the first brass ring is placed two millimeters outside the center of the motor axis. Therefore the motor swings out four millimeters in y and $z$ direction respectively to the clavicle dimensions (Figure 1). Considering the bone like material used for the experiment, the swing out of four millimeters could not be sufficient. The load in the outer y position should be up to $250 \mathrm{~N}$ and $0 \mathrm{~N}$ at the inner y position. This might not be reached in four millimeters.

With complete rigidity in the clavicle the current developed setting can have a maximum load of $400 \mathrm{~N}$. The swing out of the motor is 4 millimeters. Therefore the maximum swing out in the steelyard is 40 millimeters. The steelyard displays $40 \mathrm{~N}$. Thus the maximum load is $400 \mathrm{~N}$. A larger or smaller load can be given is a different steelyard is used.

The clavicle sawbones were placed in the epoxy adhesive. To do this the clavicle was placed in a clamp at the lateral side and placed in a cup with the adhesive at the medial side. The orientation of the clamp was fixed however the clavicle varies in orientation. These variations are due to the clavicle sawbones, who diversify, and the superior and anterior plate assembled to the Sawbone. There are slight variations in the angle and rotation visible. This could influence the results during the repetitive tests. The fixation of the Sawbone in the epoxy adhesive also can alter the outcome. The properties of this solid need to be taken into account. The 
adhesive need to be properly mixed in a ratio pale yellow: neutral of 8:10 by weight and 1:1 by volume. In this case the material becomes the hardest. It retrieves a flexural strength of $60 \mathrm{~N}$ per square millimeter.

In this study the gravitational force on the clavicle and plate was not taken into account. The clavicle bone has a weight of $20 \mathrm{~g}$. The gravitational force would be $0.2 \mathrm{~N} .{ }^{31}$ This was considered not relevant in the forces working on the clavicle by muscular action. The amount of motions chosen to simulate arm motion in the first years after implantation is based upon the clinical experience of a trauma surgeon. Literature has no conclusive data on the amount of loads a clavicle undergoes. More specific research could lead to an optimal amount of motions for simulation. In the superior plates variation in screw length is used. This could lead to lesser or better fixation of the plate in some cases. To have proper results the fixation ought to be equal. To compare the superior to the anterior plate the fixation of both plate variations should be comparable without inter-variation.

In conclusion, the test setting build can be used to test the clavicles. The lever used makes it easy to read the forces working on the clavicle. The Sawbone material was not strong enough to withstand forces needed for the experiment.

\section{RECOMMENDATION}

To be able to execute the experiment a material that can withstand at least $250 \mathrm{~N}$ pulling force is needed. These materials need to have a physical property to be able to carry the implant on the surface by the use of six screws.

Materials that match these conditions are the composite Sawbones build for the purpose of biomechanical testing. Mammalian bone grafts, human bone grafts or tissue engineered bone grafts could also be. However the anatomical difference, thus the density caused by osteoporosis, might be too large in the bone grafts. The tissue engineered Bone graft can be built to the exact wishes for the tests. A clavicle made out of a composite material, e.g. another clavicle made by Sawbone is most likely to have the best results. It has the properties for biomechanical testing and is less expensive compared to engineered bone grafts. 


\section{REFERENCES}

1. van Olden. Clavicula fracturen. n.a., 2017. https://www.sleutelbeen.info.nl

2. Mulgrew and M. Ravenscroft. Adult fractures and dislocations of the shoulder and elbow. Surgery (United Kingdom), 31(4):162-167, 2013.

3. M. Pecci and J.B. Kreher. Clavicle fractures. American Family Physician, 77(1):6570+71, 2008.

4. Van der Ven, T.K. Timmers, P.E. Flikweert, A.L.A. Van ljseldijk, and G.D.J. Van Olden. Plate fixation versus conservative treatment of displaced midshaft clavicle fractures: Functional outcome and patients' satisfaction during a mean follow-up of 5 years. Injury, 46(11):2223-2229, 2015.

5. Meijden, T.R. Gaskill, and P.J. Millett. Treatment of clavicle fractures: Current concepts review. Journal of Shoulder and Elbow Surgery, 21(3):423-429, 2012.

6. Coupe, J.A. Wimhurst, R. Indar, D.A. Calder, and A.D. Patel. A new approach for plate fixation of midshaft clavicular fractures. Injury, 36(10):1166-1171, 2005.

7. Hulsmans, M. Van Heijl, R.M. Houwert, T.K. Timmers, G. Van Olden, and E.J.M.M. Verleisdonk. Anteroinferior versus superior plating of clavicular fractures. Journal of Shoulder and Elbow Surgery, 25(3):448454, 2016.

8. McKee, H.J. Kreder, S. Mandel, R. McCormack, R. Reindl, D.M.W. Pugh, D. Sanders, R. Buckley, E.H. Schemitsch, L.M. Wild, E. Harvey, J.A. Hall, M.V. Santos, C.J. Veillette, D.B. Whelan, J.P. Waddell, D.J.G. Stephen, T.A. Axelrod, G. Berry, B. Perey, K. Panagiotopolous, B. Bulmer, M. Zomar, K. Moon, E. Kimmel, C. Erho, E. Lakoub, P. Leclair, B. Sobchak, and T.B. Stone. Nonoperative treatment compared with plate fixation of displaced midshaft clavicular fractures: A multicenter, randomized clinical trial. Journal of Bone and Joint Surgery - Series A, 89(1):1- 10, 2007.
9. Malik, G. Chiampas, and H. Leonard. Emergent evaluation of injuries to the shoulder, clavicle, and humerus. Emergency Medicine Clinics of North America, 28(4):739-763, 2010.

10. Hill, M.H. McGuire, and L.A. Crosby. Closed treatment of displaced middle third fractures of the clavicle gives poor results. Journal of Bone and Joint Surgery - Series B, 79(4):537-539, 1997.

11. [lannotti, L.A. Crosby, P. Stafford, G. Grayson, and R. Goulet. Effects of plate location and selection on the stability of midshaft clavicle osteotomies: A biomechanical study. Journal of Shoulder and Elbow Surgery, 11(5):457-462, 2002. cited By 83.

12. Harnroongroj and V. Vanadurongwan. Biomechanical aspects of plating osteosynthesis of transverse clavicular fracture with and without inferior cortical defect. Clinical Biomechanics, 11(5):290294, 1996.

13. Celestre, C. Roberston, A. Mahar,R. Oka, M. Meunier, and A. Schwartz. Biomechanical evaluation of clavicle fracture plating techniques: Does a locking plate provide improved stability? Journal of Orthopaedic Trauma, 22(4):241-247, 2008.

14. Bravman, M.L. Taylor, T. Baldini, and A.F. Vidal. Unicortical versus bicortical locked plate fixation in midshaft clavicle fractures. Orthopedics, 38(5):e411-e416, 2015.

15. Collinge, S. Devinney, D. Herscovici, T. DiPasquale, and R. Sanders. Anteriorinferior plate fixation of middle-third fractures and nonunions of the clavicle. Journal of Orthopaedic Trauma, 20(10):680686+746-747, 2006.

16. Formaini, B.C. Taylor, J. Backes, and T.J. Bramwell. Superior versus anteroinferior plating of clavicle fractures. Orthopedics, 36(7):e898-e904, 2013. 
17. Taylor, R.E. Day, R.L. Nicholls, J. Rasmussen, P.J. Yates, and K.K. Stoffel. The comminuted midshaft clavicle fracture: A biomechanical evaluation of plating methods. Clinical Biomechanics, 26(5):491-496, 2011.

18. Böstman, M. Manninen, and H. Pihlajamäki. Complications of plate fixation in fresh displaced midclavicular fractures. Journal of Trauma - Injury, Infection and Critical Care, 43(5):778-783, 1997.

19. Sathyendra and M. Darowish. Basic science of bone healing. Hand Clinics, 29(4):473481, 2013.

20. van der Helm. A finite element musculoskeletal model of the shoulder mechanism. Journal of Biomechanics, 27(5):551- 553,555-569, 1994.

21. van der Helm. Analysis of the kinematic and dynamic behavior of the shoulder mechanism. Journal of Biomechanics, 27(5):527-550, 1994.

22. [Asadi Nikooyan, H.E.J. Veeger, E.K.J. Chadwick, M. Praagman, and F.C.T. Van Der Helm. Development of a comprehensive musculoskeletal model of the shoulder and elbow. Medical and Biological Engineering and Computing, 49(12):1425-1435, 2011.

23. Ni, W. Niu, D.W.C. Wong, W. Zeng, J. Mei, and M. Zhang. Finite element analysis of locking plate and two types of intramedullary nails for treating mid-shaft clavicle fractures. Injury, 2016.

24. Holzner. Physics I workbook for dummies $2^{\text {nd }}$ edition. Wiley brand. 336 pages. 2014

25. Miller-Keane Encyclopedia and Dictionary of Medicine, Nursing, and Allied Health, Seventh Edition. Oblique fracture. 2003. Saunders, an imprint of Elsevier, Inc.

26. Dimitriou, E. Tsiridis, P.V. Giannoudis. Current concepts of molecular aspects of bone healing. Injury. 2005.

27. Giannoudis, T.A. Einhorn, D.Marsh. Fracture healing: The diamond concept. Injury. 2007
28. Hussain, C. Sermer, P.J. Prusick, L. Banfield, A. Atrey, M. Bhandari. Intramedullary Nailing Versus Plate Fixation for the Treatment Displaced Midshaft Clavicular Fractures: A Systematic Review and Meta-Analysis. Scientific Reports. Volume 6, 20 October 2016, Article number 34912.

29. Wang, L. Cheng, W.J. Guo, A.B. Li, G.J. Cheng, T. Lei, Y.M. Zhao. Plate versus intramedullary fixation care of displaced midshaft clavicular fractures: A meta-analysis of prospective randomized controlled trials. Medicine. Volume 94, Issue 41, 2015, Article number e1792

30. Van Der Meijden, M.R. Houwert, M. Hulsmans, F.J.G. Wijdicks, M.G.W. Dijkgraaf, S.A.G. Meylaerts, E.R. Hammacher, M.H.J. Verhofstad, E.J.M.M. Verleisdonk. Operative treatment of dislocated midshaft clavicular fractures: Plate or intramedullary nail fixation? Journal of Bone and Joint Surgery. Volume 97, Issue 8, 15 April 2015, Pages 613-619

31. Balvir, M.S.M. Bashir, A.S. Rahule, P. Badwaik. Determination of bilateral asymmetry of clavicle in the population of Vidarbha region of Maharashtra. Indian Journal of Public Health Research and Development. Volume 5, Issue 2, 1 April 2014, Pages 44-46

32. Sawbones, inc. clavicle left normal anatomy. Sawbones.com. 5 April 2017 accessed. Copyright to Sawbones

33. Matweb - material property data. Overview of materials. Matweb.com. accessed 5 April 2017. Copyright Matweb LLC.

34. van der Ven DJC, A. M.L. Meesters, N.W. Schurink, G.D.J. van Olden, T.K. Timmers, K. H. Slump, I.A.M.J. Broeders. Musculoskeletal modeling of midshaft clavicle fractures by using finite element analysis -manuscript. 


ADDENDUM THREE

Appendix Clavicle modeling 


\section{Appendix I}

\section{Additional information about the model}

Bolsterlee et al. ${ }^{3}$ published the EMG and joint angle data needed for the DSEM. Data was acquired from five healthy patients, 3 males and 2 females of mean age $29.2 \pm 2.0$ years, average height $176.3 \pm 6.4$ centimeters, average weight $79.5 \pm 16.6$ kilograms and average total muscle volume $2392.3 \pm 708.6 \mathrm{~cm}^{3}$. Subjects had no shoulder complaints or special training prior to EMG and joint angle acquisition.

Within the DSEM, the following global and local (clavicular) coordinate systems were defined. ${ }^{12}$ The global $x$-axis points laterally from the incisura jugularis (IJ), perpendicular to a plane fitted through processus spinale of $C 7$, processus spinale of T8, incisura jugularis and processus xiphoideus. The y-axis points upwards from the middle between the processus xiphoideus and processus spinale T8 towards the middle between the incisura jugularis and procesuss spinale $\mathrm{C7}$. The $z$-axis points backwards, perpendicular to the $x$ - and $y$-axes.

The local (clavicular) positive $x$-axis is defined as going from the incisura jugularis to acromioclavicular (AC) joint, the local positive z-axis is perpendicular to the line described by the incisura jugularis and cranium and to the $x$-axis, pointing posterioranteriorly, the local $y$-axis is defined perpendicular to $x$ - and z-axis pointing upward (Figure 1).

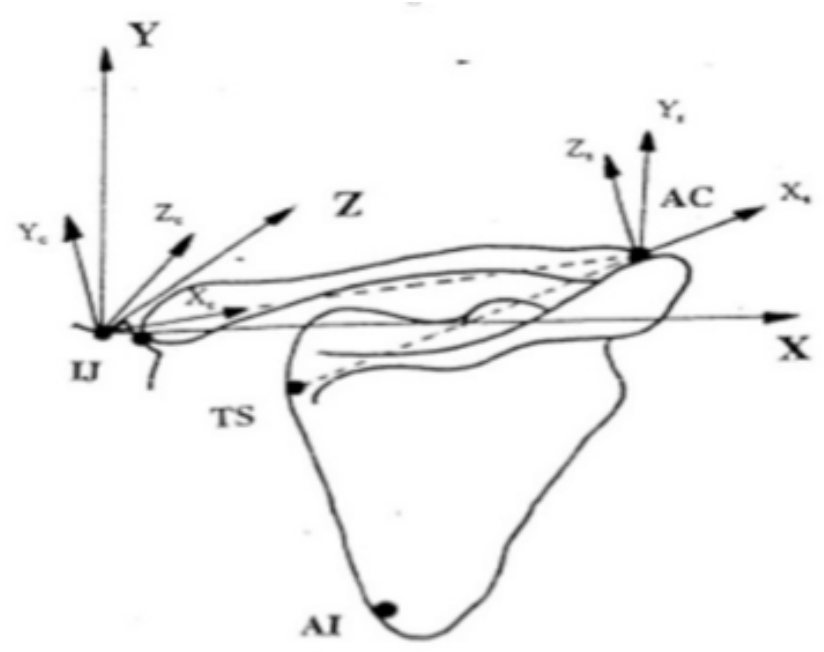

Figure 1. Global and local coordinate system of the DSEM. Adjusted from Klein Breteler (1996). 12 
In order to test the strength of different plate fixation techniques during different motions, a (left) clavicle finite element model was made of only the cortex. The FEM (finite element model) was made using a CT dataset that has been made publicly available (Laboratory of Human Anatomy and Embryology, University of Brussels (ULB), Belgium). The clavicle cortex was segmented from the dataset and exported as STL mesh file, using grayscale thresholded 3D active contour segmentation using freely available segmentation software (ITK-Snap 3.4.0-rc1, University of Pennsylvania and Utah, United States). The 3D mesh was smoothened by Laplacian smoothing and remeshed by Poisson surface reconstruction, using a freely available software package (MeshLab, Visual ComputingLab, ISTI - Italian National Research Council). The mesh was then converted to a solid, using the ScanTo3D add-in of commercially available modelling software (SolidWorks 2016 x64 Edition, Dassault Systèmes S.A., Vélizy, France). The same software was used to introduce a midshaft fracture into the model. The model was scaled to have a length of $19.1 \mathrm{~cm}$ to match that of the DSEM. The solid was then meshed for FEA, using a minimum element size of $0.067 \mathrm{~cm}$, maximum element size of $0.335 \mathrm{~cm}$ and a growth ratio of 1.1. The growth ratio was chosen as low as possible as, according to the software's manual, this results in the highest FEA accuracy. All other parameters were left default.

\section{Appendix II}

\section{Results from the Delft Shoulder and Elbow Model}

The total muscle force has been calculated for each of the muscles during abduction and anteflexion (Figures 2 and 3). The deltoid muscle is the largest contributor of force during both motions. In both cases, the maximum force does not exceed $50 \mathrm{~N}$. A difference can be seen in the activation patterns of the trapezius and pectoralis major muscle during both motions. The joint and ligament forces were also calculated (Figures 4 and 5). The force within the costoclavicular and trapezoid ligaments remain zero during the movements, as they are not implemented in the DSEM model.

On average, the joint and ligament forces are 30\% higher during abduction than in anteflexion. The maximum force during abduction does not exceed $130 \mathrm{~N}$, while during anteflexion it does not exceed $100 \mathrm{~N}$. A difference can be seen in the course of the sternoclavicular joint reaction force during abduction and anteflexion. 


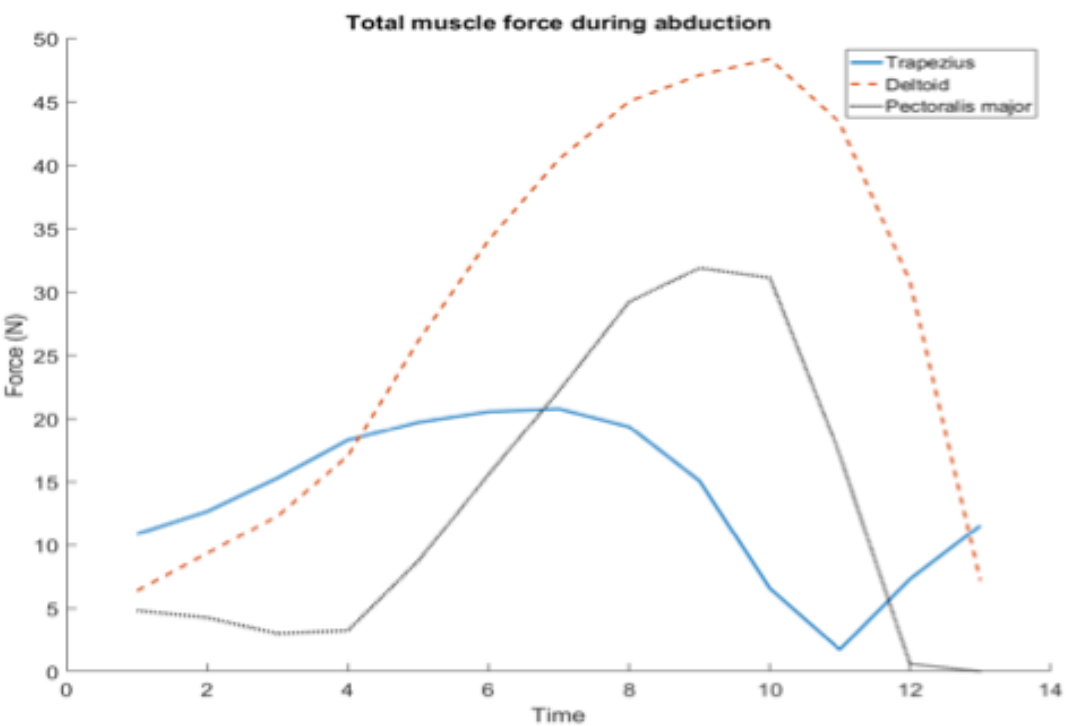

Figure 2. Total muscle force in Newton during abduction. Only non-zero forces of muscles acting on the clavicle have been depicted.

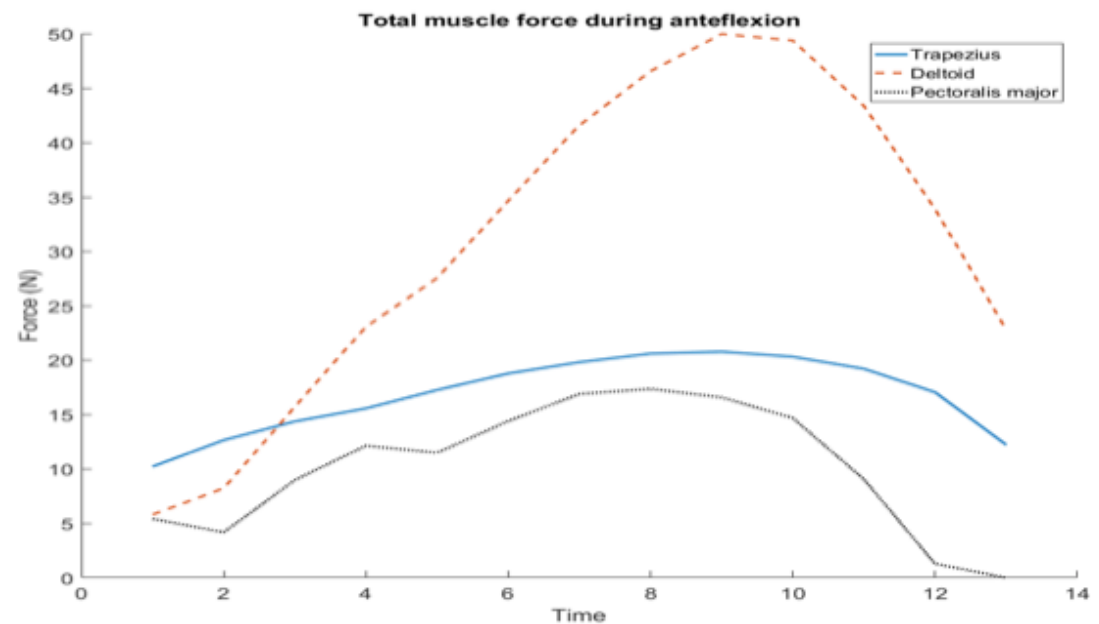

Figure 3. Total muscle force in Newton during anteflexion. Only non-zero forces of muscles acting on the clavicle have been depicted. 


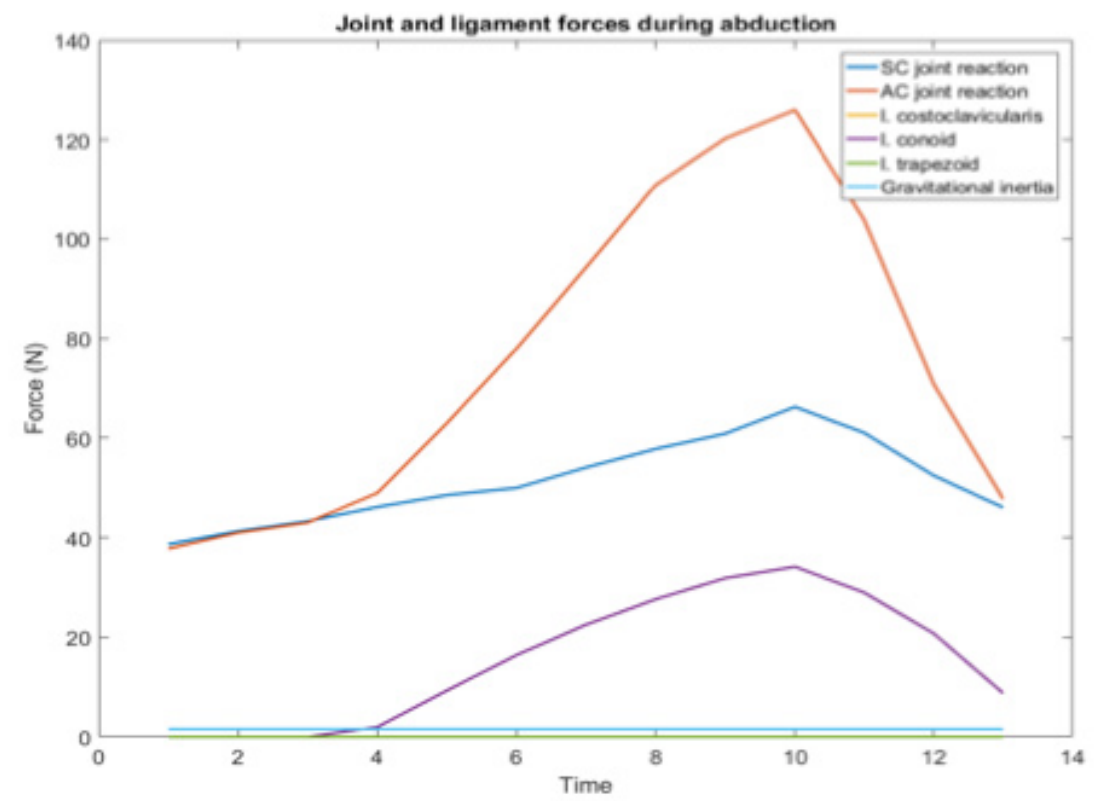

Figure 4. Joint and ligament force in Newton during abduction. The costoclavicular and trapezoid ligaments remain zero, because they have not been implemented in the model.

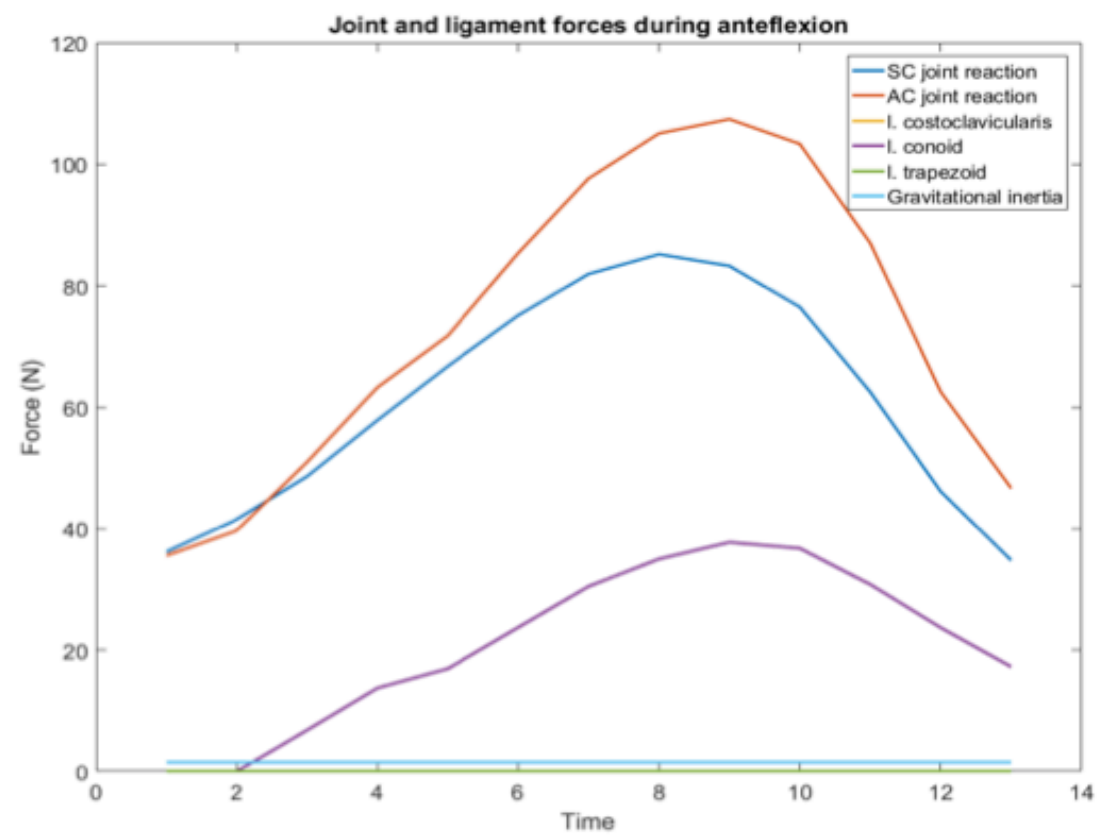

Figure 5. Joint and ligament force in Newton during anteflexion. The costoclavicular and trapezoid ligaments remain zero, because they have not been implemented in the model. 


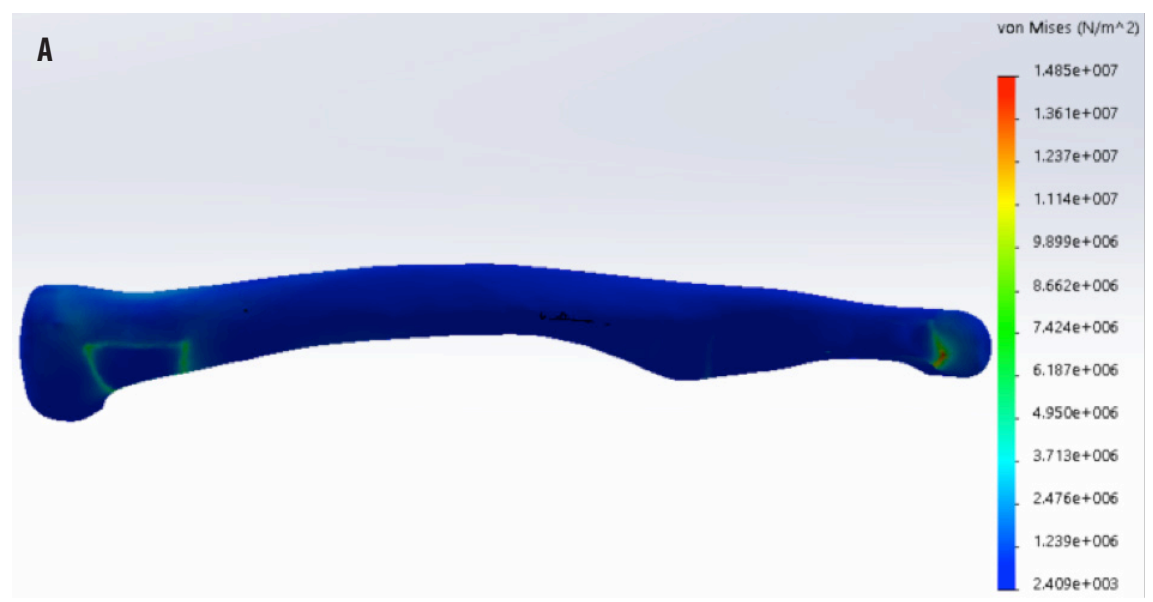

Figure 6A. A visualization of the von Mises stress (in $\mathrm{N} / \mathrm{m}^{2}$ ) on the clavicle, without a fracture, during abduction.

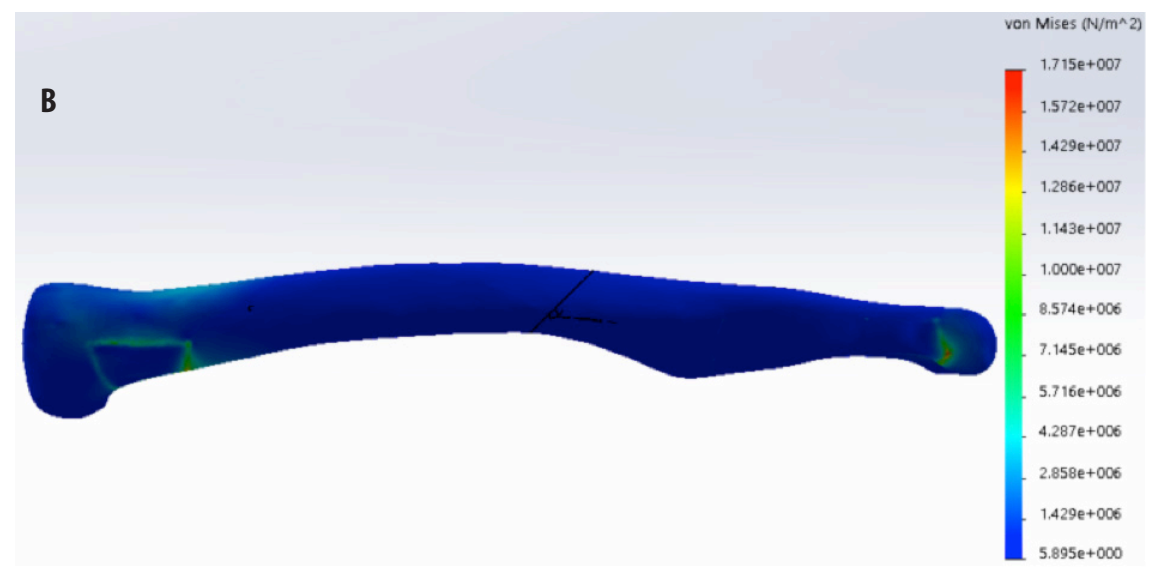

Figure 6B. A visualization of the von Mises stress (in $\mathrm{N} / \mathrm{m}^{2}$ ) on the clavicle, with the midshaft fracture, during abduction 


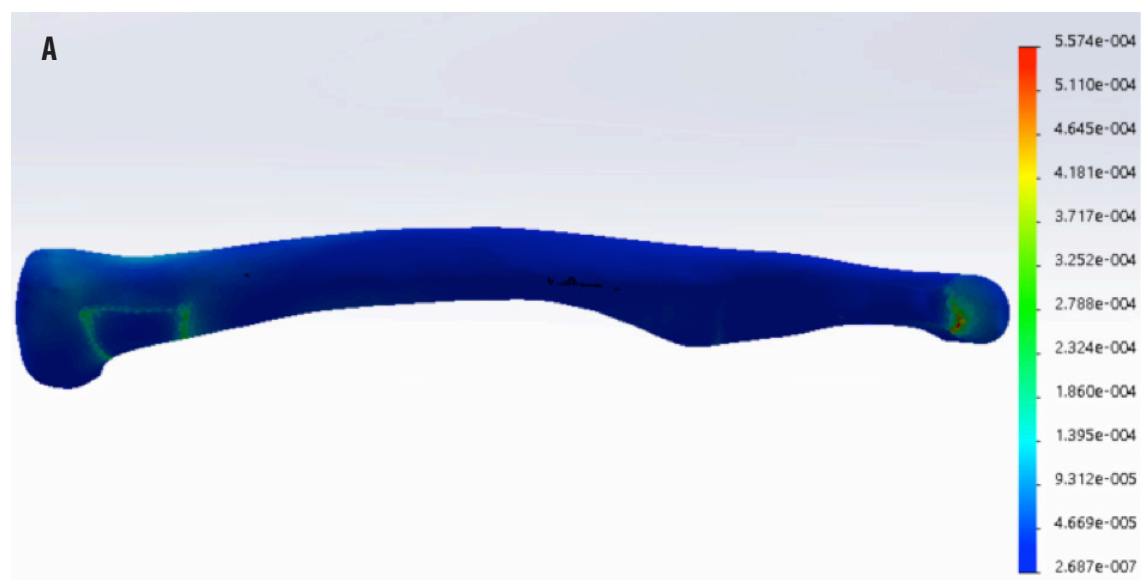

Figure 7A. A visualization of the strain of the clavicle, without a fracture, during abduction

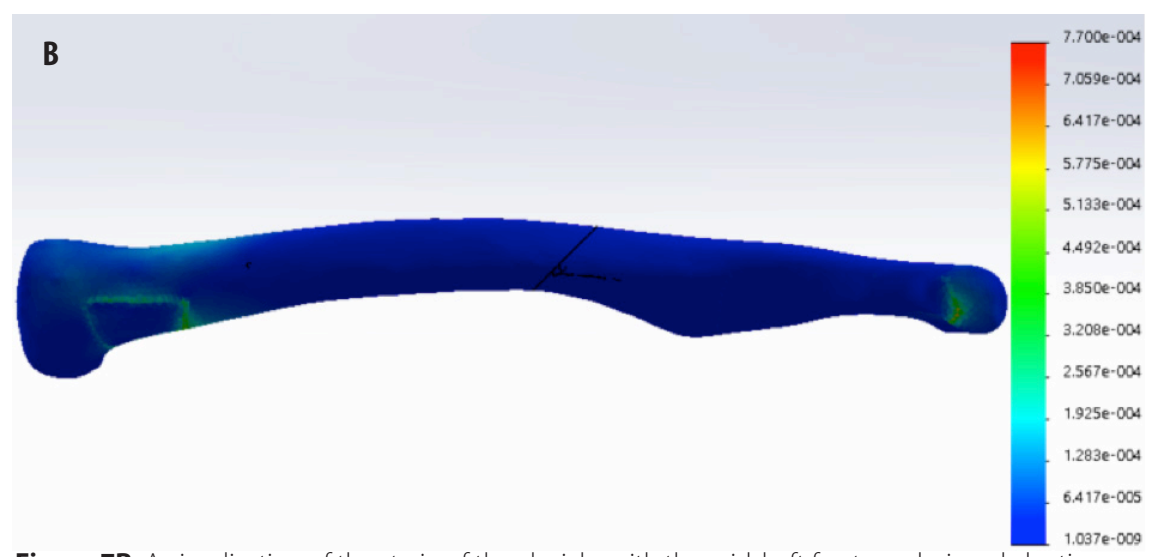

Figure 7B. A visualization of the strain of the clavicle, with the midshaft fracture, during abduction. 


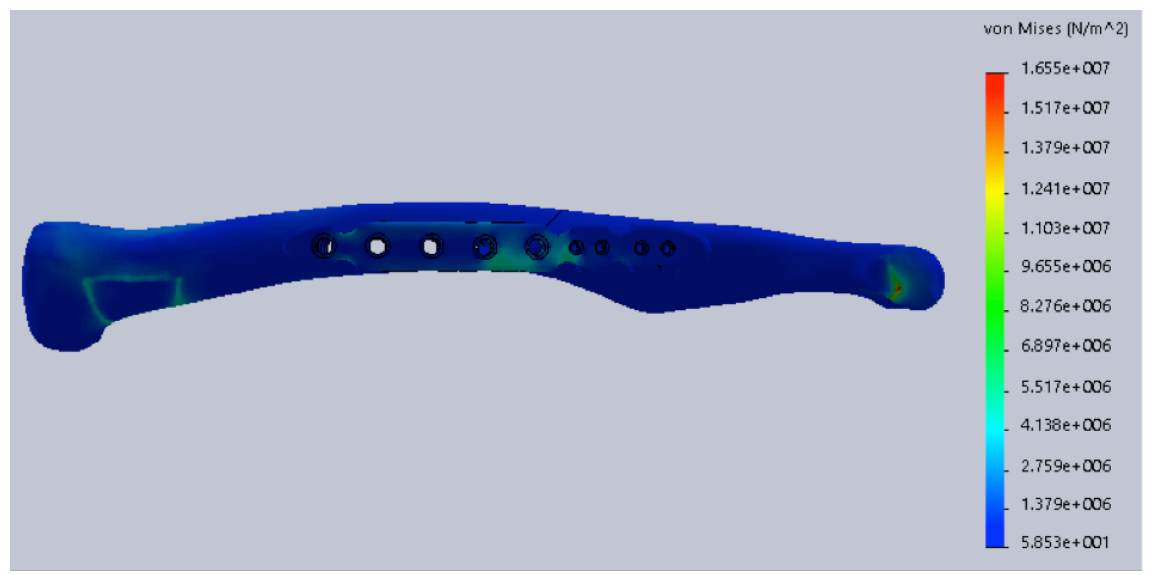

Figure 8A. A visualization of the von Mises stress (in $\mathrm{N} / \mathrm{m}^{2}$ ) on the clavicle, with the midshaft fracture and anteroinferior plate fixation, during abduction.

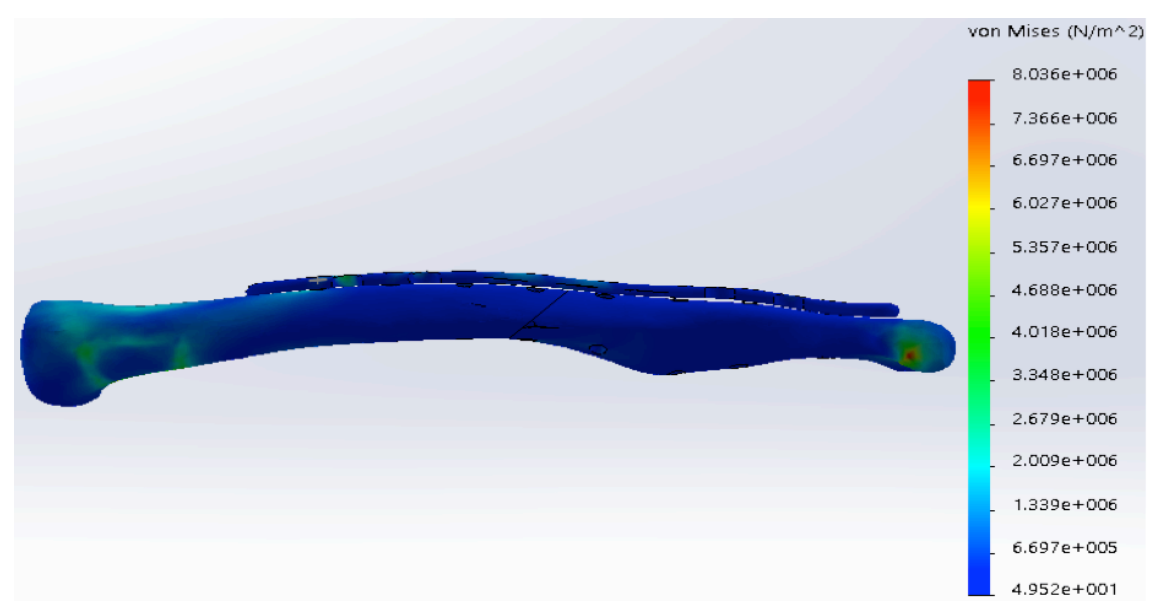

Figure 8B. A visualization of the von Mises stress (in $\mathrm{N} / \mathrm{m}^{2}$ ) on the clavicle, with the midshaft fracture and superior plate fixation, during abduction. 


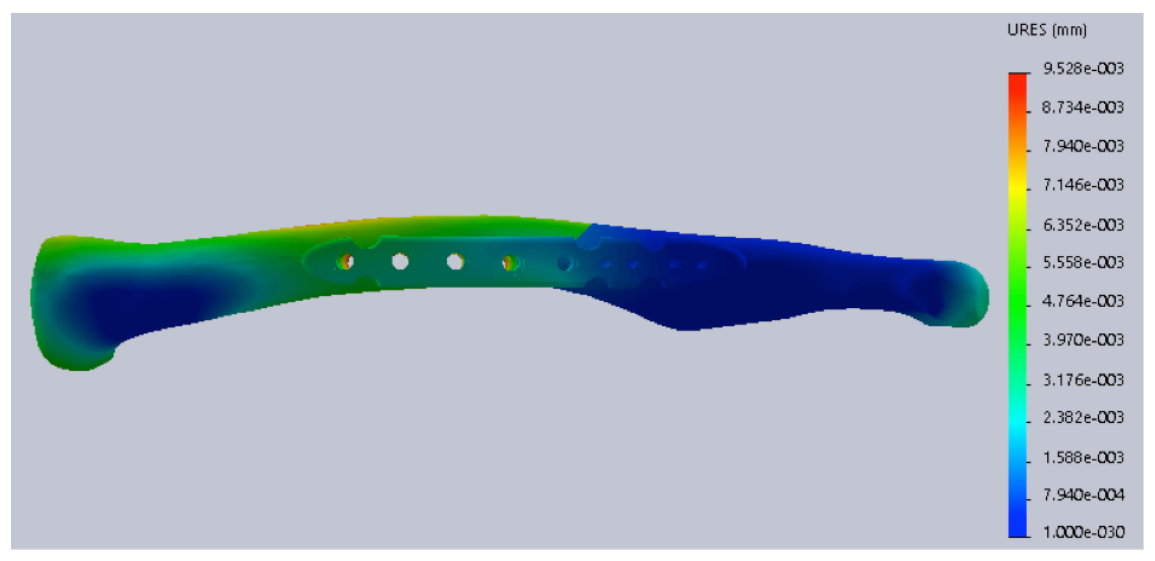

Figure 9A. A visualization of the displacement (in $\mathrm{mm}$ ) of the clavicle, with the midshaft fracture and anteroinferior plate fixation, during abduction.

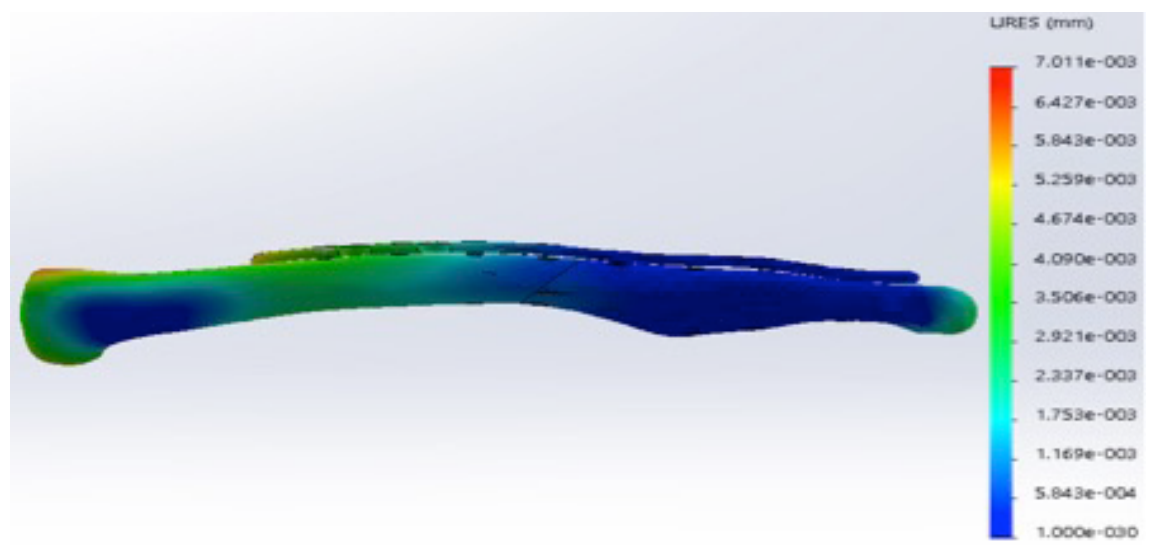

Figure 9B. A visualization of the displacement (in $\mathrm{mm}$ ) of the clavicle, with the midshaft fracture and superior plate fixation, during abduction. 


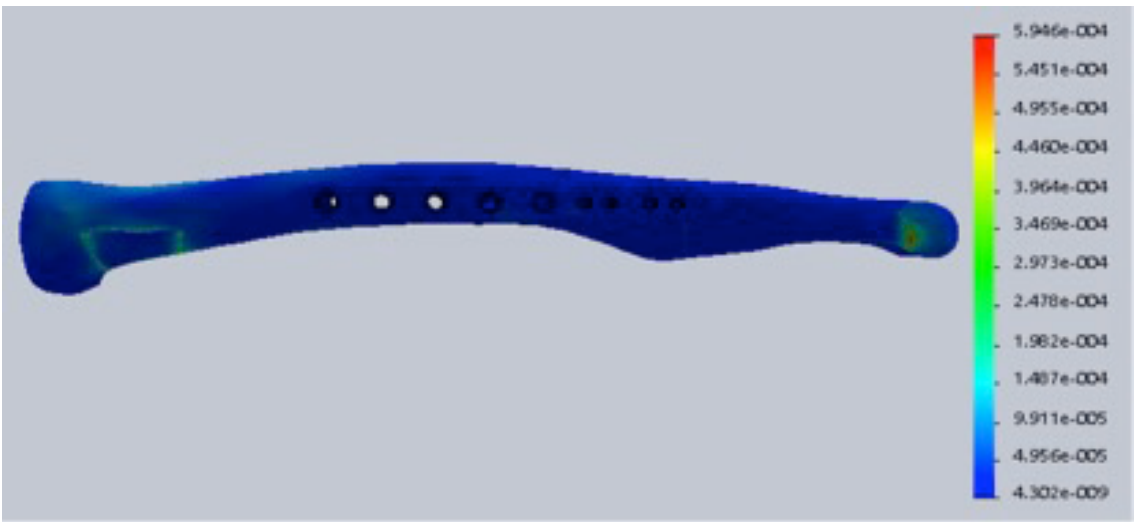

Figure 10A. A visualization of the strain of the clavicle, with the midshaft fracture and anteroinferior plate fixation, during abduction.

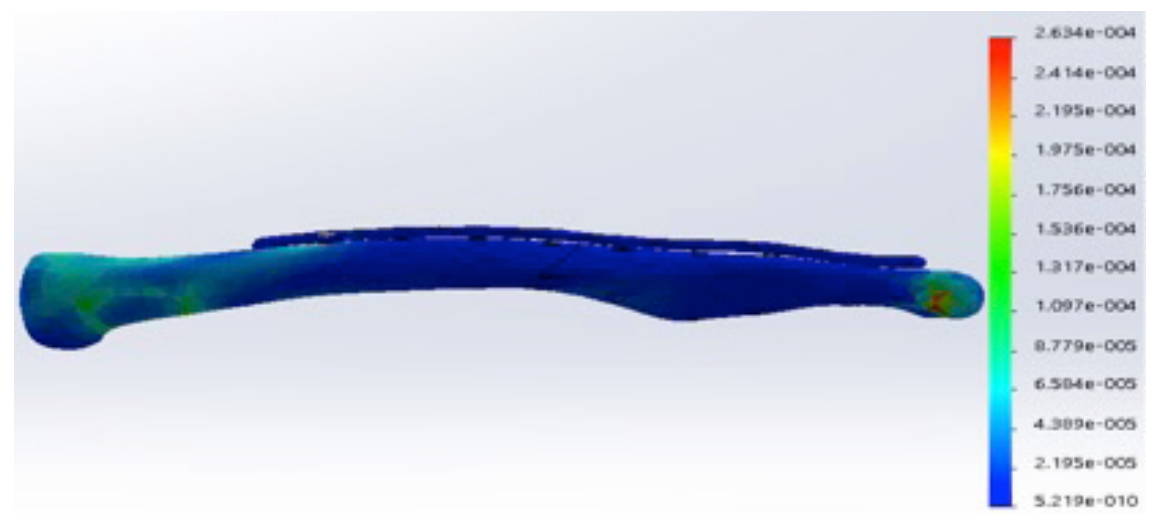

Figure 10B. A visualization of the strain of the clavicle, with the midshaft fracture and superior plate fixation, during abduction. 


\section{Results from the simulations}

The yield strength of cortical bone is $3.760 \times 10^{9} \mathrm{~N} / \mathrm{m}^{2}$. The von Mises stresses $\left(9.914 \times 10^{6} \mathrm{~N} / \mathrm{m}^{2}\right.$ without a fracture, $1.306 \times 10^{7} \mathrm{~N} / \mathrm{m}^{2}$ with a fracture $)$ stay below the yield strength (Figure 11). Also, the minimum stress is lower for the clavicle with a fracture $\left(8.541 \mathrm{~N} / \mathrm{m}^{2}\right)$ compared to without a fracture $\left(1.651 \times 10^{3} \mathrm{~N} / \mathrm{m}^{2}\right)$. The minimum strain $\left(1.108 \times 10^{-9}\right)$ is lower for the clavicle with a fracture compared to without a fracture $\left(1.548 \times 10^{-7}\right)$ (Figure 12). The mean and maximal strain are similar with and without fracture.

The maximum von Mises stresses is higher for the anteroinferior $\left(2.308 \times 10^{7} \mathrm{~N} / \mathrm{m}^{2}\right)$ plate position compared to the superior $\left(6.025 \times 10^{6} \mathrm{~N} / \mathrm{m}^{2}\right)$ plate position (Figure 13). For both plates, the von Mises stress stays below the yield strength $(9.000 \times$ $10^{8} \mathrm{~N} / \mathrm{m}^{2}$ for Ti-6Al-7Nb). The fracture displacement is small for both anteroinferior $\left(7.567 \times 10^{-3} \mathrm{~mm}\right)$ and superior $\left(6.124 \times 10^{-3} \mathrm{~mm}\right)$ plating, thus both positions provide anatomical reduction (Figure 14). Also, the strain is similar for anteroinferior $\left(4.309 \times 10^{-4}\right)$ and superior $\left(2.080 \times 10^{-4}\right)$ plating (Figure 15).

The distribution of the von Mises stresses is not the same for both plating methods (abduction: Figure 16, anteflexion: Figure 17). For anteroinferior plating, the von Mises stresses on the plate are higher. The distribution of the strain is similar to the distribution of the von Mises stresses (abduction: Figure 4 in article, anteflexion: Figure 18). 


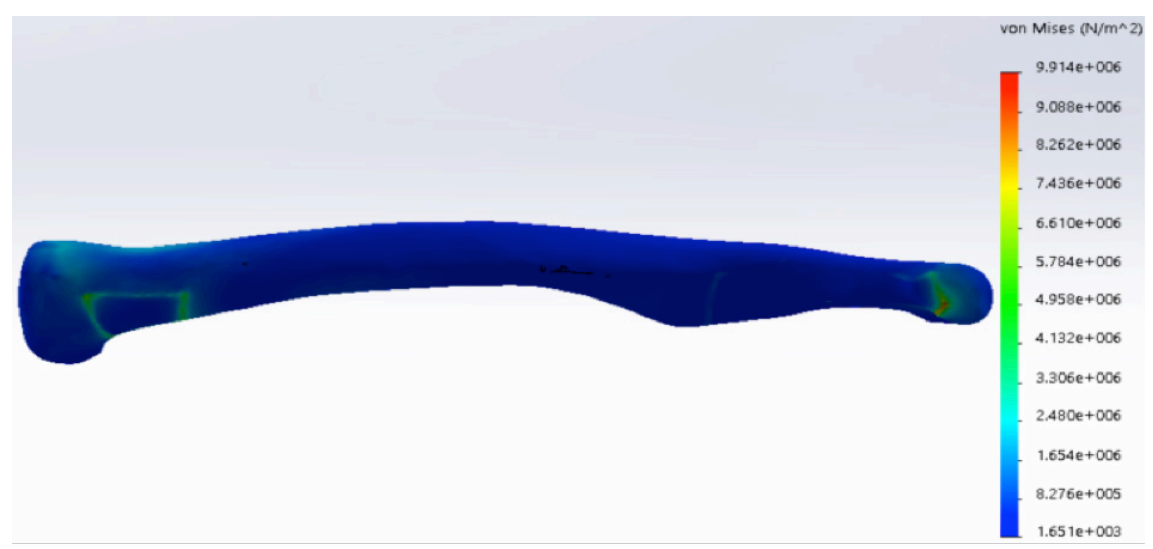

Figure 11A. A visualization of the von Mises stress (in $\mathrm{N} / \mathrm{m}^{2}$ ) on the clavicle, without a fracture, during anteflexion.

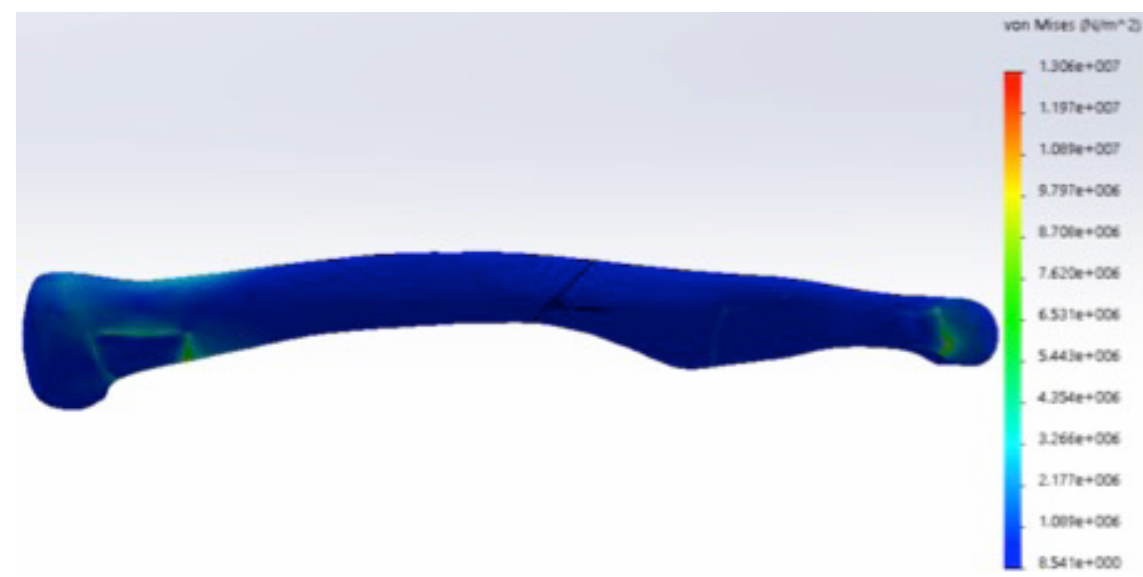

Figure 11B. A visualization of the von Mises stress (in $\mathrm{N} / \mathrm{m}^{2}$ ) on the clavicle, with the midshaft fracture, during anteflexion. 


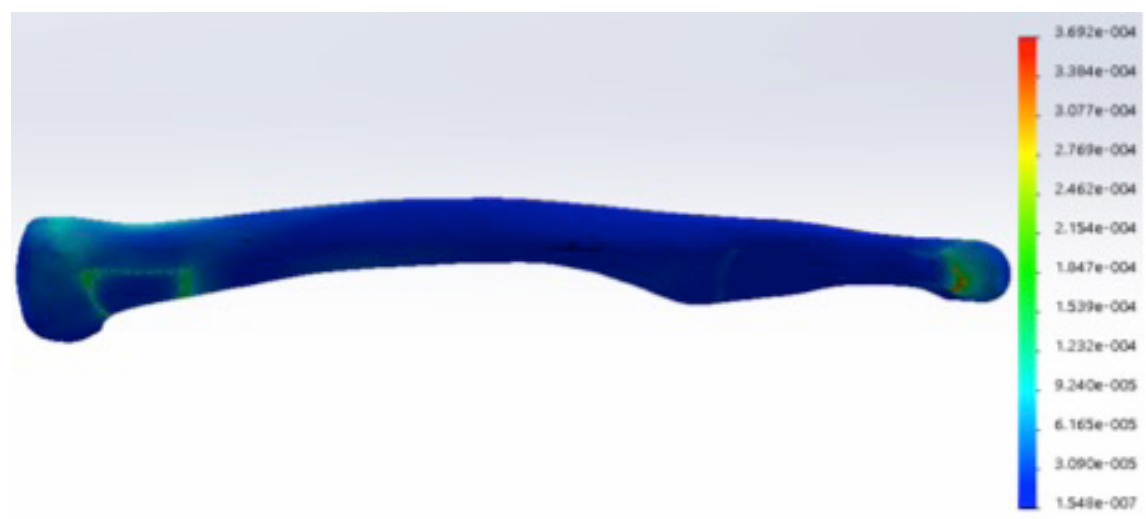

Figure 12A. A visualization of the strain of the clavicle, without a fracture, during anteflexion.

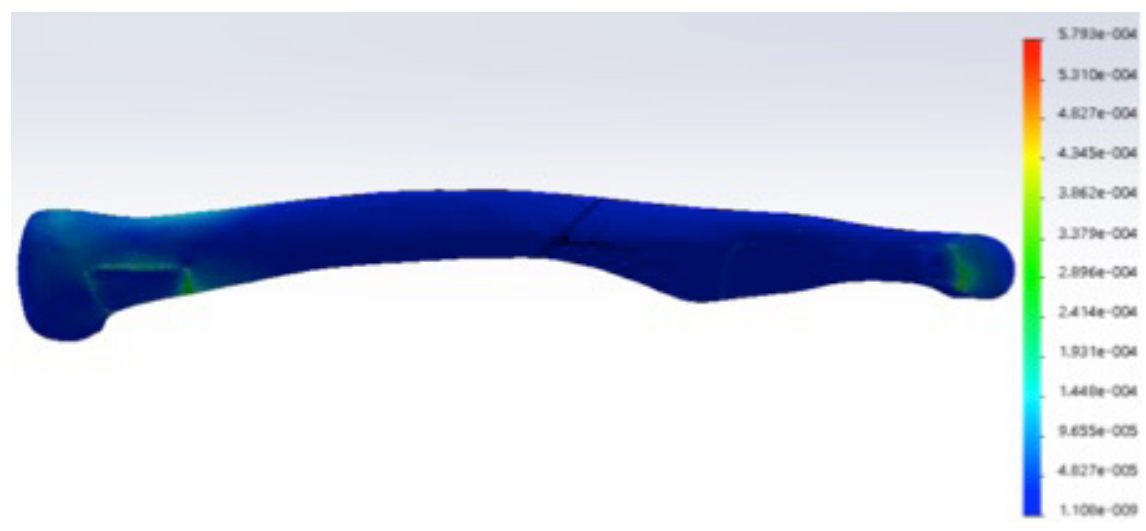

Figure 12B. A visualization of the strain of the clavicle, with the midshaft fracture, during anteflexion. 


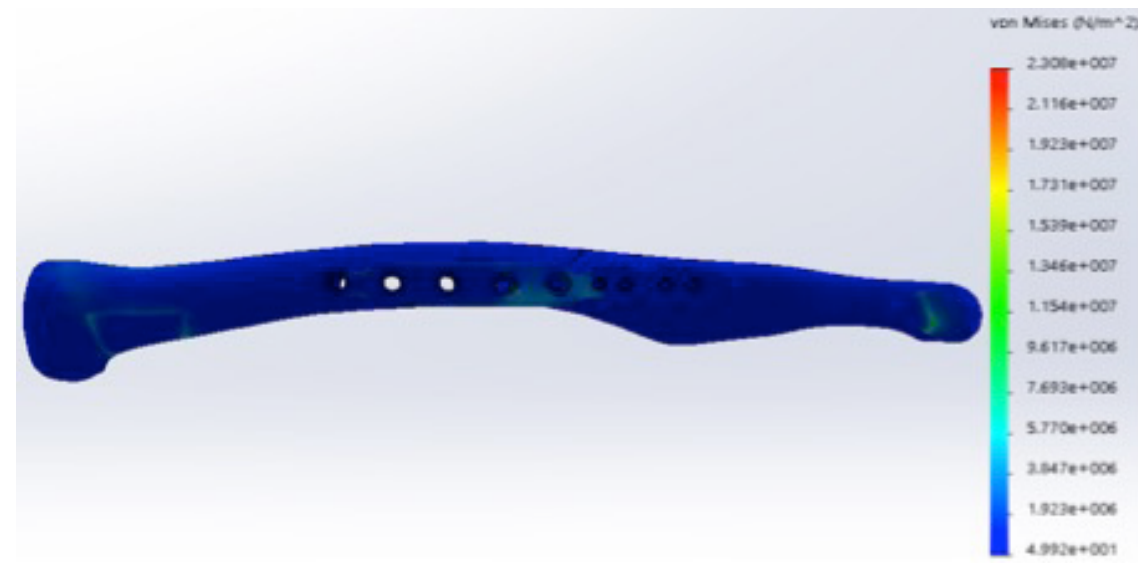

Figure 13A. A visualization of the von Mises stress (in $\mathrm{N} / \mathrm{m}^{2}$ ) on the clavicle, with the midshaft fracture and anteroinferior plate fixation, during anteflexion.

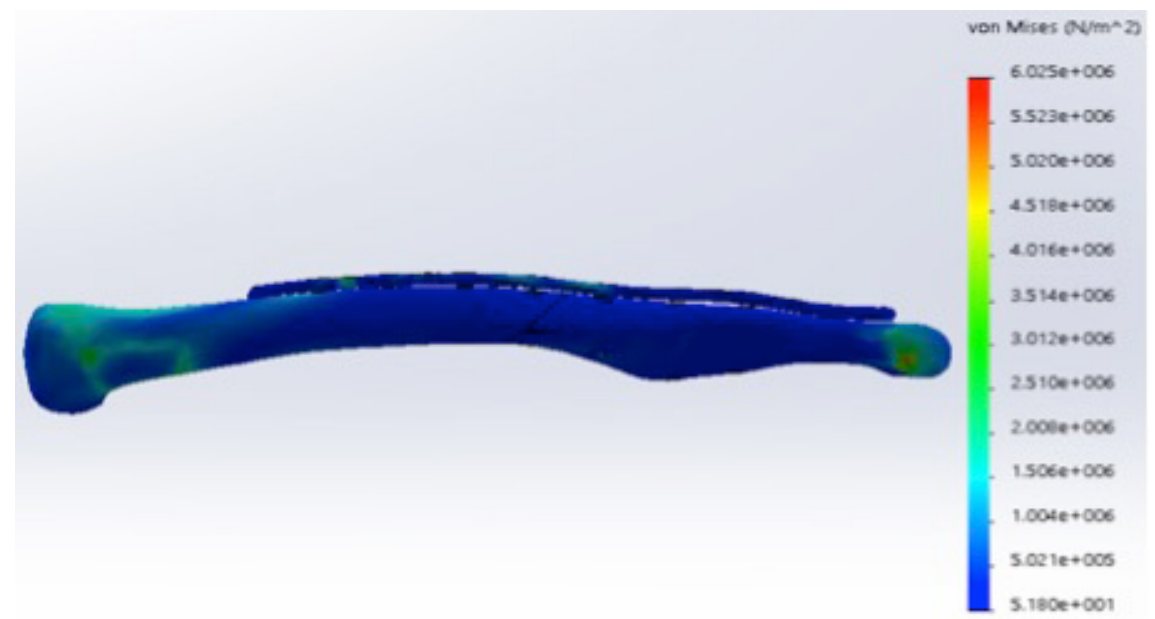

Figure 13B. A visualization of the von Mises stress (in $\mathrm{N} / \mathrm{m}^{2}$ ) on the clavicle, with the midshaft fracture and superior plate fixation, during anteflexion 


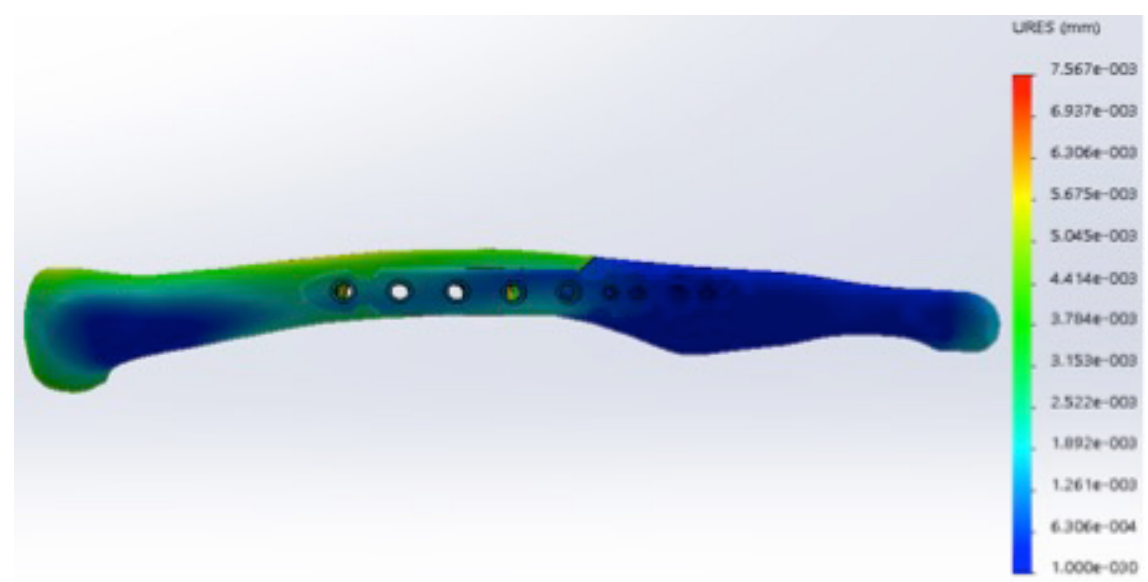

Figure 14A. A visualization of the displacement (in $\mathrm{mm}$ ) of the clavicle, with the midshaft fracture and anteroinferior plate fixation, during anteflexion.

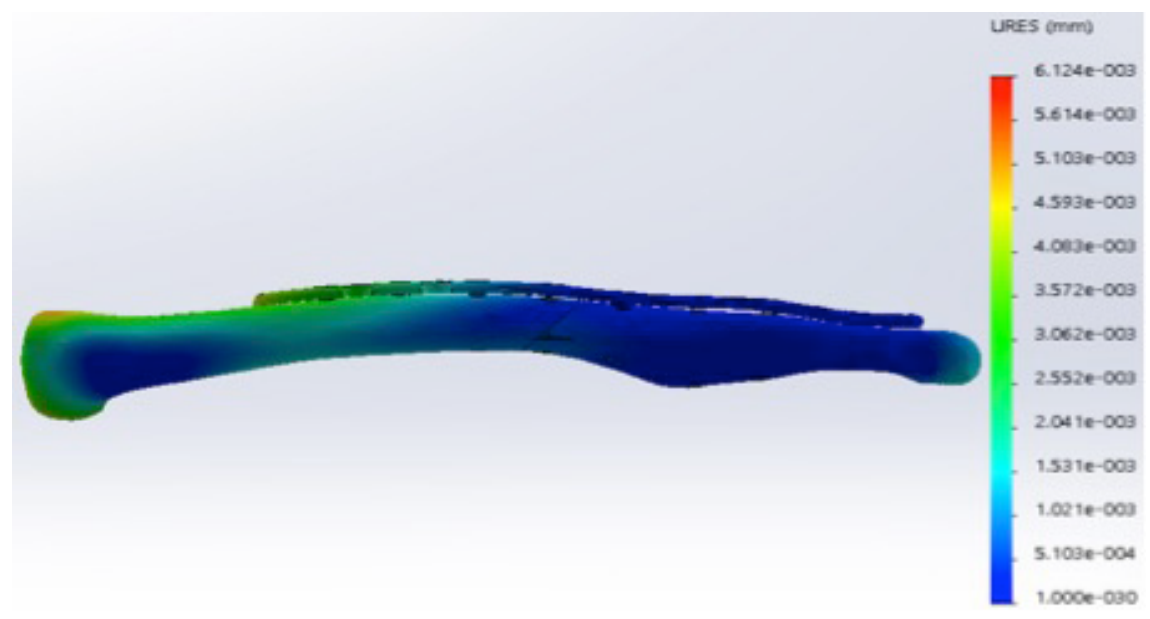

Figure 14B. A visualization of the displacement (in $\mathrm{mm}$ ) of the clavicle, with the midshaft fracture and superior plate fixation, during anteflexion 


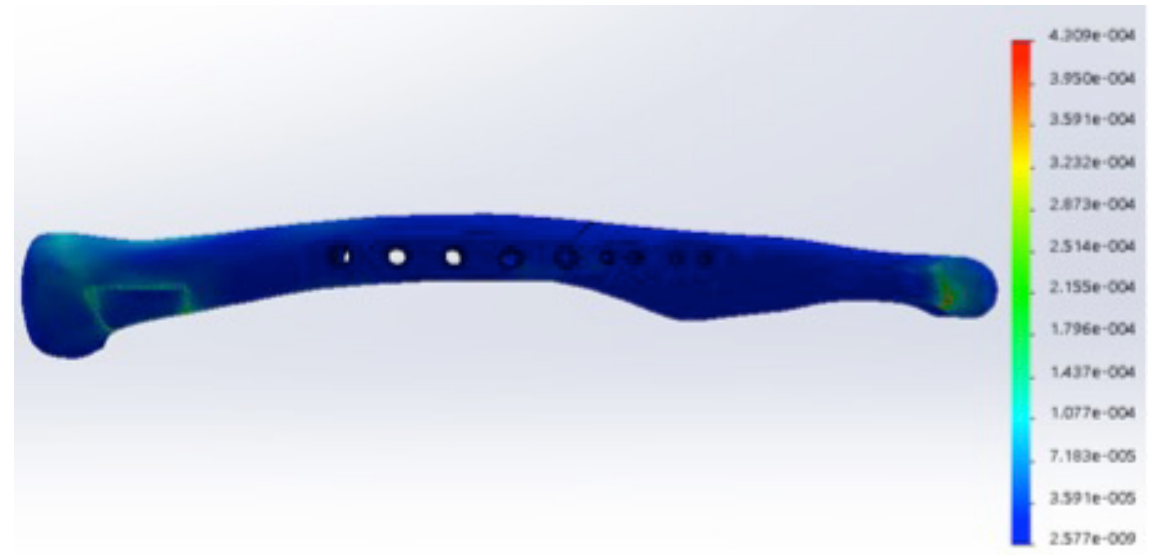

Figure 15A. A visualization of the strain of the clavicle, with the midshaft fracture and anteroinferior plate fixation, during anteflexion.

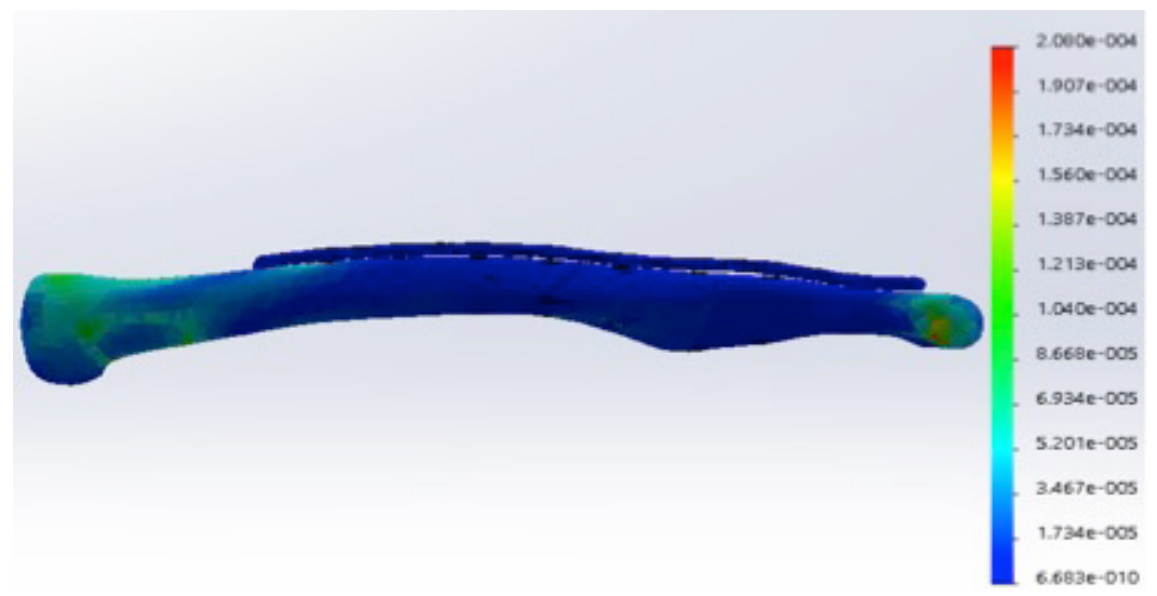

Figure 15B. A visualization of the strain of the clavicle, with the midshaft fracture and superior plate fixation, during anteflexion 


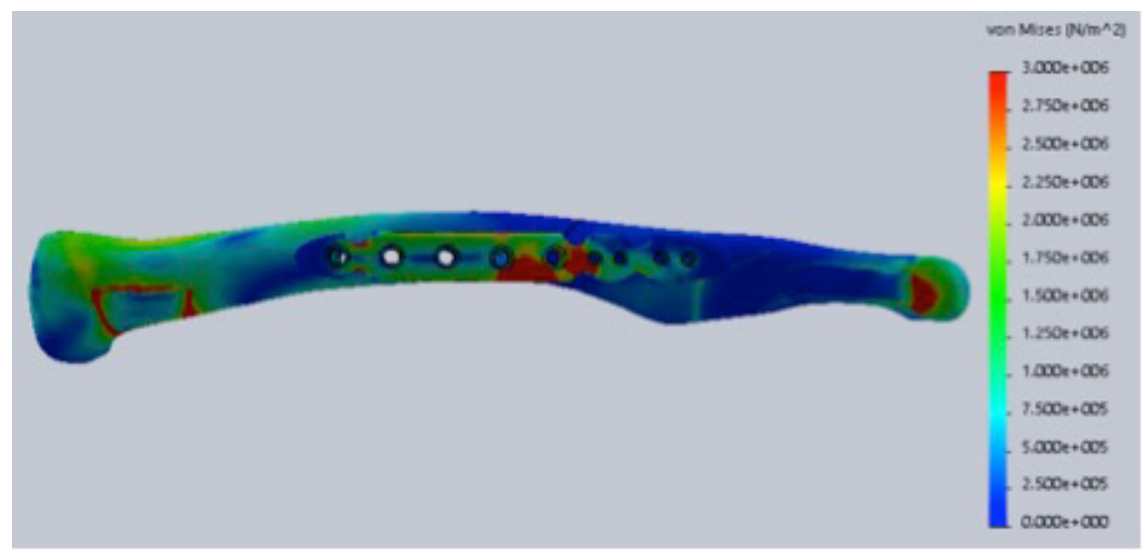

Figure 16A. A visualization of the distribution of the von Mises stress (in $\mathrm{N} / \mathrm{m}^{2}$ ) on the anteroinferior plate, with an adjusted scale, during abduction.

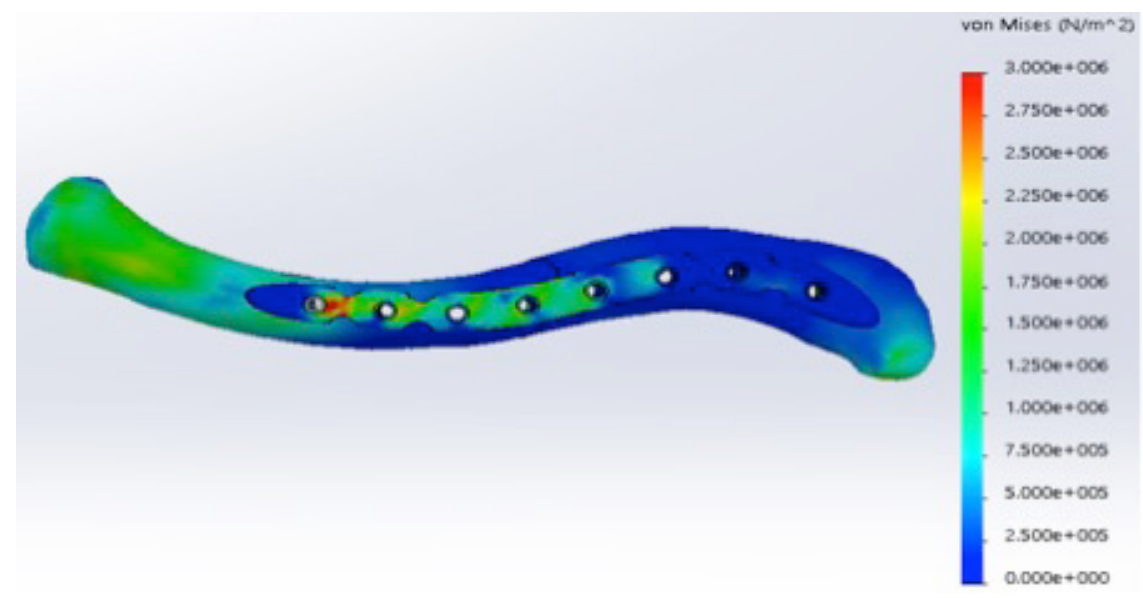

Figure 16B. A visualization (top view) of the distribution of the von Mises stress (in $\mathrm{N} / \mathrm{m}^{2}$ ) on the superior plate, with an adjusted scale, during abduction 


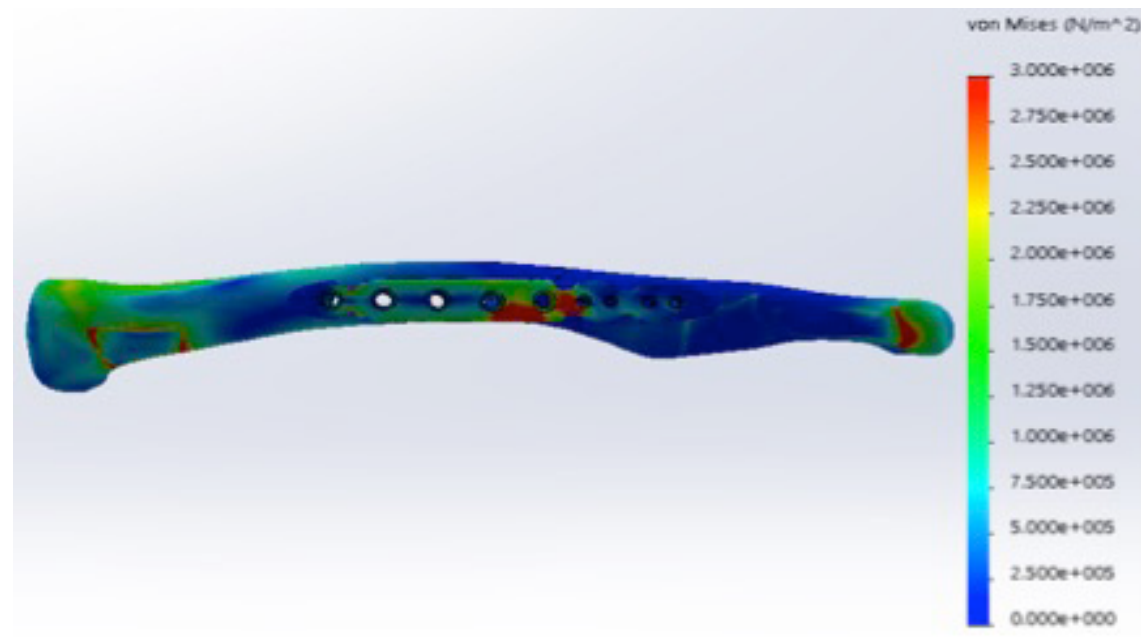

Figure 17A. A visualization of the distribution of the von Mises stress (in $\mathrm{N} / \mathrm{m}^{2}$ ) on the anteroinferior plate, with an adjusted scale, during anteflexion.

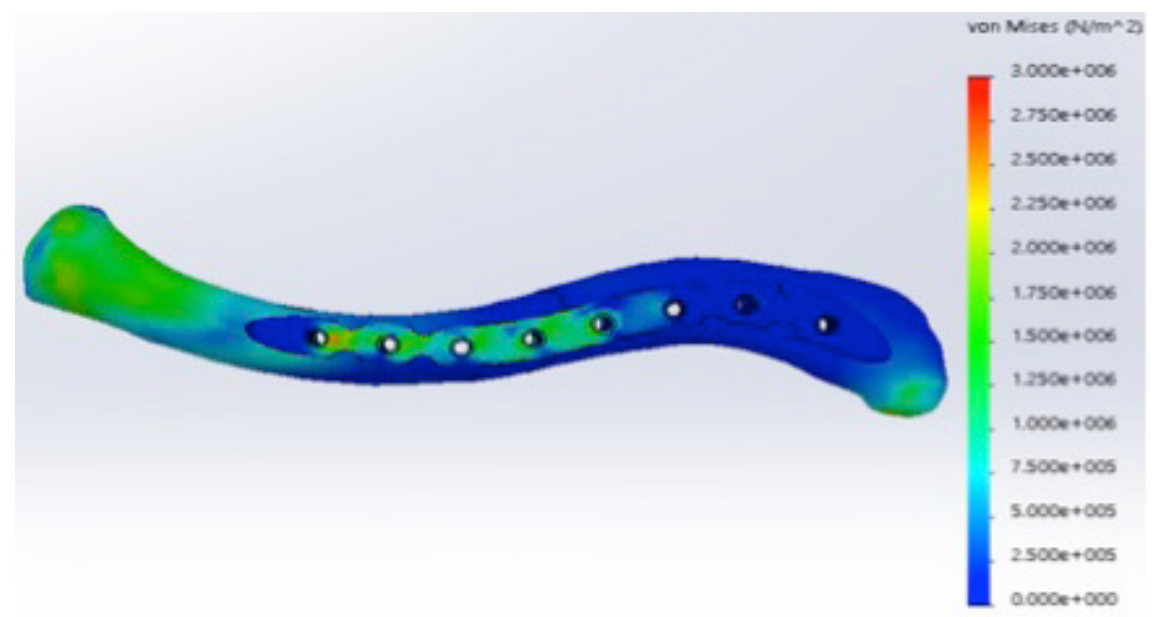

Figure 17B. A visualization (top view) of the distribution of the von Mises stress (in $\mathrm{N} / \mathrm{m}^{2}$ ) on the superior plate, with an adjusted scale, during anteflexion. 


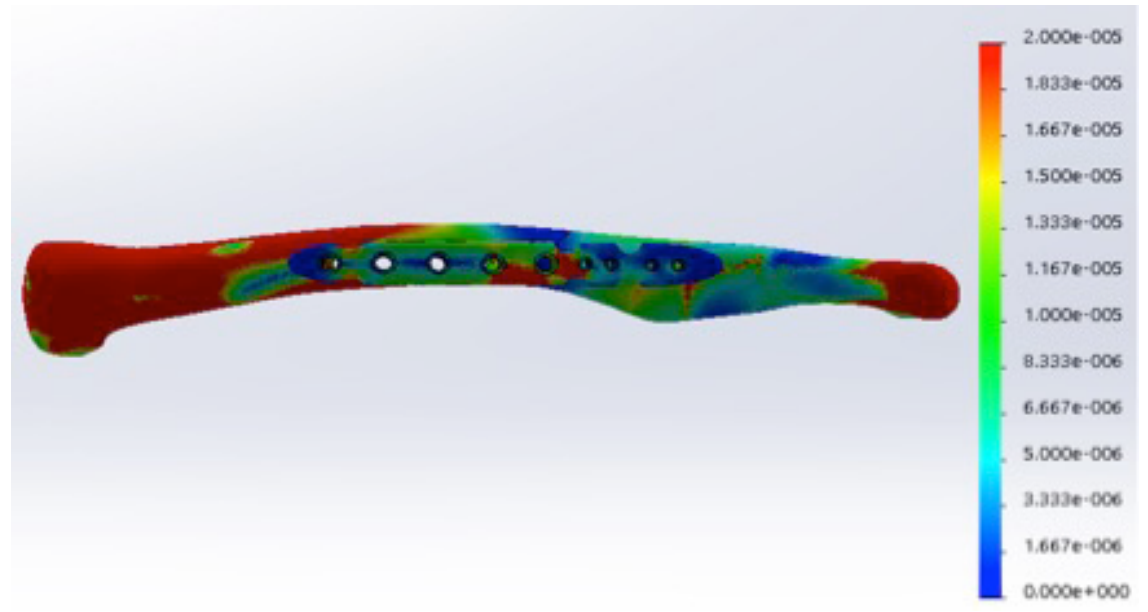

Figure 18A. A visualization of the distribution of the strain of the anteroinferior plate fixation, with an adjusted scale, during anteflexion.

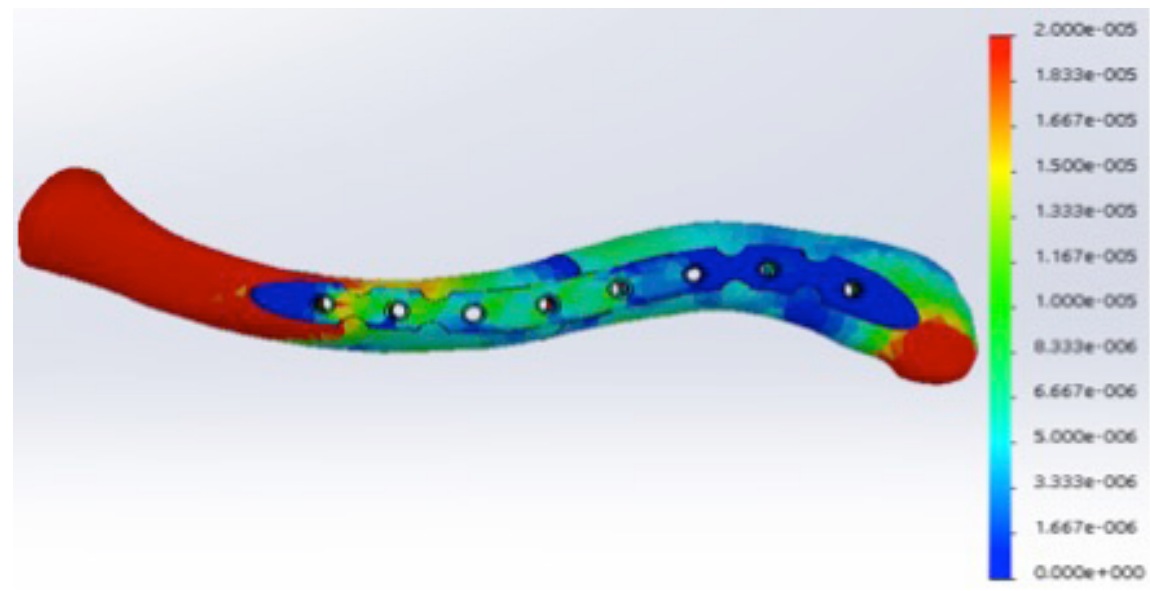

Figure 18B. A visualization (top view) of the distribution of the strain of the superior plate fixation, with an adjusted scale, during anteflexion. 


\section{Appendix III}

\section{Discussion points about the Delft Shoulder and Elbow Model and the creati- on of the finite element model}

Although in vivo data about clavicular muscle forces lacks, results seem plausible as the magnitude of the forces is similar to that of other musculoskeletal studies. 4,7, , 10 Our study expands on the number of movements that are analyzed, compared to a previous study that used musculoskeletal modelling for clavicular fractures.

7 However, it should be kept in mind that as of yet no musculoskeletal model of the shoulder has been validated. The DSEM has been reported to overestimate joint reaction forces by up to 30\% during force tasks and underestimate up to 35\% during dynamic tasks. ${ }^{8}$ However, although musculoskeletal simulations do not give exact results, they are currently the only tool to provide insight in clavicular load during everyday movements and these results are necessary for constraining the finite element model in a biomechanically justified way. The material properties of the clavicle have been chosen based on papers we came across, noting these properties. 1,2,5,11,13-16,18-20 The mean or most frequent values were chosen. It is possible that the FEM does not have the same biomechanical properties as a real clavicle, due to several steps in the process of creating the model (which result in simplification of the model). Only the cortex is used in the model, because the cancellous or trabecular bone has no significant influence on the mechanical properties of the clavicle. ${ }^{6,7}$ Therefore, the marrow is modelled as a cavity within the cortex. During the segmentation of the clavicle, the accuracy of the model is limited by the resolution of the CT scan. Structures smaller than the voxel size cannot be detected and were thus excluded from the model. As a result of this, the clavicle presented itself with jagged edges after segmentation. In order to smoothen out the edges of the clavicle, Laplacian smoothing and Poisson surface reconstruction were performed. This process caused some details to be lost. In the next step, the conversion from surface mesh to solid, the boundaries of the mesh were converted to spline surfaces. Each spline surface is a mathematical representation of the curvature of that part of the surface mesh. This surface is fitted 'as best as possible', which means that some detail was lost here as well during the fitting process. The total number of spline surfaces defines the overall goodness of fit of the solid boundary on the surface mesh. In this study, the goodness of fit was chosen to be halfway between course and fine (as defined by the modeling software) as the finer the goodness of fit was chosen, the more manual adjustments were needed to remove spline surface errors. Also, during the conversion from solid to FEM mesh, detail was lost due to discretization of the model. The basis of finite element 
modeling is to take a physical system and partition it into regions (elements) that can individually be solved by simple linear equations. The partitioning strives to approximate the continuous solution as good as possible, however discretization errors will always remain. ${ }^{17}$ 


\section{REFERENCES}

1. Amaral M, Lopes MA, Silva RF, Santos JD. Densification route and mechanical properties of Si3N4-bioglass biocomposites. Biomaterials. 2002;23(3):857-862. doi:10.1016/S0142-9612(01)00194-6.

2. Birajdar P, Bammani S, Shinde P, Bhandari R, Bedare J. Biomechanical study, 3D modeling and kinematic analysis of shoulder joint. Int J Mech Eng Technol. 2013;4(4):88-95.

3. Bolsterlee B, Veeger HEJ, van der Helm FCT. Modelling clavicular and scapular kinematics: From measurement to simulation. Med Biol Eng Comput. 2014,52(3):283-291. doi:10.1007/s11517013-1065-2.

4. Bolsterlee B. Predicting Muscle Forces in the Shoulder by Constraining the Inverse Optimisation with EMG and a Forward Muscle Model.; 2010.

5. Chen Q, Zhu C, Thouas G a. Progress and challenges in biomaterials used for bone tissue engineering: bioactive glasses and elastomeric composites. Prog Biomater. 2012;1(1):1-22. doi:10.1186/2194-0517-1-2.

6. Crönskar $M$, Rasmussen J, Tinnsten $M$. Combined finite element and multibody musculoskeletal investigation of a fractured clavicle with reconstruction plate. Comput Methods Biomech Biomed Engin. 2015;18(7):740-748.

7. Cronskär M. Strength analysis of clavicle fracture fixation devices and fixation techniques using finite element analysis with musculoskeletal force input. Med Biol Eng Comput. 2015;53:759-769. doi:10.1007/ s11517-015-1288-5.

8. Hogfors C, Sigholm G, Herberts P. Biomechanical model of the human shoulder - I. Elements. J Biomech. 1987;20(2):157-166. doi:10.1016/00219290(87)90307-1.
9. Ingram D, Engelhardt C, Farron A, Terrier A, Müllhaupt P. Improving anterior deltoid activity in a musculoskeletal shoulder model - an analysis of the torque-feasible space at the sternoclavicular joint. Comput Methods Biomech Biomed Engin. 2016;19(4):450-463. doi:http://dx.doi.org/10 .1080/10255842.2015.1042465.

10. Karlsson D, Peterson B. Towards a model for force predictions in the human shoulder. J Biomech. 1992;25(2):189-199.

11. Keaveny TM, Hayes WC. Mechanical properties of cortical and trabecular bone. Bone growth. 1993;(January 1993):285-344.

12. Klein Breteler M. Measuring muscle and joint geometry parameters for a shoulder model. 1996.

13. Kokubo T, Kim HM, Kawashita M. Novel bioactive materials with different mechanical properties. Biomaterials. 2003;24(13):2161-2175. doi:10.1016/S01429612(03)00044-9.

14. Krone R, Schuster P. An investigation on the importance of material anisotropy in finiteelement modeling of the human femur. SEA Int. 2006. doi:10.4271/2006-01-0064.

15. Moore WIRM, Graves STEG, Bain GRIB. Synthetic bone graft substitutes. ANZ J Surg. 2001;71:354-361.

16. Ni M, Niu W, Wong DW-C, Zeng W, Mei J, Zhang $M$. Finite element analysis of locking plate and two types of intramedullary nails for treating mid-shaft clavicle fractures. Injury. 2016. doi:10.1016/j. injury.2016.06.004.

17. Pointer J. Understanding accuracy and discretization error in an FEA model. ANSYS Users Conf. 2004.

18. Tupis TM, Altman GT, Altman DT, Cook HA, Miller MC. Femoral bone strains during antegrade nailing: A comparison of two entry points with identical nails using finite element analysis. Clin Biomech. 2012;27(4):354-359. doi:10.1016/j.clinbiomech.2011.11.002. 
19. Zeng L, Wei H, Liu Y, et al. Titanium elastic nail (TEN) versus reconstruction plate repair of midshaft clavicular fractures: A finite element study. PLoS One. 2015;10(5):1-12. doi:10.1371/journal.pone.0126131.
20. Zioupos P, Currey J. Changes in the stiffness, strength, and toughness of human cortical bone with age. Bone. 1998;22(1):57-66. doi:10.1016/S8756-3282(97)00228-7. 



\section{ADDENDUM FOUR}

Rehabilitation protocol of conservative treatment 



\section{Rehabilitation protocol}

The exercise protocol after conservative treatment consists of wearing a sling for a maximum of one week. Hereafter, the patient was seen in the outpatient clinic department and physical therapy (rhomboideus training) was prescribed. Rhomboideus training consisted of physiotherapy focusing mainly on retraction and mediorotation of the angulus inferior of both scapulae within individual arthrogenic limits. Herewith, the musculus rhomboideii and the musculus serratus posterior are trained. In order to prevent a scapula alata, training needs to focus on the musculus serratus anterior. After two weeks patients were allowed to extend the physical strain and full range of active motion was permitted. This requires mobility of the surrounding joint and shoulder girdle: the sternoclavicular (SC) joint the acromioclavicular (AC) joint, first and second rib, glenohumeral joint, and cervical and cervical thoracic junction. After consolidation of the fracture these joints needed to be mobilised or manipulated. Cyclists were allowed to return to competition at three weeks after surgery. 


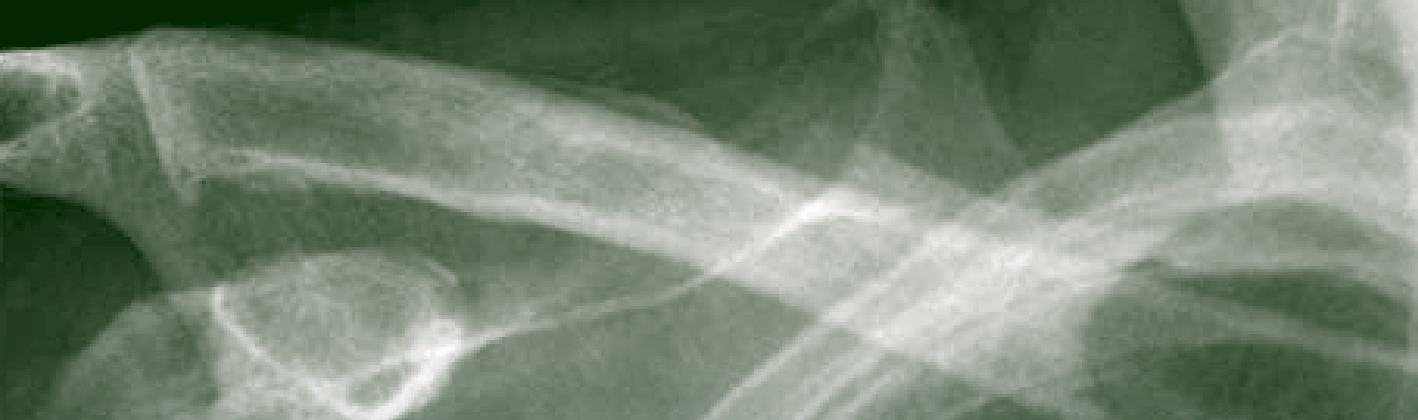